$$
\text { DOE/ER/61010-T T1 }
$$

\title{
National Institute for Global Environmental Change
}

\author{
SEMI-ANNUAL REPORT
}

to the

\section{U. S. DEPARTMENT OF ENERGY}

\author{
DISCLAIMER
}

\begin{abstract}
This report was prepared as an account of work sponsored by an agency of the United States Government. Neither the United States Government nor any agency thereof, nor any of their employees, makes any warranty, express or implied, or assumes any legal liability or responsibility for the accuracy, completeness, or usefulness of any information, apparatus, product, or process disclosed, or represents that its use would not infringe privately owned rights. Reference herein to any specific commercial product, process, or service by trade name, trademark, manufacturer, or otherwise does not necessarily constitute or imply its endorsement, recommendation, or favoring by the United States Government or any agency thereof. The views and opinions of authors expressed herein do not necessarily state or reflect those of the United States Government or any agency thereof.
\end{abstract}

\section{Reporting Period}

July 1, 1991 to December 31, 1991

\section{University of California, Davis}




\section{TABLE OF CONTENTS}

\section{Part I: Institute Overview}

Transmittal Letter

Mission, Regional Centers

Progress Toward Research Needs

Management

Financial Report

\section{Part II: Research Projects}

Midwestern Regional Center

Northeast Regional Center

Southcentral Regional Center

Southeast Regional Center

115

Western Regional Center

117

National Institute Office

\section{Indices}

Host Institutions

154

Project Title Index

156

Investigator Name Index

158 
Dr. Ari Patrinos

Atmospheric \& Climate Research Division

Department of Energy
Mr. Ted Williams

Office of Environmental Analysis

Department of Energy

\section{Dear Sirs:}

It is with pride that I transmit the Semi-Annual Report of the National Institute for Global Environmental Change for the reporting period July 1 to December 31, 1991. The report is in two parts. Part I presents the mission of the Institute, examples of progress toward that mission, a brief description of the revised management plan, and the financial report. Part II presents the statements of the Regional Center Directors along with progress reports of the projects written by the researchers themselves.

In the middle of NIGEC's second fiscal year, I am pleased to report that an increasing number of research projects have results and are able to draw conclusions. The technical results highlighted in Part I show contribution to the research needs as defined in the mission of the revised management plan. The full reports of these highlights are presented in Part II. I have purposely avoided selecting projects highlighted in Volume I of the Annual Report issued August 1, 1991.

Improved scientific understanding is needed on how increased levels of $\mathrm{CO}_{2}$ increases the growth of trees. Fakhri A. Bazzaz, Harvard University, has grown tree seedlings at elevated levels of $\mathrm{CO}_{2}$ and compared this growth to seedlings grown at normal levels. Nutrients and light also control growth and the experiments controlled these factors as well. Bazzaz found enhanced growth caused by $\mathrm{CO}_{2}$ particularly under conditions of low light and high nutrients. Enhanced growth of forests should retard, somewhat, the build-up of $\mathrm{CO}_{2}$.

Methane hydrate deposits are located beneath the Arctic permafrost. A scientific uncertainty exists as to the extent that global warming is releasing the methane and increasing the contribution of methane to global warming. S. G. Schwarz and V. T. John, Tulane University, are investigating these hypothesized processes, and work-to-date is lending credence to the mechanism. Plumes thought to be due to methane hydrate destabilization have been observed in the Arctic.

One of the potential impacts of global warming is the effect on agricultural systems. S. Geng, R. Plant and R. Loomis, University of California, Davis, are modeling the effect of climate changes on agricultural systems. Model results to date for an assumed weather pattern resulting from global environmental change, indicate that rice yields decrease 14-24\% in the Gulf Coast states and decrease 11-21\% in California. In both regions, the decrease in rice yields were due primarily to the large increase in summer temperatures. On the other hand, dryland fall-planted spring wheat yields in California increased by $62-125 \%$. This is because of ircreasing rainfall and temperatures during the winter months in California. 
An innovative experimental program has been instituted by I. Gill, Tulane University, and D. Hubbard, West Indies Laboratory. The major thrust is to develop a method of evaluating cores from coral heads and reefs to establish a proxy for sea surface temperatures for periods longer than two centuries. Thirteen cores from a single colony of coral heads and eight reef cores have been collected in the northeastern Caribbean. The cores are being dated using radiometric methods. The growth of coral depends on temperature and examining the growth should provide the proxy to temperature.

J. C. Randolph, Indiana University, is developing a policy analysis tool to project how various $\mathrm{SO}_{2}$ emission reduction strategies will affect $\mathrm{CO}_{2}$ emissions from coal-fired electrical generating F.ants. The operation of six Indiana utilities have been modelled with respect to the $\mathrm{SO}_{2}$ emission control strategies they might choose in response to the Clean Air Act Amendments of 1990. Findings to date indicate that $\mathrm{SO}_{2}$ and $\mathrm{NO}_{x}$ emissions will be reduced as utilities begin to comply with the regulations. Carbon emissions were not targeted for control and the analysis suggests that emissions of $\mathrm{CO}_{2}$ will continue to increase. The model could be used to examine regulatory options for $\mathrm{CO}_{2}$ reductions.

It is predicted that in the 21 st century $90 \%$ of the U.S. population will reside in large metropolitan areas, the supercities. Issues of environmental quality due to this concentration of growth are bound to become critical. Global warming will be one of the problems. An international workshop is planned to gather information on this problem to be used for education of the public.

During the reporting period $F$. Sherwood Rowland of the University of California, Irvine arranged a conference on atmospheric methane. Nearly 100 scientists from 10 countries attended. While carbon dioxide is 200 times more abundant than methane in the atmosphere, methane is much more efficient in absorbing and reradiating infrared energy back to the earth. The concentration of methane in the atmosphere has more than doubled in the last 200 years. A number of papers were presented on sources of methane which include swamps, peat bogs, wetlands, rice paddies and intestinal tracts of cattle, sheep, and termites. Papers were presented on methane sinks which include soil microbes and a wide variety of chemical reactions in the troposphere and stratosphere. The chair is preparing a report of the conference.

The management plan has been revised and approved by all parties as mandated by Congress. The Request for Proposal, likewise, has undergone a major revision and is being used for the FY 1992 projects.

Sincerely,

Joseph B. Knox

Director, NIGEC

April 1, 1992 


\section{PART I}

\section{MISSION}

The purpose of the National Institute for Global Environmental Change (NIGEC) is to plan jointly with the Department of Energy (DOE) and to conduct through Regional Centers a balanced research program supportive of the Department's essential mission related to Global Environmental Change. The Institute will conduct research that serves the following needs:

1. improved scientific understanding of the mechanisms of global environmental and climate change,

2. the reduction of key scientific uncertainties surrounding environmental and climate change,

3. improved assessments of the potential impact of regional environmental and climatic conditions projected for the next century,

4. development of innovative experimental or observation programs to enhance our understanding of regional scale, or ecosystem scale processes contributing to global change,

5. development and application of tools for policy and decision making that are more appropriate for the global environmental and climate change issue than those currently in use,

6. education and training opportunities to increase the flow of talented young researchers into global envirunmental change research areas, and

7. focused contributions to the education of the public, and development of new curriculum materials for educational purposes at all levels. 


\section{REGIONAL CENTERS}

The Institute's global change research is primarily performed through the Institute's Regional Centers located at Harvard University, Indiana University, Tulane University, and the University of California (Davis and Irvine), and as of September 1991, a fifth Center at The University of Alabama, Tuscaloosa.

The Regional Centers are located to serve defined geographic areas of the country (see map), and can thereby provide a means to address diversity of problems ranging from local processes to regional and global scales. Each Regional Center has the opportunity to create its own identity and selected thrusts, creating project clusters and teams that would otherwise not be operative and contributing added value to our knowledge base of Global Environmental Change. Since each Center's research program is unique, the NIGEC National Technical Advisory Committee (NTAC) performs a rigorous peer review of the projects and the integrated Center programs provides the guidance for selection of the successful research proposals.

\section{Regional Map}

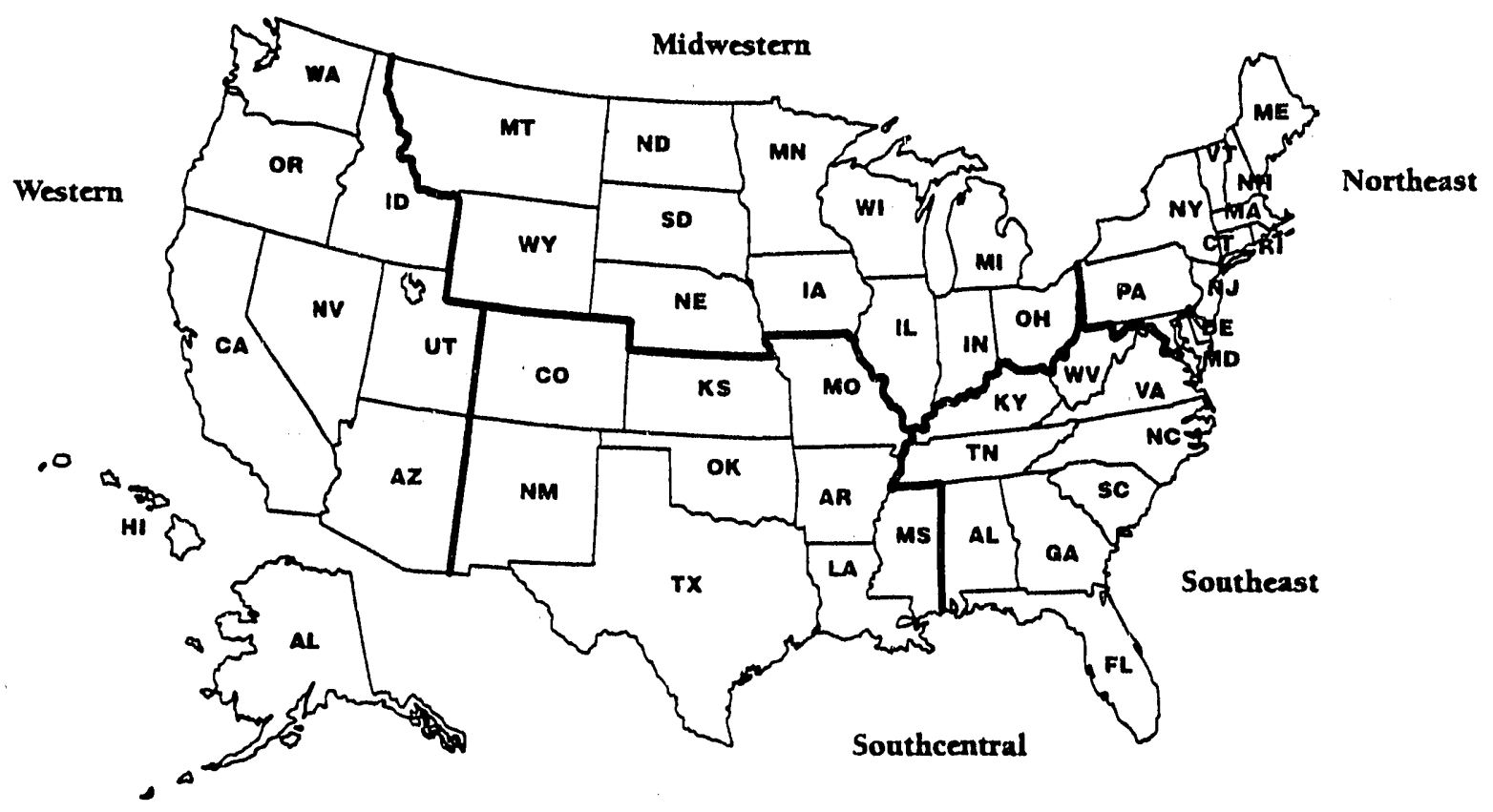




\section{EXAMPLES OF PROGRESS TOWARD RESEARCH NEEDS}

\section{Need \#1. Improved scientific understanding of the mechanisms of global environmental and climate change:}

Global $\mathrm{CO}_{2}$ Enrichment, Nutrient Dynamics, and Litter Decomposition in a Deciduous Forest Ecosystern: The Relationship between Atmospheric $\mathrm{CO}_{2}$ Levels, Plant Tissue Chemistry, and Litter Decomposition, by Fakhri A. Bazzaz, Harvard University

Three issues have been addressed in the course of the research work.

1. How temperate tree seedling growth, allocation, and physiological responses are altered by long-term elevated $\mathrm{CO}_{2}$ exposure, as a function of nutrient and light availability.

To elucidate the effects of an enriched $\mathrm{CO}_{2}$ atmosphere, six co-occurring deciduous tree species from the northeastern United States were grown for two years in a fully crossed design of light, nutrients, and $\mathrm{CO}_{2}$. The species, in the order of purported increasing shade-tolerance are: gray birch (Betula populifolia), ash (Fraxinus americana L.), red maple (Acer rubrum L.), red oak (Quercus rubra L.), yellow birch (Betula alleghaniensis Britton), and striped maple (Acer pensylvanicum) (Fowels, 1965). Seeds or germinated seedlings were collected from Harvard Forest and placed in growth chambers with controlled $\mathrm{CO}_{2}$ levels at 350 or $700 \mu \mathrm{L}$. $\mathrm{L}^{-1}$. When most of the seedlings had two true leaves, they were transplanted into 6 inch standard plastic pots with a 1:1:1 mixture of sand-perlite-peat on June 22, 1990. The transplants were then placed in glasshouse modules controlled at the corresponding $\mathrm{CO}_{2}$ level. In each glasshouse, there were three benches (blocks). Each of the three benches was divided in half and the two halves were randomly assigned to two plots. One was for high light and the other was for low light. Within each plot (i.e., light treatment) two replicate seedlings were randomly assigned to one of two nutrient treatments. This resulted in $2 \mathrm{CO}_{2} \times 2$ light $\times 2$ nutrient $\times 6$ species $\times$ 3 block $x 8$ replicates, a total of 1,152 plants.

The elevated $\mathrm{CO}_{2}\left(700 \mu \mathrm{L} . \mathrm{L}^{-1}\right)$ treatment represented the predicted values for atmospheric $\mathrm{CO}_{2}$ concentration at some time in the future, whereas the low value (350 $\mu$ L. $\mathrm{L}^{-1}$ ) was the estimated ambient $\mathrm{CO}_{2}$ level for the present decade. The high light treatment (natural light, supplemented by mercury vapor lamps) represented the light condition of a large gap in Harvard Forest $\left(300 \mathrm{~m}^{2}\right)$, whereas the low light treatment (37\% of high light) represented approximately equivalent to the light condition of understory (Sipe, 1990). The two nutrient treatments (high and low) simulated high nutrient deposition and organic matter mineralization rates (equivalent to $400 \mathrm{Kg} \mathrm{N}^{-1}$ $\mathrm{yr}^{-1}$ ) and nutrient-poor forest soil at Harvard Forest (equivalent to $40 \mathrm{Kg} \mathrm{N} \mathrm{ha}{ }^{-1} \mathrm{yr}^{-1}$ ), respectively (Aber et al., 1989). 
All leaves that naturally fell off or fell in response to a gentle touch were collected before the final harvest for leaf litter chemical analysis. When the leaves of most plants had fallen off ( 180 days after transplanting) one-third of the plants were harvested in the middle of November, 1990 to obtain the first year growth, and the remainder of the plants were moved into a garden for overwinter. In the beginning of April, 1991, plants were moved back to the glasshouse to receive the same $\mathrm{CO}_{2}$, light, and nutrient treatment as in the first year, and were repotted in 8 inch standard plastic pots. Another one-third of the plants were harvested in the middle of November, 1991. The last one-third of the plants are now in the garden for winter and will be moved back to the glasshouse $\mathrm{CO}_{2}$ modules in April, 1992.

In the first year, elevated $\mathrm{CO}_{2}$ environments significantly stimulated relative growth rate of all species. Therefore, plants grown at elevated $\mathrm{CO}_{2}$ levels were significantly heavier than those grown at ambient $\mathrm{CO}_{2}$ levels. Generally this was more pronounced under low light. The greatest stimulation of plant weight was found under the condition of low light and high nutrients. However, individual species responded differently to elevated $\mathrm{CO}_{2}$. Among the three early-successional species (gray birch, ash, and red maple), a significant increase in plant growth under elevated $\mathrm{CO}_{2}$ conditions was found only with high nutrients (see figure). The three late-successional species grown under elevated $\mathrm{CO}_{2}$ conditions (red oak, yellow birch, and striped maple) showed a greater percent increase in growth in low light than in high light. Thus, for the earlysuccessional species, the degree of enhancement of growth by elevated $\mathrm{CO}_{2}$ was more sensitive to nutrient levels, while in the late-successional species the enhancement was more sensitive to the level of light.

In the second year, however, high $\mathrm{CO}_{2}$ levels did not enhance relative growth rate (RGR) for all species. It significantly constrained RGR in red maple and yellow birch. Although plants grown at high $\mathrm{CO}_{2}$ levels still had greater size than those grown at ambient $\mathrm{CO}_{2}$ levels, the percent increase of plant weight (the ratio of total weight of plants grown at high $\mathrm{CO}_{2}$ levels to that of plants grown at ambient $\mathrm{CO}_{2}$ levels) in the second year declined for all species in the low light and low nutrient environment. In the other environments, the second year percent enhancement of biomass due to growth in elevated $\mathrm{CO}_{2}$ relative to ambient, either increased or decreased from the first year for the different species. The greater size of plants grown at high $\mathrm{CO}_{2}$ levels in the second year was primarily due to their greater RGR in the first year. Analysis of root biomass showed that in both years plants were not root-bound. How long the stimulation of plant weight in high $\mathrm{CO}_{2}$ environments can be observed depends on species and on the levels of other resources in environments.

2. How elevated $\mathrm{CO}_{2}$ concentrations and different nutrient environments influence the litter quality and litter decomposition rates from leaves of six deciduous tree species.

Leaf litter of the first year plants were analyzed by Dr. Melillo's lab. The results showed that a high $\mathrm{CO}_{2}$ environrnent in general, decreased plant tissue nitrogen content $(\% \mathrm{~N})$, and increased plant tissue lignin content $(\% \mathrm{~L})$. Thus $\mathrm{L} / \mathrm{N}$ ratios increased in high 


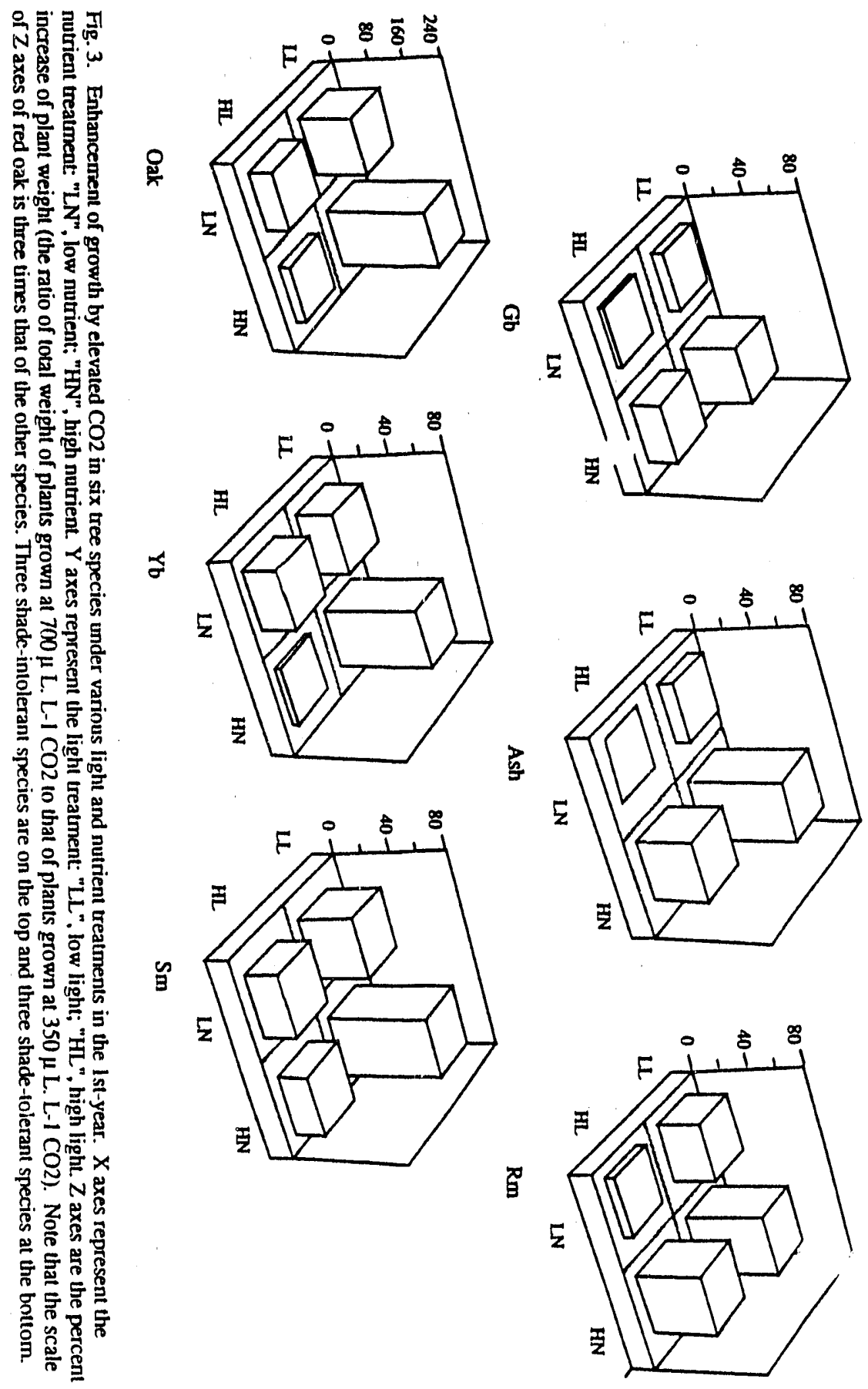


$\mathrm{CO}_{2}$ environments in most species. $\mathrm{C} / \mathrm{N}$ ratios in general increased with elevated $\mathrm{CO}_{2}$ for all environmental treatments and all species with the exception of the earlysuccessional species (gray birch, ash, and red maple) grown in high light and low nutrient conditions. For almost all treatments, the annual decay constant, $k$, is lower in elevated $\mathrm{CO}_{2}$ relative to ambient $\mathrm{CO}_{2}$ conditions; this implies a slower rate of decomposition for tissue grown in elevated $\mathrm{CO}_{2}$. An elevated $\mathrm{CO}_{2}$ environment will thus alter the amount, quality, and decomposition rates of leaf litter in temperate forest systems. These changes may decrease nutrient availability in the soil in a high $\mathrm{CO}_{2}$ world, which in turn may decrease future photosynthetic capacity of the trees. Leaf litter of the second year plants will also be analyzed by Dr. Melillo's lab.

3. How elevated $\mathrm{CO}_{2}$ influences rates of seasonal senescence in northeastern deciduous trees.

Five tree species from a New England deciduous forest ecosystem were exposed to a simulated autumn at ambient and double-ambient $\mathrm{CO}_{2}$ levels in environmental growth chambers. Air temperature and photoperiods were modified on a weekly basis to mimic conditions observed in a typical deciduous forest understory environment. Leaf abscission rates, photosynthesis, transpiration, chlorophyll, and leaf nitrogen content were monitored. Elevated $\mathrm{CO}_{2}$ had a significant impact on the dynamics of leaf fall, especially when nutrients were in short supply. Gray birch and striped maple had much higher rates $\mathrm{c} f$ leaf fall earlier in the season under elevated $\mathrm{CO}_{2}$ and low nutrients. However, red maple and yellow birch showed minimal differences in leaf fall over time. The impact of elevated $\mathrm{CO}_{2}$ levels on the chlorophyll content of leaves was more pronounced when nutrients were plentiful. The nature of this effect varied between species. For gray birch, the rate of chlorophyll degradation was greater during the early phases of senescence under elevated $\mathrm{CO}_{2}$. For the other species, the reverse pattern was observed. These results demonstrate that species-specific patterns of autumnal senescence in temperate deciduous forests are likely to change in a future elevated $\mathrm{CO}_{2}$ world, which may have an important impact on end-of-season carbon gain and nutrient cycling with the forest ecosystem.

Note: Figures showing the relative growth rate, total weight of the seedlings grown under warmer conditions, and leaf litter are presented in the Research Projects section. 


\section{Need \#2. The reduction of key scientific uncertainties surrounding environmental and climate change:}

\section{Global Warming Effects on the Release of Light Hydrocarbons from Gas Hydrate Deposits, by S. G. Schwarz and V. T. John, Tulane University}

This project involves the potential release of methane and other light hydrocarbons from gas hydrate (clathrate) deposits in Arctic regions, and its relationship to global warming. It is reported that the globally averaged tropospheric methane concentration has increased at a rate of about $1 \%$ per year during the decade beginning 1978 (Cicerone and Oremland, 1988). A portion of this increase may be from gas hydrates as evidenced by recent observations of NOAA satellites above the Arctic area (Matson, 1986; Kienle et al., 1983). Infrared imagery shows large plumes which may depict the results of gas hydrate instabilities brought on by the decline of the most recent ice age. As methane is a greenhouse gas, this could represent a significant contribution to global warming and therefore warrants further investigation. Our efforts to date have focused on evaluating the plausibility of the methane hydrate plume hypothesis and on developing a plume model to estimate the amount of carbon which is deposited in the atmosphere from observed plumes.

It is hypothesized that there is a direct link between the plumes sighted in the Arctic area and methane hydrate destabilization. Because of a downward propagating temperature wave due to the decline of the last ice age and corresponding inundation of the permafrost by the rising sea, methane hydrates located under the Arctic permafrost are melting, releasing the trapped hydrocarbons. It is suggested that, with a sufficient build up of pressure, the methane migrates along fault lines and expands substantially as it is released into the sea. Transported up to the sea surface, the gas bubbles burst, carrying with it into the atmosphere sea water in the form of jet and film drops. A large atmospheric plume is formed containing methane, water, and entrained air and water.

In our research effort, we have addressed a number of questions, the first being, "Are methane hydrates a plausible source of atmospheric methane?" We feel there exists enough evidence in the literature to support the possibility that the plumes appearing in the vicinity of Bennett Island are a result of methane hydrate destabilization. The documented existence of hydrates in the area (Kvenvolden, 1988; MacDonald, 1990), the calculations involving sea level drop during the ice age (Fairbanks, 1989; CLIMAP, 1976; Clarke et al., 1990), the calculations involving time scales of destabilization (Nisbet, 1990; MacDonald, 1990), and the images provided by satellites (Kienle et al., 1983), all lend credence to the hypothesis.

The second question relates to the state of the methane reaching the sea surface. This is critical as it provides initial conditions for the atmospheric plumes. It is proposed that as hydrates destabilize, gas accumulates and increases in pressure until it ruptures, possibly along fault lines which are known to exist in the area (Clark et al., 1990). The 
gas is vented into the sea where it is broken up into small bubbles. Assuming initial sonic velocity, preliminary calculations show that bubbles ranging in size from $1 \mathrm{~mm}$ to $1 \mathrm{~cm}$ will reach terminal velocities ranging from $<1 \mathrm{~m} / \mathrm{s}$ to $5 \mathrm{~m} / \mathrm{s}$ by the time they reach the sea surface $40 \mathrm{~m}$ above, the estimated depth of water at the plume source (Clark et al., 1990). Preliminary temperature calculations show that the $-45 \mathrm{C}$ to $-60^{\circ} \mathrm{C}$ plume top temperatures derived from satellite imagery (Matson, 1986; Kienle et al., 1983) are not possible due simply to expansion of gas from the sea floor to the estimated $7 \mathrm{~km}$ plume top height. We therefore feel a significant temperature drop occurs as the gas is forced from below the mud line into the sea, where a significant pressure drop is likely. This means the gas is probably very cold when it reaches the sea surface. Various estimates for initial temperature and velocity will be used in the model to obtain a plume which corresponds to known data.

The third question addressed regards the origin of water in the plume. Since the observed plume is the manifestation of water condensation, it becomes particularly necessary to understand the origin and propagation of the water aerosol, in order to match satellite thermal and infrared imaging data to our plume models. Several conjectures arise regarding the origin of the water aerosol: (1) Does expansion of methane subsequent to egress from the ocean cause sufficient cooling to nucleate atmospheric water vapor and form the observed plume? (MacDonald, 1990); (2) Does entrainment of the surrounding water-saturated air into the rising methane containing plume lead to a source of nucleating water in the plume? (Matson, 1986); and, (3) Does cold bubble rise in the ocean entail entrainment of frozen water and residual hydrate which form the frozen nuclei that are ejected into the atmosphere? (Clarke, 1990).

We, however, are considering another major contribution to the water aerosol based on the well-characterized physics of bubble breakage and thin film stability. The proposition is as follows. When methane bubbles reach the bulk air-water interface, they burst, releasing water droplets. These droplets are aerosol sized and can be easily transported into the atmosphere by the methane plume. When exposed to the low atmospheric temperatures the droplets can freeze, leading to ice nuclei which are also propagated by the methane plume.

The concept of water aerosol formation from bursting bubbles was first discussed in early 1950's by Woodcock, to explain salt nuclei in marine air and the transmission of marine microorganisms to coastal areas (Woodcock, 1953, 1955). The bubbles in this case are created when wave breakage entrains air into the sea, but the resulting bubble rise and breakage phenomenon should be universally valid; indeed, the mechanistic details of cloud formation have been linked to droplet ejection upon bubble breakage (Blanchard, 1969). The physics of bubble breakage has been extensively studied by several researchers; Blanchard (1989) has written an excellent review of the subject. 
Initial order of magnitude calculations indicate that a given bubble can generate at least a lundredth of its volume in aerosol production, primarily through the jet droplets. This compares favorably to the magnitude of the maximum entrainment of water from atmospheric water vapor. If, for example, the atmosphere was considered to be at $273 \mathrm{~K}$, the vapor pressure of water is about $4 \mathrm{~mm} \mathrm{Hg}$, which implies that the volume fraction of water vapor in the atmosphere is $0.5 \times 10^{-2}$, or half the aerosol production from bubble breakage. Thus, we do feel that the aerosol produced by bubbles breakage is at least as important as the contribution from entrainment of surrounding air. This information will be incorporated into the plume model boundary conditions to simulate aerosol dispersion characteristics in the plume.

The fourth question we have considered is, "Can the observed plumes be modeled by plausible boundary conditions defined by an expansion/bubble/droplet entrainment scenario?" The model being developed will predict plume trajectory, width, velocity, species concsntration, and temperature downstream of ejection from the sea surface into the stratified ambient, with gas properties at the ejection point used as boundary conditions. It will help determine if the methane hydrate scenario is plausible, and if so, estimate the quantity of methane released. After guessing some boundary conditions (ejection velocity and area, which are what we ultimately wish to determine) and calculating the plume trajectory and properties, we can compare the output with the observational data we have. If our guessed boundary conditions produce a plume similar to the observations, we have 2 reasonable estimate of the amount of carbon injected into the atmosphere.

The final question addresses the estimated methane released by observed plumes. A goal of our research is to determine the significance of the contribution from the destabilization of methane hydrates to the overall methane budget. This is being accomplished through our development of a model, giving consideration to existirg models dealing with industrial discharge (Davis, 1990; Hirst, 1971), yet specifically tailored to the Arctic hydrate plumes.

Note: References are included in the Research Projects section. 


\section{Need \#3. Improved assessments of the potential impact of regional environmental and climatic conditions projected for the next century:}

Analysis and Synthesis of Models for the Effect of Climate Change on Agricultural Systems, by S. Geng, R. Plant, and R. Loomis, University of California, Davis

\section{Objectives}

Crop Model Development: Our objectives are (1) to develop a new integrative physiological-morphological model of the whea crop that will behave realistically in high- $\mathrm{CO}_{2}$ environments, and (2) to update the ALFALFA model to match the wheat model's photosynthetic structures and microclimates.

Impact Assessment: Assess the impacts of climate and predicted climate change on dryland spring wheat yields and rice yields in the United States.

\section{Product}

Crop Model Development: Documented and tested mechanistic models of wheat (a new model) and alfalfa (modification of an existing model) that incorporate known physiological effects of $\mathrm{CO}_{2}$, air temperature, and soil water content within the framework of whole-plant growth and productivity.

Impact Assessment: Quantified impact of weather change on United States rice and wheat yields.

\section{Approack}

Crop Model Development: Wheat

Canopy photosynthesis subroutine. Programming for the canopy photosynthesis subroutine is complete and has been tested extensively and polished. The subroutine includes a modified Duncan canopy model for simulation of radiation interception (direct, diffuse, and transmitted radiation from any source through $\underline{n}$ leaf layers of any optical properties and any elevation and azimuth of display) and advanced leaf physiology (modified Farquhar-von Caemmerer photosynthesis model beginning with photon-excited electron transport and responsive to any level of stomatal conductance, temperature, and $\mathrm{CO}_{2}$.

Canopy environment subroutine. Programming, testing, and polishing are also nearly complete for a new microclimate model. This subroutine interacts with stomatal conductance to consider radiation and energy balances of each leaf. These are 
assembled (with aerodynamic transport, photosynthesis rate, and canopy resistance) to provide distributions of vapor pressure $\left(\mathrm{e}_{\mathrm{a}}\right)$, leaf temperature $\left(\mathrm{T}_{1}\right)$, and $\mathrm{CO}_{2}$. The last portion of this section (canopy thermal radiation exchange) is ready for assembly.

Soil processes. Subroutines are also complete for soil water balance (infiltration, runoff, drainage, and root uptake) and soil heat flux (leading to the profile of $\mathrm{T}_{\mathrm{s}}$ ). Thieir performance in preliminary tests is very good. A preliminary fine-root model (growth, development, water uptake) is also complete.

Plant development. Concepts for the subroutine dealing with developmental advance (phenology) have been selected and are now ready for programming.

Plant growth. Concepts for the subroutine dealing with plant growth have been selected and are nearly ready for programming.

Other. It is now clear that $e_{a}\left(\right.$ or $\left.e^{*}-e_{a}\right)$ and $\mathrm{CO}_{2}$ have direct effects on respiration, growth, and development as well as on photosynthesis. We have the clearest handle on the effects on respiration. What will be needed in the wheat model remains to be letermined.

Crop Model Development: Alfalfa

Soil temperature. A new soil temperature subroutine has been completed, validated, and submitted for publication.

Fine-root growth. A new fine-root subroutine has been completed and validated and is being prepared for publication.

Partitioning of new assimilates. Difficulties continue in choosing better concepts about pools of nonstructural carbohydrates in shoot, crown, and root tissues ard for transport among them. One major effort, at least to this point, proved unsatisfactory.

Impact Assessment: We have developed a general method to assess climate impacts on crop yields that involves a hierarchy of three types of models: a GCM, a weather generator, and a crop simulation model. Although the direction and magnitude of climate change as a result of doubling of $\mathrm{CO}_{2}$ is uncertain, this method can be reapplied if and when there is a better prediction of the expected climate change. This method may be applied with any GCM output and any crop model. The easily used weather generator and a reliable crop model are the keys to this assessment method. We have produced a method that shows the aspects of weather and climate that most heavily impact crop yields under current climate conditions. It also shows on average the kinds of changes to be expected with a given climate change. This is much more informative for assessment and mitigation purposes than perturbing one year of observed weather data and making broad statements about expected changes based on that one year. 


\section{Results to Date}

Wheal Model: Work on the wheat model is progressing well but will not be finished by the tine funding is exhausted on December 31, 1991. We are keeping in mind the need not orly for a robust wheat model but also for the ease with which this can be translated to a "big leaf" for direct coupling with mesoscale or large GC models and to generic grassland.

Alfalfa Model: Performance in hot climates and with moisture stress. The model was modified slightly in partitioning (a "shielded" reserves pool was added), respiration (quiescence under extreme stress), and response functions at high temperature.

Validation under low-elevation desert conditions of California (Imperial Valley) was excellent, as was the models performance in rescarch on irrigation management.

Impact Assessment: Keisults indicate that rice yields decrease by between $14 \%$ and $24 \%$ in the Gulf Coast states and between $11 \%$ and $21 \%$ in California. In both regions the decrease in rice yields was due primarily to the large increase in summer ternperatures. On the other hand, drylana fall-planted spring wheat yields in California increase by $62 \%$ and $125 \%$. This is because of the increased rainfall and temperatures during the winter months in California. 


\section{Need \#4. Development of innovative experimental or observation programs to enhance our understanding of regional scale, or ecosystem scale processes contributing to global change:}

\section{The Utilization of Sclerochronology to Establish Sea-Surface Temperature}

Fluctuation, by Ivan Gill, Tulane University and Dennis K. Hubbard, West Indies Laboratory

Introduction: The following report summarizes the activities of the NIGEC-sponsored coral drilling project from May through December 1991. The sample collection cruise spanned the dates June 16 - July 16, 1991 and was conducted off the southwesterı corner of Puerto Rico. Major drilling equipment was picked up from the West Indies Laboratory on St. Croix and delivered to Puerto Rico by the R/V Isla Magueyez, operated by the University of Puerto Rico (UPR). Operations in Puerto Rico were conducted off the R/V Pezmar, also operated by UPR.

Objective: The major thrust of the project is to evaluate stable isotopic sclerochronology as a tool for establishing a record of sea-surface temperatures, and if the method is viable, to produce such a record over a several century time-span. Field collection consisted of the collection of thirteen cores from single colony coral heads, as well as the collection of eight reef cores, collected with cooperative funding from NOAA. The latter show the record of Holocene reef accretion in the area and in some instances contain intervals cored through intact single coral heads that may extend the time range of temperature records. Current results of the analysis of the coral cores and reef cores are described below.

Product: This research will result in two major products:

1. Preliminary evaluation of coral isotopic records as proxies for long (greater than two centuries) time intervals.

2. A long-term (greater than two centuries) record of sea-surface temperatures for the northeastern Caribbean. This record will be a starting point for other localities worldwide, and will be free of many of the uncertainties that hinder the interpretation of terrestrial records.

\section{Approach and Results to Date}

Dive Operations: During June and July, 1991 a total of 158 dives were made by personnel associated with the program. Bottom time on logged dives totalled 274 hours and 31 minutes. Average bottom time was 105 minutes and 35 seconds, the extended time being related to the shallower depths $(20-40 \mathrm{ft})$ where most operations were conducted. At deeper depths, three dives were typically made by each diver per day. The maximum depth of operations was $100 \mathrm{ft}$. This was a reconnaissance dive, however, and no drilling was attempted at this depth. The maximum depth of drilling operations was ca. $45 \mathrm{ft}$. 
Reef Coring: Eight reef cores were recovered from the shelf off La Parguera, with a maximum length of $30 \mathrm{~m}$ below the reef surface. PAR-8 exceeded $30 \mathrm{~m}$ in length, far greater than any cores yet recovered by similar drilling systems. The distribution of cores reasonably spans the cross-shelf environments that exist in the area. These cores were collected with funding from NOAA, and may be useful in extending the record of temperature and reef growth farther into the Holocene. All reef cores have been sectioned and examined for gross characteristics and final logs have been completed.

Coral Coring: Thirteen cores of various lengths were recovered from three sites on the La Parguera shelf. Eight cores were recovered from the forereef east of the island of Turromote. Three additional cores were recovered from the front of another ridge located roughly $800 \mathrm{~m}$ seaward of the above site. A single, short $(\mathrm{ca} 60 \mathrm{~cm})$ core was recovered from a colony at the shelf edge.

The longest core exceeded $6 \mathrm{~m}$ in length. Because of intense bioerosion in the area, however, only the upper $2 \mathrm{~m}$ of this was continuous and crn be used for detailed sclerochronology. The longest uninterrup $1: \mathrm{d}$ record is $2.52 \mathrm{~m}$ in length. At an extrapolated linear-extension rate of $0.80 \mathrm{~cm} /$ year, this $2.52 \mathrm{~m}$ of growth would result in a proxy record of 315 years. While our dating precision will obviously drop below the breaks in recovery, the potential still exists for a much longer record from these cores. Also, we recovered several long $(0.50-1.00 \mathrm{~m})$ sections of $M$. annularis in our reef cores, described briefly below. Radiocarbon dates are unavailable at this time, but it is anticipated that these corals are 3,000-6,000 years old. Therefore, the possibility may exist to recover century-long records of temperature from much earlier times.

The cores have been slabbed and logged at Tulane University, and $\mathrm{x}$-radiography is close to completion. Samples for radiometric dating are presently being taken from the cores, and will be sent out for analysis. Radiometric dating results are expected in early Spring. Initial micro-sampling of the coral growth banding will start following the completion of $x$-radiography. Sample treatment will include sodium hypochlorite bleaching or treatment with a low-temperature plasma asher, depending on the results of initial treatment experiments. All samples subsequently analyzed for stable isotopes will be treated as identically as is practicable.

Note: The complete description of this project and examples of drilling logs of reef cores taken close to the coral head drilling site are included in the Research Projects section. 
Need \#5. Development and application of tools for policy and decision making that are more appropriate for the global environmental and climate change issue than those currently in use:

\section{Fuel Switching Impacts on Carbon Dioxide Emissions from Midwestern Great Lake States Electric Utilities, by J. C. Randolph, Indiana University}

Objective: The largest single factor affecting greenhouse gas emissions is the combustion of fossil fuels. The U.S. is the largest emitter of carbon dioxide in the world, and fossil fuel-fired electric generating units are major contributors to U.S. emissions. About 20-25 percent of global $\mathrm{CO}_{2}$ emissions are from the combustion of fossil fuels in the United States and approximately $28-30 \%$ of U.S. emissions arise from electricity generation. Today, approximately six million metric tons are emitted each year from fossil fuel combustion in the United States. The Department of Energy reports that U.S. electricity generation is responsible for about 7.5 percent of total worldwide emissions of carbon dioxide.

The objective of this project is to determine the effects different sulfur dioxide emissions reduction strategies will have on cariun dioxide emissions from coal-fired electric generating plants in the Midwest. Additionally, this research will identify some policy options the Department of Energy and state regulatory agencies might implement to encourage electrical utilities to implement strategies that will reduce $\mathrm{CO}_{2}$ emissions as well as $\mathrm{SO}_{2}$ and $\mathrm{NO}_{x}$ emissions.

Product: The product of this project will be a quantitative comparison of how various $\mathrm{SO}_{2}$ emissions reduction strategies will affect $\mathrm{CO}_{2}$ emissions from coal-fired electrical generating facilities in the Midwest, and a summary of policy alternatives available to the DOE.

Approach: The operations of six Indiana utilities have been modelled with respect to the $\mathrm{SO}_{2}$ emissions control strategies they might choose in response to the Clean Air Act Amendments (CAAA) of 1990. The Electric Power Research Institute's (EPRI) TELPLAN model was used to simulate utility performance, costs, and emissions. We assumed that each utility would take a least-cost approach in meeting their sulfur dioxide emission restrictions. Interviews with senior personnel in each of the utilities indicated the strategies that utility would most likely follow. The utilities generally chose to reduce emissions by a combination of retrofitting scrubbers, by blending local high-sulfur coals with low-sulfur coals, or by using western or central Appalachian low-sulfur coal.

A scenario analysis approach was used to compare future $\mathrm{CO}_{2}, \mathrm{SO}_{2}$, and $\mathrm{NO}_{\mathrm{x}}$ emissions under a base-case scenario and three regulatory scenarios. The four scenarios are: (1) a base-case scenario representing a projection of current conditions; (2) a coalswitching scenario that incorporates a shift to low-sulfur coal or low-sulfur coal blends; (3) a technology scenario that depends totally on technological emissions control devices; 
and (4) a multi-strategy scenario that uses both scrubber technology and coal-switching c: blending. The four scenarios represent possible boundaries of the utility compliance options. The coal-switch scenario and the technology scenario are the ends of a dichotomy; whereas, the multi-strategy scenario is a compromise between the two strategies.

The TELPLAN model has been adapted to estimate $\mathrm{CO}_{2}$ emissions as well as $\mathrm{SO}_{2}, \mathrm{NO}_{\mathrm{x}}$, and particulates. The model has been used to estimate the completeness of combustion of various coals to arrive at low, medium, and high estimates of $\mathrm{CO}_{2}$ emissions. Initial estimates were based on a $75 \%$ combustion of the average carbon content of selected coals. Current work incorporates more specific characteristics for various coals.

Results to Date: Initially, research focused on modeling $\mathrm{SO}_{2}, \mathrm{NO}_{x}$, and $\mathrm{CO}_{2}$ emissions from 22 electrical generating plants in Indiana. Our findings indicate that $\mathrm{SO}_{2}$ and $\mathrm{NO}_{x}$ emissions will be reduced as utilities begin to comply with the regulations set out by the CAAA. Carbon emissions were not targeted for control by the legislation and therefore our analysis suggests that emissions of $\mathrm{CO}_{2}$ will continue to steadily increase.

Estimates of $\mathrm{CO}_{2}$ emissions that were derived from the initial analysis were refined to include more detail, including estimates of coal heating value and sulfur content. All three regulatory scenarios are structured such that all utilities meet their projected demand for electricity and that all $\mathrm{SO}_{2}$ emissions are in compliance with the 1990 CAA Amendments. The technology scenario, which relies upon widespread use of flue gas desulfurization, projects the highest $\mathrm{SO}_{2}$ emissions reductions ranging from 63 to $77 \%$. However, the widespread use of scrubbers also will produce a "scrubber tax" which results in higher $\mathrm{CO}_{2}$ emissions and electric rates. Currently, each scenario is analyzed for an optimal combination of reduced $\mathrm{CO}_{2}, \mathrm{SO}_{2}$, and $\mathrm{NO}_{x}$ emissions, fuel consumption, electricity demand, and electricity rates. Preliminary results indicate that the multistrategy approach to emissions reductions is most effective for electric utilities in Indiana. At least one other state will be examined and compared with the results from Indiana. 


\section{Need \#6. Education and training opportunities to increase the flow of talented young researchers into global environmental change research areas:}

The allocation of FY 90 funds in support of postdoctoral appointees, graduate and undergraduate students, and tuition or fee remission for young scientists involved in global environmental and climate change research is shown in the table below. Through rebudgeting, allocations for these categories of support have increased slightly since the budgets were initially prepared.

Allocation of FY 90 Funds

For Student and Postdoctoral Support

(Based on budget award, in dollars)

\begin{tabular}{|l|r|r|r|r|r|}
\hline & Midwestern & Northeast & Southcentral & Western & Total \\
\hline Postdoctorates & $\$ 19,500$ & $\$ 169,031$ & $\$ 28,000$ & $\$ 134,132$ & $\$ 350,663$ \\
\hline Grad Students & 189,360 & 19,635 & 111,367 & 204,945 & 525,357 \\
\hline Undergrads & 6,000 & 32,636 & 8,800 & 30,700 & 78,136 \\
\hline $\begin{array}{l}\text { Fee Remissions, } \\
\text { Stipends }\end{array}$ & 28,000 & $-0-$ & 14,000 & 7,500 & 49,500 \\
\hline TOTAL & $\$ 242,860$ & $\$ 221,302$ & $\$ 162,167$ & $\$ 377,327$ & $\$ 1,003,656$ \\
\hline
\end{tabular}

Because research on FY 90 awards did not actually commence until September 30, 1991, nearly all projects have carried over into the second year. At the end of the first fiscal year, June 30,1991, actual expenditures in support of students and postdoctoral appointees are as shown in the table below. Expenditures at June 30, 1991 were $43 \%$ of the monies allocated for these categories of support.

Actual Expenditures of FY 90 Funds as of June 30, 1991

For Student and Postdoctoral Support

\begin{tabular}{||l|r|r|r|r|r||}
\hline & \multicolumn{1}{|c|}{ Midwestern } & \multicolumn{1}{c|}{ Northeast } & \multicolumn{1}{c|}{ Southcentral } & \multicolumn{1}{c|}{ Western } & \multicolumn{1}{c|}{ TOTAL } \\
\hline Postdoctorates & $\$ 2,700$ & $\$ 151,099$ & $\$ 23,077$ & $\$ 50,553$ & $\$ 227,429$ \\
\hline Grad Students & 83,850 & 15,598 & 23,479 & 41,877 & 164,804 \\
\hline Undergrads & 2,811 & 11,173 & 8,110 & 7,020 & 29,114 \\
\hline $\begin{array}{l}\text { Fee Remissions, } \\
\text { Tuition }\end{array}$ & 1,768 & $-0-$ & 12,783 & $-0-$ & 14,551 \\
\hline TOTAL & $\$ 91,129$ & $\$ 177,870$ & $\$ 67,449$ & $\$ 99,450$ & $\$ 435,898$ \\
\hline
\end{tabular}




\section{Need \#7. Focused contributions to the education of the public, and development of new curriculum materials for educational purposes at all levels:}

Planning is proceeding for an international workshop entitled "Supercities" scheduled for October 26-30, 1992 in San Francisco.

As we approach and enter the 21st century it is projected that a very large fraction of the world's population, six billion, will live in supercities. For example, the prediction for the U.S. is that $90 \%$ of our population will reside in large metropolitan areas, the supercities. These infrastructural focal areas will be huge users of resources and energy. National demand for energy and resource materials will be largely determined by the management and structure of the supercities. Regional as well as global environmental concerns will be coupled to these regions of human activity. Many of the immigrants to the supercities will be escaping from a declining quality of life, and from rural regions whose natural resources are being or have been exploited. The supercities in the developing nations of the Pacific Basin are at critical stages of development in that appropriate technology transfer, sharing of knowledge and common concerns, and the seeking of workable conservation measures could improve living conditions within the supercities, and address regional and global environmental degradation at the same time. Consequences of particular concern for this Workshop are:

a) the environmental degradation that resulit from the consumption of energy resources, the destruction of natural environments (open space) resulting from the consumption of other resources including land, high population densities and the like, and

b) the loss in real per capita income (and quality of life) which results from both an inefficient use of resources and the inadequate design and management of these supercities.

Corporations of the world are participants in the economic growth of the supercities through transfer of jobs from industrial nations to other countries. These enterprises can have ar international impact on the quality of life of the people of many nations. The governments are generally concerned for the economic stability and growth as well as improving the quality of life of their citizens.

It is the vision and goal of the Supercities Workshop to develop a better understanding of the problems arising from the development of supercities. Our efforts are viewed as a part of the unprecedented cooperation that is deemed necessary by many for our planet to cope with its expanding population, the hopes for a better quality of life that seems to be universal, and the objective of living more in harmony with nature than as an exploiter of natural resources. 


\section{MANAGEMENT}

The management plan for NIGEC has been revised. The management elements are shown in the organization chart on the following page.

\section{Role of the Regents of the University of California and the Omice of the President}

The Department of Energy's Environmental Sciences Division (a division within the Office of Health and Environmental Research) sponsors NIGEC. The Office of Environmental Analysis of the DOE Policy Office represents DOE on policy related research. The Regents of the University of California is the management entity of the bilateral agreement with DOE. The DOE provides guidance and definition of the program mission and balance and participates in program evaluation.

Per the Cooperative Agreement between DOE and the Regents of the University of California, the Regents subcontract with host institutions who administer regional research programs. Each host institution is responsible for the nomination and appointment of a Director of its Regional Center; that appointment requires prior DOE approval. Similarly, the host institution is responsible for the periodic evaluation of its Regional Center Director, with required input from the NIGEC Director.

The NIGEC Director is appointed, with prior DOE approval, by the President of the University of California from a short list of candidates developed by the Board of Trustees following consultation with the Regional Directors and the Board of Trustees.

The Office of the President of the University of California is responsible for the administrative and scientific integrity of NIGEC.

\section{Board of Trustees}

The twelve (12) members of the Board of Trustees of NIGEC are appointed by the UC Office of the President with concurrence of DOE and in consultation with the host. institutions. Each host institution shall nominate two candidates, one shall be from the host institution and one from outside the host institution, who shall be a scientist. Host institution nominees cannot receive NIGEC research funds. There will also be two members from DOE. The NIGEC Director will serve as an ex-officio and non-voting member of this Board. This Board shall elect its own chair and vice-chair.

The functions of the Board are:
a. to develop a slate of nominees for the NIGEC Director,
b. to concur on changes in the Management Plan and the RFP process, 
c. to conduct the annual review and evaluation of the Institute Directorate at the request of and in conjunction with the UC Office of the President, and

d. to assess, on an annual basis, the overall scientific research contributions and operation of NIGEC, including its value, effectiveness, and role as a national institute for research on global environmental change.

\section{National Institute Omice}

The National Institute Office is to be composed of a Director who will be assisted by a small supporting staff for resource management and administration. The National Institute Director shall act in a collegial manner considering the Regional Center Directors' perspectives. The responsibilities of the Director include:

- development and implementation of a strategic research plan,

- administration of the national office,

- appointment and operation of the National Technical Advisory Committee,

- dissemination of information about NIGEC,

- $\quad$ liaison with DOE,

- administration of the RFP process,

- obtaining National Technical Committee reviews of proposals,

- administration of exploratory projects, and

- development of programs within the Regional Centers to enrich programs, support young researchers, and support exploratory research. 


\section{Organizational Chart}

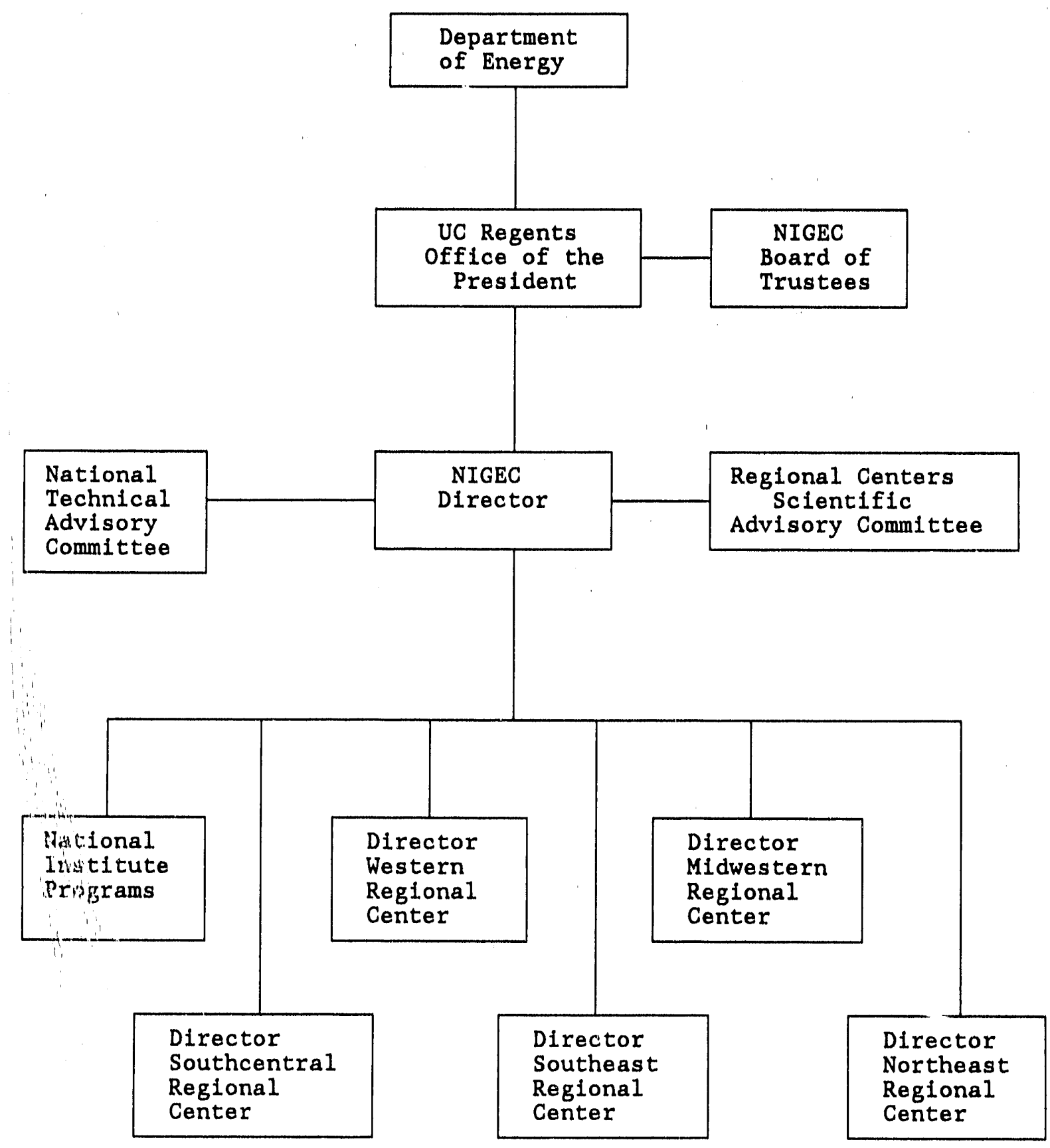


National Technical Advisory Committee (NTAC)

The National Technical Advisory Committee is appointed by the NIGEC Director in consultation with the Regional Center Directors and with the approval of DOE.

1992 NTAC Reviewers

Karl K. Turekian, Chair

Yale University

Dave Schimel

Michael Bender

University of Rhode Island

Judith A. Curry

Pennsylvania State University

Thomas Donahue

University of Michigan

Elizabeth Holland

NCAR

Jim Holton

University of Washington

Richard Houghton

Woods Hole Research Center

Gregg Marland

Oak Ridge National Lab

Gerald R. North

Texas A\&M University

William Patrick, Jr.

Louisiana State University

UCAR/CSMP

Andrew Solow

Woods Hole Oceanographic Institute

Martin Wahlen

UC San Diego

Steven Eisenreich

University of Minnesota

William Fulkerson

Oak Ridge National Lab

Joan Gosink

Colorado School of Mines

Michael Rampino

New York University

Duncan T. Patten

Arizona State University

Paul Zinke

UC Berkeley

Paul Waggoner

Agricultural Experiment Station 


\section{Regional Centers Scientific Advisory Committee (RCSAC)}

RCSAC consists of the NIGEC Director as chair, a DOE appointee, and two members appointed by each Regional Center host institution. The addresses of the host institutions are given in the Indices section. The purpose of this group is to provide a forum for discussion to enhance the regional research programs, build cross-awareness of each Center's program, develop new themes of Global Environmental Change research, and promote themes of research supportive of the DOE priority research areas.

\section{Regional Center Directors}

\section{J. C. Randolph, Director, Midwestern Regional Center, Indiana University}

Richard Wilson, Director, Northeast Regional Center, Harvard University

Robert G. Watts, Director, Southcentral Regional Center, Tulane University

Robert A. Griffin, Director, Southeast Regional Center, The University of Alabama

Marvin Goldman and F. Sherwood Rowland, Co-Directors, Western Regional Center, University of California

The Regional Center Directors have responsibility for:

- development of coherent regional programs, soliciting by appropriate mechanisms proposals for excellent projects that will play an integral role in these programs, and screening and selecting projects for the Regional Center package based on a regional technical screening review, to be submitted to NIGEC for technical review,

- development of research thrusts or themes that bring programmatic focus to areas important for global environmental change,

- daily operational matters including development of the program and conduct of the research in conjunction with the principal investigators,

- the RFP process within their institution and their Center's geographical region,

- preparation of an annual research package and a regional management plan,

- preparation of semi-annual and annual reports, and

- as an outreach goal, awarding a minimum of $50 \%$ of the research funding outside the host institution. 


\section{FINANCIAL REPORT}

This Financial Status Report is submitted in compliance with the terms of Cooperative Agreement No. DE-FC03-90ER61010 between the U.S. Department of Energy and the University of California, Davis. It has been prepared by Bette B. Francis, Fiscal Officer for NIGEC, from the fiscal reports provided by the four Regional Centers, as required in the subcontracts between the University of California, Davis and the four universities: Indiana University, Harvard University, Tulane University, and the University of California.

\section{Accounting Procedures}

The method of payment of the prime agreement between U.S. DOE and UC Davis is via advance payments as provided in the Terms and Conditions of the Federal Demonstration Project. Payment to the Regional Centers is made, per the terms of the subcontracts, on a cost reimbursable basis from invoices submitted no more frequently than monthly and no less frequently than quarterly.

Invoices submitted by each Regional Center detail expenditures for each project, in the categories typical in federal and academic accounting procedures. A cumulative invoice compiles the totals for each Regional Centel, including a summary status provision to authorize the amount due the Regional Ceriter in that reporting period. Project reports and cumulative invoices are compiled and authorized by:

\author{
Indiana University \\ Harvard University \\ Tulane University \\ University of California
}

Jan Young, Project Officer

Kathleen Callahan, Research Accounting

Stephen D. Warren, Restricted Funds Accounting

Barbara Silkebaken, Administrative Assistant

The NIGEC Fiscal Officer reviews these reports project-by-project and, if in compliance with approved budgets, approves and forwards the cumulative invoice to Jane Fong of the UC Davis Extramural Accounts Division. She reimburses each Regional Center for those approved expenses. Jane Fong also monitors and reviews all expenses of the National Office of NIGEC, in accordance with the terms and conditions of the Federal Demonstration Project.

Expenditures are approved based upon compliance with originally approved budgets or revisions in accord with the provisions of the subcontract. Budget revisions which require the approval of the NIGEC Director and UC Davis Office of Research are submitted by the Principal Investigator to the Regional Center Director and then through their Office of Research to the Director of NIGEC. When approved by the NIGEC Director, the budget revision is forwarded to the UC Davis Office of Research for final approval and then returned to the Office of Research of the Regional Center. Prior written approval is required for: 
1. acquisition of an item of equipment or other capital asset of value over $\$ 1,000$ not listed in the approved budget;

2. foreign travel for each separate trip not listed in the approved budget; and

3. expenditures for domestic travel exceeding the amount contained in the approved budget by $25 \%$ or $\$ 500$, whichever is greater.

Each Center has the flexibility to rebudget funds among the other direct costs, salaries, and benefits categories of each approved budget. Financial requirements detailed in OMB Circular A-110 (Attachments A, D, F, G, and J) and OMB Circular A-21, Cost Principles for Educational Institutions, apply to the subcontracts with the four Regional Centers. Budget changes and revisions are monitored in each Regional Center by:

- Indiana University, William Farquhar, Contract and Grant Administration

- Harvard University, Merrily Sterns, Office for Sponsored Research

- Tulane University, Michelle Christy, Office of Research and Project Administration

- University of California, Louise Ivey, Office of Research

\section{Anticipated Carryover}

Based on expenditures since the initiation of the projects and patterns of spending within each project, each Regional Center and the National Institute Office have projected expenditures at the end of the current fiscal year, June 30,1992, and show the anticipated carryover of funds into FY 92. All Regional Centers and the National Institute Office project that FY 90 funds will be expended by June 30, 1992; carryover will be of FY 91 projects continuing in the next fiscal year. Project-by-project projections on expenditures and carryover are shown in Part II of this report.

\section{Projected Spending and Anticipated Carryover June 30, 1992}

\begin{tabular}{||l|r|r|r||}
\hline & $\begin{array}{c}\text { FY } 90 \text { and FY } 91 \\
\text { Award }\end{array}$ & $\begin{array}{c}\text { Projected Expenditures } \\
@ 6 / 30 / 92\end{array}$ & $\begin{array}{c}\text { Anticipated } \\
\text { Carryover }\end{array}$ \\
\hline Midwestern Center & $\$ 3,275,190$ & $\$ 2,858,190$ & $\$ 417,000$ \\
\hline Northeast Center & $3,275,190$ & $2,901,862$ & 373,328 \\
\hline Southcentral Center & $3,200,190$ & $1,980,644$ & $1,219,546$ \\
\hline Western Center & $3,296,066$ & $2,338,498$ & 957,568 \\
\hline National Office & $1,705,314$ & $1,379,795$ & 325,519 \\
\hline NIGEC TOTAL & $\$ 14,751,950$ & $\$ 11,458,989$ & $\$ 3,292,961$ \\
\hline
\end{tabular}




\section{Financial Status}

A summary of FY 90 funds at June 30, 1991, for each Regional Center, the National Institute Office, and NIGEC consolidated totals follow.

\section{Midwestern Regional Center FY 90 Funds Financial Status June 30, 1991}

\begin{tabular}{|c|c|c|c|}
\hline Expense Categories & Budget Award & $\begin{array}{c}\text { Cumulative } \\
\text { Expenditures }\end{array}$ & Balance \\
\hline Salaries: Faculty & $\$ 152,922.00$ & $\$ 108,176.80$ & $\$ 44,745.20$ \\
\hline Postdoctorates & $2,700.00$ & $2,700.00$ & 0.00 \\
\hline Professionals & $43,400.00$ & $27,669.53$ & $15,730.47$ \\
\hline Graduate Students & $189,360.00$ & $83,850.00$ & $105,510.00$ \\
\hline Undergraduates & $6,000.00$ & $2,811.19$ & $3,188.81$ \\
\hline Administrative/Clerical & $9,550.00$ & $15,300.46$ & $-5,750.46$ \\
\hline Other & $17,051.00$ & $44,029.66$ & $-26,978.66$ \\
\hline Salaries Total & $420,983.00$ & $284,537.64$ & $136,445.36$ \\
\hline Benefits & $46,231.00$ & $31,543.14$ & $14,687.86$ \\
\hline Equipment & $177,397.00$ & $40,052.24$ & $137,344.76$ \\
\hline Travel: Domestic & $60,260.00$ & $36,495.02$ & $23,764.99$ \\
\hline Travel: Foreign & $5,200.00$ & 0.00 & $5,200.00$ \\
\hline Subcontracts & $89,000.00$ & 0.00 & $89,000.00$ \\
\hline Tuition/Fee Remissions & $28,000.00$ & $1,767.60$ & $26,232.40$ \\
\hline Other Direct Costs & $130,818.00$ & $100,888.37$ & $29,929.63$ \\
\hline Total Direct Costs & $957,889.00$ & $495,284.01$ & $462,604.99$ \\
\hline Indirect Costs & $325,111.00$ & $222,196.92$ & $102,914,08$ \\
\hline Uncommitted Funds & 0.00 & 0.00 & 0.00 \\
\hline TOTAL & $\$ 1,283,000.00$ & $\$ 717,480.93$ & $\$ 565,519.07$ \\
\hline
\end{tabular}


Northeast Regional Center

FY 90 Funds Financial Status

June 30, 1991

\begin{tabular}{|c|c|c|c|}
\hline Expense Categories & Budget Award & $\begin{array}{c}\text { Cumulative } \\
\text { Expenditures }\end{array}$ & Balance \\
\hline Salaries: Faculty & $\$ 77,765.00$ & $\$ 33,227.35$ & $\$ 44,537.65$ \\
\hline Postdoctorates & $169,030.50$ & $151,098.91$ & $17,931.59$ \\
\hline Professionals & $43,071.00$ & $29,588.28$ & $13,482.72$ \\
\hline Graduate Students & $19,635.00$ & $15,597.99$ & $4,037.01$ \\
\hline Undergraduates & $32,636.00$ & $11,172.52$ & $21,463.48$ \\
\hline Administrative/Clerical & $12,360.00$ & $11,010.00$ & $1,350.00$ \\
\hline Other & $24,000.00$ & $8,836.92$ & $15,163.08$ \\
\hline Salaries Total & $378,497.50$ & $260,531.97$ & $117,965.53$ \\
\hline Benefits & $84,283.96$ & $51,421.92$ & $32,862,04$ \\
\hline Equipment & $249,470.00$ & $225,072.53$ & $24,397.47$ \\
\hline Travel: Domestic & $25,238.00$ & $11,242.09$ & $13,995.91$ \\
\hline Travel: Foreign & 0.00 & 0.00 & 0.00 \\
\hline Subcontracts & 0.00 & 0.00 & 0.00 \\
\hline Tuition/Fee Remissions & 0.00 & 0.00 & 0.00 \\
\hline Other Direct Costs & $133,767.54$ & $81,221.99$ & $52,545.55$ \\
\hline Total Direct Costs & $871,257.00$ & $629,490.50$ & $241,766.50$ \\
\hline Indirect Costs & $386,537.00$ & $254,361.57$ & $132,175.43$ \\
\hline Uncommitted Funds & $25,206.00$ & 0.00 & $25,206.00$ \\
\hline TOTAL & $\$ 1,283,000.00$ & \$ $883,852.07$ & \$ $399,147.93$ \\
\hline
\end{tabular}




\section{Southcentral Regional Center \\ FY 90 Funds Financial Status \\ June 30, 1991}

\begin{tabular}{|c|c|c|c|}
\hline Expense Categories & Budget Award & $\begin{array}{c}\text { Cumulative } \\
\text { Expenditures }\end{array}$ & Balance \\
\hline Salaries: Faculty & $\$ 178,412.00$ & $\$ 116,574.32$ & $\$ 61,837.68$ \\
\hline Postdoctorates & $28,000.00$ & $23,076.94$ & $4,923.06$ \\
\hline Professionals & $12,672.00$ & $13,672.00$ & $-1,000.00$ \\
\hline Graduate Students & $111,367.00$ & $23,479.09$ & $87,887.91$ \\
\hline Undergraduates & $8,800.00$ & $8,110.23$ & 689.77 \\
\hline Administrative/Clerical & $18,000.00$ & $12,306.05$ & $5,693.95$ \\
\hline Other & $97,196.00$ & $26,675.47$ & $70,520.53$ \\
\hline Salaries Total & $454,447.00$ & $223,894.10$ & $230,552.90$ \\
\hline Benefits & $55,528.00$ & $20,836.56$ & $34,691.44$ \\
\hline Equipment & $154,747.00$ & $141,001.76$ & $13,745.24$ \\
\hline Travel: Domestic & $91,800.00$ & $55,230.28$ & $36,569.72$ \\
\hline Travel: Foreign & $34,100.00$ & $6,407.36$ & $27,692.64$ \\
\hline Subcontracts & 0.00 & 0.00 & 0.00 \\
\hline Tuition/Fee Remisisons & $14,000.00$ & $12,782.70$ & $1,217.30$ \\
\hline Other Direct Costs & $171,383.00$ & $69,062.28$ & $102,320.72$ \\
\hline Total Direct Costs & $976,005.00$ & $529,215.04$ & $446,789.96$ \\
\hline Indirect Costs & $306,884.00$ & $160,455.15$ & $146,428.85$ \\
\hline Uncommitted Funds & 111.00 & 0.00 & 111.00 \\
\hline TOTAL & $\$ 1,283,000.00$ & $\$ 689,670.19$ & $\$ 593,329.81$ \\
\hline
\end{tabular}




\section{Western Regional Center \\ FY 90 Funds Financial Status \\ June 30, 1991}

\begin{tabular}{|c|c|c|c|}
\hline Expense Categories & Budget Award & $\begin{array}{c}\text { Cumulative } \\
\text { Expenditures }\end{array}$ & Balance \\
\hline Salaries: Faculty & s $\quad 61,503.00$ & \$ $27,627.70$ & s $33,875.30$ \\
\hline Postdoctorates & $134,132.00$ & $124,728.08$ & $9,403.92$ \\
\hline Professionals & $19,816.00$ & $49,367.84$ & $-29,551.84$ \\
\hline Graduate Students & $204,995.00$ & $122,449.88$ & $82,545.12$ \\
\hline Undergraduates & $30,700.00$ & $43,412.10$ & $-12,712.10$ \\
\hline Administrative/Clerical & $20,250.00$ & $20,825.68$ & -575.68 \\
\hline Other & 0.00 & 0.00 & 0.00 \\
\hline Salaries Total & $471,396.00$ & $388,411.28$ & $82,984.72$ \\
\hline Benefits & $68,681.00$ & $48,391.36$ & $20,289.64$ \\
\hline Equipment & $116,145.00$ & $46,990.55$ & $69,154.45$ \\
\hline Travel: Domestic & $36,348.00$ & $19,901.85$ & $16,446.15$ \\
\hline Travel: Foreign & $25,987.00$ & $11,982.00$ & $14,005.00$ \\
\hline Subcontracts & $140,300.00$ & $23,727.66$ & $116,572.34$ \\
\hline Tuition/Fee Remisisons & $7,500.00$ & 0.00 & $7,500.00$ \\
\hline Other Direct Costs & $113,010.00$ & $52,702.13$ & $60,307.87$ \\
\hline Total Direct Costs & $979,367.00$ & $592,106.83$ & $387,260.17$ \\
\hline Indirect Costs & $303,633.00$ & $212,327.07$ & $91,305.93$ \\
\hline Uncommitted Funds & 0.00 & 0.00 & 00.0 \\
\hline TO'TAL & $\$ 1,283,000.00$ & $\$ 804,433.90$ & $\$ 478,566.10$ \\
\hline
\end{tabular}


National Institute Office

FY 90 Funds Financial Status

June 30, 1991

\begin{tabular}{|c|c|c|c|}
\hline Expense Categories & Budget Award & $\begin{array}{c}\text { Cumulative } \\
\text { Expenditures }\end{array}$ & Balance \\
\hline Salaries: Faculty & $\$ 150,005.00$ & $\$ 142,705.21$ & $\$ 7,299.79$ \\
\hline Postdoctorates & 0.00 & 0.00 & 0.00 \\
\hline Professionals & $113,227.00$ & $97,207.66$ & $16,019.34$ \\
\hline Graduate Students & 0.00 & 0.00 & 0.00 \\
\hline Undergraduates & 0.00 & 0.00 & 0.00 \\
\hline Administrative/Clerical & $77,542.00$ & $64,186.34$ & $13,355.66$ \\
\hline Other & 0.00 & 0.00 & 0.00 \\
\hline Salaries Total & $340,774.00$ & $304,099.21$ & $36,674.79$ \\
\hline Benefits & $56,623.00$ & $51,180.63$ & $5,442.37$ \\
\hline Equipment & $85,202.00$ & $66,137.00$ & $19,065.00$ \\
\hline Travel: Domestic & $45,218.00$ & $30,416.50$ & $14,801.50$ \\
\hline Travel: Foreign & $5,000.00$ & $2,356.00$ & $2,644.00$ \\
\hline Subcontracts & 0.00 & 0.00 & 0.00 \\
\hline Tuition/Fee Remisisons & 0.00 & 0.00 & 0.00 \\
\hline Other Direct Costs & $98,736.00$ & $91,075.22$ & $7,660.78$ \\
\hline Total Direct Costs & $631,553.00$ & $545,264.56$ & $86,288.44$ \\
\hline Indirect Costs & $152,447.00$ & $118,753.32$ & $33,693.68$ \\
\hline Uncommitted Funds & 0.00 & 0.00 & 0.00 \\
\hline TOTAL & $\$ 784,000.00$ & $\$ 664,017.88$ & \$ $119,982.12$ \\
\hline
\end{tabular}




\section{National Institute for Global Environmental Change \\ Consolidated Financial Report \\ FY 90 Funds Financial Status \\ June 30, 1991}

\begin{tabular}{|c|c|c|c|}
\hline Expense Categories & Budget Award & $\begin{array}{r}\text { Cumulative } \\
\text { Expenditures }\end{array}$ & Balance \\
\hline Salaries: Faculty & $\$ 620,607,00$ & $\$ 428,311.38$ & \$ $192,295.62$ \\
\hline Postdoctorates & $333,862.50$ & $301,603.93$ & $32,258.57$ \\
\hline Professionals & $232,186.00$ & $217,505.31$ & $14,680.69$ \\
\hline Graduate Students & $525,357.00$ & $245,376.96$ & $279,980.04$ \\
\hline Undergraduates & $78,136.00$ & $65,506.04$ & $12,629.96$ \\
\hline Administrative/Clerical & $137,702.00$ & $123,628.53$ & $14,073.47$ \\
\hline Other & $138,247.00$ & $79,542.05$ & $58,704.95$ \\
\hline Salaries Total & $2,066,097.50$ & $1,461,474.20$ & $604,623.30$ \\
\hline Benefits & $311,346.96$ & $203,373.61$ & $107,973.35$ \\
\hline Equipment & $782,961.00$ & $519,254,08$ & $263,706.92$ \\
\hline Travel: Domestic & $258,864.00$ & $153,285.74$ & $105,578.26$ \\
\hline Travel: Foreign & $70,287.00$ & $20,745.36$ & $49,541.64$ \\
\hline Subcontracts & $229,300.00$ & $23,727.66$ & $205,572.34$ \\
\hline Tuition/Fee Remisisons & $49,500.00$ & $14,550.30$ & $34,949.70$ \\
\hline Other Direct Costs & $647,714.54$ & $394,949.99$ & $252,764.55$ \\
\hline Total Direct Costs & $4,416,071.00$ & $2,791,360.94$ & $1,624,710.06$ \\
\hline Indirect Costs & $1,474,612.00$ & $968,094.03$ & $506,517.97$ \\
\hline Uncommitted Funds & $25,317.00$ & 0.00 & $25,317.00$ \\
\hline TOTAL & $\$ 5,916,000.00$ & $\$ 3,759,454.97$ & $\$ 2,156,545.03$ \\
\hline
\end{tabular}




\section{Science, Policy and Education Allocation}

With the concurrence of the DOE, NIGEC has adopted the following balance for the academic research program: research on the scientific aspects of global environmental change (70\%), research undergirding the development of policy strategies and options (25\%), and educational efforts (5\%). Allocations in FY 90 and FY 91 by Regional Center and National Institute Office, are shown in the following tables.

Allocation of FY 90 Funds

Science, Policy, and Education

\begin{tabular}{||l|r|r|r|r|r|r||}
\hline & Midwestern & Northeast & Southcentral & Western & National & \multicolumn{1}{|c|}{ Total } \\
\hline Science & $\$ \$ 81,515$ & $\$ 931,886$ & $\$ 1,041,689$ & $\$ 969,236$ & $\mathbf{\$ 1 0 0 , 0 0 0}$ & $\mathbf{\$ 3 , 9 0 4 , 3 2 6}$ \\
\hline Policy & 190,361 & 108,398 & 0 & 213,764 & 0 & 512,523 \\
\hline Education & 131,124 & 142,716 & 141,200 & 0 & 170,000 & 585,040 \\
\hline Uncommitted & 0 & 0 & 111 & 0 & 0 & 111 \\
\hline
\end{tabular}

Allocation of FY 91 Funds

Science, Policy, and Education

\begin{tabular}{|l|r|r|r|r|r|r||}
\hline & Midwestern & Northeast & Southcentral & Western & National & Total \\
\hline Science & $\$ 1,767,681$ & $\$ 1,230,787$ & $\$ 1,551,030$ & $\$ 1,701,047$ & $\$ 475,724$ & $\$ 6,726,269$ \\
\hline Policy & 35,386 & 374,322 & 0 & 78,654 & 0 & 488,362 \\
\hline Education & 0 & 129,430 & 113,027 & 0 & 0 & 242,457 \\
\hline Uncommitted & 39,123 & 107,651 & 103,133 & 0 & 0 & 249,907 \\
\hline
\end{tabular}

Comparison of FY 90 and FY 91 Allocations

Science, Policy, and Education

(Based on budget award, as a percent)

\begin{tabular}{||l|r|r|r|r|r|r|r|r|r|r|r|r||}
\hline & \multicolumn{2}{|c|}{ Midwestern } & \multicolumn{2}{|c|}{ Northeast } & \multicolumn{2}{|c|}{ Southcentral } & \multicolumn{2}{|c|}{ Western } & \multicolumn{2}{|c|}{ National } & \multicolumn{2}{|c|}{ TOTAL } \\
\hline FY & 90 & 91 & 90 & 91 & 90 & 91 & 90 & 91 & 90 & 91 & 90 & 91 \\
\hline Science & 73 & 96 & 79 & 67 & 88 & 88 & 82 & 96 & 13 & 52 & 78 & 87 \\
\hline Policy & 16 & 2 & 9 & 20 & 0 & 0 & 18 & 4 & 0 & 0 & 10 & 6 \\
\hline Education & 11 & 0 & 12 & 7 & 12 & 6 & 0 & 0 & 22 & 0 & 12 & 3 \\
\hline Uncommitted & 0 & 2 & 0 & 6 & 0 & 6 & 0 & 0 & 0 & 0 & 0 & 3 \\
\hline
\end{tabular}




\section{Host and Outreach Allocation}

Regional Centers were encouraged to award research funds outside of their own institutions. By the second year, FY 91 funding, $50 \%$ of research funds were to be awarded outside the host institution. Information on host and outreach allocations for FY 90 and FY 91 are shown in the following tables. The tables show the distribution, by Regional Center and National Institute Office, of allocations to host research projects, outreach research projects, and administration in FY 90 and FY 91.

Allocation of FY 90 Funds

Host, Outreach, and Administration

\begin{tabular}{|c|c|c|c|c|c|c|}
\hline & Midwestern & Northeast & Southcentral & Western & National & TOTAL \\
\hline Host & $\$ 1,094,000$ & s 797,644 & s 946,560 & \$ 616,739 & $\$$ & $\$ 3,454,943$ \\
\hline Outreach & 89,000 & 385,356 & 236,329 & 566,261 & 270,000 & $1,546,946$ \\
\hline Subtotal & $1,183,000$ & $1,183,000$ & $1,182,889$ & $1,183,000$ & 270,000 & $5,001,889$ \\
\hline Uncommitted & 0 & 0 & 111 & 0 & 0 & 111 \\
\hline Research Total & $1,183,000$ & $1,183,000)$ & $1,183,000$ & $1,183,000$ & 270,000 & $5,002,000$ \\
\hline Administration & 100,000 & 100,000 & 100,000 & 100,000 & 514,000 & 914,000 \\
\hline Grand Total & $\$ 1,283,000$ & $\$ 1,283,000$ & $\$ 1,283,000$ & $\$ 1,283,000$ & \$ 784,000 & $\$ 5,916,000$ \\
\hline
\end{tabular}

Allocation of FY 91 Funds

Host, Outreach, and Administration

\begin{tabular}{|c|c|c|c|c|c|c|}
\hline & Midwestern & Northeast & Southcentral & Western & National & TOTAL \\
\hline Host & $\$ 1,003,007$ & \$ 891,916 & $\$ 696,261$ & \$ 589,118 & $\$$ & $\$ 3,180,302$ \\
\hline Cutreach & 799,926 & 842,623 & 967,796 & $1,190,583$ & 475,724 & $4,276,652$ \\
\hline Subtotal & $1,802,933$ & $1,734,539$ & $1,664,057$ & $1,779,701$ & 475,724 & $7,456,954$ \\
\hline Uncommitted & 39,257 & 107,651 & 103,133 & 0 & 0 & 250,041 \\
\hline $\begin{array}{l}\text { Research } \\
\text { Total }\end{array}$ & $1,842,190$ & $1,842,190$ & $1,767,190$ & $1,779,701$ & 475,724 & $7,706,995$ \\
\hline Administration ${ }^{\prime}$ & 150,000 & 150,000 & 150,000 & 137,489 & 445,590 & $1,033,079$ \\
\hline Conference $^{2}$ & & & & 95,876 & & 95,876 \\
\hline Grand Total & $\$ 1,992,190$ & $\$ 1,992,190$ & $\$ 1,917,190$ & $\$ 2,013,066$ & $\$ 921,314$ & $\$ 8,835,950$ \\
\hline
\end{tabular}

${ }^{1}$ Administrative allocations are made to cach Regional Conter from the budget of the National Institute Office. In FY 91, the Western Regional Center partially met indirect cost expenses for the first $\$ 25,000$ of each subcontract to non-UC projects from its administrative allocation.

${ }_{2}^{2}$ Funds for the Methane Conference were transferred from the National Institute Office to the UC Irvine campus for administration by the Conference organizer, F, Sherwood Rowland. 
The following table is a comparison of allocations of FY 90 and FY 91 funds, showing the distribution between host and outreach projects as a percent of the sum of the host and outreach allocations at the time of this report.

\section{Allocation of FY 90 and FY 91 Funds}

Host and Outreach

(based on budget award as a percent of the sum of host and outreach research programs)

\begin{tabular}{|l|c|c|c|c|c|c|c|c|c|c|c|c||}
\hline & \multicolumn{2}{|c|}{ Midwestern } & \multicolumn{2}{|c|}{ Northeast } & \multicolumn{2}{|c|}{ Southcentral } & \multicolumn{2}{|c|}{ Western } & \multicolumn{2}{|c|}{ National } & \multicolumn{2}{|c|}{ TOTAL } \\
\hline FY & 90 & 91 & 90 & 91 & 90 & 91 & 90 & 91 & 90 & 91 & 90 & 91 \\
\hline Host & 92 & 56 & 67 & 51 & 80 & 42 & 52 & 33 & 0 & 0 & 69 & 43 \\
\hline Outreach & 8 & 44 & 33 & 49 & 20 & 58 & 48 & 67 & 100 & 100 & 31 & 57 \\
\hline
\end{tabular}




\title{
PART II
}

\section{Midwestern Regional Center Director’s Report}

\author{
J. C. Randolph, Director
}

Introduction: In response to a Congressional initiative, the U.S. Department of Energy (DOE) has sponsored the National Institute for Global Environmental Change (NIGEC) since 1989. Programs funded by the DOE and administered by NIGEC are conducted through five regional centers at Harvard University (Northeast), Indiana University (Midwestern), Tulane University (Southcentral), The University of Alabama (Southeast), and the University of California, Davis and Irvine (Western). The national office of the NIGEC is located at the University of California, Davis.

The NIGEC has developed a research program consonant with the objectives Congress identified when it created the Institute, as well as fitting within the missions of the Department of Energy. Each regional center has selected research themes that are particularly well suited to the capabilities and geographic locale of the center.

The geographic area of the Midwestern Regional Center includes the states of Ohio, Indiana, Michigan, Illinois, Wisconsin, Iowa, Minnesota, Nebraska, South Dakota, North Dakota, Wyoming, and Montana.

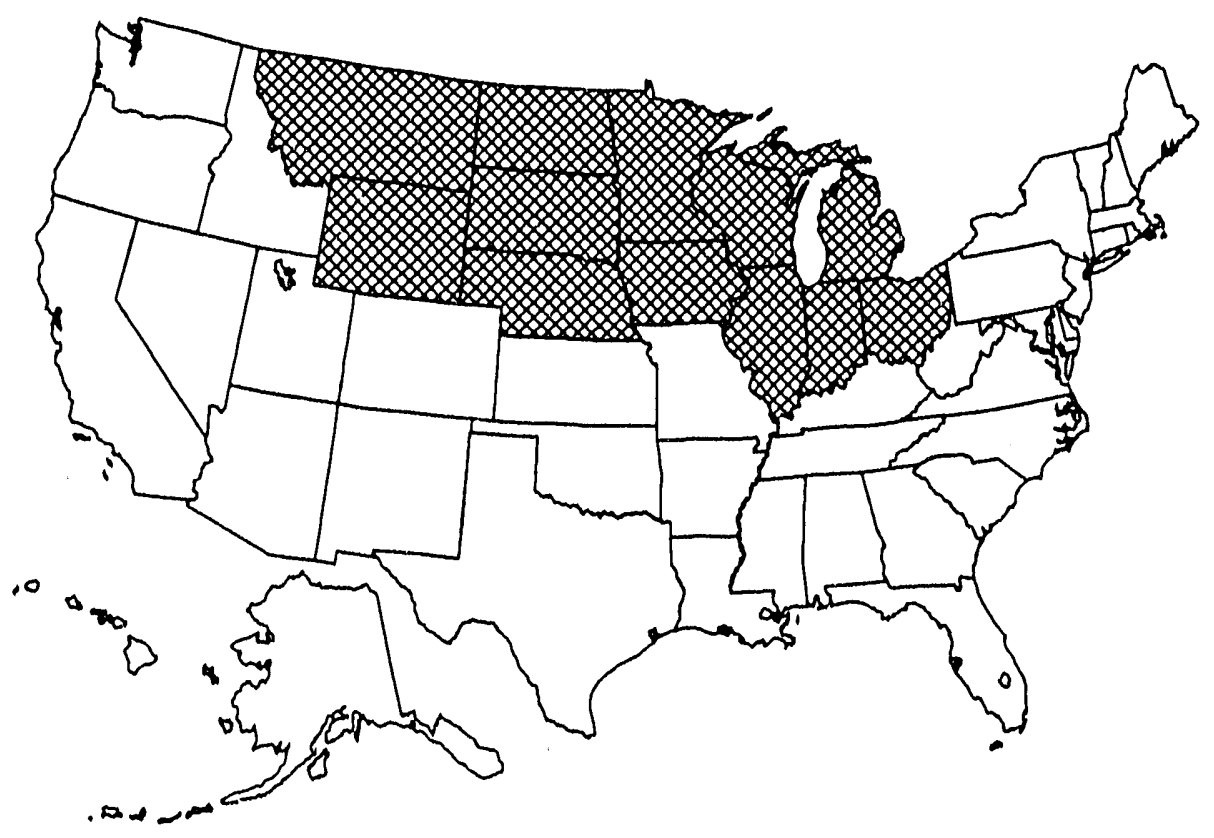

For the FY 91 research program, the Midwestern Regional Center focused on three research themes: (1) trace atmospheric gases, (2) water resources, biological productivity and their relationships to climate, and (3) policy issues related to energy use. 
Requests-for-Proposals for research projects to be undertaken during FY 91 were distributed by the Midwestern Regional Center in December, 1990. A total of 47 proposals were received and reviewed. The total amount of funds requested was $\$ 4,979,354$. These 47 proposals were received from 21 institutions in 14 states. For FY 91 the Midwestern Regional Center's geographic area included Ohio, Michigan, Indiana, Wisconsin, Illinois, Minnesota, Iowa, Missouri, North Dakota, South Dakota, Nebraska, Kansas, Montana, Wyoming, Colorado, and Utah.

\section{FY 91 Center Activities}

\section{NCGIA Conference/Workshop}

The Midwestern Regional Center was one of 12 sponsors of the First International Conference/Workshop on Integrating Geographic Information Systems and Environmental Modeling held September 15-19, 1991 in Boulder, Colorado. ${ }^{1}$ The conference attracted scientists who are researching, developing, or using geographic information system (GIS) techniques in environmental modeling.

The gual of the conference was to advance the e of GIS and spatial data for environmental applications. The focus was on environmental modeling in the fields of atmospheric science, hydrological science, land surface and subsurface processes, and ecological sciences. The conference demonstrated how using a common geographical frame of reference with GIS technology offers a better means to integrate and interpret spatial data for environmental analysis.

Many of the projects funded by the Midwestern Regional Center relate GIS and environmental modeling; therefore, it was appropriate for the Midwestern Regional Center to take a pro-active role at this conference. The Midwestern Regional Center contributed $\$ 5000$ to support four guest speakers.

\section{GIS and Remote Sensing Research Applications}

Environmental research can be spatial in nature; therefore, spatial analytic techniques such as GIS and remote sensing can provide valuable tools to environmental research. Several researchers funded by the Midwestern Regional Center are using GIS techniques in their research. The following research projects incorporate GIS and other spatial analytic techniques in their research. Drs. Arnastrong and Malanson are examining the process of dispersal, establishment, growth, and death of forest trees within a spatially explicit framework. Dr. Jelinski is using AVHRR satellite data to quantitatively monitor large scale surface dynamics and the effect of climate change on terrestrial ecosystems. Dr. Moran is using two complementary methodologies - geographic information systems and remotely sensed analysis of satellite images - to examine successional processes following land clearing in the Brazilian Amazon. Dr. Randolph is using GIS to analyze changes in biodiversity and biotic productivity resulting from global climate change in midwestern forest ecosystems. Dr. Haitjema includes spatial analysis with groundwater modeling. Dr. Willard will use this technology to evaluate the hydrologic and ecological effects of climate induced change on selected wetlands in the midwest. To facilitate research and data-sharing among the researchers at the Midwestern Regional Center a GIS laboratory was established this year.

'The other sponsors of the Conference/Workshop were: National Aeronautic and Space Administration, National Science Foundation, U.S. Army Corps of Engineers, U.S. Department of Agriculture/Forest Service, U.S. Department of Commerce/NOAA, U.S. Department of Energy/Oak Ridge National Laboratory, U.S. Department of the Interior/Fish and Wildlife Service, Environmental Management Technical Center, U.S. Department of the Interior/Geological Survey, U.S. Department of the Interior/Minerals Management Service, U.S. Environmental Protection Agency, IBM Corporation. 


\section{GIS Laboratory}

The Midwestern Regional Center operates a computing laboratory for the applications of geographic information systems (GIS) in environmental science and natural resource management. GIS is a computerbased information technology that is designed to manage, analyze, and display spatial data.

This facility includes an HP $9000 / 750$ file server that links a six-unit HP workstation cluster to personal computers, the university mainframe computers, and to each other. Several GIS software packages, both raster-based and vector-based, are in operation. Additionally, the laboratory maintains a large inventory of digital databases, including Landsat, SPOT, GCM outputs, soil maps, vegetation coverages, etc.

The GIS laboratory of the Midwestern Regional Center is designed to assist NIGEC researchers, visiting researchers, professional staff, and students better analyze and model environmental problems using GIS. The laboratory facilitates data sharing by providing an accessible data storage environment to researchers at Indiana University and at other institutions affiliated with the Midwestern Regional Center.

\section{FY 92 Program Plans}

The research themes of the Midwestern Regional Center for the FY 92 program are:

1. Atmospheric trace gases: identification, measurement, and analysis of atmospheric trace gases and aerosols, particularly those with either significant global warming potential or a significant ozone depletion potential including identification of both natural and anthropogenic sources, both short- and long-range transport, and fates or sinks of those gases.

2. Climate models: improvement of predictive capability of future responses of global and regional climates to changing atmospheric conditions.

3. Biological productivity: identification and analysis of potential impacts of global environmental change, particularly climate change, on biological productivity in both natural and agricultural ecosystems.

4. Water resources: identification and analysis of potentiai impacts of global environmental change on the quantity and quality of water resources.

5. Energy policy: policy analysis related to energy production and use that has consequences on the sources and sinks of atmospheric trace gases.

A Request-for-Proposals for FY 92 projects was written in September, 1991. During the first week of October, 645 copies of this RFP were distributed in the geographic region assigned to the Midwestern Regional Center. The Office of the Vice President for Research (or equivalent title and responsibilities) of all research universities in the area received a copy of the RFP. Additional copies were sent to deans or department chairs of schools or departments in the biological sciences, physical sciences, engineering, and applied social sciences. Approximately 100 copies were mailed to individual faculty members presently conducting research or known to have a potential interest in developing research projects relevant to global environmental change. A Notice of Intent was requested from all persons interested in submitting a proposal. These notices were requested by November 8, 1991. The Midwestern Regional Center received a total of 122 Notices of Intent.

Proposals were due December 9, 1991. Eighty-seven proposals from 28 universities in 14 states were received by the Midwestern Regional Center. Sixteen of these proposals were for continuation of projects funded by the FY 91 NIGEC research program. The number of proposals and the funds requested by theme is summarized on the next page. 
Theme

Atmospheric trace gases

Climate models

Biological productivity

Water Resources

Energy policy

Totals
Number

16

11

36

21

3

87
Amount

\$ 2,636,086

\$ $1,035,215$

\$ $4,147,858$

\$ 2,211,064

\$ 253.017

$\$ 10,283,240$

The Notice of Intent form asked proposal authors to identify three persons thought to be appropriate reviewers of their proposal. From these suggestions and from an additional list of possible reviewers developed by the center director, 245 potential reviewers were identified. Persons with direct linkages to NIGEC, possible conflicts of interest, relative inexperience, or other problems were deleted from this list. Each of the persons remaining on the list was contacted by personal letter and asked to return a response form. Ninety-four persons responded favorably. Using the information provided in a Reviewer's Response Form, 33 reviewers were selected and matched to the proposals, sorted by research theme. Each reviewer was sent a letter containing instructions about the review, a set of proposals, proposal evaluation forms, and a review return form.

Thirty reviewers returned evaluations; three reviewers were unable to complete their reviews. The goal was to obtain two external reviews of each proposal. Proposals also were reviewed by a small committee internal to the Midwestern Regional Center. This review placed particular attention on the relevancy of the proposed project to the research themes of the Midwestern Regional Center.

The proposals were evaluated using the following criteria:

- The clarity and originality of the problem statement, the expected results, and the significance of the research when the project is completed.

- The adequacy of the research methodology to be used.

- The relevance of the proposed research to one or more of the research themes of the Midwestern Regional Center.

- The relevance of the proposed research to the missions of the Department of Energy related to global environmental change research.

- The qualifications of the investigators.

- The feasibility of the proposed project, including budget and duration, and an assessment of facilities, equipment, personnel, and other support needed for successful completion of the proposed project.

All reviews were handled in a completely confidential manner. All evaluation forms were typed to eliminate distinctive handwriting or other information that might identify either the individual or the reviewer's institution or agency. Copies of the proposal evaluation forms will be sent to the project director of each proposed project upon completion of the entire NIGEC review process for the FY 92 research program. 


\title{
Climatic Influences of Land Surface Conditions in the Midwest United States
}

\author{
A. M. Carleton and S. Grimmond \\ Indiana University
}

Objective: This research examines the influence of Midwest land surface parameters in climate variations through a combination of observational and energy budget modeling approaches. Specific objectives include: (1) Identification of the role of antecedent surface and soil moisture conditions for Midwest cloud and precipitation in summer, and how these differ between cropped and forested surfaces. (2) Assessment of the diurnal variations in cloud development, its relation to surface type, and whether clouds reinforce or counter the surface climate anomalies. (3) Determination of regional surface energy budgets and how they vary between surface types and at different times.

Results to Date: Cloud Climatology: Based on the generally positive results of the "representative" case study day for convective cloudiness described in our last report, we have undertaken analysis of two days for the summer of 1987. Preliminary results tend to confirm that the convective cloud regimes may differ between cropped and forested land surfaces in the Midwest U.S. in summer under weak flow conditions.

For our initial case study day of June 25,1988 , we have now analyzed the tropospheric sounding data for two stations (Peoria and Salem, IL). Virtual temperatures $\left(T_{v}\right)$ have been computed for both stations and plotted on Skew T - log p thermodynamic diagrams. We find that for the boundary layer, the nocturnal inversion is greater (i.e., deeper and of larger magnitude) at Peoria compared with Salem; daytime lapse rates are steeper at Peoria; and the diurnal range of $T_{v}$ is considerably greater at Peoria. Since the differences in the temperature profiles in the mid-troposphere are small, we believe that the generally large contrasts in the boundary layer between the two sites are the result of contrasting land surface conditions (Peoria: cropped; Salem: forested). Our investigations of these differences are continuing. A manuscript on the preliminary results of the cloud climatology is in preparation.

Satellite Identification of Land Surface Conditions: Our attempts to order more AVHRR digital data from NESDIS continue to be frustrated by the lack of personnel at that institution. When these data become available, we shall analyze them for land surface conditions on the Geography Department's ERDAS system.

Energy Balance Studies: Analysis of energy balance measurements conducted in an agricultural region of southern Indiana during the summer 1990 are near completion (M. Rowe: Masters thesis, a manuscript for publication will then be prepared). An inter-comparison of fluxes is made between a homogeneous surface of a single crop (soybeans) and the integrated response of the agricultural region. An explanation is developed for the relation between surface and atmospheric controls and the different fluxes observed. These data are to be used to test a physically based evaporation-interception model to simulate water and energy fluxes for the region, and for the determination of the surface resistances at the local and regional scales.

\section{Supra-Regional Modeling of Groundwater Response to Climatic Change}

\author{
Hendrik M. Haitjema \\ Indiana University
}

Objective: To define the groundwater response to different scenarios of climatic change in the Midwest region.

This research goal is broken down into several specific research questions: (1) How will current piezometric surfaces change? (2) How will water supply wells be impacted in different aquifers and in 
different locations? (3) What will the difference be in unconfined and confined aquifers? (4) In which areas could an increase in groundwater withdrawals be sustained and where may we anticipate aquifer overdraft?

(5) How well can we generalize outside our immediate study area?

Product: The product of this effort take two forms: 1) initial results (maps) which can be used to identify the factors that will determine the effect of climate change on groundwater resources, and 2) tools and procedures to study groundwater response to climatic change in other areas. The tools include an interactive, graphical data preprocessor program for selecting and managing the input data required to model groundwater flow at multiple resolutions, and a public domain conjunctive surface-groundwater model for steady state regional flow modeling.

Approach: Supra-regional modeling experiments are being conducted using the analytic element method (AEM) to describe groundwater flow and a new, public domain data management preprocessor (PREPRO).

Results to Date: During the initial phase of the project comprehensive flow modeling was initiated for the entire supra-region using available data on the spatial distribution of hydrogeologic features. Subsurface flow to the stream (base flow) has been estimated using new base flow separation techniques. These estimates, along with available head data, are used to distribute recharge throughout the study area. The results of this first phase of modeling provided important insights into the differences in data resolution needed to appropriately describe flow in different areas of the Midwest. Subsequent work has indicated that the deep, limestone aquifer in the area is less sensitive to changes in recharge than the upper unconsolidated aquifers.

Modeling the interaction of the limestone and overlying sand and gravel aquifer systen is is currently proceeding. This has required that data be digitized which describes the spatial variation in aquifer transmissivities. The focus of our current activity is to determine the sources of groundwater (base flow) in the streams in the study area and identify those factors which will determine the sensitivity of the resource to changes in net recharge. Using new software developed in our lab, we are now graphically displaying the estimated base flow within a stream system as a way to better define the effects that changes in recharge could have on the interior boundary conditions (existing surface water features) for groundwater flow.

The preliminary results of this work have been presented at both a regional and an international conference during 1991. The results of recent modeling suggests that there may be significant advantages to the techniques being developed to evaluate the potential effects of climate change on groundwater availability in other, more arid settings.

\title{
Isotopic Studies of the Biogeochemical Cycle of Carbon: Relationships Between $\mathrm{pCO}_{2}$ and the abundance of ${ }^{13} \mathrm{C}$ in Sedimentary Organic Matter
}

\author{
J. M. Hayes and L. M. Pratt \\ Indiana University
}

Objectives: (1) To extend studies of relationships between $\mathrm{CO}_{2}$ levels and fractionation of carbon isotopes by producer organisms in marine environments. (2) To examine secondary fractionations of carbon isotopes within the marine foodweb, thus obtaining new information on the processes committing organic carbon either to burial or to remineralization in marine environments. (3) To evaluate preservation in sedimentary organic matter of isotopic signals originating in the water column.

Product: A study of the isotopic biogeochemistry of the water column and sediments of the Santa Monica Basin, offshore southern California, using six cruises to cover an annual cycle and comprising: (1) Measurements of concentrations and isotopic composition of dissolved $\mathrm{CO}_{2}$ and primary organic material at a variety 
of water depths. (2) Measurement of the abundances and carbon isotopic compositions of individual biomarker compounds related to organisms from various trophic levels within the foodweb. (3) Similar analyses of organic compounds in sediment cores. (4) Quantitative and isotopic analysis of all forms of sulfur in sediment cores.

Approach: We are working in collaboration with specialists in the study of marine lipids (S. G. Wakeham, Skidaway Institute of Oceanography) and of $\mathrm{CO}_{2}$ levels (C. D. Keeling, Scripps Institution of Oceanography). Cruises are being managed by contract with the Marine Sciences Center of the University of Southern California. Publications summarizing results of these investigations are forthcoming.

Results to Date: Differences between the isotopic compositions of total particulate organic carbon (POC) and dissolved inorganic carbon have been measured at $10-\mathrm{m}$ intervals within the photic zone. At the depth of the chlorophyll maximum, observed isotopic fractionations are consistent with relationships previously estimated by comparison of ice-core $\mathrm{pCO}_{2}$ values and isotopic compositions of sedimentary alkenones. At other depths within the photic zone, the same consistency is observed if primary ${ }^{12} \mathrm{C}$ contents are estimated from analyses of sterols produced by photosynthetic organisms. Contents of ${ }^{13} \mathrm{C}$ in total POC, however, differ from these primary values and reflect the effects of consumer organisms.

Isotopic compositions of numerous individual organic compounds have been observed. For example, cholesta-5-en-3 $\beta$-ol $\left(\delta^{12} \mathrm{C}_{\mathrm{PDB}} \sim-26 \%\right.$ ), thought to be produced by zooplankton, is generally enriched in ${ }^{12} \mathrm{C}$ relative to the highly abundant cholest $-5,22-\mathrm{dien}-3 \beta-\mathrm{ol}(\sim-26.8 \% 0)$, produced by phytoplankton. The saturated structural isomer, $5 \alpha(\mathrm{H})$-cholestan-3 $\beta$-ol is depleted in ${ }^{12} \mathrm{C}$ by $3-4 \%$ relative to those compounds and must have an independent source. These assignments, and the implied relationship as food source and heterotroph, are borne out by the results of the isotopic analyses.

Surface-water sterols recovered on small-particle (GF) filters from the March cruise are, in general, depleted in ${ }^{13} \mathrm{C}$ by $4-8 \%$ relative to POC. This difference of about $6 \%$ is large compared to the approximately $3 \%$ difference expected between sterol carbon skeletons and total biomass in eukaryotic plankton. This discrepancy is small but significant in that it suggests that sterol-containing algae (i.e., eukaryotes) are not the exclusive producers contributing to surface POC in March. Concentrations of GF sterols decline ten fold from the surface to bottom waters, whereas the concentration of POC declines by only four fold. The decreasing sterol/POC ratio is likely indicative of an increasing relative importance of bacteria. Independent investigations have earlier suggested that bacterial carbon accounts for $30 \%$ of POC at a depth of $100 \mathrm{~m}$ in the Santa Monica Basin and as much as $70 \%$ at greater depths.

Patterns emerge when seasonal variations in the abundances and isotopic compositions of the most abundant sterols, namely cholest-5,22E-dien-3 $\beta$-ol (A), cholesta-5-en-3 $\beta$-ol (B), 24-methylcholesta-5,22E-dien$3 \beta$-ol (C), and 24-methylcholesta-5,24(28)-dien-3 $\beta$-ol (D), are examined. The relative abundance of $\mathbf{B}$, thought to be at least partly of heterotrophic origin, is highest in samples collected well below the chlorophyll maximum. The ${ }^{12} \mathrm{C}$ contents of this compound are, however, rarely greater than those of $\mathbf{A}$ and $\mathbf{C}$, two of the three remaining abundant sterols. On the basis of known sources and quantitative dominance, an autotrophic origin is likely for both of these compounds and for D. Because it is expected that heterotrophs will be enriched in ${ }^{12} \mathrm{C}$ relative to their food sources, the isotopic results are surprising until it is recognized that $\mathbf{B}$ is enriched relative to $\mathbf{A}$ and $\mathbf{C}$ when the abundance of $\mathbf{D}$ is low. More commonly, $\mathbf{D}$ is the dominant primary sterol and is strongly depleted in ${ }^{12} \mathrm{C}$ relative to $\mathbf{A}$ and $\mathbf{C}$. The isotopic composition of the heterotrophic product $B$ can thus be logically understood as tracking that of the most abundant primary producers.

Whereas analyses of organic compounds in sediments are just beginning, work has already been completed on concentration profiles of carbon and sulfur through the uppermost $20 \mathrm{~cm}$ of sediment in two cores. Ratios of total sulfur to organic carbon are markedly depleted relative to values for environments classified as normal modern marine. These data are consistent with the hypothesis that sulfate reduction in the Santa Monica basin is inefficient despite high concentrations of reactive organic matter in the sediment. 
Intermittent incursions of oxygenated bottom waters would cause fluctuation of the $\mathrm{O}_{2} / \mathrm{H}_{2} \mathrm{~S}$ boundary within the upper 10 to $15 \mathrm{~cm}$ of sediment and would stimulate sulfur cycling. Such conditions inhibit formation of stable sulfide minerals or organic-sulfur compounds.

Stable isotopic analyses of pyrite and sulfate extracted from sediment cores are consistent with mildly reducing conditions punctuated by oxygenation events. Values of $\delta^{3} \mathrm{~S}$ for pyrite are -24.3 to $-30.0^{\circ}$ and for sulfate are 18.7 to $22.1^{\circ}$. The difference of about $50^{\circ}$ in isotopic values indicates that sulfate reduction occurred in a pore-water system that is indistinguishable from seawater and is not diffusionally limited for sulfate.

Our results suggest unusually efficient preservation of organic matter in the sediments of the Santa Monica basin due to interruption of mildly reducing benthic conditions by oxygenation events. Thus, the chemically unstable benthic environment was generally not suitable for burrowing metazoans and was less than ideal for sulfate-reducing bacterial communities.

\title{
Global Atmospheric Behavior of Polychlorinated Biphenyls
}

\author{
(formerly: Atmospheric Concentrations of Trace Level Organics: Do \\ Organochlorines Contribute to Ozone Depletion?)
}

Ronald A. Hites

Indiana University

Objective: To test two hypotheses: (1) The ecological damage caused by semivolatile chlorinated organic compounds will be dramatically amplified by slight changes in the Earth's temperature. (2) Stratospheric ozone depletion may result from the presence of these compounds in the atmosphere.

Product: Experimental data relating atmospheric concentration and temperature and the measurement of the atmospheric residence times $\left(t_{r}\right)$ of about 50 congeners of polychlorinated biphenyls (PCBs).

Results to Date: For the past 16 months, the atmospheric concentration of PCBs have been measured on the western coast of Bermuda, a location which has minimal local PCB sources. On average, one sample was taken every 3 days. The average atmospheric concentration is $0.52 \mathrm{ng} / \mathrm{m}^{3}$ with a standard deviation of 0.23 , which yields an estimate of the residence time as 220 days. These samples were analyzed by traditional high volume (hi-vol) sampling techniques, incorporating large volumes of air pulled through polyurethane foam. However, high levels of PCBs in the field blanks yielded unacceptable signal-to-noise ratios for these samples. Hence, these data provide tentative values of the measured quantities; clearly more data with lower blank levels are needed.

To increase data throughput and to lower blank levels, an automated low volume (lo-vol) air sampler was developed. This sampler also draws air through polyurethane foam, however it requires a smaller volume of air and shorter sampling times relative to the hi-vol method, allowing for daily sampling. The lovol sampler is under complete computer control, and its carousel design allows for a maximum of 18 samples to be taken per cycle. Once the polyurethane foam plugs are shipped back to our laboratory in Indiana, their PCB content will be determined by on-line supercritical fluid extraction gas chromatographic mass spectrometry (SFE-GC/MS) using selected ion monitoring (SIM) under electron capture negative ionization (ECNI) conditions.

The construction of the lo-vol sampler is complete and it is being put through a series of quality control tests before shipment 10 Bermuda. It should be installed on the island and operational within the next two months. 


\title{
The Economic Consequences and $\mathrm{CO}_{2}$ Emissions Impact of Energy Taxation
}

\author{
Kerry M. Krutilla \\ Indiana University
}

Objectives: The research is designed to comprehensively evaluate the costs and benefits of energy taxation as a policy instrument to reduce global carbon emissions. Key aspects of the research include an analysis of: (1) the impact of energy taxation on the aggregate level of U.S. economic activity; (2) the general equilibrium ramifications of energy taxation, in terms of the effects on the energy sector, related intermediate goods and final commodity sectors, and factor markets for land, labor, and capital; (3) the income redistribution effects of energy taxation; (4) the revenue effects of energy taxation on the U.S. treasury; (5) the carbon emissions reductions associated with energy taxation; (6) the environmental benefits associated with energy taxation; (7) the impact of energy taxation on the terms-of-trade and the international competitiveness of U.S. commodities.

A key objective of the analysis is to determine the least-cost mix of energy taxes (on coal, oil, and natural gas) to achieve a given carbon emissions reduction, and to evaluate how the least-cost tax mix changes as carbon emissions reductions targets become increasingly stringent.

Product: A final report which describes the methodology and results of the study, with a concluding section, based on the results, focusing on the tradeoffs and policy options associated with energy taxation as a strategy to reduce carbon emissions.

Approach: The study is based on a static general equilibrium simulation model of the United States economy, which is disaggregated to 14 producing sectors, 5 income classes, and 13 final commodities. In the base case scenario, the model is run with current structure of taxation in the economy in place. In the policy simulations, the model is rerun with energy taxes implemented; the output of these simulations is then compared with the base case, to provide a quantitative measure of the impact of the energy taxation. This procedure allows us to address objectives (1) to (4) and (7) enumerated above. Translating the fossil fuel reductions into $\mathrm{CO}_{2}$ emissions reductions (objective 5) is easily accomplished using conversion ratios widely published in the literature. To address objective (6), we rely on estimates on the monetized environmental benefits of fossil fuel reductions which are just becoming available in the published literature.

Results to Date: In our preliminary modeling work (which holds the mix of energy taxes constant), we find that energy taxation has both significant economic costs and benefits. For example, a mix of energy taxes which generates $\mathbf{\$ 1 5 0}$ billion in revenue reduces the U.S.'s output of $\mathrm{CO}_{2}$ emissions by $38 \%$, and lowers U.S. GNP (as conventionally measured) by close to $2 \%$. Output in the coal industry declines by about $60 \%$, and in the oil industry by $7 \%$, while the (tax-inclusion) price of coal and oil increase by about $250 \%$ and $40 \%$ respectively. In terms of related sectors, the manufacturing sector is the most heavily impacted; general equilibrium economic ramifications seem to generally become significant as carbon emissions reductions targets move into the $5-10 \%$ range.

We find an interesting equity impact of the energy taxation. The conventional wisdom holds increasing energy prices tend to hurt low income consumers, who spend a disproportionately large share of their disposable income on necessities, such as energy. Indeed, we document this effect. However, since the large energy consuming sectors in the economy -- such as the petrochemical industries and manufacturing industries -- are also relatively capital intensive, the rate of return on capital falls relative to wage rates, in response to the energy taxation. This general equilibrium effect counteracts the regressive impact of the direct tax effect on consumers, to the point that, in the aggregate, energy taxation is found to be nearly proportional, rather than strongly regressive, as is commonly believed.

We are now conducting simulations to evaluate the trade-off between carbon emissions reductions and revenue-raising as policy objectives of energy taxation. It turns out that optimizing the mix of energy taxes in 
order to achieve carbon emissions reductions targets in the most cost-effective manner increases the unit cost of raising revenue to a moderate degree. We are now in the process of delimiting the boundaries of this relationship more precisely in sensitivity analyses.

To date, the project findings have been presented as conference papers at the Association of Policy Analysis and Management's Annual meeting in San Francisco, October 1990, and at the Association of European and Environmental Resource Economist's annual meeting in Stockholm, June 1991. The expected completion date of the project is June 30, 1992.

\title{
The Impact of the Corporate Average Fuel Economy Standards on the Life Span and Lifetime Energy Consumption of Automobiles: A Population Dynamics Approach
}

\author{
Eric L. Mitter \\ Indiana University
}

Objective: This research is the first phase of a three-phase project to measure the lifetime energy efficiency of automobiles and the impact of the Corporate Average Fuel Economy (CAFE) Standards on the aggregate efficiency of the total fleet of private automobiles in the U.S. Lifetime efficiency is expressed as the ratio of person-miles of travel supplied by an automobile over the energy required to provide this supply of personal mobility: the higher this ratio, the higher the efficiency. The denominator is composed of four terms, (1) the energy required to manufacture an automobile, plus (2) the energy required to operate and maintain an automobile, plus (3) the energy required to process a scrapped automobile hulk, minus (4) the energy recovered by recycling the materials in the hulk. The CAFE Standards are an effort to improve this ratio by reducing the energy costs of operation.

A major result of the CAFE legislation has been to require the production of large numbers of very small, light-weight cars. These cars must be sold in order to comply with the standards. This compulsion to sell results in a reduced profit margin. In the study of the durability of durable goods, it is almost axiomatic that reduced profitability translates to reduced durability. It is hypothesized that the CAFE Standards have served to induce the production of a class of "disposable" cars that provide efficient service for a relatively short time and which then must be scrapped at a relatively early age. The major hypothesis of this research is that, when manufacturing and disposal costs for these short-lived cars are factored in, the net result is a reduction of the lifetime efficiency ratio.

Product: The product of Phase I research will be a technical report concerning the differential longevity of cars by size-class and a comparison of CAFE versus pre-CAFE era cars. The results of Phase I research will be used in future research to evaluate the differential lifetime efficiency of cars of various sizes.

Approach: A population dynamics approach will be employed to calculate the survival coefficient for cars of various sizes. The manufacture of a car comprises its "birth" and the eventual scrapping comprises its "death." By sub-dividing each vintage cohort into size classes, the differential longevity will be amenable to study. It is hypothesized that CAFE-era small cars will have a significantly lower life expectancy than large cars and pre-CAFE small cars. Data documenting the census of automobiles in the U.S., based on state vehicle registration files, are available.

Results to Date: This research relies entirely on the analysis of archival data. Because these data are proprietary and include trade names, it has been necessary to obtain clearance to gain access. Because the data are voluminous, it has been necessary to specify a reduction algorithm to create a manageable data set. These tasks were the subject of negotiation during the first year of the project. The data were delivered to the principal investigator in June, 1991. 
The analysis for this project is restricted to vehicles that are readily recognizable as passenger cars, meaning convertibles, coupes, sedans, and station wagons; all mini-vans, vans, pickup trucks, and utillty vehicles (e.g., jeeps) are excluded, as well as all larger vehicles. The identity of vehicles is resolved according to model year, make, model and body style (e.g., 1978 Ford Pinto two-door, 1976 Chevrolet Impala fourdoor, etc.). For each such uniquely identified vehicle, the data consist of curb weight, wheel base and the count of vehicles in the 50 states plus the District of Columbia. The counts reflect vehicle registrations as of July 1 for successive reporting years. The data document vehicles from model years 1970 through 1987 for reporting years 1975 through 1988.

Much effort has been expended in cleaning up various mis-coding and missing data problems, and in comparing the counts from this source with other, independent sources. These matters have been brought to a satisfactory conclusion.

Preliminary results indicate that, in gencral, small cars do have shorter service lives than large cars. Detailed analysis is on-going. The analysis will be completed and the final report produced by June, 1992.

\title{
Fuel Switching Impacts on Carbon Dioxide Emissions from Midwestern Great Lake States Electric Utilities
}

\author{
J. C. Randolph \\ Indiana University
}

Objective: The largest single factor affecting greenhouse gas emissions is the combustion of fossil fuels. The U.S. is the largest emitter of carbon dioxide in the world, and fossil fuel-fired electric generating units are major contributors to U.S. emissions. About $20-25 \%$ of global $\mathrm{CO}_{2}$ emissions are from the combustion of fossil fuels in the United States and approximately $28-30 \%$ of U.S. emissions arise from electricity generation. Today, approximately six million metric tons are emitted each year from fossil fuel combustion in the United States. The Department of Energy reports that U.S. electricity generation is responsible for about $7.5 \%$ of total worldwide emissions of carbon dioxide.

The objective of this project is to determine the effects different sulfur dioxide emissions reduction strategies will have on carbon dioxide emissions from coal-fired electric generating plants in the Midwest. Additionally, this research will identify some policy options the Department of Energy and state regulatory agencies might implement to encourage electrical utilities to implement strategies that will reduce $\mathrm{CO}_{2}$ emissions as well as $\mathrm{SO}_{2}$ and $\mathrm{NO}_{x}$ emissions.

Product: The product of this project will be a quantitative comparison of how various $\mathrm{SO}_{2}$ emissions reduction strategies will affect $\mathrm{CO}_{2}$ emissions from coal-fired electrical generating facilities in the Midwest, and a summary of policy alternatives available to the DOE.

Approach: The operations of six Indiana utilities have been modelled with respect to the $\mathrm{SO}_{2}$ emissions control strategies they might choose in response to the Clean Air Act Amendments (CAAA) of 1990. The Electric Power Research Institute's (EPRI) TELPLAN model was used to simulate utility performance, costs, and emissions. We assumed that each utility would take a least-cost approach in meeting their sulfur dioxide emission restrictions. Interviews with senior personnel in each of the utilities indicated the strategies that utility would most likely follow. The utilities generally chose to reduce emissions by a combination of retrofitting scrubbers, by blending local high-sulfur coals with low-sulfur coals, or by using western or central Appalachian low-sulfur coal. 
A scenario analysis approach was used to compare futurc $\mathrm{CO}_{2}, \mathrm{SO}_{2}$, and $\mathrm{NO}_{x}$ emissions under a base* case scenario and three regulatory scenarios. The four scenarios are: (1) a base-case scenario representing a projection of current conditions; (2) a coal-switching scenario that incorporates a shift to low-sulfur coal or low-sulfur coal blends; (3) a technology scenario that depends totally on technological emissions control devices; and (4) a multi-strategy scenario that uses both scrubber technology and coal-switching or blending. The four scenarios represent possible berundaries of the utility compliance options. The coal-switch scenario and the technology scenario are the ends of a dichotomy; whereas, the multinstrategy scenario is a compromise between the two strategies.

The TELPLAN model has been adapted to estimate $\mathrm{CO}_{2}$ emissions as well as $\mathrm{SO}_{2}, \mathrm{NO}_{x}$, and particulates. The model has been used to estimate the completeness of combustion of various coals to arrive at low, medium, and high estimates of $\mathrm{CO}_{2}$ emissions. Initial estimates were based on a $75 \%$ combustion of the average carbon content of selected coals. Curront work incorporates more specific characteristics for various coals.

Results to Date: Initially, research focused on modeling $\mathrm{SO}_{3}, \mathrm{NO}_{x}$ and $\mathrm{CO}_{2}$ emissions from 22 electrical generating plants in Indiana. Our findings indicate that $\mathrm{SO}_{2}$ and $\mathrm{NO}_{x}$ emissions will be reduced as utilities begin to comply with the regulations set out by the CAAA. Carbon emissions were not targeted for control by the legislation and therefore our analysis suggests that emissions of $\mathrm{CO}_{2}$ will continue to steadily increase.

Estimates of $\mathrm{CO}_{2}$ emissions that were derived from the initial analysis were refined to include more detail, including estimates of coal heating value and sulfur content. All three regulatory scenarios are structured such that all utilities meet their projected demand for electricity and that all $\mathrm{SO}_{2}$ emissions are in compliance with the $1990 \mathrm{CAA}$ Amendments. The technology scenario, which relies upon widespread use of flue gas desulfurization, projects the highest $\mathrm{SO}_{2}$ emissions reductions ranging from 63 to $77 \%$. However, the widespread use of scrubbers also will produce a "scrubber tax" which results in higher $\mathrm{CO}_{2}$ emissions and electric rates. Currently, each scenario is analyzed for an optimal combination of reduced $\mathrm{CO}_{2}, \mathrm{SO}_{2}$, and NO $_{x}$ emissions, fuel consumption, electricity demand, and electricity rates. Preliminary results indicate that the multi-strategy approach to emissions reductions is most effective for electric utilities in Indiana. At least one other state will be examined and compared with the results from Indlana.

\title{
Temporal and Spatial Variability of Methane Cycling in Wetland Ecosystems of the Northern Temperate Zone
}

\author{
(formerly: Spatial and Temporal Variability in Methane Emissions \\ from Wetland Ecosystems in the Northem Temperate Zone) \\ Jeffrey R. White, Indiana University \\ and \\ Kenneth H. Nealson, University of Wisconsin, Milwaukee
}

Objective: Our major objective during the past year was to continue our characterization of the spatial and temporal variability in methane fluxes from several types of peatlands common to the northern temperate zone. We also continued measurements of porewater chemistry, which have provided a detalled picture of the biogeochemical dynamics and cycling of methane, carbon substrates, and inorganic species within the peat deposits of these wetland systems.

Approach: Our research has included the following work elements. 
1) Measuremont of the temporal and spatial variability of not mothane fluxes to the atmosphore from two peat bogs overy 2-3 weoks. Soven sites woro monitored to assess both betweon and within sito variability in mothano and carbon dioxide flux. Dlurnal variations in gas flux have also been quantified at froquent intervals during tho growing season.

2) We have measured concentrations of important solutes and trace gases within the porowater of peat sediments, using passive diffusion samplers. Moasurements includo dissolved methane and carbon dioxide, conservative solutes, important redox sensitive species, carbon substrates -- acctate and formate, and the stable carbon and hydrogen isotopic composition of both ovolved methane and methane in porewaters. Porewater chemistry has been helpful in understanding the changes in methane pools within peats and possible controls on methane cycling.

3) We have also begun laboratory experiments using intact peat cores in an effort to isolate the effects of temperature and water lovel on methane flux.

4) The field and laboratory results provide a basis for our efforts to further refine a model of methane production, diffusion, and oxidation within peatlands.

Results to Date: We have completed one year of field measurements as of November 1991. The methane fluxes varied dramatically between the two peatland study sites. Net flux of methane during mid-summer in the Sphagnum-dominated system reached $850 \mathrm{mg} \mathrm{CH} \mathrm{m}^{\cdot 2} \mathrm{~d}^{\prime 1}$ beforo decreasing to less than $200 \mathrm{mg} \mathrm{CH}_{4} \mathrm{~m}^{.2}$

$\mathrm{d}^{\prime \prime}$ later in summer. In contrast, net fluxes in the leatherleaf-dominated sites only approached $75 \mathrm{mg} \mathrm{CH}_{4} \mathrm{~m}^{\cdot 2}$ $d^{\prime \prime}$ by early summer. Methane fluxes differed consistently by an order of magnitude between the two bog systems. The differences in flux rates were primarily controlled by the differences in vegetation between the two sites. The water-logged peat of the Sphagnum-dominated site warmed steadily throughout the spring months due to a lack of shrubby vegetation to shade peat deposits. In contrast, the hummock-hollow microtopography associated with leatherleaf shrubs insulated the peat deposits of the shrub-dominated site, resulting in slower warming of the peat and lower rates of methanogenesis.

Pegt temperature was not the main factor controlling the differences in net methane flux between sites, or the seasonal variations in net methane flux at each site. Changes in water level appear to be the major controlling factor. Porewater methane concentrations and water levels exhibited large seasonal variations during the first year. Diffusion gradients of dissolved methane in porewater were always greater and the diffusion distances through unsaturated peat above the water level were always smaller in the Sphagnum. dominated system. In contrast, shrubby leatherleaf vegetation and hummock-hollow microtopography may have provided for higher evapotranspiration rates, causing greater water loss in the leatherleaf-dominated bog. Methane oxidation in acrobic unsaturated peat may have suppressed net methane fluxes to the atmosphere during the drier summer months. The depth of the unsaturated zone was 2-3 times greater in the leatherleaf-dominated bog, and could contribute to the substantially lower methane fluxes and pools that we observed during the first year of the study. During periods of rising water levels, we also noted evidence of competition between sulfate reducing bacteria and methanogenic bacteria for carbon substrate (acetate). The sulfate reducers are energetically favored; methane production rates may have decreased under such conditions. The effects of peat temperature and water level in regulating methane cycling appear to be extremely important and warrant additional study, particularly since future climate change may cause significant changes in peat temperatures, evapotranspiration rates, and water levels within many peatland ecosystems. 


\title{
The Influence of Climatic Change on the Long-Term Hydrological and Blogeochemical Trajectories of North American Watershed-Lake Ecosystems
}

\author{
D. R, Whitehead, P. R. Sweets, and J, R. White \\ Indiana University
}

Objective: To use paleolimnological techniques to examine the hydrological and biogeochemical changes of North American watershed-lake ecosystems during the Holocene in response to climatic change. Wo will focus on the changes in lake blogeochemistry, lake water level, lake biota, watershed vegetation, and watershed soil processes to determine how they responded to climatic changes already documented from published studies. We are concentrating on seepage systems, where lake level change is more directly connected to climatic change than drainage systems.

The first year project sampled Florida seepage lakes. A northern component examining seepage lakes in Indiana began in FY 91 and will hopefully extend to northern Michigan in FY 92. We are developing collaborations with other workers in Minnesota, Maine, and Ontario which should permit important interregional comparisons and new advances.

In later phases, the project will be more exploratory in nature, examining the ways in which 1) powerful new techniques in diatom paleolimnology may yield direct knowledge of lake level change and hydrology, and 2) combining results from paleolimnology with single-lake and regional hydrological models to refine our knowledge of past climate change.

Thus, the two primary objectives of this pr oject may be summarized as 1) to characterize the response of lake-watershed ecosystems to past climate change (enabling modelers to assess possible effects of future climate changes), and 2) to contribute to the overall paleoclimate database, particularly the precipitation component, with both data and new methodologies.

Product: In this funding year: data on biogeochemical ( $\mathrm{pH}, \mathrm{ANC}, \mathrm{DOC}$, trophic state, some metal ions) and hydrological (principally lake-level) change in two seepage lakes in Florida over approximately the last 10,000 years. Conclusions on the meaning of these changes in response to known climatic change. Preliminary indications of the possibility that diatom paleolimnology can be used as a direct indicator of lake-level change. Possible interpretations of precipitation/evaporation ratios that explain the stratigraphic data. Initial data on Indiana sites should be available by the end of FY 91 .

Approach: Analysis of lake sediment cores (multiple) using diatom-lake variable transfer functions, pollen analysis, sediment chemistry, macrofossil analysis, and radiocarbon dating to develop stratigraphies of lakelevel change, lake biogeochemical change, and watershed vegetation. These are interpreted using published reconstructions of regional climate change. Inferred hydrological changes are analyzed using the Internal Alkalinity Generation model for corroboration and to deduce a range of possible causative factors.

Results to Date: Multiple cores were taken from a lake in the Florida Peninsula (Big Tommy) and from the north-central Panhandle (Barco) in late November 1990. The stratigraphies of the most important parameters (diatoms, pollen, sediment shemistry) are near completion. Radiocarbon dating and sediment analysis indicates that deep core sediment records from both Big Tommy (12000 YBP) and Barco Lakes (> 8000 YBP) encompass many changes in both climate and water level. Analyses of Pretty Lake in northern Indiana have begun.

At this juncture, the results from Barco Lake are the most developed. There are significant and synchronous changes in diatom flora, inferred biogeochemistry, vegetation, sediment chemistry, and probably lake water-level. Many changes generally occur between 5000 and 6500 YBP, a period considered to be a time of climatic warming. 
The pollen analysis is in general agreement with the previous pollen stratigraphies from the area. Pine is dominant from 5000 YBP to the present. Previous to that time, oak was more important. The increased percentages of aquatic pollen and Botryococcus (an alga) in the bottom section of this core (provious to 5000 YBP) Initially suggest increased productivity and macrophyte growth. Possible explanations include changes in water level or water clarity, particularly between 5000 and 6500 YBP. The organic layers just above the clay sediments would seem to indicate that the lake may have been dry before 8500 YBP. (However, previous studies suggest this may be a time of high water levels in the area; many shallow lakes became dry around 12000 YBP.) Changes in charcoal concentrations on the pollen slides indicate important fire chronology for the region.

The preliminary sediment chemistry stratigraphies indicate peaks in the concentration of several elements ( $\mathrm{Fe}, \mathrm{Mn}$, and $\mathrm{Ca}$ ) in those same intervals that pollen indicates lake stage change (5000-6500 YBP). If there are no suspected changes in the oxygenation of bottom sediments (unlikely in this lake), varying and somewhat competing hypotheses can be advasced to explain the chemical stratigraphies, such as increased erosion or groundwater flow. Early interpretation of sediment chemistry can be dangerous but these data certainly corroborate that this is an important time of change in the history of Lake Barco.

This same period is also the time of most change in diatom relative abundance. Species of Melosira become clearly dominant. Melosira is often associated with somewhat more eutrophic situations and it is the only pelagic (usu. opportunistically) genus significantly represented in the core. From 5000 YBP to the present, epiphytic species are dominant, especially Frustulia thomboides var. saxonica and Anomoeoneis serians var, brachysira. Also of interest are several areas where diatoms are very poorly preserved, often at times of floral change, again suggesting water-level change or radically different biogeochemistries.

A preliminary $\mathrm{pH}$ inference demonstrates major fluctuations in lake chemistry. Several intriguing results are immediately apparent. The extremely low pH of lakes in this region of Florida (amongst the most acidic clearwater lakes in the nation) is shown to be at least partly natural by the quick decline in $\mathrm{pH}$ from 6.0 to 5.0 soon after (presumably) filling with water at about 8500 YBP. However, there is one period of very severe $\mathrm{pH}$ depression at about 6500 YBP. This is the only time that past lake $\mathrm{pH}$ comes close to recent measurements (4.4) where low $\mathrm{pH}$ levels are thought to be partially due to acidic precipitation.

\title{
The Effect of Global Climate Change on Wetland Function and Distribution, and the Consequent Land Use and Economic Change
}

\author{
(formerly: Concept Proposal for the Study of Wetland Change \\ as a Result of Global Climate Change) \\ Daniel E. Willard \\ Indiana University
}

Objective: This study, and its related studies, describes and integrates the hydrologic, ecological, and ultimately, economic effects of potential climate-induced changes on the temporal and spatial distribution of the hydroregime within several study watersheds which vary strikingly in their major land use.

Products: In the first phase of the study, we developed and began to apply an integrated hydrologicalecological model for each study watershed. (1) Sherry Mitchell-Brucker has field tested a conjunctive surface water-groundwater model of the Pere Marquette Watershed which describes the regional hydroregime. Field predictions of the distribution of wetlands are highly accurate. The output of the model also correlates well with annual and century-long river flow data. We now begin to understand how the hydroregime will respond to alternative global environmental change scenarios. (2) 'We have completed an initial field 
mapping of the salmonid habitat in the upper Pere Marquette River. These data show that a reduction in stream level would reduce the availability of gravel beds for saimonids by as much as $80 \%$. (3) Dave Cassuto has completed $65 \%$ of the draft of the ecological history of the Pere Marquette River, Cold Running River. (4) Avram Primack has completed a manuscript on the effects of TFM, a lampricide, on invertebrate populations in the upper Pere Marquette River.

Approach: Mitchell-Brucker has presented her work at several meetings and submitted a manuscript for publication. Willard has presented the salmonid work and submitted a manuscript for publication. Several chapters of Cold Running River are under review by the University of Michigan Press. Primack has prepared a manuscript on the TFM study.

Results to Date: A requisite part of this phase included understanding and separating the relative effects of local natural change (such as water flow regulation, bank stabilization and beaver control) from global scale changes. We have evaluated the potential for change in water quality or quantity, which may affect land use and ultimately local economies. These land and water use capabilities limit prescribe the potential economic uses of the particular property within the watershed.

This interdisciplinary approach requires an integration of work in hydrology, wetland ecology, and economic analysis. In 1990-1991 we linked the watershed hydroregime model for the Pere Marquette River to population levels of invertebrates and anadromous fishes. This allows us to relate ecological resources, in addition to physical resources, to the recreational use of the river. Recreation provides the major income stream to the town of Baldwin and to Lake County.

Last summer Avram Primack surveyed potential field sites and identified three sites for seed bank experiments. Two of the sites match areas which Sherry Mitchell-Brucker has modeled intensively: (1) Baldwin Luther Swamp. The vegetation includes tamarack and leatherleaf similar to Jeff White's methane sites. (2) An intermittent creek between the Baldwin river and Sanborn Creek. Vegetation at this site is a mixture of sedges, grasses, and stunted trees. (3) Site eleven in the water quality study. Dominant plants and soils were collected at each site and identified. Ripe seeds were collected from dominant forbs when available and will also be used in germination experiments this spring.

We began transferring this approach to the agriculturally developed Kankakee River watershed. Studies on this altered watershed further expand our knowledge of how climate change affects the function of interspersed agricultural and wetland ecosystems, and how these impacts link to economic consequences. This work augments previous work on the effects of riparian vegetation along streams in an agricultural watershed. We have selected and begun site characterization on several sites which contain wetlands and fields in various spatial configurations. On these we will demonstrate the coupled effects of drainage, irrigation, and changes resulting from various predictions of climate change.

In 1991-1992 Charlotte Wolfe showed many sorts of perturbations in the Kankakee watershed. Water quality, particularly sediment load and agricultural waste products, may be the important limiters of potential use. Any change in flow will alter the distribution of these materials and affect the activities supported by the river and the entire watershed. We selected several study sites to measure and demonstrate these effects. The measurement stations chosen at the Upper Kankakee River watershed study site reflect a range of landscape types and drainage regimes. All of the stations chosen are located at the headwaters of tributaries to the main stem Kankakee River. All of the stations have hydric soils, and most are organic soils.

Avram Primack has completed the sixth year of invertebrate census on the Pere Marquette River. This study shows that the use of the lampricide TFM has no measurable effect on the macroinvertebrates of the river. The study also shows that these invertebrates provide a rich forage base for the juvenile salmonids which grow and develop in the river. 
We have mapped salmonid breeding sites (redds) on seven miles of the Quality Fishing Water of the upper Pere Marquette. Field observations show that these redds must have at least $30 \mathrm{~cm}$ of water flowing over them. A reduction in water level from the 10 year average would reduce the availability of the sites by 80\%. Using USGS and USFWS data we have begun to reconstruct the fall (breeding season) water regime for the last 20 years to examine its correlation to salmonid breeding success.

Significance of Study: This work tests the use of models for predicting and analyzing the consequences of climate change derived by examining alterations already occurring in the natural environment. The work establishes baseline conditions and functions of water resources within the watershed, with which to compare future conditions. The several joint sections of this study, taken together, will show the balance of change within a complex watershed responding to various scenarios of large scale environmental perturbations. These responses link global climate change, watershed ecological change, and local economic disturbance. 


\section{Research Projects Starting July 1, 1991}

"Amazonian Deforestation and Carbon Cycling Management" by Emilio F. Moran (Indiana University)

"Adaptation, Migration, or Extinction? A Study of the Influence of Climate Change on the Biodiversity and Biotic Productivity of Selected Biomes of North America" by J. C. Randolph (Indiana University)

"Biological Hysteresis in Climate Change Models for the Great Plains: Implications for Productivity and Hydrologic Cycles" by T. R. Seastedt and D. S. Ojima (Kansas State University)

"Trace Gas Fluxes in the U.S. Midwest: Temporal Dynamics and Biospheric Feedbacks in Agricultural Ecosystems" by G. P. Robertson, K. Paustian, and M. J. Klug (Michigan State University)

"A Study of Energy Policy in the Midwestern States" by Mary T. Bailey (University of Cincinnati)

"Effects of Environmental Factors on Phytoplankton Emissions of Dimethyl Sulfide: Implications for Climate Change" by John Birks (University of Colorado)

"Simulation Experiments of Inertia in Forest Response to Climatic Warming" by M. P. Armstrong and G. P. Malanson (University of Iowa)

"A Field Study of Methane and Carbon Dioxide Fluxes in a Boreal Wetland Ecosystem: Measurement and Analysis" by S. B. Verma and F. G. Ullman (University of Nebraska)

"Genetic Basis for Variation in Freshwater Phytoplankton Productivity Related to Water Temperature" by K. D. Hoagland, S. G. Ernst, and D. M. DeNicola (Univ. of Nebraska)

"Climate and North American Plant Formations: Associations Between the Water Balance and SatelliteDerived Vegetation Patterns" by Dennis E. Jelinski (SUNY-Buffalo)

"Potential Effects of Global Climate Change on Midwestern Lakes: Physics, Fishes and Plankton" by J. J. Magnunson (University of Wisconsin) 
Financial Status of Projects

Midwestern Regional Center

\section{FY 90 Projects}

\begin{tabular}{|c|c|c|c|c|}
\hline Project Title/Principal Investigator(s) & $\begin{array}{l}\text { Budget } \\
\text { Award }\end{array}$ & $\begin{array}{l}\text { Expenses } \\
\text { @ 6/30/91 }\end{array}$ & $\begin{array}{l}\text { Projected } \\
\text { Expenses } \\
\text { @ } 6 / 30 / 92\end{array}$ & $\begin{array}{l}\text { Anticipated } \\
\text { Carryover }\end{array}$ \\
\hline $\begin{array}{l}\text { Isotopic Studies of the Biogeochemical Cycle of Carton: } \\
\text { Relationships Between } \mathrm{PCO}_{2} \text { and the Abundance of }{ }_{15} \mathrm{C} \text { in } \\
\text { Sedimentary Organic Matter } \\
\text { J.M. Hayes and L.M. Pratt }\end{array}$ & $\$ 102,447$ & $\$ 102,447$ & $\$ 102,447$ & s-a \\
\hline $\begin{array}{l}\text { Atmospheric Concentrations of Trace Level Organics: Do } \\
\text { Organochlorines Contribute to Ozone Depletion? } \\
\text { Ronald A. Hites }\end{array}$ & 170,951 & 64,435 & 170,951 & -0 \\
\hline $\begin{array}{l}\text { The Mechanisms Controlling Methane Cycling in Two Wetland } \\
\text { Ecosystems in Michigan } \\
\text { Jeffrey R. White }\end{array}$ & 106,531 & 102,794 & 106,531 & -0 \\
\hline $\begin{array}{l}\text { Climatic Influences of Land Surface Conditions in the Midwest } \\
\text { United States } \\
\text { A. M. Carleton and C.S.B. Grimmond }\end{array}$ & 84,972 & 46,688 & 84,972 & -0 \\
\hline $\begin{array}{l}\text { Supra-Regional Modeling of Groundwater Response to Climate } \\
\text { Change } \\
\text { Henk H. Haitjema }\end{array}$ & 103,747 & 74,292 & 103,747 & 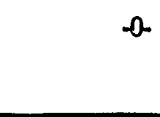 \\
\hline $\begin{array}{l}\text { Influence of Climatic Change on the Long-Term Hydrological and } \\
\text { Biogeochemical Trajectories of North American Watershed-Lake } \\
\text { Ecosystems } \\
\text { Donald R. Whitehead, P. Roger Sweets, and Jeffrey R. White }\end{array}$ & 115,279 & 82,554 & 115,279 & -0 \\
\hline $\begin{array}{l}\text { Effect of Global Climate Change on Wetland Function and } \\
\text { Distribution, and the Consequent Land Use and Economic Change } \\
\text { Daniel E. Willard, Kerry Krutilla, and Henk Haitjema }\end{array}$ & 102,588 & 97,814 & 102,588 & -0 \\
\hline $\begin{array}{l}\text { The Economic Consequences and } \mathrm{CO}_{2} \text { Emissions Impact of Energy } \\
\text { Taxation } \\
\text { Kerry Krutilla with Roy Boyd (Ohio University) }\end{array}$ & 61,302 & 24,621 & 61,302 & $-\infty$ \\
\hline $\begin{array}{l}\text { The Impact of the Corporate Average Fuel Economy Standards on } \\
\text { the Life Span and Lifetime Energy Consumption of Automobiles: A } \\
\text { Population Dynamics Approach } \\
\text { Eric L. Mitter }\end{array}$ & 25,269 & 5,051 & 25,269 & -0 \\
\hline $\begin{array}{l}\text { Fuel Switching Impacts on Carbon Dioxide Emissions from } \\
\text { Midwestern Great Lakes States Electric Utilities } \\
\text { J.C. Randolph }\end{array}$ & 103,790 & 39,717 & 103,790 & - \\
\hline $\begin{array}{l}\text { Perseus Unmanned Scientific Research Aircraft: A New Tool for } \\
\text { Global Climate Change Research } \\
\text { John Langford (Aurora Flight Sciences) }\end{array}$ & 75,000 & 0 & 75,000 & -0 \\
\hline $\begin{array}{l}\text { Center Administration } \\
\text { J.C. Randolph }\end{array}$ & 100,000 & 77,068 & 100,000 & -0 \\
\hline Geographic Information Systems Laboratory & 131,124 & -0 & 131,124 & -0 \\
\hline TOTAL & $\$ 1,283,000$ & $\$ 717,481$ & $\$ 1,283,000$ & S-O- \\
\hline
\end{tabular}


Financial Status of Projects

Midwestern Regional Center FY 91 Projects

\begin{tabular}{|c|c|c|c|}
\hline Project Title/Principal Investigator(s) & $\begin{array}{l}\text { Budget } \\
\text { Award }\end{array}$ & $\begin{array}{c}\text { Projected } \\
\text { Expenses } \\
\text { @ 6/30/92 }\end{array}$ & $\begin{array}{l}\text { Anticipated } \\
\text { Carryover }\end{array}$ \\
\hline $\begin{array}{l}\text { Supra-Regional Modeling of Groundwater Response to Climate Change } \\
\text { Hendrik M. Haitjema }\end{array}$ & $\$ 117,796$ & $\$ 117,796$ & S-O- \\
\hline $\begin{array}{l}\text { Isotopic Studies of the Biogeochemical Cycle of Carbon: Relationships Between } \\
\mathrm{PCO}_{2} \text { and the Abundance of }{ }^{13} \mathrm{C} \text { in Sedimentary Organic Matter } \\
\text { John M. Hayes and L. M. Pratt }\end{array}$ & 142,941 & 142,941 & - \\
\hline $\begin{array}{l}\text { Atmospheric Concentrations of Trace Level Organies: Do Organochlorines } \\
\text { Contribute to Ozone Depletion? } \\
\text { Ronald A. Hites }\end{array}$ & 125,655 & 105,655 & 20,000 \\
\hline $\begin{array}{l}\text { Amazonian Deforestation and Carton Cycling Management } \\
\text { Emilio F. Moran }\end{array}$ & 78,123 & 78,123 & $-\infty$ \\
\hline $\begin{array}{l}\text { Adaptation, Migration, or Extinction? A Study of the Influence of Climate } \\
\text { Change on the Biodiversity and Biotic Productivity of Selected Biomes of North } \\
\text { America. } \\
\text { J.C. Randolph }\end{array}$ & 113,890 & 63,890 & 50,000 \\
\hline $\begin{array}{l}\text { Temporal and Spatial Variability of Methane Cycling in Wetland Ecosystems of } \\
\text { the Northerm Temperate Zone } \\
\text { Jeffrey R White }\end{array}$ & 123,481 & 123,481 & - \\
\hline Kenneth H. Nealson (University of Wisconsin) & 35,725 & 25,725 & 10,000 \\
\hline $\begin{array}{l}\text { The Influence of Climatic Change on the Long-Term Hydrological and } \\
\text { Biogeochemical Trajectories of North American Watershed-Lake Ecosystems } \\
\text { D.R. Whitehead, P.R. Sweets, and J.R. White }\end{array}$ & 145,372 & 135,372 & 10,000 \\
\hline $\begin{array}{l}\text { The Effect of Global Cliamte Change on Wetland Function and Distribution and } \\
\text { the Consequent Land Use and Economic Change } \\
\text { Daniel E. Willard }\end{array}$ & 142,252 & 112,252 & 30,000 \\
\hline $\begin{array}{l}\text { Climate and North American Plant Formations: Associations Between the Water } \\
\text { Balance and Satellite-Derived Vegetation Patterns } \\
\text { Andrew M. Carleton }\end{array}$ & 13,497 & 3,497 & 10,000 \\
\hline Dennis Jelinski (State University of New York, Buffalo) & 73,749 & 23,749 & 50,000 \\
\hline $\begin{array}{l}\text { Biological Hysteresis in Climate Change Models for the Great Plains: } \\
\text { Implications for Productivity and Hydrologic Cycles } \\
\text { T.R. Seastedt and D.S. Ojima (University of Colorado) }\end{array}$ & 51,327 & 11,327 & 40,000 \\
\hline $\begin{array}{l}\text { Trace Gas Fluxes in the U.S. Midwest: Temporal Dynamics and Biospheric } \\
\text { Feedbacks in Agricultural Ecosystems } \\
\text { G.P. Robertson, K. Paustian, and M.J. KJug (Michigan State University) }\end{array}$ & 144,388 & 104,388 & 40,000 \\
\hline $\begin{array}{l}\text { A Study of Energy Policy in the Midwestern States } \\
\text { Mary T. Bailey (University of Cincinnati) }\end{array}$ & 35,386 & 30,386 & 5,000 \\
\hline $\begin{array}{l}\text { Effects of Environmental Factors on Phytoplankton Emissions of Dimethyl } \\
\text { Sulfide: Implications for Climate Change } \\
\text { John Birks (University of Colorado) }\end{array}$ & 51,780 & 46,780 & 5,000 \\
\hline $\begin{array}{l}\text { Simulation Experiments of Inertia in Forest Response to Climatic Warming } \\
\text { M.P. Armstrong and G.P. Malanson (University of lowa) }\end{array}$ & 54,193 & 49,193 & 5,000 \\
\hline
\end{tabular}




\begin{tabular}{|c|c|c|c|}
\hline Project Title/Principal Investigator(s) & $\begin{array}{l}\text { Budget } \\
\text { Award }\end{array}$ & $\begin{array}{l}\text { Projected } \\
\text { Expenses } \\
\text { @ } 6 / 30 / 92 \\
\end{array}$ & $\begin{array}{l}\text { Anticipated } \\
\text { Carryover }\end{array}$ \\
\hline $\begin{array}{l}\text { A Field Study of Methane and Carbon Dioxide Fluxes in a Boreal Wetland } \\
\text { Ecosystem: Measurement and Analysis } \\
\text { S.B. Verma and F.G. Ullman (University of Nebraska) }\end{array}$ & 139,110 & 69,110 & 70,000 \\
\hline $\begin{array}{l}\text { Genetic Basis for Variation in Freshwater Phytoplankton Productivity Related to } \\
\text { Water Temperature } \\
\text { Kyle D. Hoagland, S.G. Ernst, and D.M. DeNicola (University of Nebraska) }\end{array}$ & 66,968 & 64,968 & 2,000 \\
\hline $\begin{array}{l}\text { Potential Effects of Global Climate Change on Midwestern Lakes: Physics, Fishes, } \\
\text { and Plankton } \\
\text { John J. Magnuson (University of Wisronsin) }\end{array}$ & 147,300 & 77,300 & 70,000 \\
\hline $\begin{array}{l}\text { Director's Fund } \\
\text { J.C. Randolph }\end{array}$ & 39,257 & 39,257 & $-a$ \\
\hline $\begin{array}{l}\text { Center Administration } \\
\text { J.C. Randolph }\end{array}$ & 150,000 & 150,000 & -0 \\
\hline TOTAL & $\$ 1,992,190$ & $\$ 1,575,190$ & $\$ 417,000$ \\
\hline
\end{tabular}




\title{
Northeast Regional Center Director's Report
}

\author{
Richard Wilson, Director
}

The objective is to arrange a coordinated program of research in Global Environmental Change.

The monthly seminar has been well attended this year with speakers from a variety of areas: Dr. V. Ramanathan (Scripps Institute of Oceanography at the University of California, San Diego) was invited to give scientific information about the ARMS program of DOE; Dr. F. Sherwood Rowland, University of California, Irvine; Dr. Kerry Emanuel, Center for Meteorology and Physical Oceanography, MIT; Dr. Dale Jorgensen, Economics Department, Harvard; Dr. Michael Bender, Graduate School of Oceanography, University of Rhode Island, will talk in February on atmospheric $\mathrm{pCO}_{2}$ in the last ice age; Dr. Takahashi, Lamont Doherty Geological Observatory, Columbia University will talk in March; Dr. John Hayes, University of Indiana, will be here in April; and Dr. John Imbrie, Brown University will speak in May. These seminars are well attended and help to keep coherence in the center.

\section{Program Solicitation for 1992-1993}

In October 1991 we sent a Request for Proposals (RFP) to over 300 people to participate in the work of the center. Fifty-five Letters of Intent were received, and 47 proposals were received by 5:00 pm on December 9,1991 and were sent to reviewers by $7: 30 \mathrm{pm}$ that day. As a result of the reviews, 18 proposals were forwarded to NIGEC on January 15, 1992 as part of the Center proposal.

Director's Discretionary Fund for Innovative Activities. Approximately three-fourths of the director's discretionary fund has already been allocated. These funds are allocated after discussion with the local program committee. The allocations are noted on the list of projects above and are repeated here.

-- Dr. Peter Stone, MIT: "Coupled atmosphere-ocean climate model, $\$ 19,340$

-- Dr. Richard Waring and Dr. Richard McCreight, Oregon State University: "Classifying structural and functional characteristics at the Harvard Forest", $\$ 12,752$

-- Dr. Stein Jacobsen, Harvard: "Precise determination of climatic change over the past 1,000 years", $\$ 20,000$

- Dr. Richard Boone, Harvard Forest: "Biological and physical controls on soil organic matter," $\$ 50,000$

\section{New Projects, 1991-1992}

-- "Sources of atmospheric $\mathrm{CH}_{4}$ in the Eastern United States", R. Harriss and P. Crill, University of New Hampshire

-- "Atmosphere-biosphere exchange of nitric acid in a forest", R. Talbot and O. Klemm, University of New Hampshire

-- $\quad$ "Fate of atmospheric $\mathrm{SO}_{2}$ based on cosmogenic $35 \mathrm{~S}^{n}, \mathrm{~K}$. Turekian, Yale University

-- "Paleotemperatures for NA derived from noble gases in groundwater", W.S. Broecker, M. Stute, P. Schlosser, Lamont-Doherty Geological Observatory, Columbia University

\section{Education}

i) Case studies: Prof. W. Clark and Mr. D.M. Kennedy, John F. Kennedy School of Government, Harvard University -- The main items in the education program in 1990-91 were two case studies in global climate change. Mr. Kennedy went through key documents in the development of the U.S. global climate change program: the NASA habitability/mission to planet earth papers, the NSF/NRC books, Committee in Global Change proceedings, agency plans, CES/CEES documents, and the like. He also talked with key participants in the process, chiefly Michael McElroy and James McCarthy at Harvard and Nancy Maynard in the office of the science advisor to the President of the USA. We believe that there is an important case here, perhaps 
several, and that the first case, focusing on Bromley's need to create order and ensure value in a large, competitive, decentralized and substantively challenging enterprise, is the right one to start with.

Kennedy visited Washington to talk with people from the OSTP and CEES, the agencies, the NSF and NRC, OMB and some staff on Capitol Hill. Independent scientists and more far-flung agency staff, such as Harold Mooney and Francis Bretherton, were interviewed by telephone.

The plan for this case is to cover, very economically, the rise of the global habitability/earth system science/global climate change idea, its movement through the NRC and CGC into both the international and federal arenas, the early agency responses and OMB's critical stance, then spend the bulk of the case framing OSTP/Bromley's sense of the problem, the origin of the CES as a response to it, and telling the story of how the committee was structured, functioned, and what the early impressions of its efficacy were. Many interesting issues will appear: past experience with managing big science programs, lead-agency vs. other approaches, lessons learned from the ozone/acid rain/carbon dioxide programs, the nature of the relations between the NRC and the agencies, and the NRC and the executive, the role of the scientist as bureaucrat, the competition between big science (like EOS) and small science. Given current controversy in these circles about the cost and primacy of EOS, the case-writers hope to bring the case up to the present, in order to include that controversy, rather than end the case at an earlier time when Bromley, at least, was convinced that the CEES had worked to prevent or mediate such trouble.

The reception among the management faculty at Harvard to the cases, for use in the core MPA and MPP curricula, has been good. There is an interest in having scientific and technology management issues represented, and "global warming" seems both topical and accessible enough to be a good candidate. In fact, the discussion has turned to the idea of a global warming "module", a series of fresh cases replacing a number of substantively unrelated cases now used to teach the management of analysis, press relations, decision making under certainty, and the role of experts. The management faculty saw the first case as an example of the "czar problem": how can someone in Bromley's position, without line- or budget-authority, do the job expected of them? This is increasingly the case in federal and state governments, and one faculty member would like to use the case as soon as it is ready in a new JFK School executive program for state drug czars.

Discussion is now underway on the idea of the module and on the focus of the second case, which cannot be too far removed from the general CEES theme. For instance, a case on the substantive strategy, rather than the management, of the U.S. global climate change research program would be a wonderful way to explore how to support policy making in conditions of tremendous uncertainty. A closer look at what agencies won and gave up, and why, would be a good case on what coalition-building looks like from the bottom. A case on Dr. Mooney (or even Prof. McCarthy or Prof. McElroy) would be good for exploring the roles of experts in such processes.

The first case should be drafted in February 1992, and the second, presuming it lies in an area not too far removed from the first, by the end of March 1992.

ii) Undergraduate fellowships: The summer undergraduate fellowship program was very successful in 1991. Aid was offered to seven undergraduates, of whom five were supported at three universities (two at LDGO, two at Harvard, one at SUNY-Buffalo). The program for 1992 has been advertised widely among the universities in the area.

iii) It has been decided to support a "mini-conference" at the Lamont Doherty Geological Observatory at Columbia University in May 1992 , and about $\$ 30,000$ has been allocated for this purpose.

iv) The local program committee again decided to support the Harvard Journal of Environmental Issues (Spring 1991, Vol 1), an undergraduate magazine, at the level of $\$ 2,000$ to cover their printing costs. 


\title{
Decomposition Rates and Nutrient Dynamics in a Temperate Forest: Efrects of $\mathrm{CO}_{2}$ and Nitrogen Enrichment
}

\author{
(formerly: Relationships Between $\mathrm{CO}_{2}$ Levels, Tissue Nitrogen Content, and Litter Decomposition)
}

Jerry Melillo, Knut Nadelhoffer, and Paul Steudler

The Ecosystems Center, Marine Biological Laboratory, Woods Hole

With NIGEC funding, the staff of the Ecosystems Center is conducting two studies concerned with atmosphere-biosphere feedback mechanisms in forest ecosystems of the temperate zone. More specifically, we are considering 1) how soil warming will affect the fluxes of greenhouse gases between the land and the atmosphere, and 2) how increases in the carbon dioxide concentration of the atmosphere will alter carbon exchange between forests and the atmosphere by affecting decomposition processes. These studies are being conducted in close cooperation with other NIGEC researchers, including Dr. John Aber, Dr. F. Bazzaz, and Dr. S. Wofsy. Both studies are going well. One of the early findings from the soil warming study is briefly discussed below.

We have now operated the soil warming plots for one full growing season. We have found a strong relationship between the average daily carbon dioxide flur and soil temperature. The efflux of carbon dioxide increased exponentially with increasing soil temperature. A linear regression of temperature and the natural logarithm of carbon dioxide flux explained $92 \%$ of the variability (Fig. 1). The exponential relationship between soil temperature and carbon dioxide flux is in good agreement with the Arrhenius equation. For these data, the activation energy was about $63 \mathrm{~kJ} / \mathrm{mol}$ and the Q10 was about 2.5 .

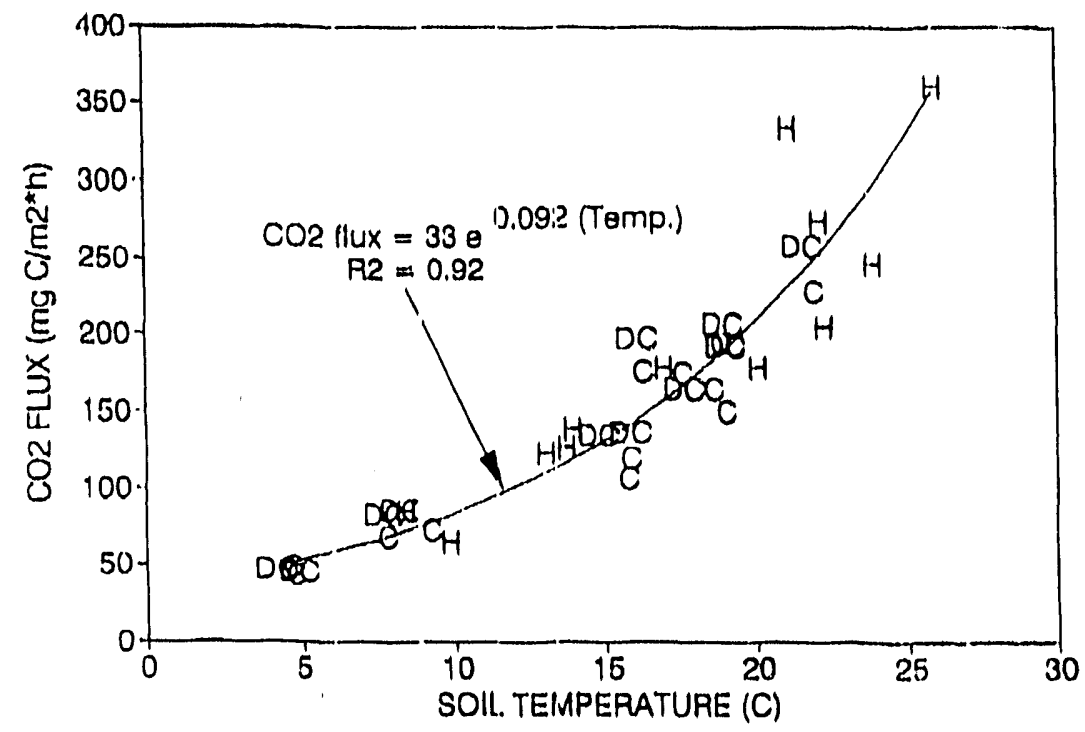

Fig. 1. $\mathrm{CO}_{2}$ flux vs $4 \mathrm{~cm}$ soil temp. soil warming plots of Harvard Forest. 


\title{
Soll Chemistry and Throughfall at Harvard Forest
}

\author{
(fomerty: Ecosystem Processes as Affected by Soll Warming) \\ John D. Aber \\ University of Now Hampshire
}

Overview: The tower-based eddy correlation measurements of atmospheric deposition at the Harvard Forest are a cornerstone of both the Harvard Forest Longuterm Ecological Research (LTER) and NIGEC research efforts. Estimation of total atmospheric nitrogen deposition to the Forest is one important aspect of this effort. The distribution of deposited nitrogen between the plant canopy and the soll system can determine how quickly it affects nutrient cycling. Nitrogen deposited to solls will be immobilized rapidly and re. released only slowly by nitrogen mineralization of soll organic matter. Nitrogen deposited to, and retained on, leaf surfaces can be used in the current year to increase foliar nitrogen content and photosynthetic rates.

In 1991, we continued sampling from a set of canopy throughfall collectors to determine the nitrogen (N) content in rain passing through the forest canopy in the control hardwood stand associated with the LTER chronic $\mathrm{N}$ addition experiment. With both wet and dry deposition being measured at the tower, throughfall values could be used to determine what fraction of the deposited $\mathrm{N}$ was reaching the forest floor and, by difference, what fraction was being retained in the canopy.

Methodology: Throughfall samples were collected in the Harvard Forest hardwood control plot from early May to October 1991. Within 48 hours of each precipitation, the volume of throughfall at each collector was measured, and a sample was collected. Samples were shipped overnight to UNH and frozen. Throughfall samples were collected in polypropylene funnels with a fiberglass mesh screen, attached to polypropylene collecting bottles by looped lab-grade tubing.

Ammonium- $\mathrm{N}$ and nitrate- $\mathrm{N}$ on all samples is being determined by automated analysis using a Technicon Autoanalyzer. $\mathrm{NH}_{4} \mathrm{~N}$ was measured by the phenol-hypochlorite-nitroprusside method (Technicon Industrial Systems 1978), $\mathrm{NO}_{s} \mathrm{~N}$ was measured by the hydrazine sulfate with copper catalyst method (Technicon Industrial Systems 1978). Total Kjeldahl nitrogen (TKN) was measured by the sodium salycilatesodium nitroprusside-hypochlorite method (Technicon Industrial Systems 1986). In this method, copper sulfate was substituted for mercuric sulfate. Complete digestion was verified by inclusion of two EPA TKN knowns in each digestion rack. $\mathrm{NH}_{4} \mathrm{~N}$ values obtained from the original pre-digestion analysis were subtracted from the TKN NH${ }_{4} \mathrm{~N}$ values to determine the organic $\mathrm{N}$ values. Analysis of collected samples is currently nearing completion.

\section{Net $\mathrm{CO}_{2}$ Exchange in Midlatitude Forests \\ (formerty: Chemical Climate in Eastern North America)}

S. C. Wofsy, J. W. Munger, M. L. Gouldin, B. C. Daube, K. A. Boering, J. D. Burley, and A. H. Goldstein,

\section{Harvard University}

The objectives of the project are to characterize the net exchange of $\mathrm{CO}_{2}$ between a midlatitude forest and the atmosphere, to examine fixed nitrogen inputs from the atmosphere, and to begin to develop an understanding of how such measurements can be generalized to global and regional scales. The approach has been to adapt direct flux measurement techniques to long-term measurements, and to integrate the measurements with ongoing work at the LTER and within NIGEC to derive information needed to generalize the results. 
The results to date include nearly-continuous measurements extending from October 1989 to the present, for eddy-correlation fluxes of $\mathrm{CO}_{2}$ and lotal nitrogon oxides. As reported in our annual roport (July 1991), this forest took up about $3000 \mathrm{kgC} / \mathrm{ha} /$ year betweon 1989 and 1991 . The uptake rate was basically tho same in the summer of 1991. A higher duty cycle was achioved this past year, providing confirmation that data gaps $\ln 1990$ (due to a lightning strike) did not blas the results on a seasonal basis. Wo also undertook a detailed study of the $\mathrm{CO}_{2}$ efflux from soils, in order to define the contribution of soils to the net $\mathrm{CO}_{2}$ exchange. Preliminary results from summer and fall soil studles indicate that the tower provides a good estimate of ecosystem respiration at night.

Wo are focusing now on complete analysis of all data, including all relovant corrections and interpolating through data gaps, in preparation for publicution of results.

\section{Risk Assessments and Elucidation of Uncertainties}

\section{(Sormerty; A Conceptual Framework for Risk Analysis of Global Environmental Change)}

\section{R. Wilson, A. Shlyakhter, and J, Lancaster Harvard University}

A book chapter on climate change as risk analysis problem has been completed and submitted to the editors. In this chapter we discuss climate change from the perspective of risk analysis. First, we set out a simple flow chart of cause and effect, describing how continued carbon dioxide emissions might lead to environmental hazards; this chart can bo used to emphasize the foci of concern. Second, we discuss how climate change ranks against the other environmental problems and hazards that have also been addressed by risk analysis. Third, we compare the nature of uncertainties in global warming with those uncertainties that risk analysts for other hazards are confronting: hazards of chemical carcinogens and safety of nuclear reactors or the chemical process industry, Fourth, we discuss the "de minimis" risk: which scenarios of future development are improbable enough to be neglected; this is closely related to the probabillity of surprise. Finally, we discuss an appropriate strategy for treating cascading uncertainties: iterative adjustment of climate models and scenarios of growth of population and energy production coupled with the periodic review of response actions.

We also performed analysis of multi-decade trends in the reported values of fundamental physical constants and projections of future energy demand and population growth, which revealed that a Gaussian, or normal, distribution grossly underestimates the frequency of events lying very far from the mean. Our approach used empirical data on the distribution of errors in prior measurements to quantify the probability of errors in posterior measurements. For example, the probability of large deviations ("surprises") in energy projection is well fit by a simple exponential and for population projections by a Gaussian (Fig. 1). The exponential asymptotic behavior appears naturally in a compound distribution where both the mean and standard deviation are normally distributed stochastic quantities.

A comparison of Gaussian and exponential threshold probabilities for sea-level rise by 2050 and 2100 A.D. is presented in Fig. 2. In the "business-as-usual" scenario the normal distribution places the probability in 2050 A.D. of extreme sea-level rise greater than 1 meter at $0.5 \%$ in contrast to the $5 \%$ probability based on an exponential distribution: a difference of an order of magnitude.

\section{References}

A. Shlyakhter and R. Wilson "Climate Change as Risk Analysis Problem", chapter in Policy Implications of Climate Change, W. Clark and H. Lee, eds, submitted.

A. Shlyakhter and D. Kammen "Evidence Against Gaussian Distribution of Errors from Trends in Measurements of Physical Constants and Projections of Global Change", submitted to Nature. 
Figure 2.

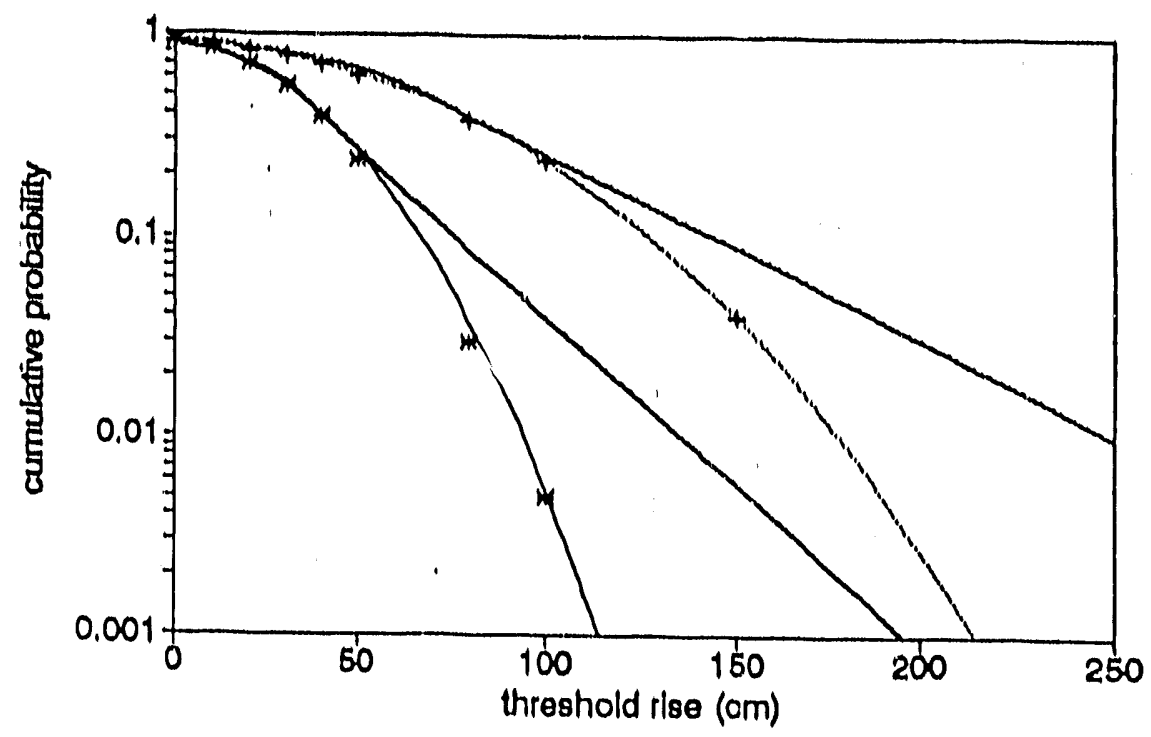

\begin{tabular}{|lll}
\hline 2050 Gauss & -2050 expon. & Oerlemans, 2050 \\
-2100 Gauss & -2100 expon. & + \\
\hline
\end{tabular}

Figure 3.

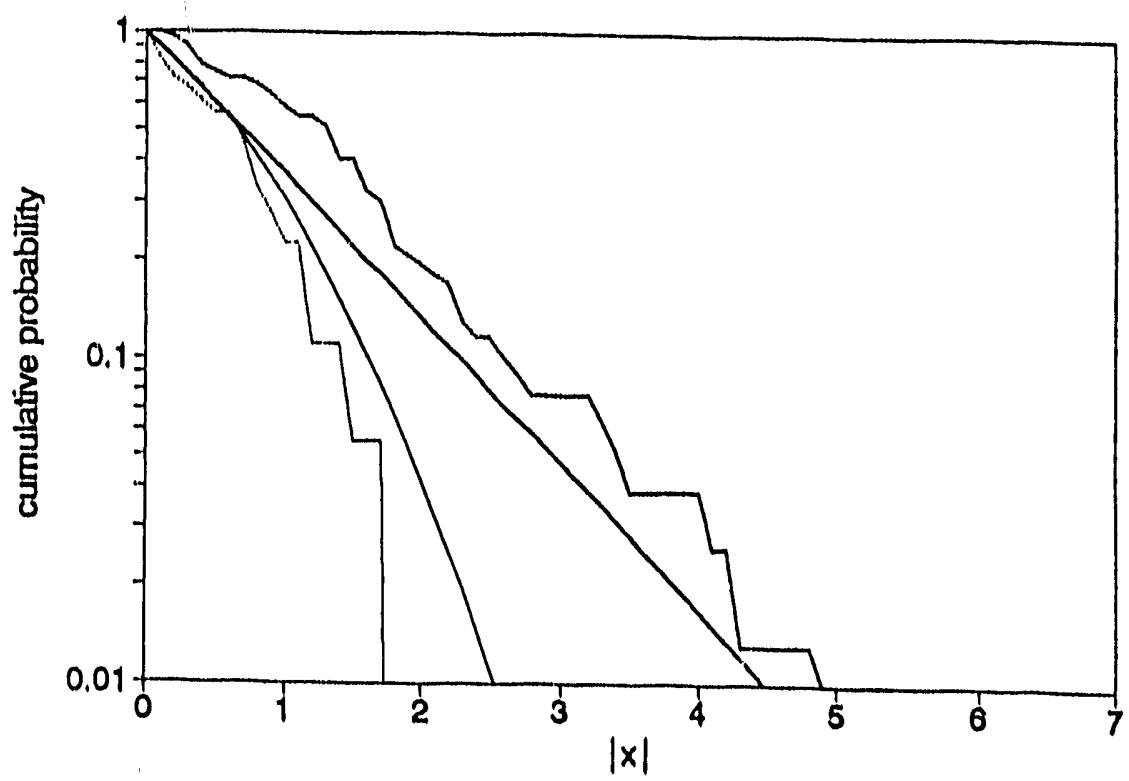

U.S, energy - Population - Gaussian - exporientlal

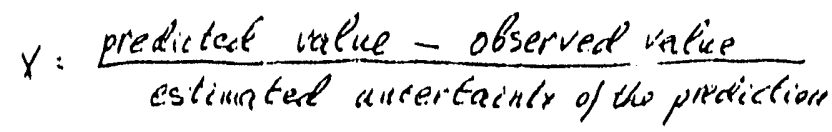




\title{
Past Climates and Factors Regulating Past Climate Change
}

\author{
M. B. McElroy and B. D. Marino \\ Harvard University
}

Research efforts during the 1991-92 funding period have focused on reconstruction of the carbon isotopic composition of the atmosphere during the historic period as well as during glacial times using a C4 plant proxy.

\section{Results to Date:}

Modern Flants. To further characterize the carbon isotopic air-plant relationship we have undertaken a series of growth chamber studies to determine the precision of the transfer function for a variety of C3 and C4 plants, including Zea mays. The experiments are being performed in collaboration with Hyrum Johnson of the USDA, Southern Plains Area Grassland, Soil and Water Research Laboratory, Temple, Texas. The chamber (actually a tunnel) is especially suited for our studies since uptake by plants causes a reduction in $\mathrm{CO}_{2}$ along the length of the tunnel simulating depressed levels of $\mathrm{CO}_{2}$ during past epochs. Two manuscripts describing these studies are nearing completion.

Historic and Prehistoric Periods. We have extended these studies to about 1845 for the historic period using maize samples and a $\mathrm{C} 4$ dicot, Atriplex confertifolia, obtained from herbarium collections. We have obtained preliminary data for the prehistoric period, back to about 2000 B.C., and are awaiting the results of over 40 radiocarbon dates. The prehistoric materials consist of both carbonized and uncarbonized cobs and kernels and require extensive characterization to assure comparability between tissue type. The prehistoric samples should provide a high resolution record of changes for the carbon isotopic composition of atmospheric $\mathrm{CO}_{2}$ during the late Holocene.

Glacial/Interglacial Studies. The occurrence of macrofossils of Atriplex confertifolia dating back to about 40,000 years BP allows our analysis to be extended to glacial times. Currently, there are few measurements of the isotopic composition of $\mathrm{CO}_{2}$ derived from ice for this period. Data and related modeling results are summarized in a manuscript submitted to Nature. Briefly, our results indicate that glacial atmosphere was as much as 1 per mil more depleted in ${ }^{12} \mathrm{C}$ as compared to the pristine interglacial atmosphere. This is a surprising observation and provides a new constraint on acceptable models.

Planned Research: Given the promising nature of our results to date we are expanding and refining the analyses of additional materials. For the historic period, spanning about 1700 to the present, we intend to fill in as many of the existing gaps as possible. We have about 300 additional samples. For the Holocene we have about 100 samples of maize and Atriplex spanning about 4000 to $1500 \mathrm{BP}$. Additional glacial age Atriplex are in hand and now being analyzed. Many will be directly dated by AMS. Other suitable C4 from the glacial period will be analyzed. For all the plants used we will continue growth chamber studies to verify and determine the overall precision of the transfer function as well as to characterize the environmental influences on the carbon isotopic composition of both $\mathrm{C} 3$ and $\mathrm{C} 4$ plants. We will continue modeling efforts representing both the historic and glacial periods. 


\title{
Global $\mathrm{CO}_{2}$ Enrichment, Nutrient Dynamics, and Litter Decomposition in a Deciduous Forest Ecosystem: The Relationship between Atmospheric $\mathrm{CO}_{2}$ Levels, Plant Tissue Chemistry, and iitter Decomposition
}

\author{
(formerly: Atmosphere-Biosphere Exchange in the Plant Canopy)
}

Fakhri A. Bazzaz

Harvard University

1. How temperate tree seedling growth, allocation, and physiological responses are altered by long-term elevated $\mathrm{CO}_{2}$ exposure, as a function of nutrient and light availability.

To elucidate the effects of an enriched $\mathrm{CO}_{2}$ atmosphere, six co-occurring deciduous tree species from the northeastern United States were grown for two years in a fully crossed design of light, nutrients, and $\mathrm{CO}_{2}$ 'The species, in the order of purported increasing shade-tolerance are: gray birch (Betula populifolia), ash (Fraxinus americana L.), red maple (Acer nubrum L.), red oak (Quencus rubra L.), yellow birch (Betula alleghaniensis Britton), and striped maple (Acer pensylvanicum) (Fowels, 1965). Seeds or germinated seedlings were collected from Harvard Forest and placed in growth chambers with controlled $\mathrm{CO}_{2}$ levels at 350 or $700 \mu \mathrm{L}$. L ${ }^{-1}$. When most of the seedlings had two true leaves, they were transplanted into 6 inch standard plastic pots with a 1:1:1 mixture of sand-perlite-peat on June 22, 1990. The transplants were then placed in glasshouse modules controlled at the corresponding $\mathrm{CO}_{2}$ level. In each glasshouse, there were threw benches (blocks). Each of the three benches was divided in half and the two halves were randomly assigned to two plots. One was for high light and the other was for low light. Within each plot (i.e., light treatment) two replicate seedlings were randomly assigned to one of two nutrient treatments. This resulted in $2 \mathrm{CO}_{2} \times 2$ light $\times 2$ nutrient $\times 6$ species $\times 3$ block $\times 8$ replicates, a total of 1152 plants.

The elevated $\mathrm{CO}_{2}\left(700 \mu \mathrm{L} . \mathrm{L}^{-1}\right)$ treatment represented the predicted values for atmospheric $\mathrm{CO}_{2}$ concentration at some time in the future, whereas the low value $\left(350 \mu \mathrm{L}\right.$. $\left.\mathrm{L}^{-1}\right)$ was the estimated ambient $\mathrm{CO}_{2}$ level for the present decade. The high light treatment (natural light, supplemented by mercury vapor lamps) represented the light condition of a large gap in Harvard Forest $\left(300 \mathrm{~m}^{2}\right)$, whereas the low light treatment (37\% of high light) represented approximately equivalent to the light condition of understory (Sipe, 1990). The two nitrient treatments (high and low) simulated high nutrient deposition and organic matter mineralization rates (equivalent to $400 \mathrm{Kg} \mathrm{N} \mathrm{ha}^{-1} \mathrm{yr}^{-1}$ ) and nutrient-poor forest soil at Harvard Forest (equivalent to $40 \mathrm{Kg} \mathrm{N} \mathrm{ha}^{-1} \mathrm{yr}^{-1}$ ), respectively (Aber et al., 1989).

All leaves that naturally fell off or fell in response to a gentle touch were collected before the final harvest for leaf litter chemical analysis. When the leaves of most plants had fallen off ( 180 days after transplanting) one-third of the plants were harvested in the middle of November, 1990, to obtain the first year growth, and the remainder of the plants were moved into a garden for overwinter. In the beginning of April, 1991, plants were moved back to the glasshouse to receive the same $\mathrm{CO}_{2}$, light, and nutrient treatment as in the first year, and were repotted in 8 inch standard plastic pots. Another one-third of the plants were harvested in the middle of November, 1991. The last one-third of the plants are now in the garden for winter and will be moved back to the glasshouse $\mathrm{CO}_{2}$ modules in April, 1992.

In the first year, elevated $\mathrm{CO}_{2}$ environments significantly stimulated relative growth rate (RGR) of all species (Fig. 1). Therefore, plants grown at elevated $\mathrm{CO}_{2}$ levels were significantly heavier than those grown at ambient $\mathrm{CO}_{2}$ levels (Fig. 2). Generally this was more pronounced under low light. The greatest stimulation of plant weight was found under the condition of low light and high nutrients. However, individual species responded differently to elevated $\mathrm{CO}_{2}$. Among the three early-successional species (gray birch, ash, and red maple), a significant increase in plant growth under elevated $\mathrm{CO}_{2}$ conditions was found only with high nutrients (Fig. 3). The three late-successional species grown under elevated $\mathrm{CO}_{2}$ conditions (red oak, yellow birch, and striped maple) showed a greater percent increase in growth in low light than in 
high light. Thus, for the early-successional species, the degree of enhancement of growth by elevated $\mathrm{CO}_{2}$ was more sensitive to nutrient levels, while in the late-successional species the enhancement was more sensitive to the level of light.

In the second year, however, high $\mathrm{CO}_{2}$ levels did not enhance RGR for all species (Fig. 1). It significantly constrained RGR in red maple and yellow birch. Although plants grown at high $\mathrm{CO}_{2}$ levels still had greater size than those grown at ambient $\mathrm{CO}_{2}$ levels (Fig. 2), the percent increase of plant weight (the ratio of total weight of plants grown at high $\mathrm{CO}_{2}$ levels to that of plants grown at ambient $\mathrm{CO}_{2}$ levels) in the second year declined for all species in the low light and low nutrient environment (Fig. 4). In the other environments, the second year percent enhancement of biomass due to growth in elevated $\mathrm{CO}_{2}$ relative to ambient, either increased or decreased from the first year for the different species. The greater size of plants grown at high $\mathrm{CO}_{2}$ levels in the second year was primarily due to their greater RGR in the first year. Analysis of root biomass showed that in both years plants were not root-bound. How long the stimulation of plant weight in high $\mathrm{CO}_{2}$ environments can be observed depends on species and on the levels of other resources in environments.

2. How elevated $\mathrm{CO}_{2}$ concentrations and different nutrient environments influence the litter quality and litter decomposition rates from leaves of six deciduous tree species.

Leaf litter of the first year plants were analyzed by Dr. Melillo's lab. The results showed that a high $\mathrm{CO}_{2}$ environment in general, decreased plant tissue nitrogen content $(\% \mathrm{~N})$, and increased plant tissue lignin content (\%L) (Fig. 5). Thus $\mathrm{L} / \mathrm{N}$ ratios increased in high $\mathrm{CO}_{2}$ environments in most species. $\mathrm{C} / \mathrm{N}$ ratios in general increased with elevated $\mathrm{CO}_{2}$ for all environmental treatments and all species with the exception of the early-successional species (gray birch, ash, and red maple) grown in high light and low nutrient conditions. For almost all treatments, the annual decay constant, $\mathrm{k}$, is lower in elevated $\mathrm{CO}_{2}$ relative to ambient $\mathrm{CO}_{2}$ conditions; this implies a slower rate of decomposition for tissue grown in elevated $\mathrm{CO}_{2}$. An elevated $\mathrm{CO}_{2}$ environment will thus alter the amount, quality, and decomposition rates of leaf litter in temperate forest systems. These changes may decrease nutrient availability in the soil in a high $\mathrm{CO}_{2}$ world, which in turn may decrease future photosynthetic capacity of the trees. Leaf litter of the second year plants will also be analyzed by Dr. Melillo's lab.

3. How elevated $\mathrm{CO}_{2}$ influences rates of seasonal senescence in northeastern deciduous trees.

Five tree species from a New England deciduous forest ecosystem were exposed to a simulated autumn at ambient and double-ambient $\mathrm{CO}_{2}$ levels in environmental growth chambers. Air temperature and photoperiods were modified on a weekly basis to mimic conditions observed in a typical deciduous forest understory environment. Leaf abscission rates, photosynthesis, transpiration, chlorophyll, and leaf nitrogen content were monitored. Elevated $\mathrm{CO}_{2}$ had a significant impact on the dynamics of leaf fall, especially when nutrients were in short supply. Gray birch and striped maple had much higher rates of leaf fall earlier in the season under elevated $\mathrm{CO}_{2}$ and low nutrients. However, red maple and yellow birch showed minimal differences in leaf fall over time. The impact of elevated $\mathrm{CO}_{2}$ levels on the chlorophyll content of leaves was more pronounced when nutrients were plentiful. The nature of this effect varied between species. For gray birch, the rate of chlorophyll degradation was greater during the einly phases of senescence under elevated $\mathrm{CO}_{2}$. For the other species, the reverse pattern was observed. These results demonstrate that speciesspecific patterns of autumnal senescence in temperate deciduous forests are likely to change in a future elevated $\mathrm{CO}_{2}$ world, which may have an important impact on end-of-season carbon gain and nutrient cycling with the forest ecosystem. 


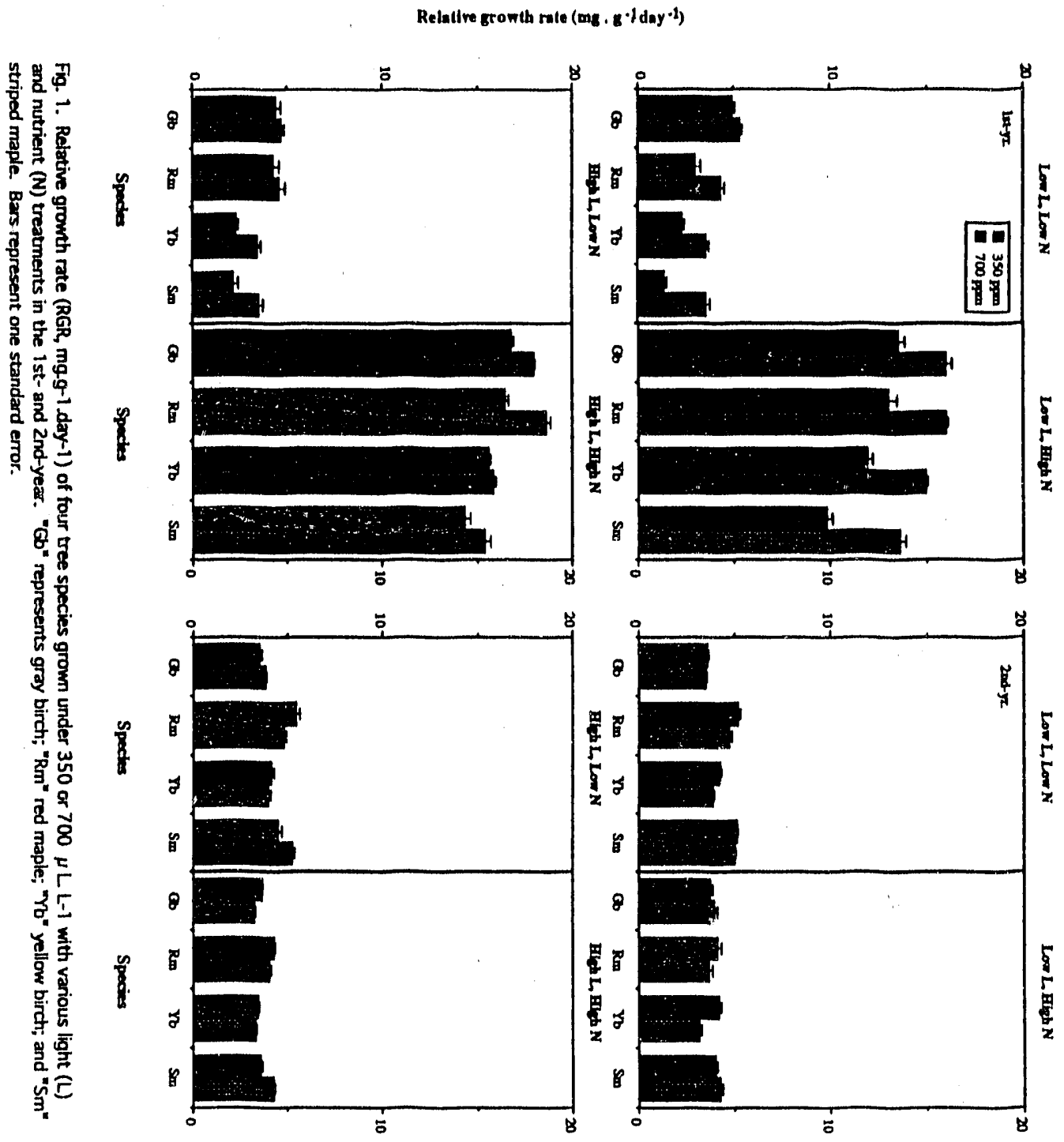




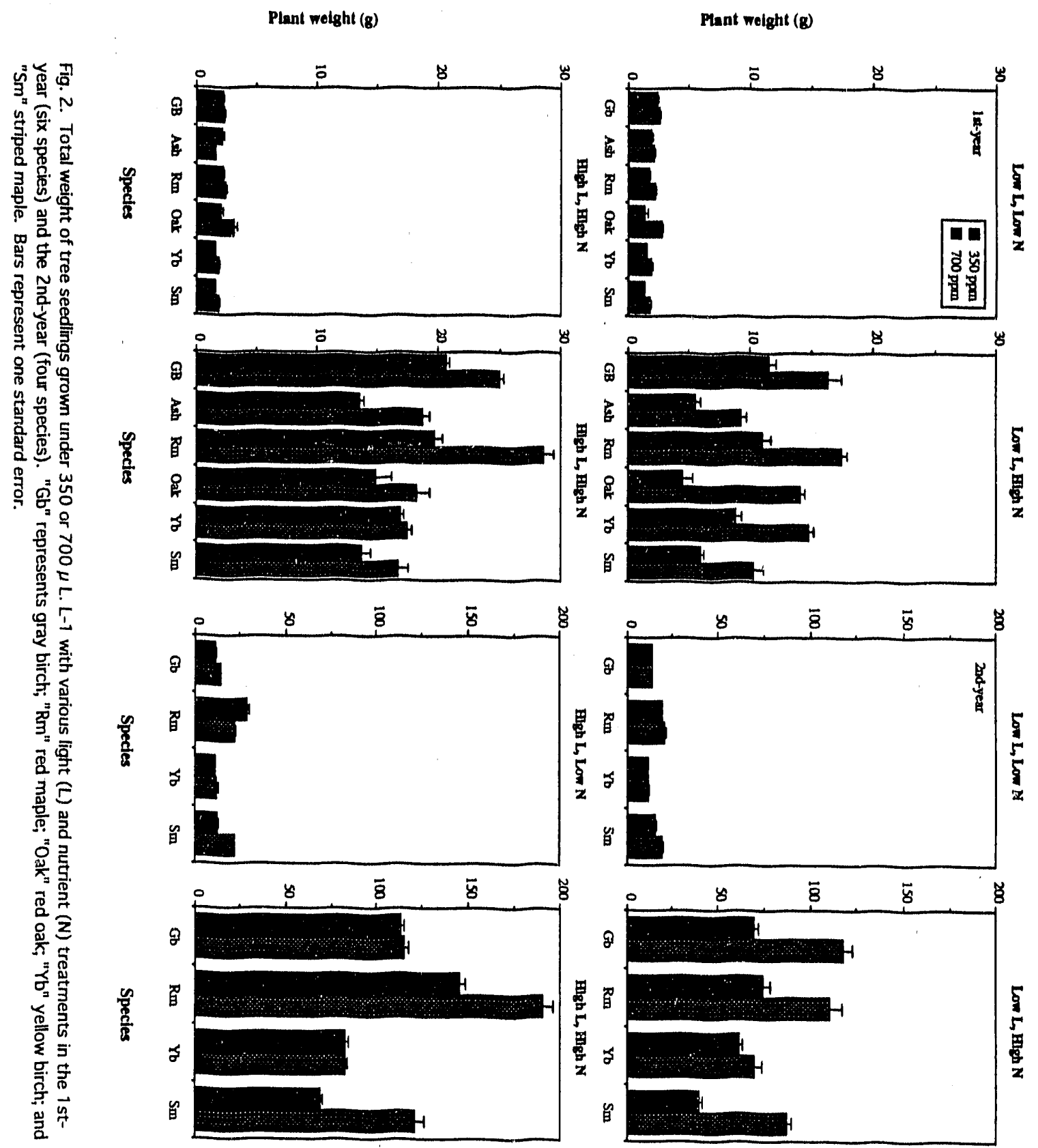




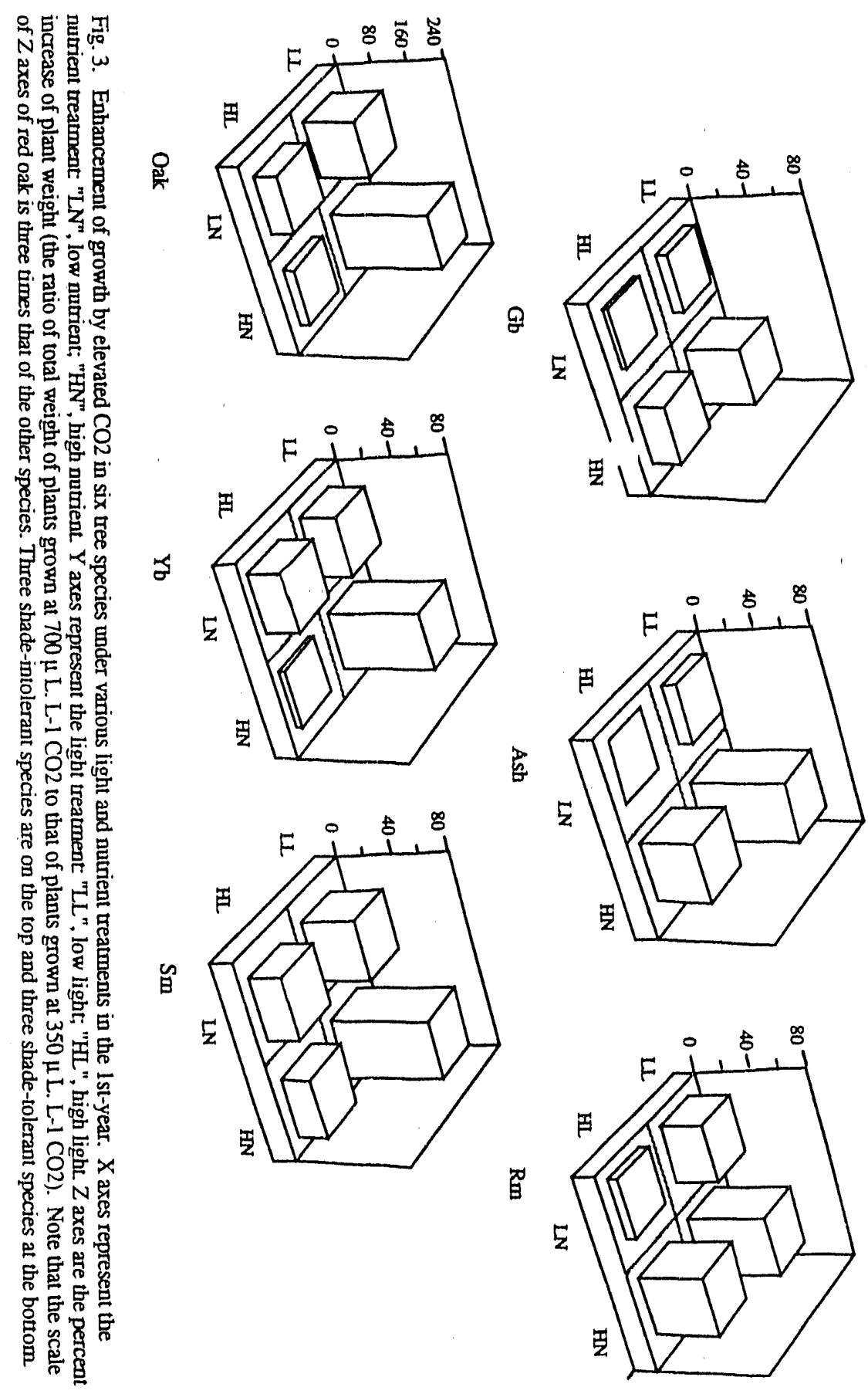


Percent increase of weight Percent increase of RGR

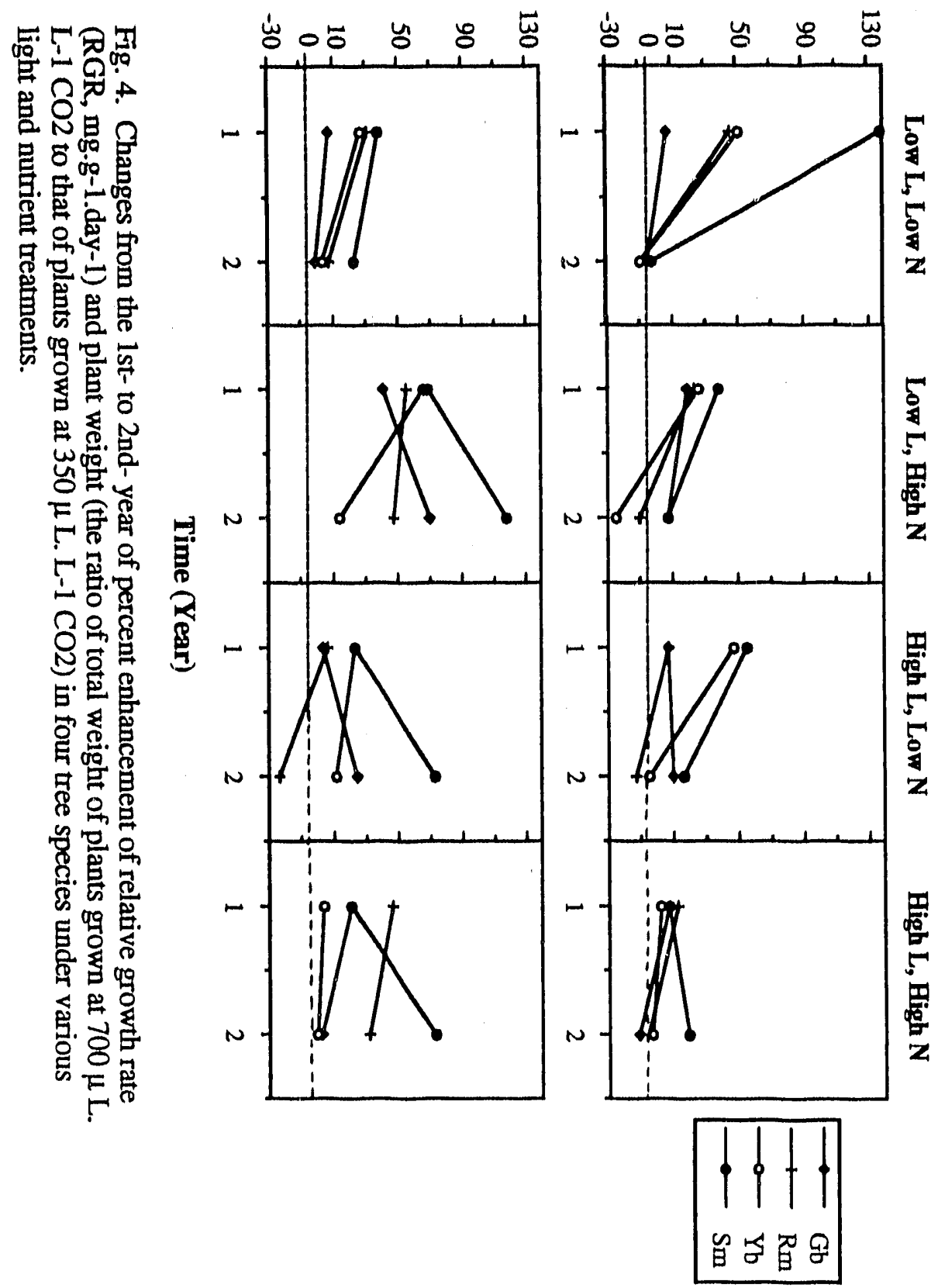




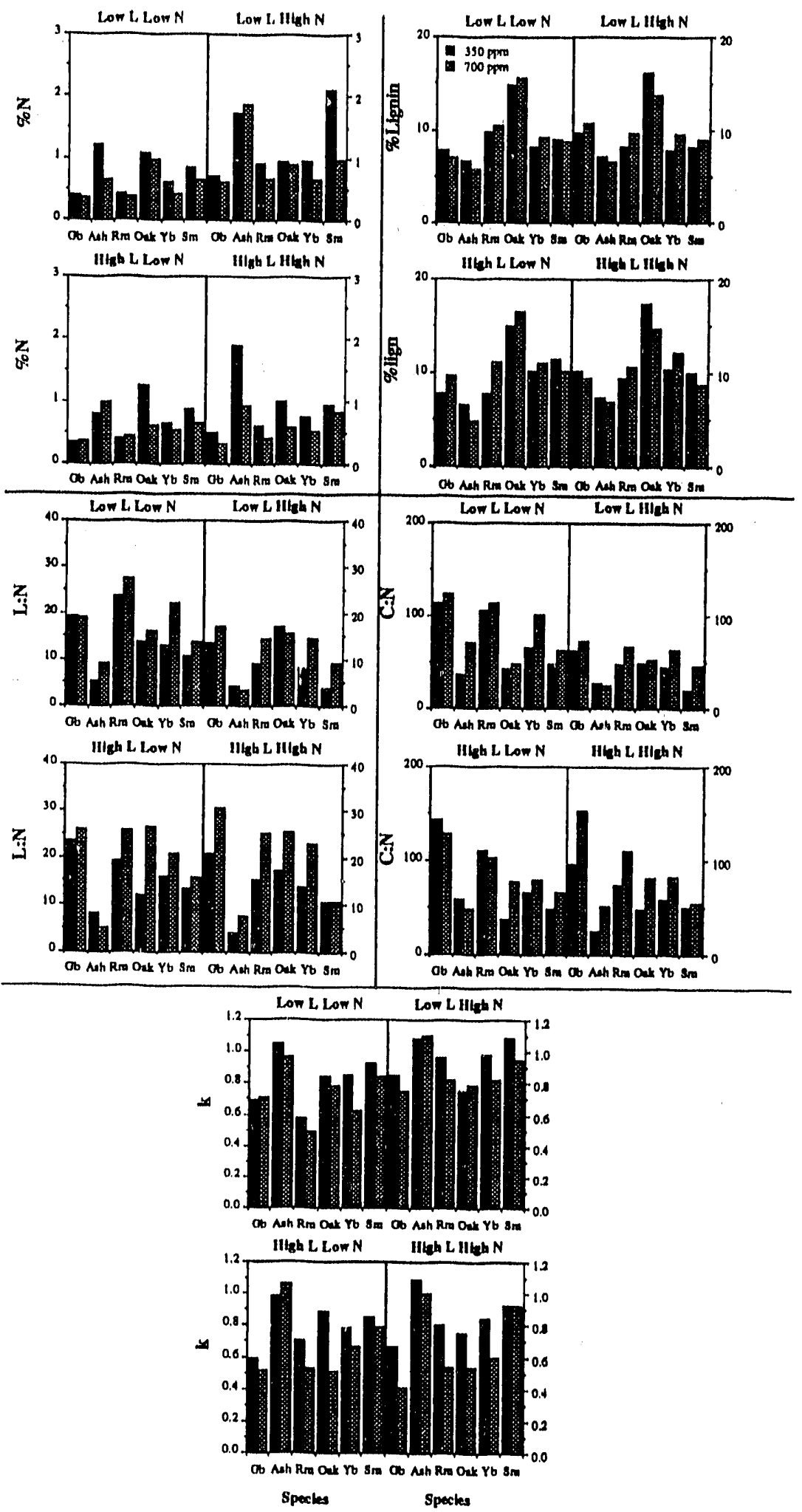

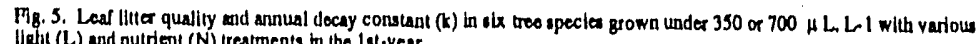
lighil (L) and nutrient (N) treatements to the lat-year. 


\title{
Turbulence and Turbulent Exchange at Harvard Forest
}

\author{
(formerly: Factors that Influence the Surface Energy Budget) \\ D. R. Fitzjarrald and K. E. Moore \\ SUNY - Albany
}

\section{Objectives:}

1. To assess uncertainty in eddy flux estimates by finding how well the heat budget can be closed by measurements;

2. To obtain seasonal time series of radiative properties of the forest (albedo, surface radiation temperature) and the atmosphere above (global solar radiation, sky radiation, photosynthetically active radiation) for use in empirical radiative parameterization schemes;

3. To investigate the mechanisms of forest-atmosphere turbulent exchange, focusing on how air is conducted from deep within the canopy to the atmosphere and vice versa; and

4. To incorporate some features of these mechanisms into new or modified parameterizations suitable for larger-scale models.

Product: We will produce: a) the longest-term study to date of the frequency of occurrence of coherent structures within the forest, as well as measures of their efficacy for transporting water vapor, trace gases, heat, and momentum; b) a seasonal catalog of the components of the radiation and heat budgets above the forest, as well as subcanopy fluxes; and c) a variety of empirical and mechanistic models relating turbulent transports to elements of the radiation budget.

Approach: Our approach is to maintain continuous measurements of the components of the forest heat balance and the subcanopy turbulent environment at several locatious within the presumed tower "footprint". Table 1 gives the measurements currently being acquired. Our suite of radiation instruments has been installed at Harvard Forest since early July, 1991. Measurements of the net radiation, as well as its components, upward and downward fluxes of longwave radiation (via Eppley PIRs), and incoming and reflected solar radiation (Kipp and Zonen pyranometers) upward and downward PAR flux (LI-COR), are being logged as 20 -minute averages.

Five sonic anemometers have been incorporated into the ASRC observations. These are 3-axis sonic anemometers (Applied Technologies, Inc.) at the top of the $30 \mathrm{~m}$ tower (the Harvard instrument), one below the canopy on the large tower $(11.3 \mathrm{~m})$, and one on an auxiliary tower $30 \mathrm{~m}$ west (predominant upwind) of the large tower at $6.6 \mathrm{~m}$. These instruments operate at all times; we have had very good data recovery rates since August for these instruments. Direct measurements of temperature fluctuations are made at each sonic anemometer. At two smaller masts, we operated Campbell Scientific, Inc. single axis sonic anemometers approximately $30 \mathrm{~m}$ at right angles to the axis of the large and auxiliary towers, as indicated in the schematic (Fig. 1). Since August 15 we have also recorded the $\mathrm{CO}_{2}$ signal from the Harvard instrument with an intake at the tower base sonic. We also obtained the mean temperature and humidity gradient data from the Harvard group in order to assess the changing environmental stability. We now regularly log onto the Harvard Forest computer by modem to check on instrument status and to download small files.

Results to Date: Measurements of the components of the radiation budget, and the net radiation over the forest, as well as soil temperatures and heat flux, have been made continuously since July 3,1991.

Subcanopy turbulent flux measurements were begun on August 2, 1991, and have continued to this date. Accordingly, we are in a position to observe both seasonal changes and short-term phenomena which constitute the mechanisms of forest-atmosphere exchange. 
1) Seasonal changes: Preliminary data for seasonal change during autumn 1991 show marked changes in radiation and turbulent properties both before and after leaf fall. The noon albedo (Fig. 2) at the forest top shows a monotonic decrease from July 4 (day 185) through leaf fall (after 290). The possibility that the decrease during July and August is due to maturation of leaves and may affect evapotranspiration rates is a topic for further study. The drop from $16 \%$ when fully leafed to $8 \%$ when bare, is consistent with previous studies. In the PAR wavelength band (400-700 nm), the albedo remained constant until September, but rose abruptly after leaf fall. We hypothesize that this may be due to the brighter appearance of the dry leaves on the forest floor.

With data already in hand, we already have one of the longest time series of measurements of heat and moisture fluxes at forest floor ever compiled. We have found that, on average, there is no large difference in eddy heat fluxes at the tower base and at the auxiliary tower. This is an important finding, since using the eddy correlation technique in the confined space of the inner canopy is often questioned. Energy balance components are illustrated by the time series of components of the radiation budget (Fig. 3) and the sensible heat flux at forest top and bottom (Fig. 4). Heat flux at the forest floor during the late summer peaked before noon and remained positive during the daytime hours despite the presence of weak static stability there. After leaf fall, periods of static instability near the forest floor produced definite positive heat which was approximately balanced by the now upward soil heat flux. An example of the total energy balance for a sample day (Fig. 5) indicates that approximate closure can be obtained which has been done at other forested sites (e.g., Verma et al., 1986): there are no apparent shortcomings due to the local topography with the Harvard Forest site. We are in the process of completing this work, alternating between direct observation and a modified Bowen ratio approach to estimate latent heat fluxes depending on instrument performance.

In early autumn, above-canopy heat fluxes as a fraction of the available net radiation increased over their summer-time values, probably due to the decreasing role of transpiration as the leaves senesced. After leaf fall, the mean daily subcanopy heat fluxes increased by a factor of two (Fig. 6), while the above-canopy heat fluxes were beginning their seasonal decline, with the decreasing net radiation. The subcanopy heat flux is nearly balanced by the soil heat flux, which by late fall has changed sign, resulting in the subcanopy air being heated by the soil.

We found that the mean daytime drag coefficient $\left(U^{2} / u^{* 2}\right)$ did not vary over this season (Fig. 7). The consequence of removing the same amount of momentum from the atmosphere without leaves is that the momentum is conducted further into the canopy, as indicated by the seasonal changes in $u^{*}$ at forest floor. Preliminary results indicate that the vertical velocity skewness at the top of the tower, an indicator of the importance of transport of turbulence into the canopy, changed from approximately -0.05 in August to -0.20 in November. We are encouraged by the quality of data thus far.

We anticipate using the accumulating data set to describe the flux history of the forest during and after strong synoptic events, such as frontal passages. It seems reasonable that regional climate change might be manifested by a change in the synoptic frequency; thus, a composite of the "normal" forest response to these cvents could be used to make a transport estimate given a synoptic climatology.

\section{2) Short-term phenomena:}

a) In the daytime, the canopy top and the subcanopy environment are well-coupled only intermittently, through the presence of wind gusts. Analyses of the scale of the transports and the events which couple the two environments are underway, utilizing the technique of wavelet analysis. An example is given in Fig. 9.

b) We have been noting the existence of nocturnal wave motions (Fig. 10) in the subcanopy environment, and cataloging the changing stability conditions in the canopy, which are conducive to wave motions. 
F1g. 1. Dlagram of tower and mast layout at Harvard Foreat.

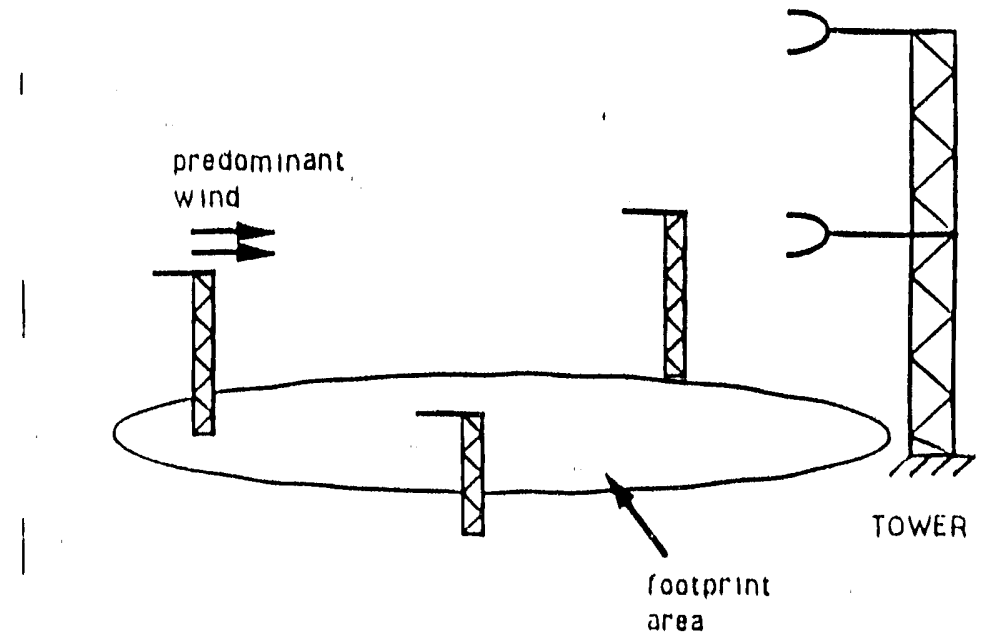

Fig. I

Fig. 2. Boxplot of the weekly mid-day shortwave albedo above the forest.

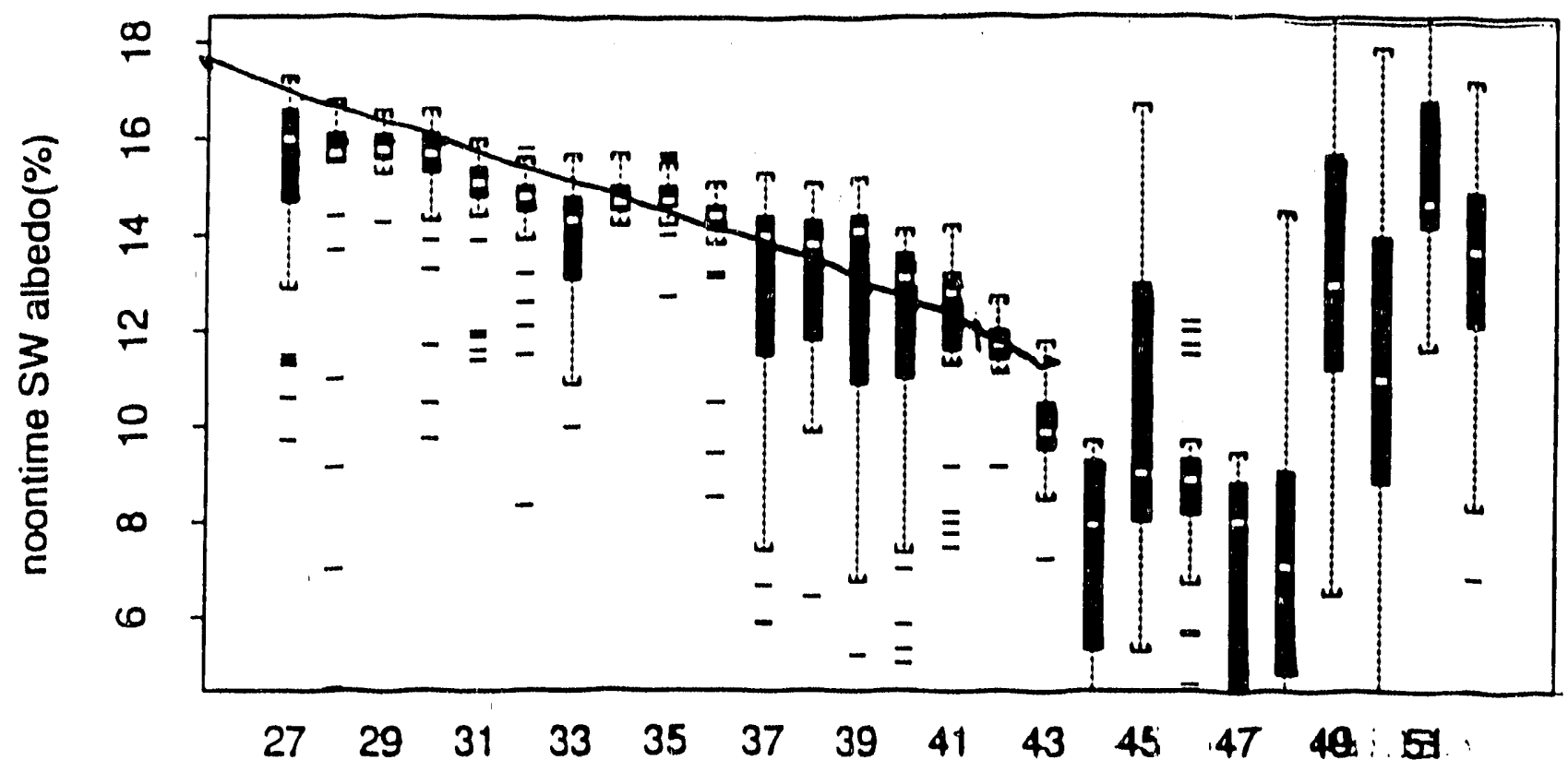

weekly display 
Fig. 5. Componenta of the heat budget at the top of the foreat. H 1 . sensible heat, LE Is latent heat flux, $R_{N}$ la nat radiation.
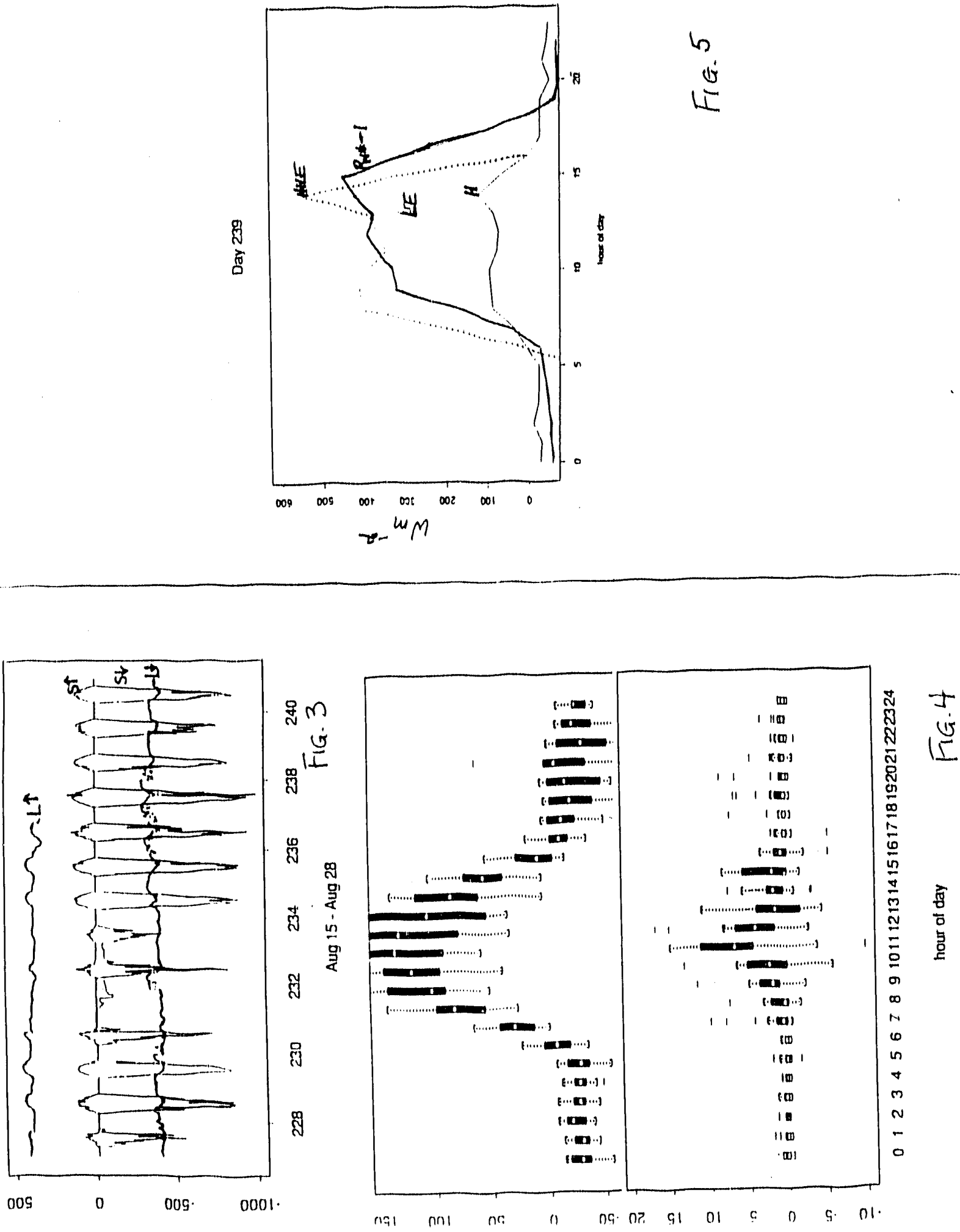

Fig. 3. Example time series of the components of the net radiation: $S$ is solar, $\mathrm{L}$ is longwave.
Fig. 4. Senstble heat fluxes at the top and bottom of the large Harvard forest tower for two weeks in August, 1991. Fluxes are in $\mathrm{Wm}^{-2}$. 

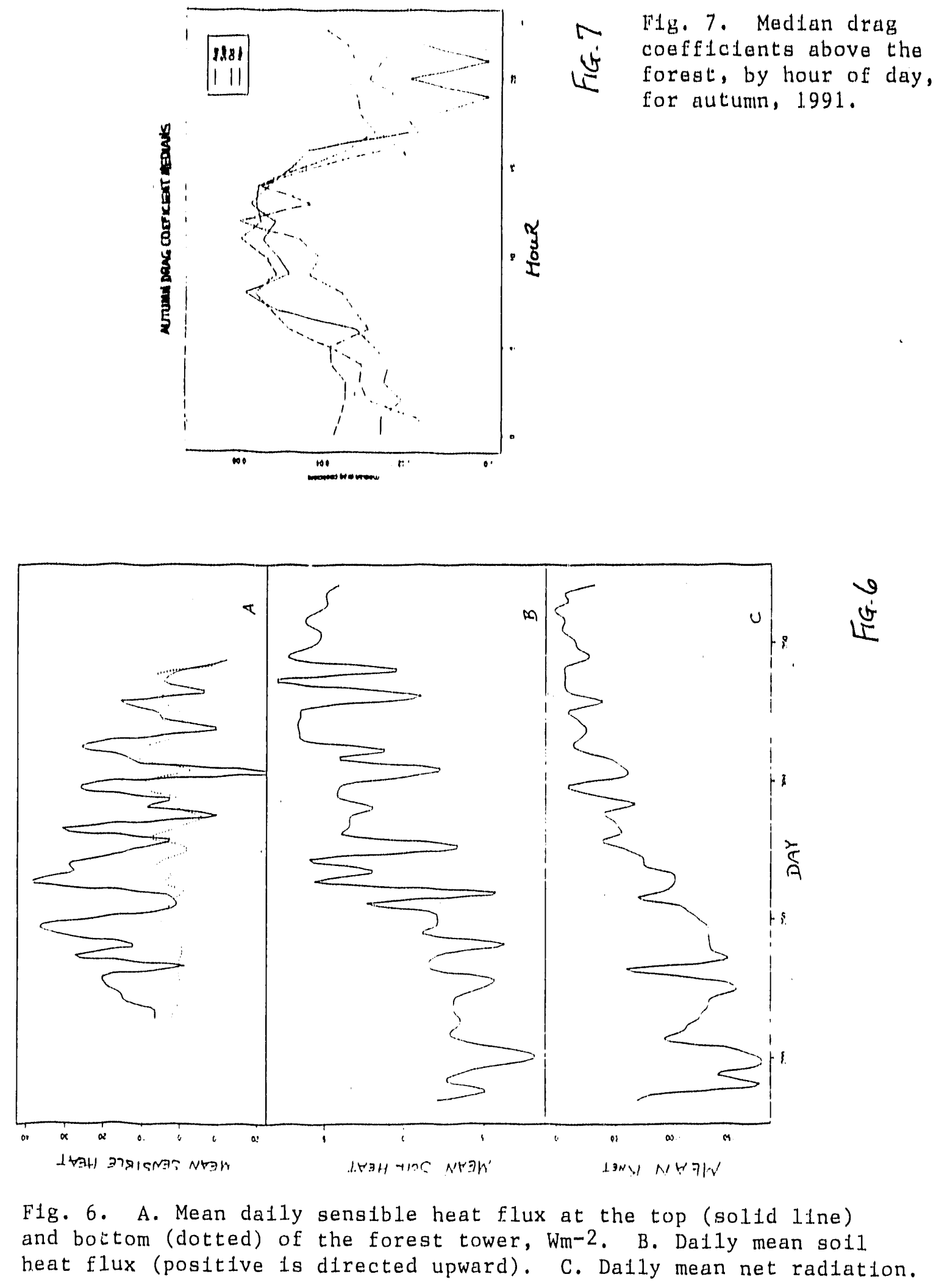
Fig. 8. Wavelet analysis of a gust event on August 12, 1991. An 800second pertod 18 presented. The vertical axts to the scale of the wavelet transform, and the clrcled area Indicates the perfod of the gust. A. wavelet amplitudes at the top of the foregt, $B$, wavelet amplitudes at the bottom.
Fig. 9. TIme serles of a nocturnal wave event in the morning of October 24, 1991. Solld line 1s the vertical velocity, dotted line is temperature.

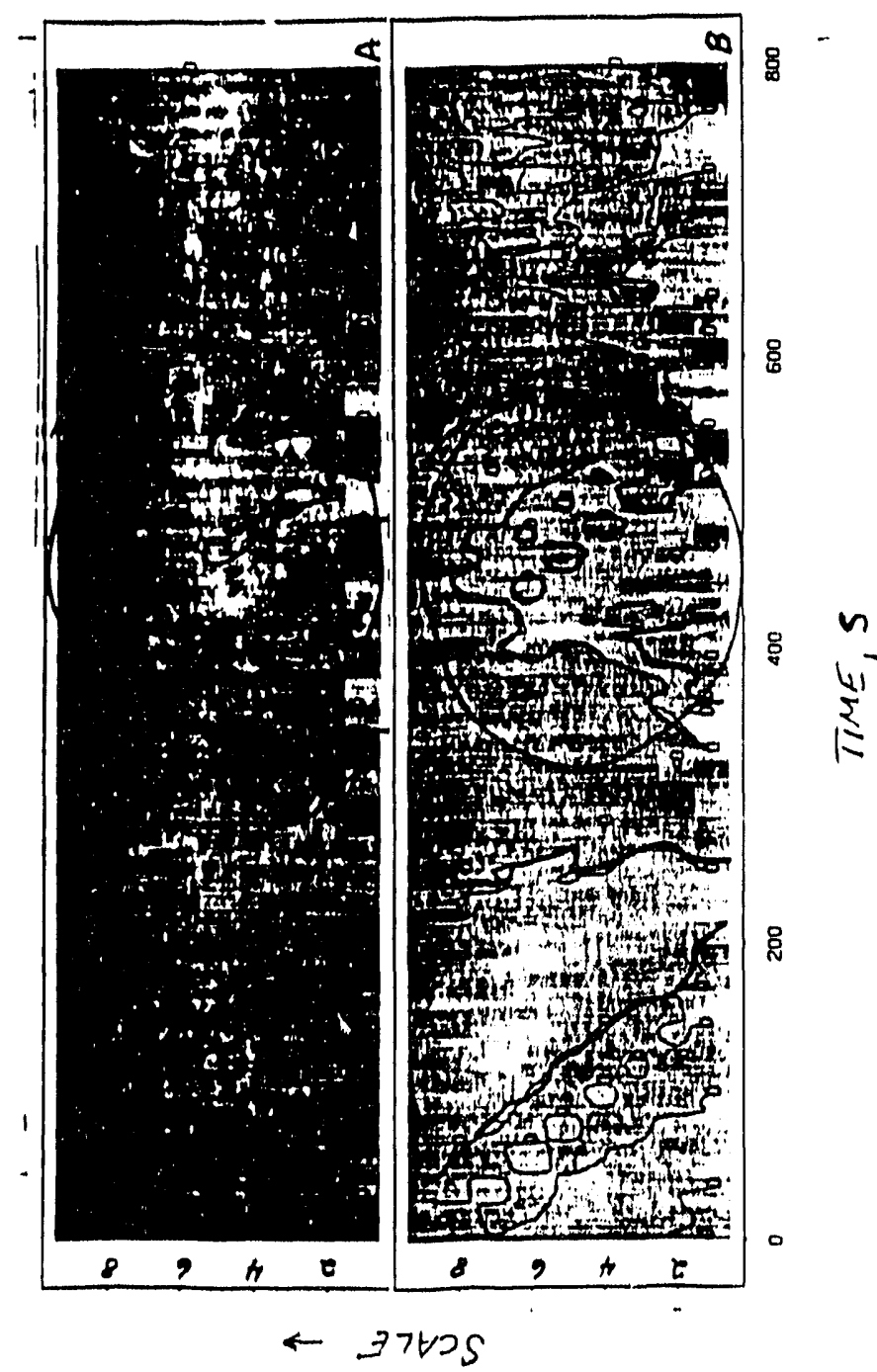

$\frac{a}{v}$
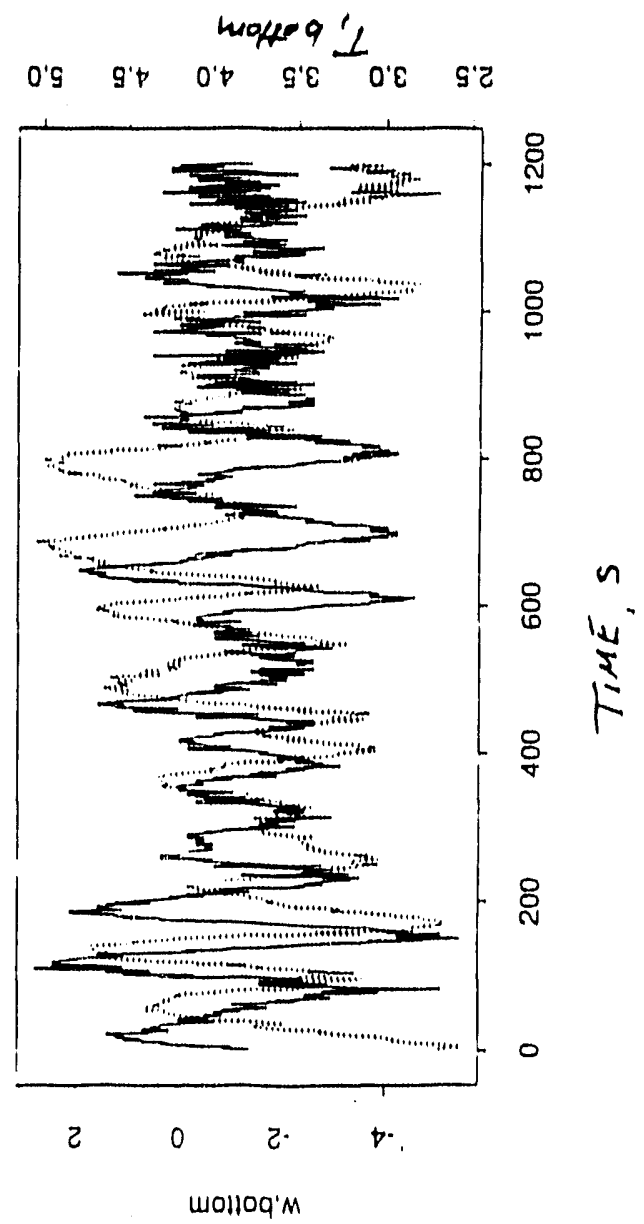


\title{
International Research Archive on Science Pollcy Dimensions of Global Environmental Change
}

\author{
William Clark \\ Harvard University
}

We have laid the groundwork for a special collection of environmental policy documents in the international domain. Wo have talked with users, document sources, and librarians both at Harvard and other institutions. We have targeted as our audience two groups: researchers currently involved in policy issues, and scholars of the future who will be interested in these crucial years of the emergence of international environmental policy as a discipline in its own right. We have developed our collecting policy (Topics: literature of national and international science policy of global environmental change, in particular the greenhouse and ozone depletion aspects of climate change; types of material: ephemeral or "gray" literature, i.e., not available through standard publishing channels, widely disseminated, or easy to obtain.)

Scope: We have had discussions with a variety of likely users of the collection, and have been in touch with about 10 other library and document collections of environmental materials (list available), as well as joining the Special Libraries Association which numbers 600 environmental librarians as members. We have also begun contacting other "gray literature" collections around the world. In these ways we are attempting to assure the best focus and utility for our collection and minimize overlap with collections elsewhere.

Structure: We have designed a cataloging procedure both appropriate for the types of material included and compatible with Harvard's HOLLIS online library catalog. We plan to arrange to load our reccrds into the HOLLIS catalog, where they will be accessible to researchers worldwide via TELNET/INTERNET. We have developed our computer record form in Notebook II database format (sample available).

Acquisitions: Our strategy is to work in two directions, to obtain both historical and upcoming materials.

a. Backward-looking: we are using several retrospective surveys which identify key policy documents from previous periods, including: Victor Hart, "The Greenhouse Effect Out of the Garbage Can: Science and U.S. Policy for Climate Change Research Before 1974"; Cavender, "The Greenhouse Effect in the FRG: A History of Social Learning", Prokop, "Climate Change and Ozone Depletion in the USSR: A Preliminary Policy History." (Copies available on request). Using available research collections and gifts, we have some 500 non-current items.

b. Forward-looking: we have been placed on the mailing lists of 12 organizations, and are continuing to locate key sources. This has resulted in receipt of 264 current items.

\section{Progress Reports Not Submitted:}

Education Fellowships for Undergraduates in Environmental Sciences, by Michael B. McElroy, Harvard University

Physical Basis for Climate Change Models, by R. M. Goody, Harvard University (the work has been completed and a Technical Report is in progress)

Bellagio II: Managing the Transition to a Global Climate Change Regime, by Eugene B. Skolnikoff and Abram Chayes, MIT and Harvard University (the work has been completed and a Technical Report is in progress) 


\section{Research Projects Starting July 1, 1991}

"Decision Making in Coastal Areas Undergoing Uncertain Environmental Change" by Ann Bostrom, $H$. Dowlatabadi, B. Fischoff, G. Morgan, A. Patwardhan, and M. Small (Carnegie-Mellon University)

"Uncertainty, Signals, and Public Perceptions of Climate Change" by J. X. Kasperson, O. Renn, R. Kasperson, and H. P. Peters (Clark University)

"Regional Temperatures from Noble Gases in Relict Groundwaters" by W. S. Broecker, P. Schlosser, and M. Stute (Columbia University)

"Sources of Atmospheric Methane in the Eastern United States" by Robert C. Harriss and P. Crill (University of New Hampshire)

"Nitric Acid Over Midlatitude Forests" by Robert W. Talbot and Otto Klemm (University of New Hampshire)

"On the Elicitation and Combination of Expert Opinion Regarding Global Sea Level Rise" by Andrew R. Solow and James M. Broadus (Woods Hole)

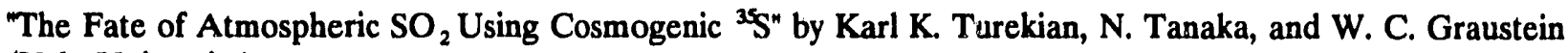
(Yale University)

"A Coupled Atmosphere-Ocean Climate Model" by Peter H. Stone (MIT)

"Classifying Structural and Functional Characteristics of Forest Ecosystems from an Ultralight Survey at Harvard Forest" by Richard H. Waring (Oregon State University)

"How Close is Close Enough?" by Myron B. Fiering, P. P. Rogers, and A. Solow (Harvard University) 
Financial Status of Projects

Northeast Regional Center

FY 90 Projects

\begin{tabular}{|c|c|c|c|c|}
\hline Project Title/Principal Investigator(s) & $\begin{array}{l}\text { Budget } \\
\text { Award }\end{array}$ & $\begin{array}{l}\text { Expenses } \\
\text { @ 6/30/91 }\end{array}$ & $\begin{array}{l}\text { Projected } \\
\text { Expenses } \\
\text { @ } 6 / 30 / 92\end{array}$ & $\begin{array}{l}\text { Atnticipated } \\
\text { Carryover }\end{array}$ \\
\hline $\begin{array}{l}\text { Net Exchange of } \mathrm{CO}_{2} \text { in Midlatitude Forests } \\
\text { Steven C. Wofsy }\end{array}$ & $\$ 200,000$ & $\$ 200,000$ & $\$ 200,000$ & so \\
\hline $\begin{array}{l}\text { Factors That Influence the Surface Energy Budget } \\
\text { D.R. Fitzjarrald (State University of New York, Albany) }\end{array}$ & 90,000 & 26,597 & 90,000 & -0 \\
\hline $\begin{array}{l}\text { Atmospheric } \mathrm{CO}_{2} \text { Enrichment, Nutrient Dynamics, and Litter } \\
\text { Decomposition in a Deciduous Forest Ecosystem: Patterns of Carbon } \\
\text { Allocation Among Plant Organs, Leaf Litter Quality and Patterns of } \\
\text { Senescence } \\
\text { F.A. Bazzaz }\end{array}$ & 126,000 & 128,035 & 126,000 & -0 \\
\hline $\begin{array}{l}\text { Relationships Between } \mathrm{CO}_{2} \text { Levels, Tissue Nitrogen Content, and } \\
\text { Litter Decomposition } \\
\text { J.M. Melillo (Marine Biology Laboratory, Woods Hole) }\end{array}$ & 130,000 & 70,985 & 130,000 & -0 \\
\hline $\begin{array}{l}\text { Soil Chemistry and Throughfall at Harvard Forest } \\
\text { John D. Aber (University of New Hampshire) }\end{array}$ & 50,000 & 24,304 & 50,000 & - \\
\hline $\begin{array}{l}\text { Past Climates and Factors Regulating Past Climate Change } \\
\text { Michael B. McElroy }\end{array}$ & 137,840 & 135,256 & 137,840 & 0 \\
\hline $\begin{array}{l}\text { Simple Models for Climate Process Studies } \\
\text { Richard Goody and Brian Farrell }\end{array}$ & 97,840 & 55,841 & 97,840 & - \\
\hline $\begin{array}{l}\text { Risk Analysis for Global Warming } \\
\text { Richard Wilson }\end{array}$ & 73,248 & 66,861 & 73,248 & -0 \\
\hline $\begin{array}{l}\text { Education Fellowships for Undergraduates in Environmental Sciences } \\
\text { Michael B. McElroy }\end{array}$ & 109,200 & 42,989 & 109,200 & - \\
\hline $\begin{array}{l}\text { Bellagio II: Managing the Transition to a Global Climate Change } \\
\text { Regime } \\
\text { Eugene B. Skolnikoff (Massachusetts Institute of Technology) and } \\
\text { Abram Chayes (Harvard University) }\end{array}$ & 35,150 & 104 & 35,150 & -0 \\
\hline $\begin{array}{l}\text { Perseus Unmanned Scientific Research Aircraft: A New Tool for } \\
\text { Global Climate Change Research } \\
\text { John Langford (Aurora Flight Sciences) with .James Anderson } \\
\text { (Harvard University) }\end{array}$ & 75,000 & 75,000 & 75,000 & -0 \\
\hline $\begin{array}{l}\text { International Research Archive } \\
\text { William Clark }\end{array}$ & 33,516 & - & 33,516 & -0 \\
\hline $\begin{array}{l}\text { Precise Determination of Climate Changes Over the Past } 1000 \text { Years } \\
\text { Stein Jacobsen }\end{array}$ & 20,000 & -0 & 20,000 & f. \\
\hline $\begin{array}{l}\text { The Fate of Atmospheric } \mathrm{SO}_{2} \text { Using Cosmogenic }{ }^{35}{ }^{1} \\
\text { Karl K. Turekian et al (Yale University) }\end{array}$ & 5,206 & -0 & 5,206 & -0 \\
\hline $\begin{array}{l}\text { Center Administration } \\
\text { Richard Wilson }\end{array}$ & 100,000 & 57,879 & 100,000 & -0 \\
\hline TOTAL & $\$ 1,283,000$ & $\$ 883,851$ & $\$ 1,283,000$ & S-O \\
\hline
\end{tabular}

\footnotetext{
${ }^{1}$ This award is a supplement to cover unexpected expenses in Karl Turekian's FY 91 project, utilizing uncommitted FY 90 funds.
} 
Financial Status of Projects

Northeast Regional Center

FY 91 Projects

\begin{tabular}{|c|c|c|c|}
\hline Project Title/Principal Investigator(s) & $\begin{array}{l}\text { Budget } \\
\text { Award }\end{array}$ & $\begin{array}{l}\text { Projected } \\
\text { Expenses } \\
\text { @ } 6 / 30 / 92\end{array}$ & $\begin{array}{l}\text { Anticipated } \\
\text { Carryover }\end{array}$ \\
\hline $\begin{array}{l}\text { Direct Measurements of Carbon Dioxide and Nitrogen Oxde Fluxes in Central New } \\
\text { England } \\
\text { Steven C. Wofsy, J. William Munger, and B.C. Daube }\end{array}$ & $\$ 201,650$ & S 199,000 & \$ 2,650 \\
\hline $\begin{array}{l}\mathrm{CO}_{2} \text { Rise, Nutrient Dynamics, and Litter Decomposition in a Deciduous Forest } \\
\text { Ecosystem Relationship Between } \mathrm{CO}_{2} \text { Levels, Tissue Chemistry, and Litter } \\
\text { Decomposition } \\
\text { Fakhri A. Bazaaz }\end{array}$ & 169,880 & 163,767 & 6,113 \\
\hline $\begin{array}{l}\text { Isotopic Composition of Atmospheric } \mathrm{CO}_{2} \text { From Plant Proxies for Historical Times } \\
\text { Michael B. McElroy and B.D. Marino }\end{array}$ & 192,000 & 187,000 & 5,000 \\
\hline $\begin{array}{l}\text { How Close is Close Enough? } \\
\text { Myron B. Fiering, P.P. Rogers, and A. Solow }\end{array}$ & 76,320 & 74,839 & 1,481 \\
\hline $\begin{array}{l}\text { The Layout of Risk Assessments and Understanding of Uncertainties by Analogy } \\
\text { Richard Wilson, Eric Fajer, and A. Shlyakhter }\end{array}$ & 72,636 & 72,636 & -0 \\
\hline $\begin{array}{l}\text { Decision-Making in Coastal Areas Undergoing Uncertain Environmental Change } \\
\text { Ann Bostrom, H. Dowlatabadi, B. Fischhoff, G. Morgan, A. Patwardhan, and M. } \\
\text { Small (Carnegie-Mellon University) }\end{array}$ & 79,167 & 79,167 & -0 \\
\hline $\begin{array}{l}\text { Uncertainty, Signals, and Puhlic Perceptions of Climate Change } \\
\text { J.X. Kasperson, S. Whenn, R. Kasperson, and H.P. Peters (Clark University) }\end{array}$ & 74,850 & 74,850 & $-a$ \\
\hline $\begin{array}{l}\text { Regional Temperatures from Noble Gases in Relict Groundwaters } \\
\text { W. S. Broecker, P. Schlosser, and M. Stute (Columbia University) }\end{array}$ & 100,465 & 100,465 & - \\
\hline $\begin{array}{l}\text { Turbulence and Turbulent Exchange at Harvard Forest } \\
\text { David R. Fitzjarrald and K.E. Moore (State University of New York, Albany) }\end{array}$ & 90,000 & 90,000 & -0 \\
\hline $\begin{array}{l}\text { Sources of Atmospheric Methane in the Eastern United States } \\
\text { Robert C. Harriss and P. Crill (University of New Hampshire) }\end{array}$ & 33,725 & 33,725 & -0 \\
\hline $\begin{array}{l}\text { Nitric Asid wat Whidlatitude Porests } \\
\text { Robert W. Thithot and Otto Klemm (University of New Hampshire) }\end{array}$ & 50,000 & 50,000 & -0 \\
\hline $\begin{array}{l}\text { On the Elicitation and Combination of Expert Opinion Regarding Global Sea Level } \\
\text { Rise } \\
\text { Andrew R. Solow and James M. Broadus (Woods Hole Oceanographic Institution) }\end{array}$ & 71,349 & -0 & 71,349 \\
\hline $\begin{array}{l}\text { Decomposition Rates and Nutrient Dynamies in a Temperate Forest: Effects of } \mathrm{CO}_{2} \\
\text { and Nitrogen Enrichment } \\
\text { J.M. Melillo, K. Nadelhoffer, and P. Steuviler (Woods Hole Marine Biological } \\
\text { Laboratory) }\end{array}$ & 147,020 & 147,020 & 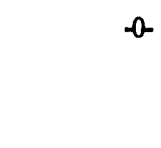 \\
\hline $\begin{array}{l}\text { The Fate of Atmospheric } \mathrm{SO}_{2} \text { Using } \mathrm{Co} \text { mogenic }{ }^{35} \\
\text { Karl K. Turekian, N. Tanaka, and W.C. Graustein (Yale University) }\end{array}$ & 104,194 & 0 & 104,194 \\
\hline $\begin{array}{l}\text { Soil Chemistry and Throughfall at Harvard Forest } \\
\text { John D. Aber (University of New Hampshire) }\end{array}$ & 47,792 & 47,792 & -0 \\
\hline
\end{tabular}




\begin{tabular}{|c|c|c|c|}
\hline Project Title/Principal Investigator(s) & $\begin{array}{l}\text { Budget } \\
\text { Award }\end{array}$ & $\begin{array}{l}\text { Projected } \\
\text { Expenses } \\
@ 6 / 30 / 92 \\
\end{array}$ & $\begin{array}{l}\text { Anticipated } \\
\text { Carryover }\end{array}$ \\
\hline $\begin{array}{lc}\text { Director's Fund-Committed: } & \\
\text { A Coupled Atmosphere-Ocean Climate Model } & 19,340 \\
\text { Peter Stone (Massachusetts Institute of Technology) } & \\
\text { Classifying Structural and Functional Characteristics of Forest Ecosystems from an } \\
\text { Ultralight Survey at Harvard Forest } \\
\quad \text { Richard H. Waring (Oregon State University) } \\
\text { Biological and Physital Controls on Soil Organic Matter Quality and } \\
\text { Quantity } \\
\quad \begin{array}{l}\text { Richard D. Boone } \\
\text { Vegetation Spectral Reflectance Signature }\end{array} \\
\quad \text { Peter Bakwin (University of Colorado) } & 50,000 \\
\end{array}$ & 94,061 & $\begin{array}{r}19,340 \\
12,752 \\
36,311 \\
11,969\end{array}$ & $\begin{array}{r}-0 \\
0 \\
13,689 \\
-0\end{array}$ \\
\hline $\begin{array}{l}\text { Director's Fund-Uncommitted } \\
\text { Richard Wilson }\end{array}$ & 27,764 & $-a$ & 27,764 \\
\hline $\begin{array}{l}\text { Educational Projects } \\
\text { Richard Wilson }\end{array}$ & 129,430 & 80,430 & 49,000 \\
\hline $\begin{array}{l}\text { Center Administration } \\
\text { Richard Wilson }\end{array}$ & 150,000 & 137,799 & 12,201 \\
\hline Uncommitted Funds & 79,887 & -0 & 79,887 \\
\hline TOTAL & $\$ 1,992,190$ & $\$ 1,618,862$ & \$ 373,328 \\
\hline
\end{tabular}




\title{
Southcentral Regional Center Director's Report
}

\author{
Robert G. Watts, Director
}

Introduction: The Southcentral Regional fenter is located at Tulane University with offices in the Lindy Claiborne Boggs Center. In accorduntwe vith the objective of NIGEC to attract more creative scientists with expertise and interest into the arest it global cliange, the Southcentral Regional Center has made an effort to attract proposals from and award fiuding to a broad spectrum of the science and engineering disciplines within the stated interests of Department of Energy's Global Change Program. The core program as outlined by the DOE involves four general areas of research: the Global Carbon Cycle (interpreted here as the global greenhouse gas cycle), Climate Detection and Models of Climate Change, Vegetation $P_{\text {fisearch, }}$ and Resource Analysis. Research into the global greenhouse cycle involves understanding the global dynamics of sources and sinks of greenhouse gases so that attempts might be made to predict their future atmospheric concentrations. Climate modeling and detection involves understanding the climate system with the goal of determining whether, and how, climate will change under greenhouse gas forcing, reducing the uncertainty of current models, and detecting climatic change within the inherent complexities of the system. Vegetative research involves understanding how plants effect and are affected by changes in greenhouse gases, particularly carbon dioxide. The general concept of resource analysis is to examine ways that climate and vegetative change might impact health and resource sectors such as hydrology, ecosystems, agriculture, shorelines, and fisheries. The research program of the Southcentral Regional Center of NIGEC encompasses each of the areas. We briefly describe in the following paragraphs the research and educational activities conducted by the Southcentral Regional Center during the period of June to December 1991.

The Management of the Southcentral Regional Center: The management team for the Southcentral Regional Center consists of the Director, Dr. Robert G. Watts, an A-sociate Director, Dr. Victor J. Law, an Administrative Assistant, Susan Williams, and a Technician/Laboratory Supervisor, Mr. Juan W. Parke. A Steering Committee, appointed by the Provost with the advice and consent of the Dean of Engineering and the Director, meets monthly to consider Center policy recommendations and to advise the Director and the Associate Director on policy matters, new research themes, and other matters. 'The Steering Committee also helps to screen proposals from both Tulane and other regional institutions and provides guidance as to which proposals best fit into the thrust of the Center.

The Technician/Laboratory Supervisor works with the various scientists to maintain their laboratories, maintains the computer facilities, helps in the proposal solicitation process, and helps to maintain contact with researchers from other universities. The Administrative Assistant, in addition to the usual secretarial duties, maintains the records and budgets of the Center.

Request for Letters of Intent For FY 92-93 Research Projects: In the early Fall a request for Letters of Intent was mailed to universities and research facilities in the Southcentral Region. The Southcentral Region includes the states of Arkansas, Colorado, Kansas, Louisiana, Mississippi, Missouri, New Mexico, Oklahoma, and Texas. The Request for Letters of Intent were sent to the Vice Presidents for Flesearch, Department Heads, and Deans (or equivalent) for each of the universities in the region that were judged to have viable graduate programs in at least one area that could in some way be related to global change studies. A list of people who had in the last two or three years asked for information from the Carbon Dioxide Information Center in Oak Ridge, Tennessee was obtained from that office, and requests for Letters of Intent were sent to those persons. In addition, request for Letters of Intent were sent to approximately 50 researchers whom the Director personally knew were actively engaged in global change research. More than 580 requests were mailed. Approximately 62 Letters of Intent were received from eight states and 16 different universities and research facilities. 
Request for Proposals For FY 92-93 Research Projects: Once the Letters of Intent were received there was a five week span for the preparation and submission of research proposals. We received 56 proposals from eight states and 15 different universities and research facilities.

The Regional Technical Review process was conducted by an outside mail review. We feel this provides the best possible review by allowing for specialized review and by reducing any possible conflict of interest. The reviews period was December 15, 1990 to January 10, 1991.

Research Focus Areas: Since our last report NIGEC-Snithcentral has continued to develop its three research focus areas: modeling of sources and sinks of radiatively important constituents, impacts of radiatively important constituents and global climate change, and the prediction and detection of climate change. One of the strengths of the research focus areas lies in the interdisciplinary nature of the research being done and the connectedness of the projects to one another. The sources and sinks of radiatively important constituents focus area has 12 projects which are placed into three research groups categorized as oceanic biogeochemistry, terrestrial biogeochemistry, and atmospheric chemistry.

The oceanic biogeochemistry research group presently involves work being done by Lynn Koplitz, Anil Menawat and Robert Watts, and S. Schwarz and V. John. New to this group for FY 91-92 is G. Cutter (Old Dominion University), "Production and Sea-Air Flux of Carbonyl Sulfide in the Coastal Environment", and C. Paull (University of North Carolina-Chapel Hill), "Sampling the Marine Gas-Hydrate Reservoir: Assessing the Methane Inventory, Internal Dynamics, and Potential of Methane Discharges to the Atmosphere".

L. Koplitz's work is exploring the relationship of dissolved iron $\left(\mathrm{Fe}^{2+}\right)$ on both dissolved carbon dioxide and subsequently atmospheric carbon dioxide. This work is not studying the indirect link between $\mathrm{CO}_{2}$ and Fe by way of biological metabolic pathways (i.e., photosynthesis) but instead is hypothesizing a direct link by way of the aqueous complexation of $\mathrm{Fe}$ with bicarbonate. This insoluble $\mathrm{Fe}^{2+}-.\left(\mathrm{HCO}_{3}{ }^{\circ}\right)$ complex would, of course, change the stoichiometry and more importantly the thermodynamic balance of $\mathrm{CO}_{2(\mathrm{~s})}$ and $\left(\mathrm{HCO}_{3}{ }^{\circ}\right)$, and also change the biological availability of $\mathrm{Fe}$ in an aqueous environment. This complexation phenomena could change the assumptions, made in many papers, of the biological availability of $\mathrm{Fe}$ and therefore its subsequent effects. A paper entitled "The Role of Aqueous.Iron in $\mathrm{CO}_{2}$ Uptake: Direct Chemical Effects" is in preparation to be presented to the American Chemical Society.

The work by Menawat and Watts is another part of the ocean biogeochemistry research group. It involves the study of oceanic carbon chemistry and atmospheric $\mathrm{CO}_{2}$. The importance of modeling the "biological pump" for $\mathrm{CO}_{2}$ in the oceans is well known, but the inherent complexity of doing so makes it a difficult task. The work by Menawat and Watts is unique in that is does not use simple mass balancing stoichiometry but instead uses irreversible thermodynamic, elemental analysis, and reduction potential values to evaluate the carbon chemistry. The work by Menawat and Watts has one publication pending and another manuscript under preparation.

The work by Schwarz and John is a modeling project of the light hydrocarbons discharged from gas hydrate by using plume modeling for analysis. Another feature of their project is a determination of how the release of light hydrocarbons from gas hydrate will respond to chaining environmental conditions. This project is to be closely linked to the project by C. Paull.

The terrestrial biogeochemistry research subgroup consists of work by V. Law and D. Patrick and has expanded due to FY 91-92 funding to include R. Burke, "Methane Emissions from Natural Wetlands", T. Smith and H. Shugart (University of Virginia), "Modeling Patterns of Carbon Dioxide Flux from Forest Ecosystems: Implications of Climate Change", and F. Sass (Rice University), "Trace Gas Exchange with the Atmosphere from the Gulf Coast Agricultural Wetlands". 
The work by Law and C. Lindau is a joint project with Louisiana State University (Baton Rouge) and is both a modeling study and empirical analysis of $\mathrm{CH}_{4}$ production during rice production. During this report period this project has produced two papers for presentation and has one paper pending review.

Atmospheric chemistry forms the third research group within the sources and sinks of radiatively important constituents focus group. At present there is only one investigator in this group but with the FY 91-92 research awards it will increase to three investigators. B. Koplitz is investigating the photochemistry of chlorofluorocarbons and haloethanes, in particular the production of and molecular reactivity of photolytically produced hydrogen. Koplitz is photolyzing certain halocarbon molecules such as $\mathrm{CH}_{3} \mathrm{CH}_{2} \mathrm{CL}$ and is forming $\mathrm{CL}+\mathrm{H}+\mathrm{CH}_{2} \mathrm{CH}_{2}$. One of the significant features of this reaction is the subsequent formation of radiatively important constituents by the hydrogen radical.

For example: $\quad \mathrm{H}+\mathrm{O}_{2}->\mathrm{OH}+\mathrm{O}$

$$
\begin{aligned}
& \mathrm{O}+\mathrm{N}_{2} \rightarrow \mathrm{NO}+\mathrm{O} \\
& \mathrm{NO}+\mathrm{O}_{2} \rightarrow \mathrm{NO}_{2}+\mathrm{O}
\end{aligned}
$$

This potential source is a factor that is little understood, and with the replacement of the CFCs with HFCs the ozone depletion would be reduced, but at the possible expense of aggravating anthropogenic climate change by the undesired production of atmospheric radiatively important constituents.

Our second research focus area is the detection and prediction of climate change. Using a variety of one, two, and three dimensional energy balance climate models, $R$. Watts is studying the effect of the vertical circulation of the ocean on transient climate change and on the distribution of climate change. Future directions for this research include plans to use energy balance climate models and a GCM together with paleoclimate data in an attempt to calibrate the models and reduce the uncertainty in predictions of climate change due to increased greenhouse gases. This research will be in cooperation with M. Hoffert et al. (New York University).

Another project in the climate change detection and predication research focus area is a project by I. Gill. His work involves the isotope analysis of Caribbean corals to reconstruct a temperature record with possible seasonal variations. Since our last report Gill has begun the isotopic and trace element analysis of the substantial amount of material gathered in the field. These samples may provide the materials that would allow for reconstructed temperature records for several hundred years. The importance of this record for "ground truthing" climate model attempts to predict past climate is invaluable and relates directly to the research funded by NIGEC for $91-92$ by Hoffert, Rampino, Schlesinger, and Watts on the study of paleoclinates. Their project entitled, "Climate Sensitivity, Paleoclimates, and Climate-Model Verification and Calibration" received funding late and is not presenting a semi-annual progress report. Also in our research focus area of the detection and prediction of climate change is a project by G. North (Texas A\&M), "Estimation of Climate Sensitivity".

Our third research focus group is the impacts of climate change. This has two projects which are in the research groups of biological and physical impacts.

The biological impacts research group has work being done by G. Cameron and is focusing on the potential change in the biodiversity of small mammals in the Southcentral United States. This project offers a unique potential for modeling the possible impacts of climate change by using Geographical Information System (GIS) technology, rodent populations (because of their food-chain linkage, rodents provide a high sensitivity group), and the diverse environmental gradient offered by the Southcentral United States. Work to date includes the production of a GIS of the study area, the building of a necessary database to produce a vulnerability index for the various species, and a publication has been submitted for review.

The physical impacts research group has work being done by K. Papadopoulos. Many characteristics of soil, for example, agriculture productivity or erosion resistance, are derived in large part from the physicochemical properties of the soil's components. Yet the physico-chemical changes in soil caused by various 
environmental factors is poorly understood at the fundamental level. Papadopoulos' work is concentrating on the changes in clay, a significant component of soils.

The Southcentral Regional Center of NIGEC had one global climate change policy related project in FY 90-91. This was a workshop entitled "The Engineering Response to Global Climate Change: Planning a Research and Development Agenda". The workshop was held in Palm Coast, Floricia, June 1-6, 1991. Seventy-five engineers and scientists representing industry, government, and universities attended the workshop. A book detailing the results of the workshop is expected in the summer of 1992.

A second workshop entitled, The Engineering Response to Global Climate Change: Towards a NonFossil Energy World for the 21st Century", will be held late summer c.. early fall 1992. 


\title{
The Utilization of Sclerochronology to Establish Sea-Surface Temperature Fluctuation
}

\author{
(formerty: The Utilization of Sclerochronology to Establish Annual Isotopic and \\ Temperature Fluctuation Histories in Coastal Seawater) \\ Ivan Gill, Tulane University \\ and \\ Dennis K. Hubbard, West I/adies Laboratory
}

Introduction: The following report summarizes the activities of the NIGEC-sponsored coral drilling project from May through December 1991. The sample collection cruise spanned the dates June 16 - July 16, 1991 and was conducted off the southwestern corner of Puerto Rico. Major drilling equipment was picked un from the West Indies Laboratory on St. Croix and delivered to Puerto Rico by the R/V Isla Magueyez, operated by the University of Puerto Rico (UPR). Operations in Puerto Rico were conducted off the R/V Pezmar, also operated by UPR.

Objective: The major thrust of the project is to evaluate stable isotopic sclerochronology as a tool for establishing a record of sea-surface temperatures, and if the method is viable, to produce such a record over a several century time-span. Field collection consisted of the collection of thirteen cores from single colony coral heads, as well as the collection of eight reef cores, collected with cooperative funding from NOAA. The latter show the record of Holocene reef accretion in the area and in some instances contain intervals cored through intact single coral heads that may extend the time range of temperature records. Current results of the analysis of the coral cores and reef cores are described below.

Product: This research will result in two major products:

1. Preliminary evaluation of coral isotopic records as proxies for long (greater than two centuries) time intervals.

2. A long-term (greater than two centuries) record of sea-surface temperatures for the northeastern Caribbean. This record will be a starting point for other localities worldwide, and will be free of many of the uncertainties that hinder the interpretation of terrestrial records.

\section{Approach and Results to Date}

Dive Operations: During June and July, 1991 a total of 158 dives were made by personnel associated with the program. Bottom time on logged dives totalled 274 hours and 31 minutes. Average bottom time was 105 minutes and 35 seconds, the extended time being related to the shallower depths $(20-40 \mathrm{ft})$ where most operations were conducted. At deeper depths, three dives were typically made by each diver per day. The maximum depth of operations was $100 \mathrm{ft}$. This was a reconnaissance dive, however, and no drilling was attempted at this depth. The maximum depth of drilling operations was ca. $45 \mathrm{ft}$.

Reef Coring: Eight reef cores were recovered from the shelf off La Parguera, with a maximum length of 30 $\mathrm{m}$ below the reef surface. PAR-8 exceeded $30 \mathrm{~m}$ in length, far greater than any cores yet recovered by similar drilling systems. The distribution of cores reasonably spans the cross-shelf environments that exist in the area. These cores may be useful in extending the record of temperature and reef growth farther into the Holocene. All reef cores have been sectioned and examined for gross characteristics. Final logs have been completed and an example is shown in Fig. 1.

Coral Coring: Thirteen cores of various lengths were recovered from three sites on the La Parguera shelf. Eight cores were recovered from the forereef east of the island of Turromote. Three additional cores were recovered from the front of another ridge located roughly $800 \mathrm{~m}$ seaward of the above site. A single, short (ca $60 \mathrm{~cm}$ ) core was recovered from a colony at the shelf edge. 
The longest core exceeded $6 \mathrm{~m}$ in length. Because of intense bioerosion in the area, however, only the upper $2 \mathrm{~m}$ of this was continuous and can be used for detalled sclerochronology. The longest uninterrupted record is $2.52 \mathrm{~m}$ in length. At an extrapolated linear-extension rate of $0.80 \mathrm{~cm} /$ year, this $2.52 \mathrm{~m}$ of growth would result in a proxy record of 315 years. While our dating precision will obviously drop below the breaks in recovery, the potential still exists for a much longer record from these corres. Also, we recovered several long $(0.50-1.00 \mathrm{~m})$ sections of $M$. annularis in our reef cores, described briefly below. Radiocarbon dates are unavailable at this time, but it is anticipated that these corals are 3,000-6,000 years old. Therefore, the possibility may exist to recover century-long records of temperature from much earlier times.

All cores were recovered from single-clone colonies of $M$. annularis. Every effort was made to not abrade or otherwise damage the coral beyond the obvious impact of the resulting core hole. After the cores were completed, we inserted a cement plug to discourage bioerosion around the hole left by coring. In some instances, we poured concrete into the hole to prevent the introduction of bioeroders from below. As a final attempt to minimize any impact from our coring, we opted to drill either very recently killed surfaces or else areas along their margin between living and dead coral. In this manner, we virtually eliminated any possibility of opening new scars that could accelerate degradation of the already stressed community.

The cores have been slabbed and logged at Tulane University, and $\mathrm{x}$-radiography is close to completion (Fig. 1). Samples for radiometric dating are presently being taken from the cores, and will be sent out for analysis. Radiometric dating results are expected in early Spring. Initial micro-sampling of the coral growth banding will start following the completion of $x$-radiography. Sample treatment will include sodium hypochlorite bleaching or treatment with a low-temperature plasma asher, depending on the results of initial treatment experiments. All samples subsequently analyzed for stable isotopes will be treated as identically as is practicable.

Fig. 1 Examples of

drilling logs of reef

cores taken close t.

the coral head

drilling site.

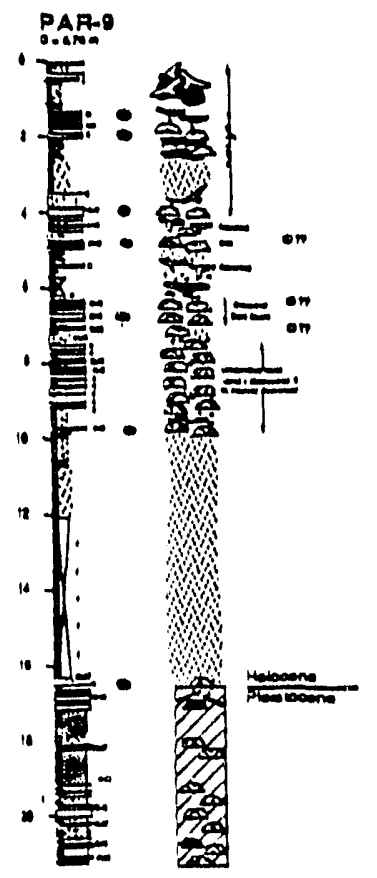

92
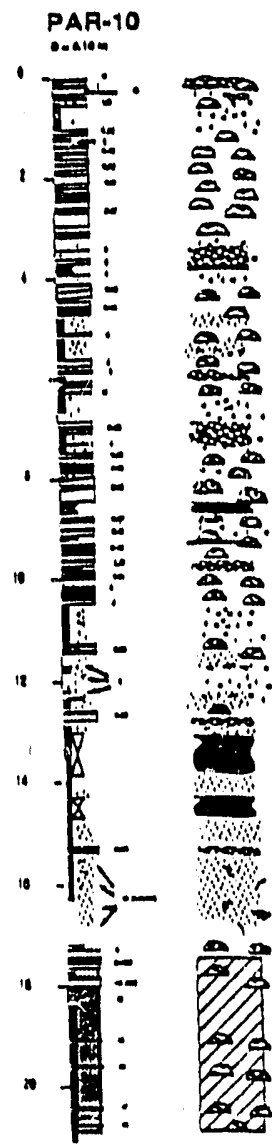

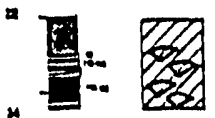

0.10. $24.42 \mathrm{~m}$

$\bullet$

$m$

-
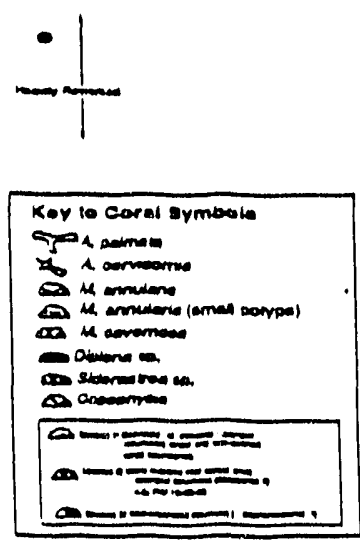


\title{
Chemical Controls on the Sinks and Sources of Carbon Dioxide: The Role of Iron
}

\author{
Lynn.V. Koplitz \\ Loyola University
}

Objective: Our goal is to investigate connections between dissolved iron in natural bodies of water and changes in atmospheric carbon dioxide levels. We hypothesize that there is a direct chemical link between local iron concentrations and the rate of uptake of from the air. Others have suggested an indirect link through phytoplankton which prosper in the presence of higher iron levels; increased phytoplankton populations, or bloorns, take up more $\mathrm{CO}_{2}$ during photosynthesis. This goal can be subdivided and stated more specifically as follows: (1) To study the aqueous complex behavior of iron with bicarbonate under various conditions of $\mathrm{pH}$, chloride concentration, partial pressures of carbon dioxide and oxygen, and temperature. It is important to characterize the thermodynamics and behavior of these soluble species in order to understand their effect on the chemistry of oceans and other natural bodies of water. Complexes like these may also play a role in limiting the loon transport systems of marine phytoplankton, thereby significantly influencing organic carbon production in the oceans. (2) To determine precipitation rates of various carbonate phases. Carbon dioxide absorbed loom air into water equilibrates with bicarbonate which in turn equilibrates with carbonate $\left(\mathrm{CO}_{3}{ }^{2+}\right)$. When certain metal lons such as $\mathrm{Ca}^{2+}, \mathrm{Mg}^{2+}$, or $\mathrm{Fe}^{2+}$ are present, insoluble carbonate salts will precipitate. The rate of such precipitation wili ultimately influence the rate of uptake of $\mathrm{CO}_{2}$. It will also affect the residence time of metals, such as iron, in the water column. The ability of phytoplankton to utilize iron as a micronutrient will be curtailed by short residence times, i.e., fast precipitation rates. In addition, trace amounts of iron may cause other carbonate phases to precipitate faster by providing a special mechanism for the process.

Product: These investigations will lead to a better understanding of the rates of chemical and biological uptake of $\mathrm{CO}_{2}$ from the atmosphere by the hydrosphere. It may be necessary to reevaluate the current bias toward treating the ocean as a vast homogeneous sink for $\mathrm{CO}_{2}$ and focus some attention on waters with variable compositions. Waters near the continental shelves, for example, account for roughly $10-20 \%$ of the area of the oceans and contain 10-100 times as much dissolved iron as open ocean. If iron affects the rate of $\mathrm{CO}_{2}$ uptake, then the continental margins could account for far more than their fair share of the total $\mathrm{CO}_{2}$ absorbed.

Approach: The experimental approach involves electronic absorption spectroscopy coupled with factor analysis as a means to identify and characterize soluble complexes (referred to as Phase 1 in the original proposal) along with particle counting to determine precipitation rates of insoluble salts (Phase 3). Further studies of the complexes will be done with infrared internal spectroscopy at a later date (originally called Phase 2). The method for analyzing complexes was developed on, and has been applied to, other chemical systems in our laboratory. The particle counting method is just being developed after the acquisition of an appropriate instrument. Precipitated phases will be collected and then identified by powder $\mathbf{x}$-ray diffraction at Tulane University's Geology Department. All solutions are prepared with degassed deionized water and handled in a nitrogen-filled glove box.

Results to Date: Since January 1991, when funds actually became available for us to work on this project, three undergraduates and the PI have spent various amounts of time on Phases 1 and 3 . During the spring semester, Remy Gross took preliminary UV absorption spectra of $\mathrm{Fe}^{2+} / \mathrm{HCO}_{3}$ solutions which showed an ink absorbance in solutions with the same iron content but varied bicarbonate concentrations (see Progress Report submitted 2/91). After accounting for the absorption by free $\mathrm{HCO}_{3}$ this indicates some complexation of the iron by bicarbonate. He also set up the particle counter and its controlling $\mathrm{PC}$ late in the semester and learned how to use the instrument.

Jessica Urbanik's spectroscopic work on an extended range of solution concentrations $\left(10^{-5} \mathrm{M}<\left[\mathrm{Fe}^{2+}\right]<\right.$ $10^{-3} \mathrm{M}, 10^{-4} \mathrm{M}<\left[\mathrm{HCO}_{3}\right]<10^{-2} \mathrm{M}, 6.0<\mathrm{pH}<8.5$ ) has shown that the UV spectra are much more difficult to 
interpret than we had thought earlier. Bicarbonate, carbonate, and hydroxide all have their own UV absorbance bands and are all present in varying concentrations along with the iron, It is generally not a simple matter to account for their contributions to the spectra by subtraction or other means since their concentrations in each solution are not precisely known. Therefore, we are currently beginning to look at the near infrared region of the spectrum where a ligand-field band of $\mathrm{Fe}^{2+}$ occurs. The other aforementioned species do not absorb in this region.

Susan Harris, has been devoting part of her research time to determining relative precipitation rates for and by using the particle counter. She and Jessica have confirmed that iron carbonate is less soluble than calcium carbonate at $\mathrm{pH}=8$ and $\mathrm{T}=298 \mathrm{~K}$, in agreement with their respective solubility products of $2.1 \mathrm{x}$ $10^{-11}$ and $3.84 \times 10^{\circ}$. More importantly, the iron phase precipitates about three times faster than the calcium phase when each is precipitated separately a slightly saturated solution.

Our next test will be to find out how the presence of a small amount of iron affects the precipitation rate of $\mathrm{CaCO}_{3}$ as this is the major phase precipitated from seawater. We hope to eventually assemble a flow-through cell so that natural conditions, where dissolved iron and bicarbonate/carbonate are continuously recharged, can be simulated. Other investigations will include varying the solution chloride concentration, partial pressures of carbon dioxide and oxygen, and texture.

Another result during the reporting period is a paper entitled, "The role of aqueous iron in $\mathrm{CO}_{2}$ uptake: direct chemical effects", which is in preparation to be presented to the American Chemical Society.

Finally, it is worth emphasizing that part of the results of these studies has been to involve three exceptional undergraduate students in scientific research related to global warming. Jessica, Susan and Remy are chemistry majors. But each of them changed to chemistry from something else (physics, biology and business, respectively) when they realized that environmental issues were more relevant to their futures. This experience has been, and will continue to be, extremely important to all of them as they become bona fide environmental scientists.

\title{
Carbon Dioxide, Climate and the Deep Ocean Circulation: Carbon Chemistry Model
}

\author{
Anil S. Menawat and Robert G. Watts \\ Tulane University
}

Objective: The objective of this study is to investigate the role of oceanic carbon chemistry in modulating the atmospheric levels of $\mathrm{CO}_{2}$. Oceans have been the primary sink of the excess anthropogenic carbon pumped into the atmosphere since the beginning of the industrial period. The suspended particulate matter in the deep ocean plays an important role as a carrier of carbon and other elements critical to the fate of $\mathrm{CO}_{2}$. In addition, it provides sites for oxidation-reduction reactions and microbiological activities. Overall, it is an intricate system of complex chemical, physical, and biological processes. This report describes the interconversions of different forms of the organic and inorganic nutrients, and how to include this in the ocean circulation models. The approach taken here is to include the driving force behind the transformations along with the mass balancing by stoichiometry. Our technique differs from the existing literature in that it includes the thermodynamic considerations of imbalance in chemical potential.

Product: In the first phase of this study we have concentrated on elucidating the mechanisms of interactiuns among the suspended particulate matter (SPM) and the water column. Our approach is unique in that it considers the processes at the extent of reaction level, instead of the popular Redfield ratio approach. This prevents us from defining fictitious compounds to balance the stoichiometry and allows to include the driving forces behind the processes involved. This is a thermodynamic approach in comparison with the mass 
balancing only by stoichiometry. The principal mechanisms of transfer are reaction, sorption, and solubilization, which are the outcomes of the imbalance of the chemical potential. The clear advantage of a thermodynamic over a stoichiometric model is obvious because the former not only provides the direction of transfer, but also provides the extent of transfer. At a later stage we will incorporate this information in a distributive model of the ocean carbon cycle used successfully in the past. The distributive models retain the basic feature of the commonly used box models.

Approach: Upon comparing various sinks and sources of carbon, evidently oceans are the primary sinks for the excess fossil carbon pumped into the atmosphere since the beginning of the industrial period. The rate of transfer of this excess carbon to the world oceans largely determines the rate at which we can safely burn fossil fuels. In the last three decades, carbon dioxide contributed to an increase in the global temperature by $0.08^{\circ} \mathrm{C}$. This increase in temperature by $\mathrm{CO}_{2}$ is equivalent to the increase by all other greenhouse gases, like CFCs, methane, etc., collectively. Oceans, being the largest reservoir in the carbon cycle with about 38,000 $\mathrm{Gt}$ of carbon reservoir, clearly will be the ultimate destination for most of the anthropogenic carbon used. It is important to understand the type and magnitude of the internal transfer processes of $\mathrm{CO}_{2}$ in the ocean to make accurate estimaces of the total carbon flux between the world oceans and the atmosphere. Ocean carbon cycle is a complex web with several processes ranging from pure transport of nutrients to chemical and biological interconversions.

The organic matter in the ocean, either as a part of suspended particulate or dissolved organic matter, consists of several organic molecules. It is nearly impossible to keep track of all of these individually. We, therefore, employ molecules representing groups with similar properties in furiher analysis to minimize the effort. The groups we choose to use are carbohydrates, proteins (polypeptides), and lipids. Each group carries a spectrum of degree of reduction resulting in different extent of reactions, hence, affinity. We divide some of these broader groups into subgroups with similar degree of reduction. A corresponding molecule represents each such subgroup in further analysis. Carbohydrates and lipids are relatively easy to handle in this respect for most of the compounds have similar properties, thus glucose and tripalmitin represent these groups respectively. The proteins, however, are a different story.

The focus of this work is on the organic carbon chemistry of the ocean. Current modeling techniques use Redfield ratios, a molecular balancing technique using yield coefficients, where researchers devised fictitious and non-existing molecules to satisfy the stoichiometry. The proposed methodology is not dependent on this approach, thus details of this are omitted here. In our approach, we write the constituents (amino acids, carbohydrates, and lipids) of both particulate and dissolved forms of organic matter for the demineralization reactions in the ocean and perform elemental balancing instead of molecular. This eliminates the need to define any fictitious compounds by using real representative molecules and the stoichiometry is physically realizable, unlike the Redfield ratio approach. Writing the stoichiometry of a certain reaction does not guarantee that the reaction may actually take place. The degree of reduction, which is the number of electrons available for transfer upon the combustion (oxidation) of a compound, of the reactants determines whether the proposed reaction may actually take place or not. This provides a thermodynamic measure for the feasibility as well as for the extent of reaction. Thus "affinity of a reaction" expressed in "degree of reduction" becomes a feasibility measure. Above thermodynamic property - the degree of reduction - thus defines the extent of reaction for the demineralization reactions.

A comprehensive mass transfer model for ocean comprises mass and energy conservation with entropy production over an infinitesimal volume with biological, bioorganic, and inorganic chemistry. The ocean is an open system with exchanges of mass, as well as energy, with the atmosphere. The theory of choice, therefore, is irreversible thermodynamics to give a dynamics character to the model instead of assuming equilibrium. Non-equilibrium thermodynamics treatment of such a system requires the formulation of constraints to the conversion terms appearing in the balance equations of two extensive properties: energy and entropy. Combining the first and second laws of thermodynamics allows the use of thermodynamic efficiency. This concept enables us to ensure the feasibility of the transfer processes involved in the ocean interior. The concept of thermodynamic efficiency thus becomes a useful tuning device for our model, 
adding another advantage to this approach.

As of this reporting period a publication is in preparation and is to be submitted to "Biogeochemistry".

\title{
Global Warming Effects on the Release of Light Hydrocarbons from Gas Hydrate Deposits
}

\author{
S. G. Schwarz and V. T. John \\ Tulane University
}

This project involves the potential release of methane and other light hydrocarbons from gas hydrate (clathrate) deposits in Arctic regions, and its relationship to global warming. It is reported that the globally averaged tropospheric methane concentration has increased at a rate of about $1 \%$ per year during the decade beginning 1978 (Cicerone and Oremland, 1988). A portion of this increase may be from gas hydrates as evidenced by recent observations of NOAA satellites above the Arctic area (Matson, 1986; Kienle et al., 1983). Infrared imagery shows large plumes which may depict the results of gas hydrate instabilities brought on by the decline of the most recent ice age. As methane is a greenhouse gas, this could represent a significant contribution to global warming, and therefore warrants further investigation. Our efforts to date have focused on evaluating the plausibility of the methane hydrate plume hypothesis and on developing a plume model to estimate the amount of carbon which is deposited in the atmosphere from observed plumes.

It is hypothesized that there is a direct link between the plumes sighted in the Arctic area and methane hydrate destabilization. Because of a downward propagating temperature wave due to the decline of the last ice age and corresponding inundation of the permafrost by the rising sea, methane hydrates located under the Arctic permafrost are melting, releasing the trapped hydrocarbons. It is suggested that, with a sufficient build up of pressure, the methane migrates along fault lines and expands substantially as it is released into the sea. Transported up to the sea surface, the gas bubbles burst, carrying with it into the atmosphere sea water in the form of jet and film drops. A large atmospheric plume is formed containing methane, water, and entrained air and water.

In our research effort, we have addressed a number of questions, the first being, "Are methane hydrates a plausible source of atmospheric methane?" We feel there exists enough evidence in the literature to support the possibility that the plumes appearing in the vicinity of Bennett Island are a result of methane hydrate destabilization. The documented existence of hydrates in the area (Kvenvolden, 1988; MacDonald, 1990), the calculations involving sea level drop during the ice age (Fairbanks, 1989; CLIMAP, 1976; Clarke et al., 1990), the calculations involving time scales of destabilization (Nisbet, 1990; MacDonald, 1990), and the images provided by satellites (Kienle et al., 1983), all lend credence to the hypothesis.

The second question relates to the state of the methane reaching the sea surface. This is critical as it provides initial conditions for the atmospheric plumes. It is proposed that as hydrates destabilize, gas accumulates and increases in pressure until it ruptures, possibly along fault lines which are known to exist in the area (Clark et al., 1990). The gas is vented into the sea where it is broken up into small bubbles.

Assuming initial sonic velocity, preliminary calculations show that bubbles ranging in size from $1 \mathrm{~mm}$ to $1 \mathrm{~cm}$ will reach terminal velocities ranging from $<1 \mathrm{~m} / \mathrm{s}$ to $5 \mathrm{~m} / \mathrm{s}$ by the time they reach the sea surface $40 \mathrm{~m}$ above, the estimated depth of water at the plume source (Clark et al., 1990). Preliminary temperature calculations show that the $-45^{\circ} \mathrm{C}$ to $-60^{\circ} \mathrm{C}$ plume top temperatures derived from satellite imagery (Matson, 1986; Kierde et al., 1983) are not possible due simply to expansion of gas from the sea foor to the estimated $7 \mathrm{~km}$ plume top height. We therefore feel a significant temperature drop occurs as the gas is forced from below the mud line into the sea, where a significant pressure drop is likely. This means the gas is probably 
very cold when it reaches the sea surface. Various estimatcis for initial temperature and velocity will be used in the model to obtain a plume which corresponds to kjown data.

The third question addresses the origin of water $i_{i}$ the plume. Since the observed plume is the manifestation of water condensation, it becomes parti ularly necessary to understand the origin and propagation of the water aerosol, in order to match sitellite thermal and infrared imaging data to our plume models. Several conjectures arise regarding the origil of the water aerosol: (1) Does expansion of methane subsequent to egress from the ocean cause sufficient cooling to nucleate atmospheric water vapor and form the observed plume? (MacDonald, 1990); (2) Does entrainment of the surrounding water-saturated air into the rising methane-containing plume lead to a source of nucleating water in the plume? (Matson, 1986); and (3) Does cold bubble rise in the ocean entail entrainment of frozen water and residual hydrate which form the frozen nuclei that are ejected into the atmosphere? (Clarke, 1990).

We, however, are considering another major contribution to the water aerosol based on the wellcharacterized physics of bubble breakage and thin film stability. The proposition is as follows. When methane bubbles reach the bulk air-water interface, they burst, releasing water droplets. These droplets are aerosol sized and can be easily transported into the atmosphere by the methane plume. When exposed to the low atmospheric temperatures the droplets can freeze, leading to ice nuclei which are also propagated by the methane plume.

The concept of water aerosol formation from bursting bubbles was first discussed in the early 1950's by Woodcock, to explain salt nuclei in marine air and the transmission of marine microorganisms to coastal areas (Woodcock, 1953, 1955). The bubbles in this case are created when wave breakage entrains air into the sea, but the resulting bubble rise and breakage phenomenon should be universally valid; indeed, the mechanistic details of cloud formation have been linked to droplet ejection upon bubble breakage (Blanchard, 1969). The physics of bubble breakage has been extensively studied by several researchers; Blanchard (1989) has written an excellent review of the subject.

Initial order of magnitude calculations indicate that a given bubble can generate at least a hundredth of its volume in aerosol production, primarily through the jet droplets. This compares favorably to the magnitude of the maximum entrainment of water from atmospheric water vapor. If, for example, the atmosphere was considered to be at $273 \mathrm{~K}$, the vapor pressure of water is about $4 \mathrm{~mm} \mathrm{Hg}$, which implies that the volume fraction of water vapor in the atmosphere is $0.5 \times 10^{-2}$, or half the aerosol production from bubble breakage. Thus, we do feel that the aerosol produced by bubble breakage is at least as important as the contribution from entrainment of surrounding air. This information will be incorporated into the plume model boundary conditions to simulate aerosol dispersion characteristics in the plume.

The fourth question considers, "Can the observed plumes be modeled by plausible boundary conditions defined by an expansion/bubble/droplet entrainment scenario?" The model we developed will predict plume trajectory, width, velocity, species concentration, and temperature downstream of ejection from the sea surface into the stratified ambient, with gas properties at the ejection point used as boundary conditions. It will help determine if the methane hydrate scenario is plausible, and if so, estimate the quantity of methane released. After guessing some boundary conditions (ejection velocity and area, which are what we ultimately wish to determine) and calculating the plume trajectory and properties, we can compare the output with the observational data we have. If our guessed boundary conditions produce a plume similar to the observations, we have a reasonable estimate of the amount of carbon injected into the atmosphere.

The final question addresses the estimated methane released by observed plumes. A goal of our research is to determine the significance of the contribution from the destabilization of methane hydrates to the overall methane budget. This is being accomplished through our development of a model, giving consideration to existing models dealing with industrial discharge (Davis, 1990; Hirst, 1971), yet specifically tailored to the Arctic hydrate plumes. 


\title{
References
}

Blanchard, D.C. (1969) The oceanic production rate of cloud nuclei. J. Rech. Atmos 4:1-6.

Blanchard, D.C. (1989) The ejection of drops from the sea and their enrichment with bacteria and other materials: a review. Estuaries 12:127-137.

Cicerone, R. and R. Oremland (1988) Biogeochemical aspects of atmospheric methane. Global Biogeochemical Cycles, 2.

Clarke, J. W., P. St. Armand, and M. Matson (1990) Possible cause of plume in the vicinity of Bennett Island, East Siberian Sea, Soviet Far Arctic. An Hypothesis, manuscript.

CLIMAP Project Members (1976) The Surface of the ice-age Earth. Science 191:1131.

Davis, L.R. (1990) A review of buoyant plume modeling, ASME-AIAA Joint Thermophysics Conference, Heat Transfer Division Symposium, Seattle, WA, 139:85.

Fairbanks, R.G. (1989) A 17,000 year glacio-eustatic sea level record: influence of glacial melting rates on the Younger Dryas event and deep-ocean circulation. Nature 342:637.

Hirst, E. A. (1971) Analysis of round, turbulent, buoyant jets discharged to flowing stratified ambients. Oak Ridge National Laboratory, Report ORNL 4685.

Kienle, J., J.G. Roederer and G.E. Shaw (1983) Volcanic event in Soviet Arctic. EOS, 64, 20:377.

Kvenvolden, K.A. (1988) Methane hydrates and global climate. Global Biogeochemical Cycles, 2, 3:221-229. MacDonald, G.J. (1990) Role of methane clathrates in past and future climates. Climatic Change, 16:247.

281.

Matson, M. (1986) Large plume events in the Soviet Arctic. EOS, 27, 48:1372-1373.

Nisbet, E.G. (1990) The end of the ice age. Canadian J. of Earth Science, 27:148.

Woodcock, A.H. (1953) Salt nuclei in marine air as a function of altitude and wind force. J. Meteor., 10:362371.

Woodcock, A.H. (1955) Bursting bubbles and air pollution. Sewage and Industrial Wastes, 27:1189-1192.

\section{Photochemistry Relevant to Ozone Depletion and Global Warming}

\author{
Brent Koplitz \\ Tulane University
}

Objective: Our investigation into global problems such as ozone layer depletion and global warming occurs at the microscopic level. We are interested in fundamental molecular change, with the aim of relating it to real-world macroscopic phenomena. One of our research goals is to explore fundamental photochemistry relevant to ozone depletion and global warming. Ultraviolet radiation can initiate many different reactions involving small molecules. The goals of our work are focused in three areas: (1) photochemistry of hydrogen-containing chlorofluorocarbons, haloethanes, and their associated radicals, (2) bimolecular reactivity of these radicals with compounds such as $\mathrm{O}_{2}$, and (3) generation and reactivity of $\mathrm{O}$ atoms resulting from $\mathrm{O}_{3}$ photolysis.

Product: There is a variety of information resulting from our experiments. For example, our experiments provide a measure of the propensity for $\mathrm{H}$-atom production resulting from the photolysis of globally important greenhouse gases and known ozone depletors. Consider the photochemistry of 1,1,1-trichloroethane $\left(\mathrm{CCl}_{3} \mathrm{CH}_{3}\right)$ with respect to $\mathrm{H}$-atom production. Our results have shown that this molecule is clearly photochemically active with respect to $\mathrm{H}$-atom production. Furthermore, the alternatives to existing chlorofluorocarbons (CFCs) such as CFC-12 $\left(\mathrm{CCl}_{2} \mathrm{~F}_{2}\right)$, widely used in refrigerators and car air conditioning units, are in fact hydrogen-containing molecules. For example, $\mathrm{HFC}-141 \mathrm{~b}\left(\mathrm{CH}_{2} \mathrm{FCH}_{3}\right)$ and HCFC-124 ( CHClFCF $\left._{3}\right)$ are leading candidates to replace CFCs. Below, we discuss our results to date on photochentistry of these and other haloethanes. Our experiments are also designed to ultimately yield information about absorption properties of the HCFC radicals, their bimolecular reactivity with $\mathrm{O}_{2}$, and the 
absorption properties of the peroxide radicals thus formed. The experiments can provide insight into the breakdown of haloethane molecules in the troposphere as well as the stratosphere.

Approach: $\mathrm{H}$-atom (as well as $\mathrm{C} 1$ atom) production arising from the photolysis of baloethanes such 1,1,1-trichloroethane, HCFC-141b, and HCFC-124, can be monitored in the laboratory. In all of these cases, Doppler spectroscopy on the $\mathrm{H}$ atom allows us to investigate the energetics of $\mathrm{H}$-atom production. This type of measurement is important because it provides us with a measure of the kinetic energy of the $\mathrm{H}$ atom and thus gives insight into its potential reactivity. We can also examine the optical absorption properties of transient radical intermediates by using $1+1$ ionization techniques. In terms of physical setup, photolysis of the molecule of interest is achieved using an excimer laser (two-color photolysis experiments utilize a laser from the Tulane Laser Laboratory) operational at a variety of wavelengths. The probe laser generates tunable visible radiation, and frequency tripling of the dye laser output in a cell containing krypton or xenon allows vacuum ultraviolet (VUV) radiation to be produced. For detection, a time-of-flight mass spectrometer (TOFMS) is used, since ion detection is particularly sensitive. Samples can be introduced via molecular leak or supersonic expansion, thus enabling experiments to be performed under collisonal as well as collisonless conditions.

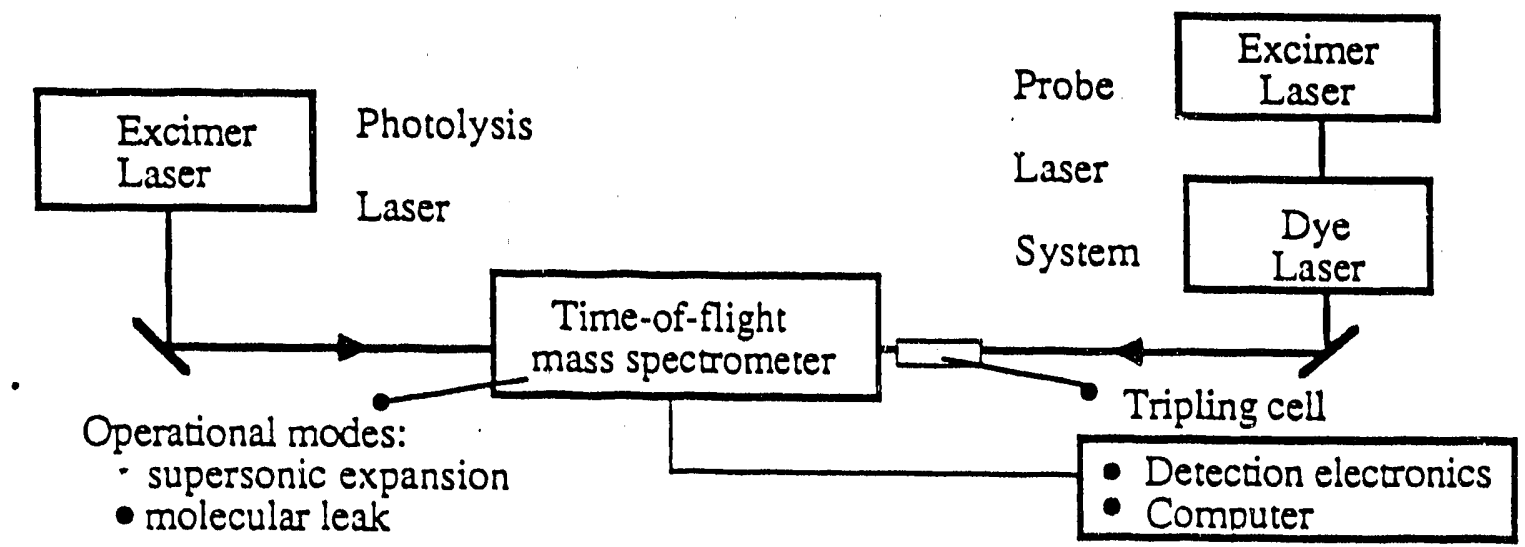

Figure 1. Schematic diagram of experimental apparatus.

Results: The funding for this DOE project became official in Fall, 1990. Since that time, our investigations into the ultraviolet (UV) photochemistry of small molecules have progressed well. Six papers have been written on model systems:

"Photolysis of Iodoethane: Atomic Hydrogen Generation", Subhash Deshmukh, Jeffrey L. Brum, and Brent Koplitz, Chemical Physics Letters 176:198-202 (1991).

"Site-Specific Bond Cleavage Leading to H-Atom Production in the Photolysis of 2-Iodopropane", Jeffrey L. Brum, Subhash Deshmukh, and Brent Koplitz, Journal of the American Chemical Society 113:1432-1434 (1991).

"Site-Specific Branching Ratios for H-Atom Production Resulting from the 193 and $248 \mathrm{~nm}$ Photolysis of 1-Iodopropane", Jeffrey L. Brum, Subhash Dishmukh, and Brent Koplitz, Journal of Physical Chemistry 95:8676-8680 (1991).

"Conclusive Evidence for Site-Specific Bond Cleavage Resulting from 248 nm Photolysis of the Ethyl Radical", J. L. Bruin, S. Deshmukh, and B. Koplitz, Journal of Chemical Physics 95:2200-2202 (1991).

"Determining Dissociation Pathways in the $193 \mathrm{~nm}$ Photolysis of Monoethylamine", Xioadong Xu, Subhahsh Deshmukh, Jeffrey L. Brum, and Brent Koplitz, Chem. Phys. Lett. 188:32-36 (1992). 
"Site-Specific Photochemistry", Brent Koplitz, Jeffrey L. Brum, Subhash Deshmukh, Xiaodong Xu, Zhongrui Wang, and Yu-Fong Yen, SPIE Proceedings (1992) in press.

We are very excited about recent results in our laboratory involving halocarbon photochemistry. Consider chloroethane, $\mathrm{CH}_{3} \mathrm{CH}_{2} \mathrm{Cl}$. One might expect that absorption by $\mathrm{CH}_{3} \mathrm{CH}_{2} \mathrm{Cl}$ of a single UV photon at $193 \mathrm{~nm}$ would simply cleave the $\mathrm{C}-\mathrm{Cl}$ bond. Indeed, this primary photochemical event occurs, but we also observe that a non-negligible amount of atomic hydrogen is produced. However, we can dramatically increase $H$-atom production by simply using two photolysis wavelengths $(193+248 \mathrm{~nm})$. Here, it is photon absorption by the ethyl radical that is important. This H-atom "enhancement" channel may be very significant in producing atomic hydrogen in the atmosphere. For example, one of our primary target molecules, $\mathrm{CCl}_{3} \mathrm{CH}_{3}$, has been shown to produce significant amounts of atomic hydrogen upon irradiation with $193 \mathrm{~nm}$ light. But since the $\mathrm{C}-\mathrm{Cl}$ bond is weaker, one would expect the primary photochemical process to be formation of the $\mathrm{CCl}_{2} \mathrm{CH}_{3}$ radical. Will this radical also absorb a UV photon and enhance $\mathrm{H}$-atom production, as is the case with chloroethane? Can we use turnable UV radiation to map out a fragment "yield" spectrum for the radical? This spectrum should be very similar to an absorption spectrum for the radical. This type of information is important but difficult to obtain for transient species such as radicals.

The chemical industry has plans to replace CFC-12 $\left(\mathrm{CC1}_{2} \mathrm{~F}_{2}\right)$ and $\mathrm{CFC}-11\left(\mathrm{CC1}_{3} \mathrm{~F}\right)$ with H-containing alternatives such as HCFC-141b and HCFC-123. It is imperative that the photochemistry of these compounds be explored. Our preliminary studies on HCFC-124 have identified a small, but non-negligible $\mathrm{H}$-atom signal. Can $\mathrm{H}$-atom production be enhanced in the manner described above? We strongly suspect that $\mathrm{H}$ atoms can be readily generated photolytically. Furthermore, the bimolecular reactivity of the radical is an important process to be characterized for possible impact in both the lower and the upper atmosphere. Experiments are underway to address these issues.

\title{
References
}

1. Chemical and Engineering News September 3, 6 (1990).

2. J.L. Brum, S. Deshmukh, and B. Koplitz, Chem. Phys. Lett. 95:2200 (1990).

\section{The Engineering Response to Global Climate Change: Planning A Research and Development Agenda}

\author{
Robert G. Watts \\ Tulane University
}

Objective: To bring together experts from a variety of engineering disciplines that will affect or be affected by climate change for the purpose of producin : scientifically documented plan for future research and technological development directions for the engineering response to potential global climate change.

Product: A book, to be publi. hed by early Fall 1992, that presents goals and approaches to their accomplishment, for responding to greenhouse induced climate change through prevention of greenhouse gas increases, mitigative measures, and adaptive strategies.

Approach: The workshop was in the planning stages for nearly two years. We set out to target participation by the engineering and scientific communities from a brond variety of fields and from industry, government, and the academic communities.

The workshop was initially separated into seven panels or working groups: Sources of Greenhouse Gases, Energy Supply, Demand Reduction, Control of Sinks or Climate, Agritechnology, Ground and Surface 
Water, and Sea Level and Coastal Areas. Leaders were then recruited for each of the panels, and were asked in turn to recruit approximately ten people whom they judged to be the most knowledgeable and creative thinkers in the area for which they were responsible. International participation was encouraged as far as the budget would allow, and leaders were encouraged to recruit participants from all three sectors; government agencies, industry, and academia. The mix eventually was $\mathbf{2 3}$ from government or national laboratories, 16 from industry, and 29 from universities. Six people represented four foreign countries; Japan, Germany, England, and India.

In an opening plenary, each workshop leader presented a brief talk about his group's topic. Each group then received instructions to convene and establish one or a small number of specific goals that the engineering community should aim to accomplish with regard to the topic of their group. During the second plenary, these goals were discussed by the entire workshop. The seven leaders were then given instructions to convene their groups and to produce a list of approaches to accomplish the goals they had set. In the third plenary, the very long list of specific actions was grouped into approximately thirty clusters. Interdisciplinary groups of two to five persons then worked to flesh out the approaches and make recommendations for each of the approaches. After a brief plenary, the groups broke into the original seven working groups to discuss the final product, which had been previously typed and distributed.

Results to Date: Final editing of the book is in progress. The first chapter of the book is an introduction to the problem, including a brief overview of the problem of climatic change and the engineering response, a little history, and an overview of the book. Chapters two through eight are the results of the largely preworkshop writings of the seven working groups outlining their topics. The final chapter is the major result of the workshop. It contains the fleshed out approaches to the engineering response to global climate change, including recommendations for future research, development and deployment as the best engineering judgment of the 68 engineers and scientists present. Expected date to the printer is June 1, 1992.

\title{
Recent and Paleo-Climatic Variations and the Greenhouse Gas-Climate Signal: Detecting Climate Change
}

\author{
(formerty: Recent Climatic Variations and the Greenhouse Gas-Climate Signal: Detecting Climate Change)
}

\author{
Robert G. Watts \\ Tulane University
}

Objective: To investigate the mechanisms by which changes in the rate of deep water production can affect the climate of the Earth, to understand the cause or causes of the Younger Dryas-Bolling oscillation, and to relate its causes to recent climatic variability.

Product: Having previously shown that a decrease in the rate of deep water production on the order of $10 \%$ could have produced a cooling of the surface water of the ocean large enough to completely offset the greenhouse warming signal, we are now investigating the transient response of a variety of energy balance models of various complexities in order to elucidate the physical natures of the various time constants within the earth-atmosphere-ocean system. A paper entitled "Time Scales in Energy Balance Climate Models" is in preparation.

Results to Date: Results of our one-dimensional study have been published in Climatic Change (Watts and Morantine, Climatic Change, Vol. 18, 1991). If a $10 \%$ decrease in the rate of deep water production 
beginning in 1940 is superposed on a model forced by increased atmospheric heating due to the greenhouse effect, the essential form of the global temperature data is reproduced. The essential form of the deep water response is also reproduced. Physically, when the basin scale upwelling decreases, heat from the upper ocean layer diffuses into the intermediate depths, cooling the upper layer and warming the ocean at intermediate depths. We estimate that if a decrease in basin scale upwelling large enough to warm the intermediate water by $0.1^{\circ} \mathrm{C}$ occurred in just $15 \%$ of the ocean, the loss of heat from the surface would be more than enough to completely offset greenhouse heating of the surface. We feel that this is a largely overlooked internal variability that is potentially more important than the natural variability of the solar constant or cloudiness.

The abyssal flow generated in the North Atlantic Ocean results in northern migration of surface waters required to feed the deep water production. The deep water supplied to the Pacific and Indian Oceans is formed in the southern hemisphere resulting in a southern migration of surface waters to compensate for this water budget. The upwelling rate in the Atlantic seems to be more vigorous than in the Pacific and Indian Oceans (McGraw-Hill Encyclopedia, p. 30). In addition to this fact, the surface temperatures in the North Atlantic are warmer than the North Pacific, which leads to enhanced evaporation reinforcing in the thermohaline circulation.

In view of the fact that the upwelling rate in the oceans influences the vertical temperature profile, and the upwelling rates in the Atlantic are more vigorous in the current state of operation, any mixing of water masses between the Atlantic and the rest of the world's oceans should influence the energy balance between these water masses. In order to illustrate this, a simple experiment was performed.

The Atlantic Ocean is represented by a one-dimensional energy balance model, and the rest of the world's oceans are represented by another. Each model is a transient upwelling diffusion energy balance model that is coupled to the other by assuming that there is an advective transport ( $20 \mathrm{~Sv}$, see Birchfield and Broecker, 1990) between the major water masses. The vertical temperature structures in the two masses are influenced by the different upwelling rates; thus, a sensible heat exchange occurs.

In the absence of this coupling, the surface temperatures would both approach a surface temperature that would represent the radiative equilibrium temperature of the system. When this phenomenon is incorporated into the model, the water mass possessing the highest rate of upwelling approaches a steadystate surface temperature that is warmer than the other water mass. This result would enhance evaporation, and hence, reinforce the more vigorous upwelling rate in the Atlantic. What would happen if the upwelling rate in the Pacific and Indian Oceans was to exceed that in the Atlantic for some reason?

In a previous paper (Morantine and Watts, J. Geophys. Res., Vol. 95, pp. 7563-7571, 1990), we investigated the transient response of a one-dimensional ocean-atmosphere energy balance climate model to both radiation and upwelling forcing. We pointed out in that paper that while the step response of the model is influenced mainly by the time constant associated with the ocean mixed layer, the response to the more realistic ramp forcing is influenced also by a time constant associated with the deep ocean. In our paper which is in preparation, we show that this time constant is strongly influenced by upwelling rate and is associated with the heat capacity of the thermocline. The time constant can be quite different for different latitudes. 


\title{
The Efrects of Global Warming on the Interfacial Properties and Structure of Soil
}

\author{
(formerty: The Effects of Climatic Change on the Interfacial Properties and Texture of Soil)
}

\author{
Kyriakos Papadopoulos
}

Tulane University

Scope of the Study: Investigation of the effects of climatic changes on soil morphology is important for predicting vegetation change patterns. The physical phenomenon which controls soil morphology is the one involved in the process of particle coagulation or aggregation when soil is wet. Therefore, in order to predict the effects of climatic changes on soil morphology, an insight into the process of soil particle aggregation is necessary. In general, a few of the important factors which affect particle aggregation in a system are temperature, salinity, and particle surface chemistry.

Global warming caused by the greenhouse effect influences the above factors affecting particle aggregation directly or subtly. Besides imparting the obvious temperature effect, global warming is expected to result in increased precipitation, which in turn may raise the salinity level of soil due to a rise of sea level. In addition, the augmented wetting of soil due to increased precipitation will trigger surface alteration in soil particles which will lead to an alteration of their surface properties.

The experimental section of this study examines effects of factors such as temperature, salinity, and radiation on the process of soil particle aggregation, through monitoring the particle size distributions and surface potential of clay particles in suspensions subjected to selected conditions. Observations made from the experiments are to be extrapolated to predict the effects of global warming on soil structure and texture.

Experiments Performed: Clay was chosen as the experimental material because most soil contains a high percentage of clay, and because clay particles provide a major portion of the surface area available in soil.

1. Two identical highly concentrated aqueous suspensions of Kaolinite clay were prepared in the laboratory. One suspension was aged at ambient temperature while the other was aged in an oven maintained at $50^{\circ} \mathrm{C}$. The particle size distributions of both the suspensions were monitored regularly over a period of time (in days). The measurements of particle size distributions were performed using the Coulter Counter Model TAII particle size analyzer.

The results showed that the kaolinite particles were very stable towards coagulation since there was no significant change in the particle size distribution over a period of time (Fig. 1). The slight initial change in size of the kaolinite particles indicated that there was diffusion of water into the particle pores causing the clay particles to swell. The same experiments indicated that for Kaolinite particles, temperature had little effect on particle aggregation since the particle size distributions were almost identical (Figs. 1 and 2) in the two suspensions maintained at two different temperatures. However, this should not be considered as the conclusive inference, since the time period over which the data were acquired may not be sufficient for temperatures to show any effect on particle aggregation.

2. Micrographs (Fig. 3) showing the clay particles were procured for two suspensions of Illite clay -one containing $\mathrm{NaCl}$ at a concentration of $0.1 \mathrm{M}$ and the other free of $\mathrm{NaCl}$. These micrographs showed the expected result, i.e., the clay particles formed compact aggregates when suspended in $\mathrm{NaCl}$ solution, and loose aggregates when suspended in distilled water. This observation essentially implies that salinity promotes particle aggregation in clay samples. Hence, an increment in soil salinity will favor the formation of compact aggregates over loose aggregates of soil particles. 
Theoretical Work: Mud is a concentrated suspension of soil. In the theoretical work done, a model system comprised of two eccentric spherical surfaces (Fig. 4) has been proposed to approximate the colloidal configuration in concentrated suspensions. It may be noted that models (e.g., Wigner-Seitz cell) similar to the one proposed in this study had been used in past studies on concentrated suspensions. The process of particle aggregation in concentrated suspensions is currently being studied using the proposed model system.

Work is in progress in which an expression for the stability ratio ' $W$ ' of concentrated suspensions will be developed. Since stability ratio is the ratio of the rates of fast and slow soagulation of particles, it provides a quantitative measure of the rate of coagulation or particle aggregation in a suspension. Also, the stability ratio being a function of parameters such as temperature, salinity, etc., indicates how the coagulation rate depends on these parameters. However, in order to obtain the stability ratio for a suspension, one needs to quantify first the interparticle forces which govern particle aggregation. The most important interparticle forces are the ones due to electrical double layer (EDL) and van der Waals (VDW) interaction. In the present study, the energies associated with these interactions have been quantified for the model system through numerical and analytical means. From these interaction energy calculations, one should be able to predict the trends in particle aggrepgation, and therefore should be able to derive information regarding the compactness and structure of the aggregates formed.

A paper entitled "The Electrical Double Layer Interaction Between Two Eccentric Spherical Surfaces" has just been accepted for publication in the Journal of Colloid and Interface Science. Two other papers based on this research are in the preparatory stage. 
Figure I

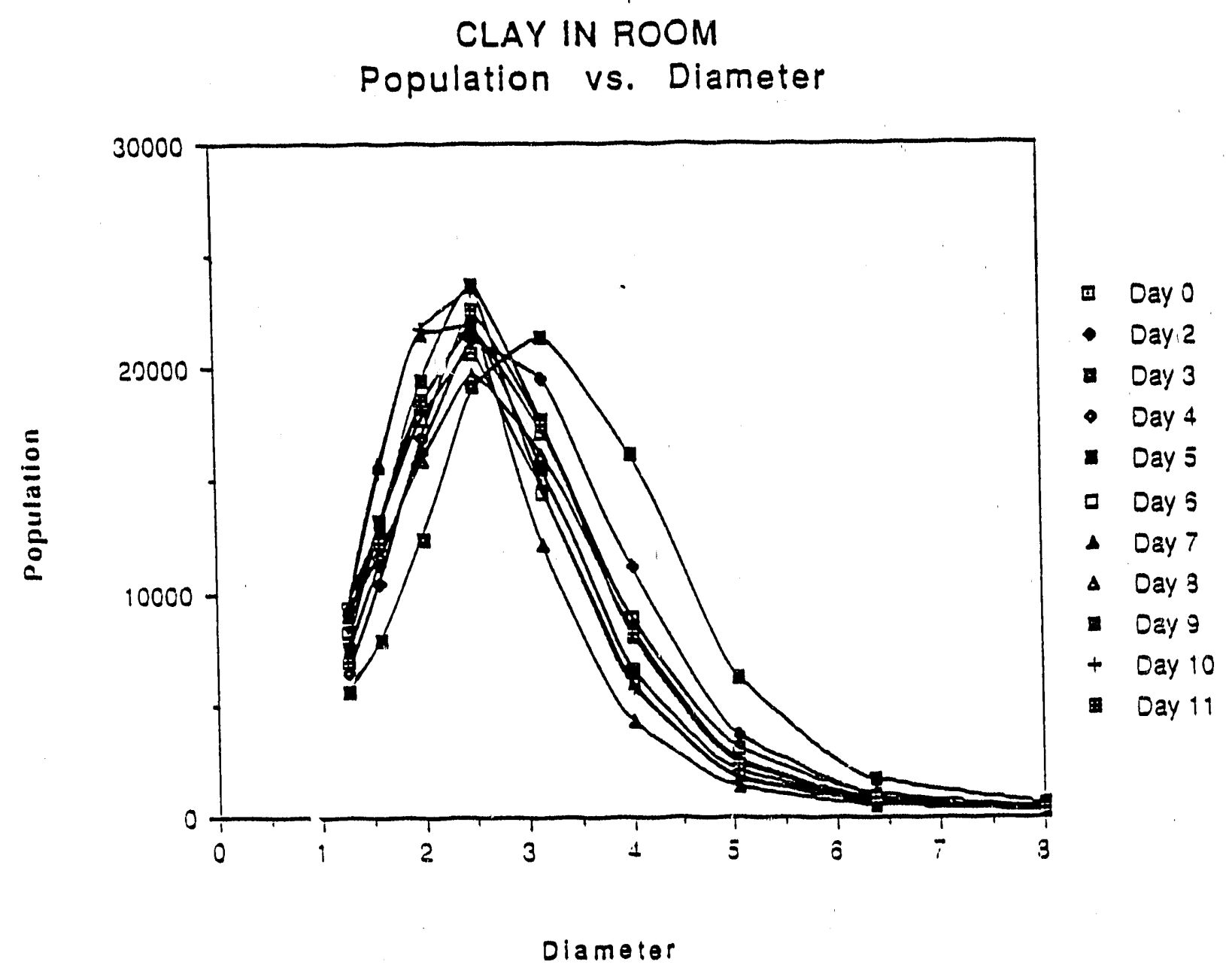

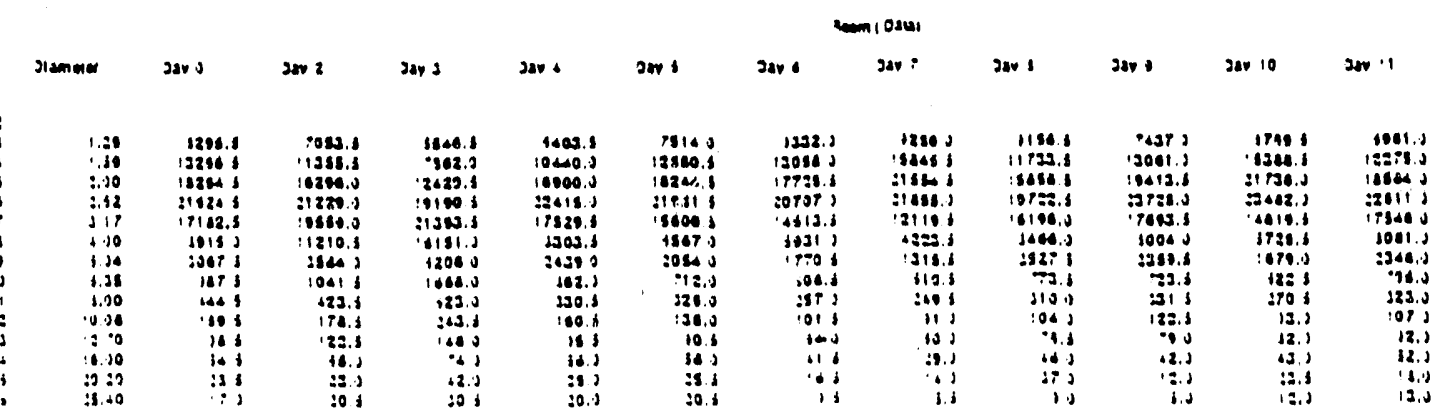


Figure II

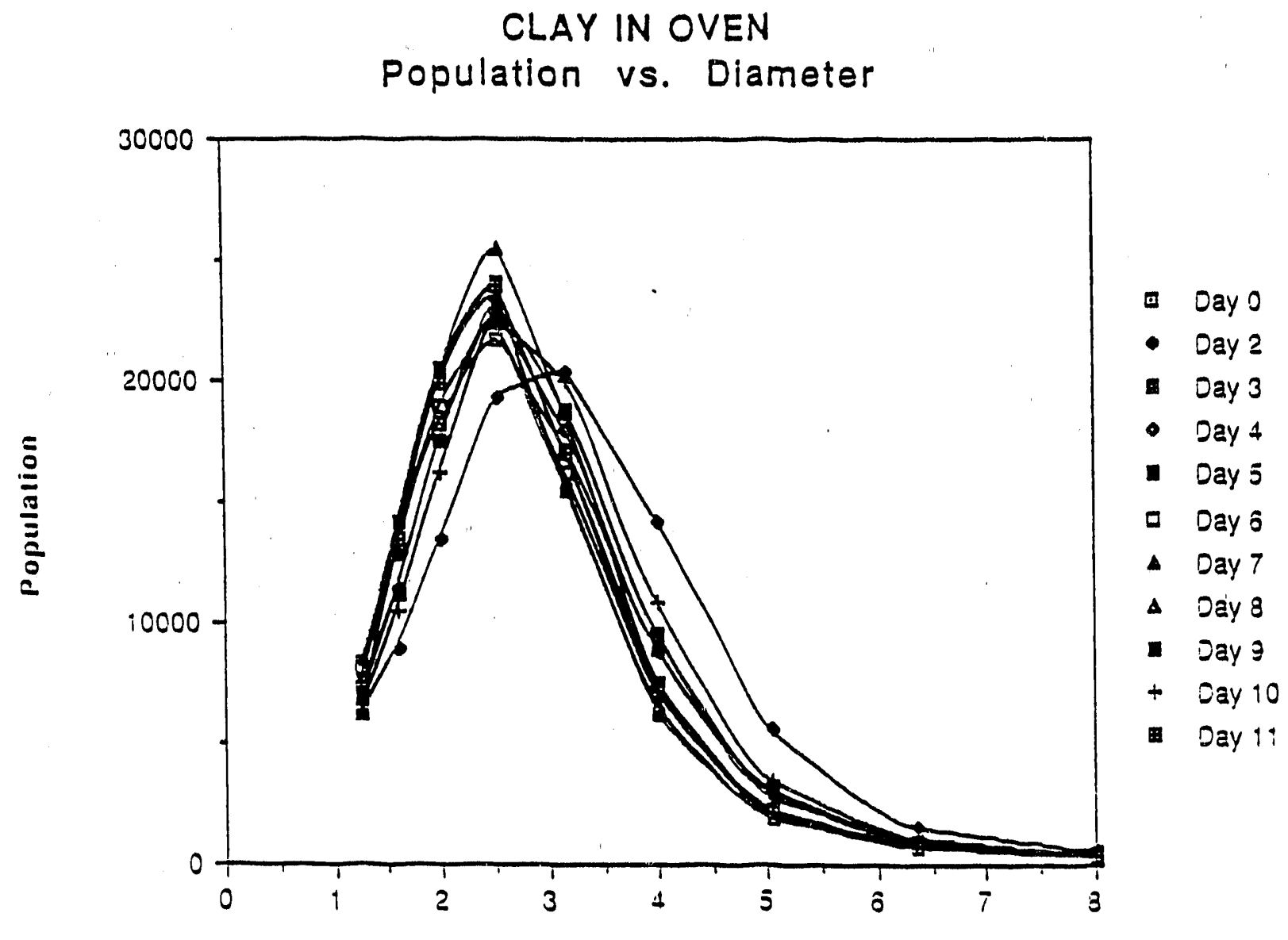

Diameier

\begin{tabular}{|c|c|c|c|c|c|c|c|c|c|c|c|}
\hline \multirow[b]{2}{*}{ Jismour } & \multirow[b]{2}{*}{$20 v .2$} & \multirow[b]{2}{*}{ Sov : } & \multicolumn{8}{|c|}{$\operatorname{sen} 10 \mathrm{mal}$} & \multirow[b]{2}{*}{ Id" } \\
\hline & & & sar $\mathrm{S}$ & Sav “ . & sav $\mathrm{i}$ & $2004+$ & Sav : & 2000 1 & sopt & 20010 & \\
\hline 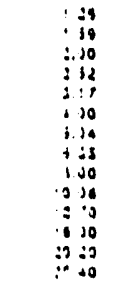 & 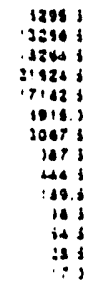 & 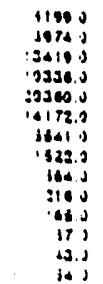 & 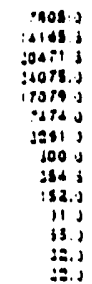 & 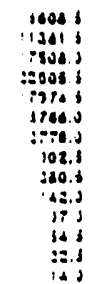 & 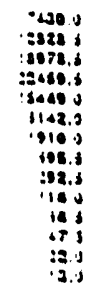 & 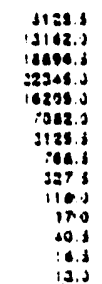 & 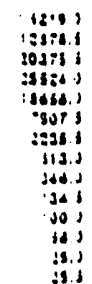 & 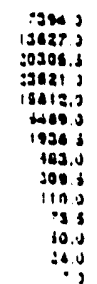 & 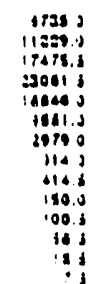 & 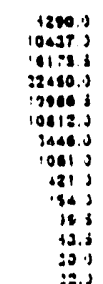 & 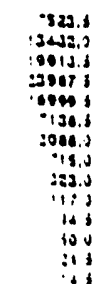 \\
\hline
\end{tabular}


Fig 3. Micrographs of Illite particles

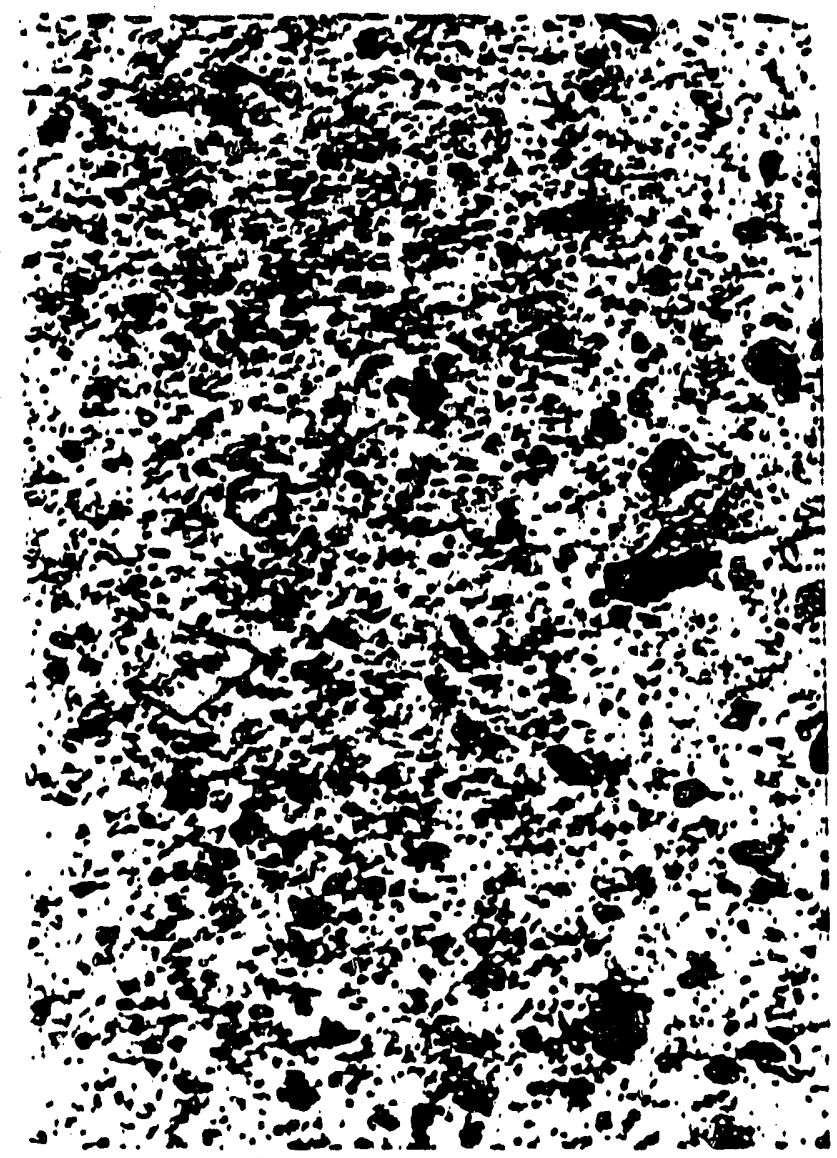

Ulite with $0.1 \mathrm{M} \mathrm{NaCl}$

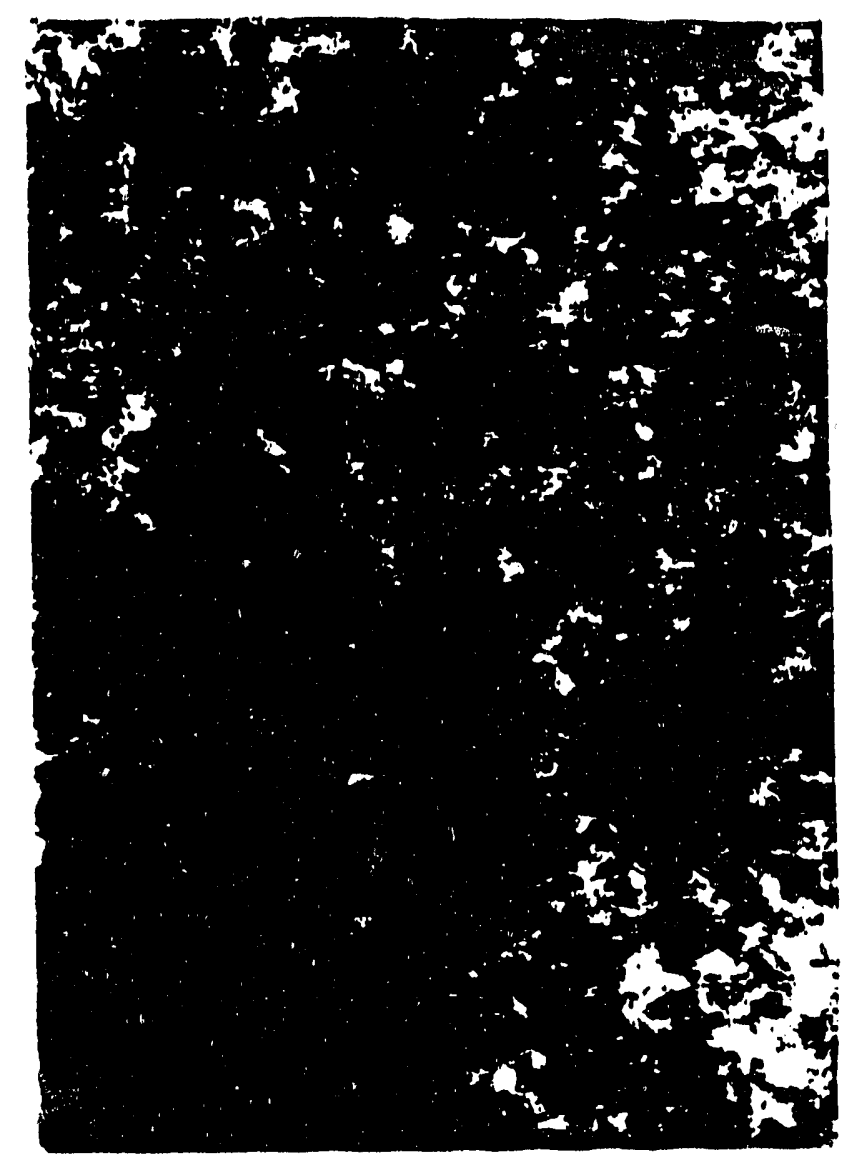

Ulite without $\mathrm{NaCl}$

F1g. 4 The Eccentric Sphere Model

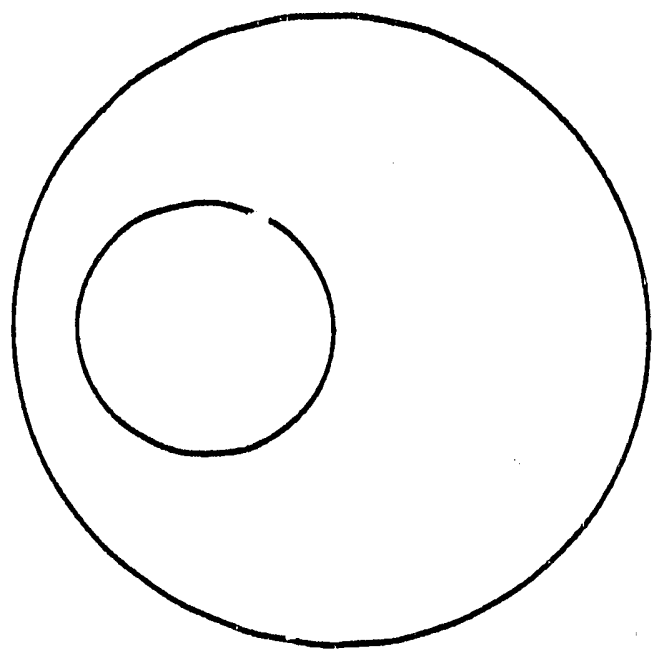




\title{
Formation and Emissions of Methane in Rice Soils: Experimental Determination and Modeling Analysis
}

\author{
V. J. Law, W. H. Patrick, C. W. Lindau, and K. C. O'Connor \\ Tulane University and Louisiana State University
}

\section{Experimental Objectives:}

1. Study the effects of soll redox-pH conditions on $\mathrm{CH}_{4}$ production. Laboratory studies wili be conducted to determine the effect of the intensity of anaerobiosis on the production of $\mathrm{CH}_{4}$ in floinded soils. In these studies the effects of $\mathrm{Eh}$ and $\mathrm{pH}$ on $\mathrm{CH}_{4}$ emissions in a rice soil from Louisiana (Crowley silt loam) will be determined by incubating the soil in controlled $\mathrm{Eh} / \mathrm{pH}$ micrecosnas. The systems are equipped so that a range of Eh values going from moderately reduced to highly reduced will be maintained for several weeks and the $\mathrm{CH}_{4}$ emissious measured. Of interest here will be the critical soil redox potential at which $\mathrm{CH}_{4}$ is produced in flooded rice soils.

Six $\mathrm{Eh} / \mathrm{pH}$ microcosms have been purchased and set up to measure $\mathrm{CH}_{4}$ production under contrulled Eh and $\mathrm{pH}$ conditions. Methane production from the Crowley silt loam soil (Typic Albaqualf) under controlled Eh levels of $-250,-200,-100$ and $0 \mathrm{mv}$ and $\mathrm{pH}$ levels of 5.5 and 7.0 is now being investigated in the laboratory.

The effect of organic matter on $\mathrm{CH}_{4}$ production is being condusted under laboratory conditions. Organic matter at rates of $0,0.1,0.5$, and $2 \%$ of the soil dry weight has, been added to the Crowley silt loam soil in sealed incubation bottles and flooded. Methane concentrations in the headspace gases were measured over a 33-day incubation period. Measured $\mathrm{CH}_{4}$ emissions showed a positive correlation with increasing concentration of added organic matter. After 33 days the $\mathrm{CH}_{4}$ headspace concentrations for the $0,0.1,0.6$ and $2.0 \%$ organic matter treatments were approximately $3,36,8,000$ and $20,000 \mu \mathrm{L} \mathrm{CH}_{4} \mathrm{~L}^{-1}$ air, respectively.

In addition, greenhouse experiments will be set up in the fall to measure soil entrapped $\mathrm{CH}_{4}$ and to investigate $\mathrm{CH}_{4}$ emissions as affected by fertilizer type, organic matter, and sulfate additions to a rice planted (Lemont variety) flooded soil.

2. Effect of soil properties on $\mathbf{C H}_{4}$ production. Twelve soils representing the major U.S. rice growing areas and two soils from major rice growing areas in India have been collected for this laboratory experiment. The rice soils from California (Yolo loam, Sacramento clay, Stockton clay), Texas (Beaumont clay), Arkansas (Desha silt loam, Herbert silt loam), Mississippi (Dundee silt clay loam, Dowling clay, Tunica clay), Louisiana (Crowley silt loam, Sharkey clay), Florida (Pahokee organic soil), and India (Cuttack- sandy loam, Colmbatore - Noyyal series), will be incubated under flooded conditions and $\mathrm{CH}_{4}$ production rates determined. Soils will be air-dried, passed through a 100-mesh sieve and texture, EC, pH, organic matter, CEC and total N determined on each soil. Duplicate 250 grams of air-dry soil mixed with $0.2 \%$ rice straw will be placed in glass incubation tubs and flooded. The submerged soils will be incubated in the dark at $30^{\circ} \mathrm{C}$ and at $0,5,10,20,30$, and 40 days after flooding, headspace gas samples will be collected and soil $\mathrm{CH}_{4}$ production rates calculated. Correlations will be run between $\mathrm{CH}_{4}$ production and the soil parameters listed above. Classification of the 14 rice soils is now underway and laboratory incubation experiments measuring the $\mathrm{CH}_{4}$ production rates of each soil are being set up at this time and should be completed in about 6-8 months.

3. Seasonal $\mathrm{CH}_{4}$ emissions from Louisiana flooded rice fields. Field experiments will be conducted at the Rice Research Station, Crowley, Louisiana. Methane evolution rom flooded rice plots will be measured with treatments of $\mathrm{N}$ source, $\mathrm{N}$ application rate, and $\mathrm{N}$ timings. Methane emissions as affected by rice cultures will also be investigated. Rice varieties, Lemont, Mars and Texmont, commonly grown in Louisiana and at the Rice Research Station, will be used in this field experiment. 
Modeling Objectives:

1. Model construction. Mathematical models will be constructed from the principles of transport phenomena and applied to various segments of the rice field system, namely wet soil, root system, plant stems, surrounding water, and air. Simplifying assumptions will be applied where applicable to reduce the complexity of the model. The models will consist of algebraic and differential equations that will be solved by suitable numerical methods.

2. Parameter identification and model verification. Based on both field and laboratory data, adjustable model parameters will be determined. This will be accomplished where possible through the use of nonlinear regression analysis and/or maximum likelihood estimation.

3. Exploration with the model. Once a verified and tuned model exists, it can be used to study a variety of scenarios that would be prohibitive to study by exhaustive experimentation.

4. Use the model to predict optimal scenarios for rice production. The finalized model(s) will be used to answer questions pertaining to minimization of methane emissions, optimal fertilizer application levels and types, and other controllable parameters.

Completed Field Research: A field experiment was conducted at the Rice Research Station to determine $\mathrm{CH}_{4}$ emission rates from a flooded rice field after application of three levels of urea- $\mathrm{N}$ fertilizer. Test plots were drill-seeded with the semidwarf, early long-grain Lemont rice cultivar on April 9, 1990 and permanent flood was established May 22, 1990. Twelve plexiglas chambers $(25 \mathrm{~cm} \times 25 \mathrm{~cm} \times 70 \mathrm{~cm})$ were placed $10 \mathrm{~cm}$ into the soil before permanent flood and contained 11 rice seedlings at the 4-5 leaf stage. Floordwater was maintained to a depth of $5-10 \mathrm{~cm}$ within the chambers over the first crop growing season.

Urea fertilizer granules were broadcast onto the dry soil surface two hours before permanent flood at 100,200 and $300 \mathrm{~kg} \mathrm{~N} \mathrm{ha}^{-1}$. Each treatment was replicated three times and the three remaining chambers were used as controls (no $N$ applied). At $0,7,14,21,28,31,35,38,42,45,49,52,56,63,66,70,77,80$ and 86 days after $\mathrm{N}$ application, chambers were sealed for 1-2 hours and $\mathrm{CH}_{4}$ evolution into the chamber headspace was determined.

Emissions of $\mathrm{CH}_{4}$ were highly variable over the first cropping season but a significant urea fertilizer effect was observed. Two peak $\mathrm{CH}_{4}$ emission periods were observed and occurred $11 \mathrm{~d}$ after panicle differentiation and during the grain ripening stag s. Maximum $\mathrm{CH}_{4}$ emissions from the $0,100,200$, and 300 urea- $\mathrm{N}$ treatments were 6.0, 8.9, 9.8 and $11.2 \mathrm{~kg} \mathrm{CH} \mathrm{ha}^{-1} \mathrm{~d}^{-1}$, respectively. These flux measurements correspond to approximately $210,300,310$, and $370 \mathrm{~kg} \mathrm{CH}_{4}$ evolved ha ${ }^{-1}$ over the 86-day sampling period for the four treatments.

The results from this field study showed that $\mathrm{CH}_{4}$ emissions increased as the application rate of urea-N was increased. The $\mathrm{CH}_{4}$ emission values reported probably reflect minimum total yearly $\mathrm{CH}_{4}$ fluxes because a second or ratoon crop is commonly grown in south Louisiana. The second crop was not sampled for $\mathrm{CH}_{4}$ fluxes in this study. In addition, the first crop rice straw remains in the field and may have a significant effect on $\mathrm{CH}_{4}$ emissions during the ratoon crop. These results will appear in Lindau, et al. (1991).

Current Field Research: Twenty-four plexiglas gas collection chambers have been set up at the Rice Research Station, Crowley, Louisiana, to measure $\mathrm{CH}_{4}$ emissions from the rice field during the 1991 growing seasons. Methane emissions as affected by $\mathrm{N}$ source (urea, $\left.\left(\mathrm{NH}_{4}\right)_{2} \mathrm{SO}_{4}\right), \mathrm{SO}_{4}$ additions and organic matter additions are being investigated. In addition, a urease (NBTP) and a nitrification inhibitor (DCD) have been added to six chambers to determine their effect on $\mathrm{CH}_{4}$ emissions. Gas samples are being collected twice a week over the first crop growing season (May 15 - August 15) and will also be collected during the ratoon crop (August 15 - October 15). 
In addition to $\mathrm{CH}_{4}$ flux measurements, pore "'ater equilibrators are being used in the flooded rice field to investigate $\mathrm{CH}_{4}$ production and movement in the flooded soil profile. The equilibrators are placed in the field plots (three plots with plants and three plots without rice plants) four times during the growing season to determine the distribution of dissolved $\mathrm{CH}_{4}$ as a function of depth and season.

Completed Modeling Research: Several components of candidate models have been constructed. The modeling software Stella II is being used during the exploratory phase and FORTRAN77 code is the production language for the models. The most complete portion involves the kinetics oi methane production. Here we use a Monod kinetic model as follows:

$$
\begin{aligned}
& \frac{d S}{d t}=-\frac{k S x}{K_{s}+S} s \\
& \frac{d s}{d t}=Y \frac{d S}{d t}-b x
\end{aligned}
$$

where:

$$
\begin{aligned}
& S=\text { substrate (acetate) concentration } \\
& \mathbf{X}=\text { mass of methanogenic bacteria } \\
& \mathbf{t}=\text { time } \\
& \mathbf{K}=\text { rate constant } \\
& \mathbf{Y}=\text { yieid coefficient } \\
& \mathbf{b}=\text { decay rate } \\
& \mathbf{K}_{\mathbf{8}}=\text { Monod rate constant }
\end{aligned}
$$

Typical values for the adjustable coefficients in this model are:

$$
K_{s}=10 \mathrm{mg} / \mathrm{L} \quad \mathrm{Y}=0.05 \quad \mathrm{~b}=0.01 / \text { day } \quad \mathrm{k}=2 / \text { day }
$$

Given data of methane production versus time, software has been written and tested to better define the four adjustable parameters of this model. This software involves combining a fourth order Runge-Kutta solution for the above differential equations with a nonlinear regression analysis code. While these parameters migt: be determinable from field data, we are attempting to define them for the Crowley silt loam from laboratory experiments. Replicate systems consisting of soil and water samples taken from the field have been set up. Measured amounts of acetic acid are added at regular intervals and methane production versus time data are collected. At this time, the systems are just beginning to produce significant amounts of methane so that optimal results are not yet avaiiable.

Current Modeling Research: Other subsystems where less complete models are under development include flow of gasses produced by methanogenesis through the soil, which will involve properties of the soil, and transport of methane through the plant itself, which will include parameters associated with the type of cultivar. Gas transport through the soil is being modeled both as one-dimensional flow of a compressible, ideal gas through a granular solid and as flow through porous media; at this point it is not obvious which set of equations is most appropriate and for highly different soils, different models might be necessary. Transport of gas though the plant is being modeled using the Stefan-Maxwell equations for one-dimensional multicomponent diffusion using an effective diffusivity, which is partly dependent upon the plant stem properties. We are also considering active transport mechanisms such as that induced by $\mathrm{CO}_{2}$ dissolution in the rice flocd water. It is anticipated that our first working models for the complete system will be available before the end of this summer. 
Results to Date: Laboratory studies bave been conducted to determine the effect of the intensity of anaerobinsis on the production of $\mathrm{CH}_{4}$ in flooded soils. In these studies the effects of $\mathrm{Eh}$ and $\mathrm{pH}$ on $\mathrm{CH}_{4}$ emissions in a rice soil from Louisiana (Crowley silt loam) were determined by incubating the soil in controlled $\mathrm{Eh} / \mathrm{pH}$ microcosms. Experiments are also being carried out to determine the contribution of the mijor sources of carbon $\left(\mathrm{CO}_{2}\right.$ or acetate) to the production of $\mathrm{CH}_{4}$ in flooded rice soils. Samples of soil are being preincubated at various Eh values and either ${ }^{14} \mathrm{C}$-labelled plant material or $\mathrm{CO}_{2}$ added to the soil. All of these experiments are still in progress and ure well within the anticipated schedule.

Field experiments at Louisiana, Arkansas, and Florida rice fields were conducted in the summer of 1991 and furtl er studies will be continued in the summer of 1992. In these experiments, the flux box method was used to determine $\mathrm{CH}_{4}$ emissions as a function of soil redox-pH conditions and other soil properties. Of particular interest are experimental sites to which ( $\left(\mathrm{JH}_{4}\right)_{2} \mathrm{SO}_{4}$ has been used as a fertilizer. These experiments were designed to measure the quantitative effect of the presence of sulfate ions on the production of methane. Samples for the summer 1991 study are now being analyzed and results will be forthcc oning within the near future.

Cultures of methanogenic bacteria have been, rroduced from soils taken from the field experimental sites. Experiments are nnderway to determine the decay rate of acetate as it is utilized by methanogens. These data will allow the determination of parameters in a Monod kinetic model. Of particular interest will be the variation of these parameters with temperature and soil type. Software has been perfected to utilize these experimental data to determine the kinetic model parameters.

Modeling efforts to simulate methane flux from rice fields have been very fruitful. Models now exist that consider carbon sources from organic matter originally in the soil and that provided by the rice plant. The models exhibit the seasonal variations in methane flux and can be "tuned" to more precisely simulate methane flux for specific rice fields. When combined with kinetic parameters provided by experiments as described above, these models can be used to simulate fields for which they have not been precisely tuned.

\section{References}

Lindau, C. W., P. K. Bollich, R. D. DeLaune, W. H. Patrick, and V. J. Law (1991). Effect of urea fertilizer on $\mathrm{CH}_{4}$ emissions from a Louisiana, USA rice field. Plant and Soil 136:195-203.

\section{Progress Reports Not Submitted:}

Impact of Global Environmental Change on Biodiversity of Mammals in the Southcentral United States, by Guy N. Cameron, University of Houston 


\section{Resea:ch Projects Starting July 1, 1991}

"Climate Sensitivity, Paleoclimates and Climate-Model Verification/Calibration: A Pilot Study" by M. I. Hoffert and M. M. Rampino (New York University)

"Production and Sea-Air Flux of Carbonyl Sulfide in the Coastal Environment" by G. A. Cutter (Old Dominion University)

"Trace Gas Exchange with the Atmosphere from the Gulf Coast Agricultural Wetlands" by R. L. Sass and F. M. Fisher (Rice University)

"Methane Emissions from Natural Wetlands" by J. Meyer and R. Burke (University of Georgia)

"Estimation of Climate Sensitivity" by Gerald R. North (Texas A\&M)

"Sampling the Marine Gas-Hydrate Reservoir: Assessing the Methane Inventory, Internal Dynamics, and Potential of Methane Discharges to the Atmosphere" by Charles K. Paull (University of North Carolina)

"Modeling Patterns of $\mathrm{CO}_{2}$ Flux from Forest Ecosystems: Implications of Climate Change" by T. M. Smith and H. H. Shugart (University of Virginia) 
Financial Status of Projects

Southcentral Regional Center FY 90 Projects

\begin{tabular}{|c|c|c|c|c|}
\hline Project Title/Principal Investigator(s) & $\begin{array}{l}\text { Budget } \\
\text { Award }\end{array}$ & $\begin{array}{l}\text { Expenses } \\
\text { @ 6/30/91 }\end{array}$ & $\begin{array}{l}\text { Projected } \\
\text { Expenses } \\
\text { @ } 6 / 30 / 92\end{array}$ & $\begin{array}{l}\text { Anticipated } \\
\text { Carryover }\end{array}$ \\
\hline $\begin{array}{l}\text { Impact of Global Environmental Change on Biodiversity of Mammals } \\
\text { in the Southcentral United States } \\
\text { Guy N. Cameron (University of Houston) }\end{array}$ & $\$ 77,551$ & $\$ 3,733$ & $\$ 77,551$ & \$- \\
\hline $\begin{array}{l}\text { Utilization of Sclerochronology to Establish Annual Isotopic and } \\
\text { Temperature Fluctuation Histories in Coastal Seawater } \\
\text { Ivan Gill }\end{array}$ & 121,219 & 85,806 & 121,219 & -0 \\
\hline $\begin{array}{l}\text { Photochemistry Relevant to Ozone Depletion and Global Warming } \\
\text { Brent Koplitz }\end{array}$ & 103,866 & 86,712 & 103,866 & -0 \\
\hline $\begin{array}{l}\text { Chemical Controls on the Sinks and Sources of Carbon Dioxide: The } \\
\text { Role of Iron } \\
\text { Lynn Koplitz (Loyola University) }\end{array}$ & 37,675 & 18,275 & 37,675 & -0 \\
\hline $\begin{array}{l}\text { Formation and Emission of Methane in Rice Soils: Expet nental } \\
\text { Determination and Modeling Analysis } \\
\text { Victor J. Law (Tulane University) }\end{array}$ & 108,173 & 99,552 & 108,173 & $-a$ \\
\hline William H. Patrick, Jr. (Louisiana State University) & 121,103 & 24,253 & 121,103 & -0 \\
\hline $\begin{array}{l}\text { Carbon Dioxide, Climate and the Deep Ocean Circulation: Carbon } \\
\text { Chemistry Model } \\
\text { Anil S. Menawat and Robert G. Watts }\end{array}$ & 202,091 & 128,541 & 202,091 & $-a$ \\
\hline $\begin{array}{l}\text { The Effects of Global Warming on the Interfacial Properties anc } \\
\text { Structure of Soil } \\
\text { Kyriakos Papadopoulos }\end{array}$ & 99,986 & 47,790 & 99,986 & -0 \\
\hline $\begin{array}{l}\text { Global Warming Effects on the Release of Light Hydrocarbons from } \\
\text { Gas Hydrate Deposits } \\
\text { Stephen G. Schwartz and Vijay T. John }\end{array}$ & 103,854 & 58,094 & 103,854 & $-a$ \\
\hline $\begin{array}{l}\text { Recent Climatic Variations and the Greenhouse Gas-Climate Signal: } \\
\text { Detecting Climate Change } \\
\text { Robert G. Watts }\end{array}$ & 66,171 & 19,519 & 66,171 & $-\infty$ \\
\hline $\begin{array}{l}\text { Workshop on the Engineering Response to Global Climate Change: } \\
\text { Planning a Research and Development Agenda } \\
\text { Robert G. Watts }\end{array}$ & 141,200 & 49,972 & 141,200 & $-a$ \\
\hline $\begin{array}{l}\text { Center Administration } \\
\text { Robert G. Watts }\end{array}$ & 100,000 & 67,423 & 100,000 & $-a$ \\
\hline Uncommitted Funds & 111 & 0 & 111 & \\
\hline TOTAL & $\$ 1,283,000$ & $\mathbf{S 6 8 9 , 6 7 0}$ & $\$ 1,283,000$ & so \\
\hline
\end{tabular}


Financial Status of Projects

Southcentral Regional Center

FY 91 Projects

\begin{tabular}{|c|c|c|c|}
\hline Project Title/Principal Investigator(s) & $\begin{array}{l}\text { Budget } \\
\text { Award }\end{array}$ & $\begin{array}{l}\text { Projected } \\
\text { Expenses } \\
\text { @ 6/30/92 }\end{array}$ & $\begin{array}{l}\text { Anticipated } \\
\text { Carryover }\end{array}$ \\
\hline $\begin{array}{l}\text { Recent and Paleo-Climatic Variations and the Greenhouse Gas-Climate Signal: } \\
\text { Detecting Climate Change', Robert G. Watts }\end{array}$ & $\$ 61,280$ & $\$ 13,080$ & S 48,200 \\
\hline $\begin{array}{l}\text { Photochemistry Relevant to Ozone Depletion and Global Warming } \\
\text { Brent Koplitz }\end{array}$ & 88,468 & 36,861 & 51,607 \\
\hline $\begin{array}{l}\text { Global Warming Effects on the Release of Light Hydrocarbons from Gas } \\
\text { Hydrate Deposits, Stephen G. Schwartz and Vijay T. John }\end{array}$ & 105,328 & 51,239 & 54,089 \\
\hline $\begin{array}{l}\text { Pormation and Emission of Methane in Rice Soils: Experimental Determination } \\
\text { and Modeling Analysis, Victor J. Law }\end{array}$ & 130,585 & 70,987 & 59,598 \\
\hline C.W. Lindau (Louisiana State University) & 141,285 & 51,632 & 89,653 \\
\hline $\begin{array}{l}\text { Fux of Methane from Natural Wetlands: Experimental Study and Modeling } \\
\text { Analysis, Sanjoy K. Bhattacharya and Victor J. Law }\end{array}$ & 197,573 & 22,573 & 175,000 \\
\hline $\begin{array}{l}\text { Second Workshop: Engineering Response to Global Climate Change } \\
\text { Robert G. Watts }\end{array}$ & 113,027 & 8,027 & 105,000 \\
\hline $\begin{array}{l}\text { Climate Sensitivity, Paleoclimates and CLimate-Model Verification/Calibration: A } \\
\text { Pilot Study } \\
\text { Martin I. Hoffert and Michael M. Rampino (New York University) }\end{array}$ & 138,959 & 52,345 & 86,614 \\
\hline $\begin{array}{l}\text { Production and Sea-Air Flux of Carbonyt Sulfide in the Coastal Environment } \\
\text { Gregory A. Cutter (Old Dominion University) }\end{array}$ & 57,102 & 33,908 & 23,194 \\
\hline $\begin{array}{l}\text { Trace Gas Exchange with the Atmosphere from the Gulf Coast Agricultural } \\
\text { Wetlands, Ronald L. Sass and Frank M. Fisher (Rice University) }\end{array}$ & 92,061 & 27,500 & 64,561 \\
\hline $\begin{array}{l}\text { Methane Emissions from Natural Wetlands } \\
\text { Judy Meyer (University of Georgia) with Roger Burke (Environmental } \\
\text { Protection Agency) }\end{array}$ & 56,621 & 24,118 & 32,503 \\
\hline $\begin{array}{l}\text { Estimation of Climate Sensitivity } \\
\text { Gerald R. North (Texas A\&M) }\end{array}$ & 62,172 & 22,427 & 39,745 \\
\hline $\begin{array}{l}\text { Sampling the Marine Gas-Hydrate Reservoir: Ascessing the Methane Inventory, } \\
\text { Internal Dynamics, and Potential of Methane Discharges to the Atmosphere } \\
\text { Charles K. Paull (University of North Carolina) }\end{array}$ & 99,295 & 38,145 & 61,150 \\
\hline $\begin{array}{l}\text { Modeling Patterns of } \mathrm{CO}_{2} \text { Flux from Forest Ecosystems: Implications of Climate } \\
\text { Change, Thomas M. Smith and H.H. Shugart (University of Virginia) }\end{array}$ & 87,368 & 36,403 & 50,965 \\
\hline $\begin{array}{l}\text { Impact of Giobal Environmental Change on Biodiversity of Mammals in the } \\
\text { Southcentral United States } \\
\text { Guy N. Cameron (University of Houston) }\end{array}$ & 93,433 & 17,650 & 75,783 \\
\hline $\begin{array}{l}\text { Director's Fund } \\
\text { Robert G. Watts }\end{array}$ & 100,000 & 18,965 & 81,035 \\
\hline $\begin{array}{l}\text { Center Administration } \\
\text { Robert G. Watts }\end{array}$ & 150,000 & 67,159 & 82,841 \\
\hline Subcontract Administration & 139,500 & 104,625 & 34,875 \\
\hline Uncommitted Funds & 3,133 & 0 & 3,133 \\
\hline TOTAL & $\$ 1,917,190$ & $\$ 697,644$ & $\$ 1,219,546$ \\
\hline
\end{tabular}

\footnotetext{
${ }^{1}$ This project is a collaboration between Hoffert and Rampino at New York University and Watts at Tulane.
} 


\title{
Southeast Regional Center Director's Report
}

\author{
Robert A. Griffin, Director
}

\section{Organization and Progress}

The Southeast Regional Center of the National Institute for Global Environmental Change (NIGEC) was initiated during this reporting period. The host institution is The University of Alabama, Tuscaloosa. The Southeast Regional Center is charged with the challenging mission of developing a program in the southeastern region which supports the DOE's tasks within the federal Global Change Research Program. As part of developing this program, a Management Plan has been developed which addresses the Center's philosophy and research thrusts, as well as the management and oversight aspects of the Center.

The seminal events and actions in the formation and early operations of the Southeast Regional Center during the reporting period are summarized below:

Sept. 11-12, 1991

Sept. 28-29, 1991

Sept. 30, 1991

Oct. 15, 1991

Nov. 5-6, 1991

Nov. 15, 1991

Dec. 6, 1991

Dec. 16, 1991

Jan. 8-10, 1992

Jan. 15, 1992
Site visit to Tuscaloosa by Dr. J. Knox, NIGEC Director, and Dr. J. Elwood, DOE Project Officer, to review the program and its development.

Participation by Professors Griffin and Brett in the Regional Center Directors meeting held near Bloomington, Indiana. The new management structure of NIGEC was agreed upon, the request for proposal and review process was finalized, the regional thrusts were defined, and there was agreement on the geographic redistribution of the states and territories to be included within each region.

The Management Plan for the Southeast Regional Center was submitted to NIGEC and DOE for review and approval.

Over 500 Requests for Proposals (RFP) to participate in the research program administered by the Southeast Regional Center were disiributed.

Professors Griffin, Brett, and Greening visit Oak Ridge National Laboratory to tour facilities, review projects, and coordinate DOE supported research in the southeast region.

Letters of Intent to submit proposals received by Southeast Regional Center. Development of a slate of reviewers was begun.

Fifty-nine proposals received for potential funding by the Southeast Regional Center.

Peer review panel and proposal delivery to reviewers completed.

Southeast Regional Center peer review panel meets in Tuscaloosa to evaluate proposals.

Submit Southeast Regional Center research package to NIGEC for review. 


\section{Status of the Research Programs}

The Request for Proposals was considered quite successful with a total of 59 submitted to the Southeast Regional Center. An excellent distribution was obtained with proposals being received from 20 universities in nine states. All categories were represented with approximately 50 scientific investigations, eight policy studies, and one educational program being proposed.

Proposals were received December 6, 1991 and were reviewed by members of the Southeast Regional Center peer review panel for potential inclusion in the research package to be forwarded to NIGEC on January 15, 1992 for further review and potential funding. The Region's peer review panel consisted of 16 scientists and engineers. The peer review panel met in Tuscaloosa, Alabama on January 8-10, 1992 to evaluate the proposals.

\section{Calendar of Events for January 1 to June 30, 1992}

March 23-24, 1992

Regional Centers Scientific Advisory Committee meets to review program package.

April 1, 1992 Full NIGEC package prepared.

April 15, 1992

Submission of total science package and budgets to DOE for preparation of funding agreement.

May 15, 1992

Regional Center to announce awards to faculty.

June 30, 1992 Annual Report of research projects due to NIGEC.

July 1, 1992 Start date for research. 


\title{
Western Regional Center Director's Report
}

\author{
F. Sherwood Rowland and Marvin Goldman, Co-Directors
}

The primary goal of the Western Regional Center (WESTGEC) is to promote high-quality, innovative, interdisciplinary research related to global climatic change. The research projects will focus on the following themes:

1. Agricultural, hydrological, and ecological effects of global climate change.

2. Atmospheric and oceanographic modeling of global climate change.

3. Climate forcing by trace gases.

4. Assessment of the impacts of global environmental change, and policy/educational aspects of the human response to such change.

Within these themes, the suggested funding guidelines provided by the DOE are: $70-75 \%$ in physical and biological science, $20-25 \%$ policy-related programs, and 5\% educational projects.

Research proposals may include public education, workshop series for development of research agendas, global change seminar series, study groups, and innovative or exploratory research programs. Emphasis is placed on the participation of skilled. young scientists, especially to include graduate students and post-doctoral candidates moving into investigations of global environmental change.

A major theme of WESTGEC is the understanding of the role of the changing concentrations of trace gases in the global atmosphere. These changes in trace gases, and in the particulates which result from their further chemical modification, play vital roles in many of the most pressing global problems: stratospheric ozone depletion, greenhouse effect, arid rain, climate change. While the evidence for increasing concentrations in the atmosphere of $\mathrm{CO}_{2}, \mathrm{CH}_{4}, \mathrm{~N}_{2} \mathrm{O}$, and CFCs is compelling, knowledge of their sources and sinks is less certain, and such knowledge is prerequisite to any efforts to alter their emission rates.

The agricultural land component of the regional themes is concerned with the effects of climate and $\mathrm{CO}_{2}$ change on the productivity of crops, forests, and other natural vegetation. The feedback between these vegetation and soil surfaces and the atmospheric chemistry and climate are also considered.

In the area of policy and assessments, emphasis is on the development of tools to aid in understanding parametric uncertainties and modeling assumptions that are necessary in evaluation and prioritization.

\section{Plans for the Future}

The Western Regional Center plans to host a series of topical workshops, involving our principal investigators and our regional scientific technical committee. The purpose will be to both improve interaction and communication amongst our awardees and to develop a focused approach to the specific themes we wish to emphasize in our research over the near term. An additional goal will be to identify topics and projects worthy of future support and to explore options for funding, interaction, and synergy. Implicit in this goal is a much expanded interdisciplinary interaction, especially between the natural and social science intersection of the themes. 
The Western Region held its first annual NIGEC Conference in Huntington Beach, California, on January 5-10, 1992, on the topic "Atmospheric Methane". The papers and discussions included the following topics:

- Methane emissions accompanying rice agriculture

- Atmospheric measurements of methane, carbon dioxide, carbon monoxide, nitrous oxide, molecular oxygen, methyl chloroform, and other gases as they relate to atmospheric methane

- Many aspects of environmental problems related to methane

- Isotopic composition of atmospheric methane and its variations

- Laboratory measurements of kinetic rate constants important for methane in the atmosphere

- The role of land-based biology as source and sink for methane and other gases for the atmosphere

- Measurements of methane concentrations in air samples from ice cores

- The contributions of trace gases to the greenhouse effect (i.e., methane)

- Two- or three-dimensional models of the atmosphere as related to methane

- Methane oxidation in soils and waters 


\title{
Modeling Analyses of Methane Emissions from Ruminants
}

\author{
R. L. Baldwin \\ University of California, Davis
}

\section{Objectives}

1. Modify an existing dynamic simulation model of ruminant digestion and metabolism which has the capability of estimating methane emissions from ruminants based upon definition of species, age, body weight, and estimates of feed composition and intame.

2. Challenge/evaluate/verify model predictions against data on methane emissions for a wide range of feedstuffs and feeu' intakes. Introduce changes/corrections as required.

3. Refine current estimates of the contribution of ruminants to methane emissions for California, the United States and world-wide.

4. Structure model to interface with economic elements for cost-benefit analyses of possible interventions directed to reduction of methane emissions by ruminants.

\section{Progress}

Objectives 1 and 2: The model has been modified and applicability to dairy and beef cattle, lactating water buffalo, and sheep verified in terms of accurate predictions of methane emissions, digestible and metabolizable energy, and animal performance. Goodness of fits of predicted data to observations as indicated by $\mathrm{r}^{2}$ are 0.99 for digestible and metabolizable energy and 0.97 for methane emissions.

Objective 2: Several errors particular to diet types were identified and addressed in a February progress report. These included separation of $\beta$-hexose into separate hemicellulose and cellulose pools, examination of explicit fermentation stoichiometry, and reductions in protein degradation and digestion. After these corrections were made in the model, prediction of nutrient passage from the reticulo-rumen was found to be inadequate. Small particle and liquid passage, which had been constant rates previously, were determined to be variable functions of feed intake. Equations for small particle and liquid passage were developed by regression on data from Robinson et al. (Can. J. An. Sci., 1982). At the same time, the model was expanded to enable simulation of animals of various body sizes and physiological conditions, not only lactating dairy cattle. Validation of the model in these situations against detailed experimental data has been completed, and is currently being detailed in two papers, one directed at a lay audience and one for peer-reviewed publication.

Objective 3: Accurate estimates of metabolizable energy are essential to improving upon current estimates of methane emissions from ruminants. Current estimates are based on crude estimates of feed quality and intake. Our model generates accurate predictions of both feed quality and animal performance. This enables us to cross check between estimates of feed intake and animal productivity data. This adds another level of verification which will be embedded in our estimates of methane emissions from ruminant livestock and augment the credibility considerably. We have undertaken analyses of methane emissions from U.S. ruminants on a regional basis.

Objective 4: We have undertaken analyses of effects of bovine somatotropin and increasing genetic potential on methane emissions in dairy cattle as a case study of cost-benefit analyses. With an approximate $29 \%$ sreater milk production in high genetic potential as compared to average cows, methane per unit of milk was reduced $14 \%$. Somatotropin treatment, which results in a $15-25 \%$ increase in milk production, also derreased methane per unit of milk $14 \%$ on average. 
At this time, we are analyzing the cost-benefit relationslips of several other methane reduction opportunities including: defaunation of the rumen, herd composition changes, pasture management, dietary manipulations such as fat feeding, use of ionophores, and urea supplementation of poor quality forages. The next area of research will be developing estimates of methane emissions from ruminant livestock in India.

\section{References}

Baldwin, R.L., J.H.M. Thornley and D.E. Beever (1987) Metabolism of the lactating cow II. Digestive elements of a mechanistic model. Journal Dairy Research 54:107-131.

J. R. Knapp and R. L. Baldwin (199?) Regional Estimates of Methane Emissions U.S. Dairy and Beef Cattle (University of California, Davis (report)

Overview: Utilizing a computer simulation model of bovine metabolism, estimates of methane emissions from dairy and beef cattle in the United States were made. The estimates for dairy cattle are given in Tables 1 and 2 on a regional basis with groups of animals separated on the basis of age and physiological status. Estimates for beef cattle are given in Tables 3 and 4 on a similar basis. Estimates for all cattle in the United States are in Table 5. Sources of information are given in table footnotes. Regions represent agroclimates, areas of similar crop production, and animal management practices. Discussion of animal management and the expertise incorporated into the simulations is given in the following sections. Seasonal effects on feed/forage availability and animal management were included in the simulations.

\section{Dairy Cattle}

Bull (male) calves born to dairy cows are sold as veal calves at a young age or are raised for beef purposes. Therefore, they are not included in the dairy cattle estimates. Heifer (female) calves are raised to weaning age on milk replacement diets. At approximately four months of age, they are weaned onto forage containing diets. Until this time, their stomach functions are similar to those of non-ruminant animals. There is little microbial fermentation and methane production in calves on milk replacer diets.

After weaning, calves are normally fed a forage-based diet and supplemented with concentrates to reach a body weight of approximately $300 \mathrm{~kg}$ at one year of age. At fourteen to fifteen months, it is desirable for the heifer to weigh approximately $325 \mathrm{~kg}$ and be reproductively mature, i.e., able to be bred and become pregnant. Under good management, the heifer should be bred at this age so as to calve and enter dier first lactation at 24 months.

Pregnant heifers are fed diets similar to non-lactating cattle. These diets are mostly forage with little cuncentrate supplementation. The objective is to allow the heifer to continue growing to a body weight of $459,500 \mathrm{~kg}$ at calving, yet not have an animal that is overly fat. Over-conditioning or over-fattening has been "hown to decrease milk production over the entire lifetime of the cow.

Once a heifer calves, she enters the milking herd. Milking cows are fed diets ranging from $60 \%$ concentrate: $40 \%$ forage to $40 \%$ concentrate: $60 \%$ forage. A typical lactation averages 305 days, at which time the cow is "dried off". Dry cows are fed mostly forage diets as discussed above. Under ideal management, a cow is rebred within 100 days of calving so she will calve again in 12 months. In reality, the average calving interval in the U.S. is about 13 months. For the purposes of this report, it was assumed that cows lactated 305 days and were non-lactating for 60 days. It is likely that with a 13 month calving interval, both the lactation and the dry period are extended equally.

The animals depicted in Table 1 are milk cows, both lactating and non-lactating. Reported (observed) and predicted milk production are given on a $\mathrm{kg}$ milk/cow basis. Methane is given on a per animal basis (cow) and on a per $\mathrm{kg}$ milk basis for milking cows. Table 2 shows replacement heifers in two 
groups, 0-12 months of age and 12-24 months of age. Not included in Table 1 or 2 are bull calves for reasons discussed above, and mature breeding bulls, which are a very small percent of total dairy animal numbers.

\section{Beef Cattle}

In the N. Atlantic, S. Atlantic, N. Central and much of the S. Central regions, beef cattle are usually kept in small herds on small pastures (less than 100 animals on less than 100 acres) in a "less extensive" management situation. In some of the S. Atlantic (Oklahoma, Texas) and Western states, larger herds of cattle graze and range over a more extensive area. During the winter in the N. Atlantic and N. Central regions, beef cattle may be housed indoors. Indoors or outdoors, they will be fed low quality forages (grass hays, corn silage). Animals in the S. Atlantic, S. Central and West will be supplemented with hay during the winter to augment poor grazing. Numbers of beef cows and replacement heifers with predicted methane emissions are given in Table 3.

Calving in beef cattle generally occurs in the spring, although there are regional exceptions. The reason for spring calving is that the nutritional quality of available grazing is the highest at that time and this allows the beef cows to lactate to their best potential to nourish the calves and have the calves reach optimal weaning weights.

At weaning time (five to seven months of age), heifer calves being retained to replace cows will stay with the breeding cow herd. These heifers will be consuming the same diets as the mature cows. In the less extensive situations, the heifers may be supplemented with some concentrates similar to what dairy heifers would receive. These heifer calves should reach $200 \mathrm{~kg}$ and $325 \mathrm{~kg}$ body weight at 12 and 24 months of age, respectively. They should reach reproductive maturity and be bred at about 15 months, so as to calve at 24 months of age. As mature animals, they will weigh approximately $400 \mathrm{~kg}$. These weights are typical of medium-frame cattle, that is animals of Angus-Hereford breeding.

Also at weaning time, animals destined for market can follow two scenarios. These scenarios are depicted in Fig. 1. The first scenario begins with weanling animals entering a feedlot. During the first stage in the feedlot, the animals will be fed a diet of $80 \%$ forage: $20 \%$ concentrate until they reach weights of 270 $\mathrm{kg}$. At that time, the diet will be switched to a second stage of $50 \%$ forage:50\% concentrate mix until weights of $350 \mathrm{~kg}$ are reached. Then the arimals will be fed a "finishing ration" of 10\% forage:90\% concentrate until market weights of $500 \mathrm{~kg}$ are attained.

Alternatively (Fig. 1), the weanlings can be held on pasture or range with the breeding cow herd until they are yearlings and weigh approximately $270 \mathrm{~kg}$. Then they enter the feedlot at the "second stage" above, where they are fed a $50 \%$ forage: $50 \%$ concentrate diet. From this point on, they are handled the same as the animals which entered the feedlot as weanlings. When they weigh $350 \mathrm{~kg}$, they are switched to the finishing ration and marketed at $500 \mathrm{~kg}$.

Currently, $20 \%$ of market calves enter the feedlot directly at weaning while $80 \%$ are held until they are yearlings. The basis for the decision is financial. Capital is tied up for a shorter period of time when calves enter the feedlot when they are weanlings as compared to entering as yearlings. In Fig. 1, it can be seen that the days to market is increased by 90 days by holding the market calves on range. If the calves were actually held on the range for more time, the days to market would be greater. Generally, when interest rates are high, more calves are moved into the feedlot as weanlings. 
Age upon entering feedlot:

WEANLING

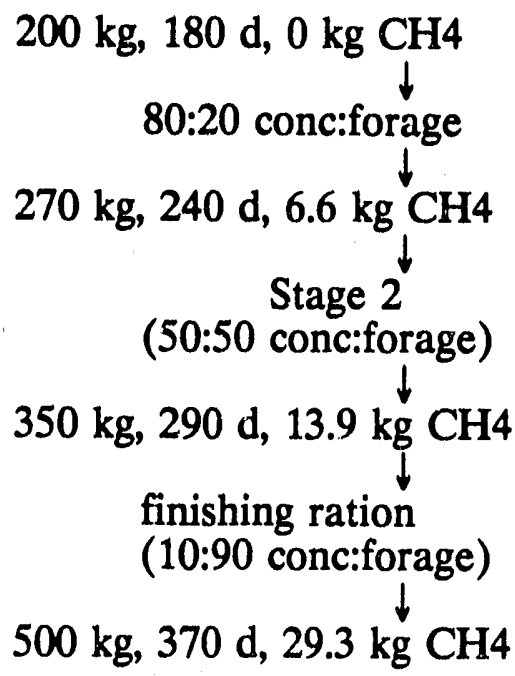

YEARLING

$200 \mathrm{~kg}, 180 \mathrm{~d}, 0 \mathrm{~kg} \mathrm{CH} 4$
range/pasture

$270 \mathrm{~kg}, 335 \mathrm{~d}, 23.8 \mathrm{~kg} \mathrm{CH} 4$

(50:50 conc:forage)

$350 \mathrm{~kg}, 385 \mathrm{~d}, 33.0 \mathrm{~kg} \mathrm{CH} 4$
finishing ration
(10:90 conc:forage)
$500 \mathrm{~kg}, 460 \mathrm{~d}, 51.9 \mathrm{~kg} \mathrm{CH} 4$

Fig. 1. Simulation of feedlot scenarios with body weight ( $\mathrm{kg})$, age (d), and cumulative methane emissions (kg CH4).

Total numbers of feedlot cattle and predicted methane emissions are given in Table 4. Most feedlots (97\%) are in the N. Central region, with the remainder in the S. Central and West and none in the N. or S. Atlantic regions (Schoeff and Castaido, 1990). This is reflected in the animal numbers in Table 4. Also, four major packing companies slaughter and process $80 \%$ of the feedlot cattle. Given that feedlots are located near packing plants, little change in location of feedlots is anticipated (Schoeff aud Castaldo, 1990).

Results to Date: Table 5 shows methane production on a regional basis for both dairy and beef of cattle. Regional variance in estimates of methane emissions reflect differences in animal numbers within the regions. In dairy cattle, highest estimates are for the $\mathrm{N}$. Central and West regions where large populations of dairy cattle are kept. In beef cattle, the same is true for the $\mathrm{N}$. and S. Central regions.

Annual total methane and milk production for dairy cattle are $1.134 \mathrm{Tg}$ and $67.63 \mathrm{Tg}$, respectively. Including methane produced by replacement heifers and dry cows gives a $\mathrm{kg}$ methane/kg milk value of 0.017 . Calculating methane per unit of product on a regional basis is not valid as animals are transported between regions. Total annual methane for beef cattle including breeding cows and replacement heifers is $3.654 \mathrm{Tg}_{\mathrm{g}}$.

The total for ali cattle in the United States is $4.789 \mathrm{Tg} / \mathrm{yr}$. This value is lower than the $6.8 \mathrm{Tg} / \mathrm{yr}$ reported by Lerner et al. (1988), which did not account for differing methane emission by animals of different ages and physiological states. Also, cattle populations, primarily dairy, have decreased since the mid 1980 's. The current prediction of $4.8 \mathrm{Tg} / \mathrm{yr}$ is also less than that estimated by Reuss et al. (1990), probably due to over-estimation of feed intake and methane $/ \mathrm{kg}$ feed in that study.

Overall confidence in predictions of methane emissions given in this report is high. Various factors that can affect methane emissions, e.g., seasonal and regional variation in forage quality and availability, regional differences in management systems, age and physiological status of the animals, etc., have been taken into consideration. Model predictions compart well with expected levels of animal production, demonstrating that animals are being accurately represented. 
Table 1. U.S. dairy cattle. Numbers (millions), milk production $(\mathrm{kg} / \mathrm{yr})$, and methane production (ch4) ${ }^{1}$ for mature cattle (lactating and non-lactating) across five regions ${ }^{2,3}$.

\begin{tabular}{|c|c|c|c|c|c|c|}
\hline REGION & $\begin{array}{l}\text { MILK C } \\
\text { number }\end{array}$ & $\begin{array}{l}\text { DWS } \\
\text { obs. } \\
\text { milk }\end{array}$ & $\begin{array}{l}\text { pred. } \\
\text { milk }\end{array}$ & $\frac{\text { ch4 } 4}{\text { cow }}$ & $\frac{\mathrm{ch} 4}{\mathrm{~kg} \text { milk }}$ & ch4 \\
\hline N. Atlantic & 1.795 & 6707 & 6717 & 82 & 0.012 & 0.147 \\
\hline S. Atlantic & 0.71 & 6103 & 6082 & 76 & 0.012 & 0.054 \\
\hline N. Central & 4.497 & 6814 & 6830 & 80 & 0.012 & 0.360 \\
\hline S. Central & 1.156 & 5560 & 5441 & 73 & 0.013 & 0.084 \\
\hline West & 1.972 & 7239 & 7226 & 73 & 0.01 & 0.144 \\
\hline
\end{tabular}

TOTAL

0.789

${ }^{1}$ Units for methane are: 1 )ch $4 / \mathrm{cow}$ is $\left.\mathrm{kg} / \mathrm{cow} / \mathrm{yr}, 2\right) \mathrm{ch} 4 / \mathrm{kg}$ milk is $\mathrm{kg} / \mathrm{kg}$, and 3)ch4 is $\mathrm{Tg} / \mathrm{yr}(1 \mathrm{e}+9 \mathrm{~kg} / \mathrm{yr})$.

${ }^{2}$ North Atlantic staces: Maine, New Hampshire, Vermont, Massachusetts, Rhode Island, Connecticut, New York, New Jersey, Pennsylvania. North Central states: Ohio, Indiana, Illinois, Michigan, Wisconsin, Minnesota, Iowa, Missouri, North Dakota, South Dakota, Nebraska, Kansas. South Atlantic states: Delaware, Maryland, Virginia, West Virginia, North Carolina, South Carolina, Georgia, Florida. South Central states: Kentucky, Tennessee, Alabama, Mississippi, Arkansas, Louisiana, Oklahoma, Texas. West states: Montana, Idaho, Wyoming, Colorado, New Mexico, Arizona, Utah, Nevada, Washington, Oregon, California, Alaska, Hawaii.

${ }^{3}$ Sources of animal numbers and milk production data are: 1) R.W. Schoeff and D.J. Castaldo. 1990. Market data 1990: A comprehensive report on livestock and poultry inventories and feed usage potentials. Feed Management 41:10. 2) California Dairy Industry Statistics. 1990. California Department of Food and Agriculture. 3)Feedstuffs 1990 Reference Issue 62:12. 
Table 2. U.S. dairy cattle. Numbers (millions) and methane production (ch4) ${ }^{1}$ for dairy replacement heifers across five regions ${ }^{2,3}$.

\begin{tabular}{|c|c|c|c|c|c|c|}
\hline \multirow[b]{2}{*}{ REGION } & \multirow{2}{*}{$\begin{array}{l}0-12 \mathrm{mos} \\
\text { number }\end{array}$} & \multirow{2}{*}{ ch4 } & \multicolumn{3}{|c|}{ REPLACEMENT HEIFERS } & \multirow{2}{*}{$\begin{array}{c}12-24 \text { mos } \\
\text { ch } 4\end{array}$} \\
\hline & & & $\operatorname{ch} 4$ & number & $\frac{\text { ch4 }}{\text { heifer }}$ & \\
\hline N. Atlantic & 0.712 & 19 & 0.014 & 0.712 & 63 & 0.045 \\
\hline S. Atlantic & 0.268 & 19 & 0.005 & 0.268 & 55 & 0.015 \\
\hline N. Central & 1.987 & 19 & 0.038 & 1.987 & 63 & 0.125 \\
\hline S. Central & 0.405 & 19 & 0.008 & 0.405 & 55 & 0.022 \\
\hline West & 0.833 & 19 & 0.016 & 0.833 & 70 & 0.058 \\
\hline TOT & & & 0.080 & & & 0.265 \\
\hline
\end{tabular}

${ }^{1}$ Units for methane are: 1)ch4/heifer is $\mathrm{kg} /$ heifer/yr, and 2)ch4 is $\mathrm{Tg} / \mathrm{yr}(1 \mathrm{e}+9 \mathrm{~kg} / \mathrm{yr})$.

${ }^{2}$ North Atlantic states: Maine, New Hampshire, Vermont, Massachusetts, Rhode Island, Connecticut, New York, New Jersey, Pennsylvania. North Central states: Ohio, Indiana, Illinois, Michigan, Wisconsin, Minnesota, Iowa, Missouri, North Dakota, South Dakota, Nebraska, Kansas. South Atlantic states: Delaware, Maryland, Virginia, West Virginia, North Carolina, South Carolina, Georgia, Florida. South Central states: Kentucky, Tennessee, Alabama, Mississippi, Arkansas, Louisiana, Oklahoma, Texas. West states: Montana, Idaho, Wyoming, Colorado, New Mexico, Arizona, Utah, Nevada, Washington, Oregon, California, Alaska, Hawaii.

${ }^{3}$ Sources of animal numbers and milk production data are: 1) R.W. Schoeff and D.J. Castaldo. 1990. Market data 1990: A comprehensive report on livestock and poultry inventories and feed usage potentials. Feed Management 41:10. 2) California Dairy Industry Statistics. 1990. California Department of Food and Agriculture. 3)Feedstuffs 1990 Reference Issue 62:12. 


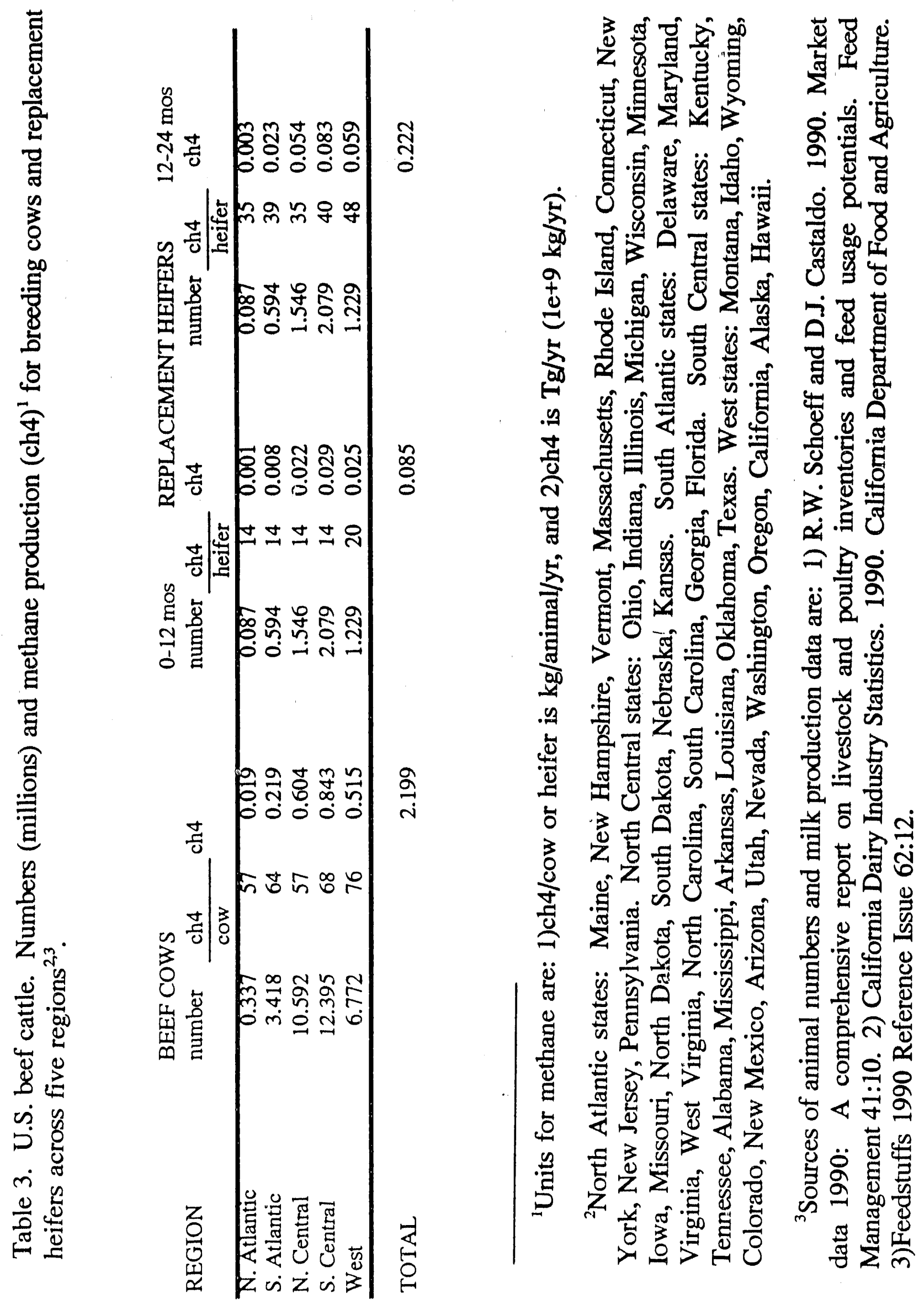


Table 4. U.S. beef cattle. Numbers (millions) and methane production (ch4) ${ }^{1}$ for feedlot cattle across three regions ${ }^{2,3}$.

\begin{tabular}{lrll} 
REGION & $\begin{array}{l}\text { FEEDLOT CATTLE } \\
\text { number }\end{array}$ & \multicolumn{1}{c}{ ch4 } \\
& & animal & \\
\hline N. Atlantic & 0 & & \\
S. Atlantic & 0 & & \\
N. Central & 12.805 & 50 & 0.640 \\
S. Central & 5.51 & 50 & 0.276 \\
West & 4.64 & 50 & 0.232 \\
\hline TOTAL & & & 1.148
\end{tabular}

${ }^{1}$ Units for methane are: 1)ch4/animal is $\mathrm{kg} / \mathrm{animal} / \mathrm{yr}$, and 2)ch4 is $\mathrm{Tg} / \mathrm{yr}(1 \mathrm{e}+9$
$\mathrm{kg} / \mathrm{yr})$.

${ }^{2}$ North Atlantic states: Maine, New Hampshire, Vermont, Massachusetts, Rhode Island, Connecticut, New York, New Jersey, Pennsylvania. North Central states: Ohio, Indiana, Illinois, Michigan, Wisconsin, Minnesota, Iowa, Missouri, North Dakota, South Dakota, Nebraska, Kansas. South Atlantic states: Delaware, Maryland, Virginia, West Virginia, North Carolina, South Carolina, Georgia, Florida. South Central states: Kentucky, Tennessee, Alabama, Mississippi, Arkansas, Louisiana, Oklahoma, Texas. West states: Montana, Idaho, Wyoming, Colorado, New Mexico, Arizona, Utah, Nevada, Washington, Oregon, California, Alaska, Hawaii.

${ }^{3}$ Sources of animal numbers and milk production data are: 1) R.W. Schoeff and D.J. Castaldo. 1990. Market data 1990: A comprehensive report on livestock and poultry inventories and feed usage potentials. Feed Management 41:10. 2) California Dairy Industry Statistics. 1990. California Department of Food and Agriculture. 3)Feedstuffs 1990 Referenos Issue 62:12. 

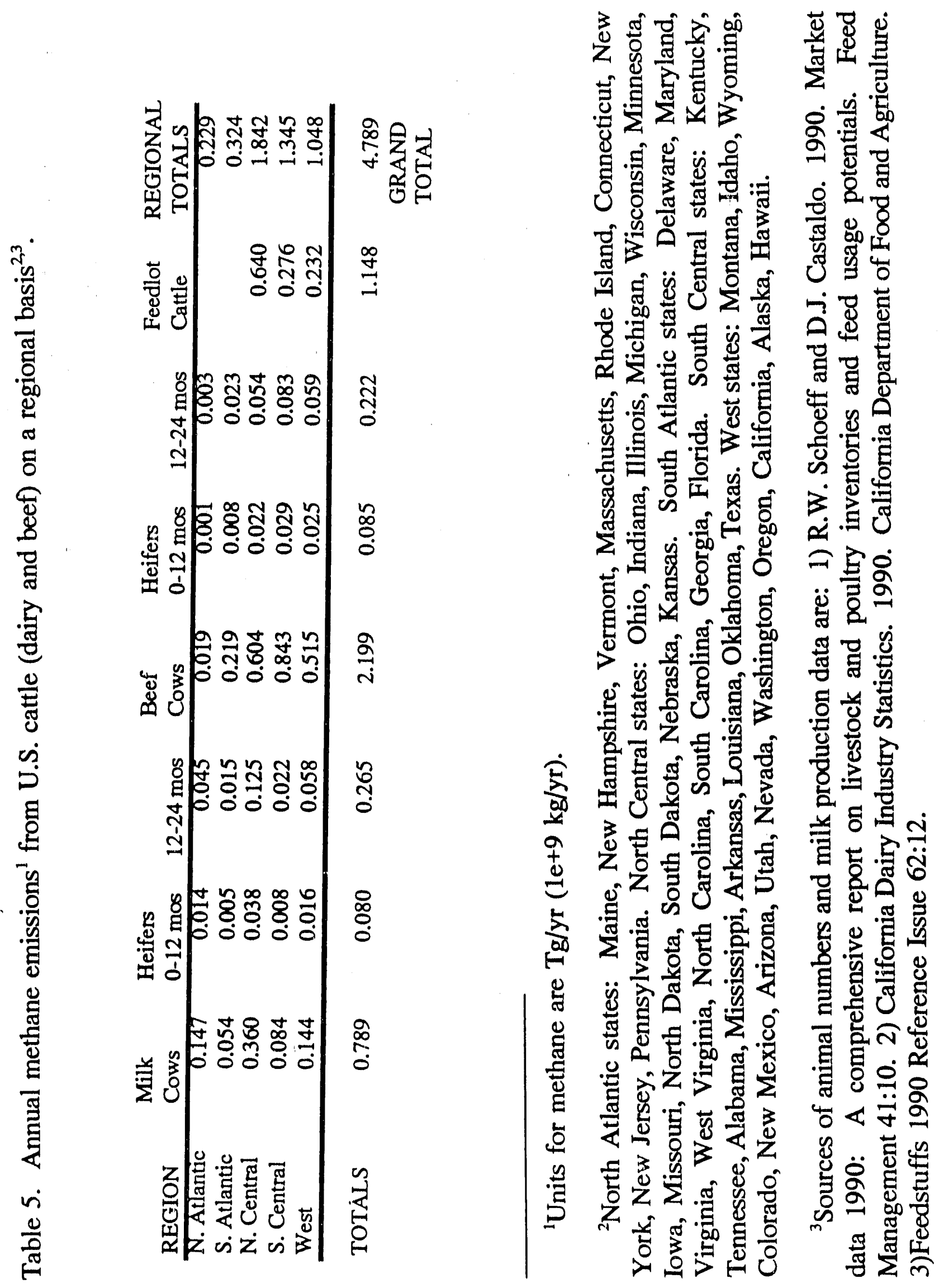


\title{
California Ecological Program
}

\author{
Daniel B. Botkin and Robert A. Nisbet
}

University of California, Santa Barbara

We have loaded an ERDAS version of the CAL-VEG vegetation map into our database. We have upgraded our computing system to do the analysis. We did quite a lot of research in the UCSB Map and Imagery Library and on the telephone trying to identify digital data that we could use. We found that the only suitable digital terrain data was at a 1:250,000 scale. The state of California is covered by parts of about 50 digital files of terrain data; each one is $\mathbf{4 0}$ megabytes in size. This large data size, plus the very large effort necessary to stitch these together, led us to conclude that we could not accomplish the task during the term of the grant. Our alternative task was to identify maps at a suitable scale with suitable contour lines that we could digitize into our database. After much research, we determined that the best map series was the $1: 1,000,000$ USGS series, even though the contour interval was variable at higher elevations. We will acquire maps from this series from local sources and begin digitizing.

\author{
Analysis of Global Energy Studies \\ Paul P. Craig \\ University of California, Davis
}

We have completed interviews. All interviews have been transcribed. We are in the process of analyzing data. We are planning two papers, both of which are in early draft form. One paper will examine European views of the United States. The other will examine the views of European policy makers regarding global climate change. Our work shows a consistently greater government interest in global climate change action in Europe than in the United States. At the same time, the U.S. is clearly perceived as a leader in the development of the science, and in encouraging public interest. An area of particular interest is the emphasis in Europe on continuity and a sense of connection with those who have gone before, and who will come later. From a policy perspective, enhanced understanding of these motivations may prove useful in crafting agreements that will prove broadly acceptable.

\section{Analysis and Synthesis of Models for the Effect of Climate Change on Agricultural Systems}

\author{
S. Geng, R. Plant, and R. Loomis \\ University of California, Davis
}

\section{Objectives}

Crop Model Development: Our objectives are: (1) to develop a new integrative physiological-morphological model of the wheat crop that will behave realistically in high- $\mathrm{CO}_{2}$ environments, and (2) to update the ALFALFA model to match the wheat model's photosynthetic structures and microclimates.

Impact Assessment: Assess the impacts of climate and predicted climate change on dryland spring wheat yields and rice yields in the United States. 


\section{Product}

Crop Model Development: Documented and tested mechanistic models of wheat (a new model) and alfalfa (modification of an existing model) that incorporate known physiological effects of $\mathrm{CO}_{2}$, air temperature, and soil water content within the framework of whole-plant growth and productivity.

Impact Assessment: Quantified impact of weather change on United States rice and wheat yields.

\section{Approach}

\section{Crop Model Development: Wheat}

Canopy photosynthesis subroutine. Programming for the canopy photosynthesis subroutine is complete and has been tested extensively and polished. The subroutine includes a modified Duncan canopy model for simulation of radiation interception (direct, diffuse, and transmitted radiation from any source through $\mathbf{n}$ leaf layers of any optical properties and any elevation and azimuth of display), and advanced leaf physiology (modified Farquhar-von Caemmerer photosynthesis model beginning with photon-excited electron transport and responsive to any level of stomatal conductance, temperature, and $\mathrm{CO}_{2}$ ).

Canopy environment subroutine. Programming, testing, and polishing are also nearly complete for a new microclimate model. This subroutine interacts with stomatal conductance to consider radiation and energy balances of each leaf. These are assembled (with aerodynamic transport, photosynthesis rate, and canopy resistance) to provide distributions of vapor pressure $\left(e_{2}\right)$, leaf temperature $\left(T_{1}\right)$, and $\mathrm{CO}_{2}$. The last portion of this section (canopy thermal radiation exchange) is ready for assembly.

Soil processes. Subroutines are also complete for soil water balance (infiltration, runoff, drainage, and root uptake) and soil heat flux (leading to the profile of $T$ ). Their performance in preliminary tests is very good. A preliminary fine-root model (growth, development, water uptake) is also complete.

Plant development. Concepts for the subroutine dealing with developmental advance (phenology) have been selected and are now ready for programming.

Plant growth. Concepts for the subroutine dealing with plant growth have been selected and are nearly ready for programming.

Other. It is now clear that $\mathrm{e}_{1}$ (or $\mathrm{e}^{-} \mathrm{e}_{1}$ ) and $\mathrm{CO}_{2}$ have direct effects on respiration, growth, and development as well as on photosynthesis. We have the clearest handle on the effects on respiration. What will be needed in the wheat model remains to be determined.

\section{Crop Model Development: Alfalfa}

Soil temperature. A new soil temperature subroutine has been completed, validated, and submitted for publication.

Fine-root growth. A new fine-root subroutine has been completed and validated and is being prepared for publication.

Partitioning of new assimilates. Difficulties continue in choosing better concepts about pools of nonstructural carbohydrates in shoot, crown, and root tissues, and for transport among them. One major effort, at least to this point, proved unsatisfactory.

Impact Assessment: We have developed a general method to assess climate impacts on crop yields that involves a hierarchy of three types of models: a GCM, a weather generator, and a crop simulation model. Although the direction and magnitude of climate change as a result of doubling of $\mathrm{CO}_{2}$ is uncertain, this 
method can be reapplied if and when there is a better prediction of the expected climate change. This method may be applied with any GCM output and any crop model. The easily used weather generator and a reliable crop model are the keys to this assessment method. We have produced a method that shows the aspects of weather and climate that most heavily impact crop yields under current climate conditions. It also shows on average the kinds of changes to be expected with a given climate change. This is much more informative for assessment and mitigation purposes than perturbing one year of observed weather data and making broad statements about expected changes based on that one year.

\title{
Results to Date
}

Wheat Model: Work on the wheat model is progressing well but will not be finished by the time funding is exhausted on December 31, 1991. We are keeping in mind the need not only for a robust wheat model but also for the ease with which this can be translated to a "big leaf" for direct coupling with meso-scale or large GC models and to generic grassland.

Alfalfa Model: Performance in hot climates and with moisture stress. The model was modified slightly in partitioning (a "shielded" reserves pool was added), respiration (quiescence under extreme stress), and response functions at high temperature. Validation under low-elevation desert conditions of California (Imperial Valley) was excellent, as was the model's performance in research on irrigation management.

Impact Assessment: Results indicate that rice yields decrease by between $14 \%$ and $24 \%$ in the Gulf Coast states and between $11 \%$ and $21 \%$ in California. In both regions the decrease in rice yields was due primarily to the large increase in summer temperatures. On the other hand, dryland fall-planted spring wheat yields in California increase by $62 \%$ and $125 \%$. This is because of the increased rainfall and temperatures during the winter months in California.

\section{Interactive Effects of Heat Stress and Elevated Carbon Dioxide Concentration on Plant Reproduction}

\author{
Anthony E. Hall \\ University of California, Riverside
}

Objectives: 1. To predict the influences of a duubling in $\mathrm{CO}_{2}$ on plant tolerance to heat, and determine the extent to which heat-induced damage to floral development is influenced by carbohydrate supplies. 2. To select plant genotypes with contrasting heat tolerance and harvest index (the ratio of seed to total shoot biomass) for studies of their responses to heat and $\mathrm{CO}_{2}$. 3. To evaluate associations between harvest index and carbon isotope discrimination. 4. To develop plans for a cost-efficient system to study plant responses to $\mathrm{CO}_{2}$ enrichment and elevated night-time temperatures under field conditions.

Product: The results of these studies will facilitate prediction of the impact of a doubling in $\mathrm{CO}_{2}$ and increases in temperature (due to global climate change) on crop productivity and should provide selection criteria whereby plant breeders can develop cultivars more suited to the environments of the next century.

Approach: Many plant species are particularly sensitive to heat during reproductive development. Growth of species with the $\mathrm{C}_{3}$ photosynthetic system usually is enhanced by $\mathrm{CO}_{2}$ enrichment, but effects on fruit and seed production have not been adequately described, especially for hot environments. Cowpea (Vigna unguiculata) genotypes with contrasting heat tolerance during reproductive development and harvest index were used as a model system to study the interactive effects of elevated $\mathrm{CO}_{2}$ and heat stress. Initial studies took advantage of the precision and repeatability of growth chambers. Plans were developed for future controlled-environment studies under field conditions which should more accurately predict responses in natural environments. 


\section{Results since the annual report of June 30, 1991:}

Objective 1. We have now completed a set of growth chamber studies with three contrasting cowpea genotypes (CB5, 7964, and 518) that have similar genetic backgrounds at present-day levels of $\mathrm{CO}_{2}(350$ $\mathrm{ppm}$ ), elevated $\mathrm{CO}_{2}(700 \mathrm{ppm})$, and optimal $\left(20^{\circ} \mathrm{C}\right)$ and high $\left(30^{\circ} \mathrm{C}\right)$ night temperatures in a $2 \times 2$ factorial design. Statistical analyses are not yet available for the data that are presented, but the main conclusions are based upon large differences that are reliable. All studies with elevated $\mathrm{CO}_{2}$ were repeated.

Elevated $\mathrm{CO}_{2}$ resulted in large increases in starch levels in leaves, stems and peduncles of all genotypes under optimal and high night temperatures (Table 1). Total sugars also increased, with elevated $\mathrm{CO}_{2}$, in peduncles under optimal temperature but not with high night temperatures or with leaves or stems (Table 1). The only obvious genotypic effect was that the heat-tolerant genotype (\#518) had more sugars and less starch in peduncles under high night temperature than the other genotypes (Table 1).

Leaf area was not affected by $\mathrm{CO}_{2}$, but elevated $\mathrm{CO}_{2}$ did increase total shoot biomass production under optimal temperature, but not under high night temperature (Table 2). Flower production or the lack of flower production by the most heat-sensitive genotype (CB5) under high night temperature was not influenced by $\mathrm{CO}_{2}$ (Table 2). Pod set of all genotypes was increased by elevated $\mathrm{CO}_{2}$, except for the two heat-sensitive genotypes under high night temperature which did not produce pods in these conditions (Table 2). For genotypes producing pods, the numbers of pods and pod weights were increased by elevated $\mathrm{CO}_{2}$, and the heat-tolerant genotype (\#518) gave the largest responses (Table 2).

Measurements of photosynthesis demonstrated that although this species exhibited increases in photosynthesis with short-term increases in $\mathrm{CO}_{2}$ (compare columns 1 with 2 , and 3 with 4 in Table 3 ), downward regulation occurred so that toward the end of the growth cycle, plants grown under elevated $\mathrm{CO}_{2}$ had similar photosynthesis as plants grown under ambient levels of $\mathrm{CO}_{2}$ (compare columns 1 and 4 in Table 3). It has often been assumed that plants growing under higher $\mathrm{CO}_{2}$ will have smaller stomatal conductances and, therefore, use less water, but the data obtained in this study (compare columns 1 and 4 in Table 3) do not support this assumption.

Plants grown under elevated $\mathrm{CO}_{2}$ exhibited chlorotic mottling of leaves, under either optimal or high night temperatures, but we did not detect differences in leaf chlorophyll content due to $\mathrm{CO}_{2}$ (Tbl 4). Plants grown under higher night temperature had slightly less chlorophyll and dry weight per unit leaf area (Tbl 4).

Conclusions Concerning Objective 1: A doubling in $\mathrm{CO}_{2}$ did not make the plants more tolerant to heat with respect to biomass production, reproductive development, or pod production, even though it substantially enhanced starch levels in leaves, stems, and peduncles. A heat-tolerant genotype was most responsive to $\mathrm{CO}_{2}$ enrichment under either optimal or high night temperatures. Starch accumulations, chlorotic mottling of leaves, and downward regulation of photosynthetic capacity indicated that cowpea is not well-adapted to elevated $\mathrm{CO}_{2}$ environments; this hypothesis should be tested more rigorously in more natural environments.

Objective 2. Field studies demonstrated that several advanced breeding lines have contrasting heat tolerance and high harvest index, and would be effective material for testing the influences of these characters on interactive responses to elevated $\mathrm{CO}_{2}$ and heat stress. Genotype $\mathrm{H8-9}$ had the highest harvest index (ratio of seed yield to total shoot biomass) in a field study comparing 24 genotypes (Table 5), and was significantly higher than CB5, which has been used as a control cultivar in earlier studies. Genotype 160 also had a very high harvest index in another field study but only has partial heat tolerance. Genotypes H8-9, 160, and CB5 could provide effective materials for studies of interactive responses to elevated $\mathrm{CO}_{2}$ and heat because they have similar genetic backgrounds but substantial differences in harvest index and heat tolerance. These lines would be useful for testing whether genotypes with higk ir harvest index are more responsive to $\mathrm{CO}_{2}$ enrichment, and the interactive effects of heat stress and heat tolerance. Genotype H8-9 also had high discrimination against the isotope ${ }^{2} \mathrm{C}$. 
Objective 3. We are testing for correlations between carbon isotope discrimination and harvest index using parents, $F_{1}$, and $F_{2}$ populations from crosses between two sets of parents that have contrasting carbon isotope discrimination and similar earliness. These analyses are being done but have not been completed. We are testing whether high carbon isotope discrimination can be used as an indirect selection criteria for high harvest index, which, if our hypothesis is correct, could result in selecting plants that are more responsive to elevated $\mathrm{CO}_{2}$ than current cultivars.

Objective 4. Our studies of the interactive effects of heat stress and elevated $\mathrm{CO}_{2}$ on contrasting cowpea genotypes produced important results, but they were conducted in growth chambers, and studies are needed to confirm and extend these results under more natural conditions. We have developed plans for a cost-efficient system to study plant responses to elevated $\mathrm{CO}_{2}$ and different night temperatures under field conditions. Open-top chambers with both flow-through and recirculatory air systems (Fig. 1 from Drake et al., 1989) would be used. The experimental design would involve $2 \times 2$ factorial treatments (ambient or elevated $(700 \mathrm{ppm}) \mathrm{CO}_{2}$ and ambient or higher $\left(+10^{\circ} \mathrm{C}\right)$ night temperature), with three replications requiring 12 open-top chambers. Inside each chamber there would be three contrasting cowpea genotypes. 'During the day, only the flow-through air system would be operating, and six of the 12 chambers would receive $\mathrm{CO}_{2}$ enrichment to $700 \mathrm{ppm}$. During the night, only the recirculatory air system would be operating and six of the 12 chambers would receive heating to $+10^{\circ} \mathrm{C}$ above ambient. This level of heating is chosen berause the Riverside night-time temperatures are relatively cool and earlier studies (Nielsen and Hall, 1985a) had shown that $+10^{\circ} \mathrm{C}$ would simulate the hotter conditions experienced in the cowpea production area in the Central Valley of California. In addition, we need to obtain a strong heat stress, and earlier field studies (Nielsen and Hall, 1985b) had shown that $+10^{\circ} \mathrm{C}$ can substantially reduce pod set of the cowpea cultivar CB5, which is sensitive to heat. In the proposed field studies, we would benefit from facilities and expertise provided by the Statewide Air Pollution Research Center at the University of Callfornia, Riverside.

\section{References}

Drake B.G., Leadley P.W., Arp W.J., Nassiry D., and P.S. Curtis (1989) An open top chamber for field studies of elevated atmospheric $\mathrm{CO}_{2}$ concentration on saltmarsh vegetation. Functional Ecology 3:363-371. Nielsen C.L. and A.E. Hall (1985a) Responses of cowpea (Vigna unguiculata (L.) Walp.) in the field to high night air temperature during flowering. I. Thermal regimes of production regions and field experimental system. Field Crops Res, 10:167-179.

Nielsen C.L. and A.E. Hall (1985b) Responses of cowpea (Vigna unguiculata (L.) Walp.) in the field to high night air temperature during flowering. II. Plant responses. Field Crops Res. 10:181-196. 
Table 1. Interactive effects of heat stress and elevated $\left[\mathrm{CO}_{2}\right]$ on carbohydrate levels in cowpeas

\begin{tabular}{|c|c|c|c|c|c|}
\hline \multirow[b]{2}{*}{$\begin{array}{l}\text { Day/night } \\
\text { temperatures }\end{array}$} & \multirow[b]{2}{*}{ Genotypes } & \multicolumn{2}{|c|}{ Total sugars } & \multicolumn{2}{|c|}{ Starch } \\
\hline & & $\begin{array}{r}{\left[\mathrm{CO}_{2}\right]} \\
350 \mathrm{ppm}\end{array}$ & $\begin{array}{c}{\left[\mathrm{CO}_{2}\right]} \\
700 \mathrm{ppm}\end{array}$ & $\begin{array}{c}{\left[\mathrm{CO}_{2}\right]} \\
350 \mathrm{ppm}\end{array}$ & $\begin{array}{r}{\left[\mathrm{CO}_{2}\right]} \\
700 \mathrm{ppm}\end{array}$ \\
\hline \multicolumn{2}{|l|}{ A. Leaves } & -.-- & - & - & 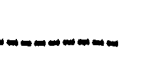 \\
\hline \multirow[t]{2}{*}{$33 / 20^{\circ} \mathrm{C}$} & $\begin{array}{l}\text { CB5 } \\
7964 \\
518\end{array}$ & $\begin{array}{l}64 \\
44 \\
47 \\
\end{array}$ & $\begin{array}{l}78 \\
57 \\
69 \\
\end{array}$ & $\begin{array}{r}95 \\
73 \\
108 \\
\end{array}$ & $\begin{array}{r}206 \\
241 \\
246 \\
\end{array}$ \\
\hline & Mean & 52 & 68 & 92 & 231 \\
\hline \multirow[t]{2}{*}{$33 / 30^{\circ} \mathrm{C}$} & $\begin{array}{l}\text { CB5 } \\
7964 \\
518\end{array}$ & $\begin{array}{l}53 \\
55 \\
61 \\
\end{array}$ & $\begin{array}{l}62 \\
61 \\
78 \\
\end{array}$ & $\begin{array}{l}63 \\
68 \\
65 \\
\end{array}$ & $\begin{array}{r}112 \\
134 \\
74 \\
\end{array}$ \\
\hline & Mean & 56 & 67 & 66 & 106 \\
\hline \multicolumn{6}{|l|}{ B. Stems } \\
\hline \multirow[t]{2}{*}{$33 / 20^{\circ} \mathrm{C}$} & $\begin{array}{l}\text { CB5 } \\
7964 \\
518\end{array}$ & $\begin{array}{l}81 \\
88 \\
65 \\
\end{array}$ & $\begin{array}{l}76 \\
59 \\
49 \\
\end{array}$ & $\begin{array}{l}6 \\
9 \\
8 \\
\end{array}$ & $\begin{array}{l}34 \\
37 \\
44 \\
\end{array}$ \\
\hline & Mean & 78 & 61 & 8 & 38 \\
\hline \multirow[t]{2}{*}{$33 / 30^{\circ} \mathrm{C}$} & $\begin{array}{l}\text { CB5 } \\
7964 \\
518\end{array}$ & $\begin{array}{l}66 \\
55 \\
50 \\
\end{array}$ & $\begin{array}{l}85 \\
83 \\
68 \\
\end{array}$ & $\begin{array}{r}7 \\
14 \\
7 \\
\end{array}$ & $\begin{array}{l}48 \\
92 \\
71 \\
\end{array}$ \\
\hline & Mean & 57 & 79 & 9 & 70 \\
\hline \multicolumn{6}{|l|}{ C. Peduncles } \\
\hline \multirow[t]{2}{*}{$33 / 20^{\circ} \mathrm{C}$} & $\begin{array}{l}\text { CB5 } \\
7964 \\
518\end{array}$ & $\begin{array}{l}199 \\
170 \\
161 \\
\end{array}$ & $\begin{array}{l}258 \\
257 \\
201 \\
\end{array}$ & $\begin{array}{l}21 \\
26 \\
27 \\
\end{array}$ & $\begin{array}{r}87 \\
142 \\
100 \\
\end{array}$ \\
\hline & Mean & 177 & 239 & 25 & 110 \\
\hline \multirow[t]{2}{*}{$33 / 30^{\circ} \mathrm{C}$} & $\begin{array}{l}\text { CB5 } \\
7964 \\
518\end{array}$ & $\begin{array}{r}63 \\
60 \\
111 \\
\end{array}$ & $\begin{array}{r}59 \\
74 \\
131 \\
\end{array}$ & $\begin{array}{r}29 \\
12 \\
8 \\
\end{array}$ & $\begin{array}{r}126 \\
94 \\
33 \\
\end{array}$ \\
\hline & Mean & 78 & 88 & 17 & 84 \\
\hline
\end{tabular}


Table 2. Interactive effects of heat stress and elevated $\left[\mathrm{CO}_{2}\right]$ on growth and reproductive development of cowpeas

\begin{tabular}{|c|c|c|c|c|c|}
\hline $\begin{array}{l}\text { Day/night } \\
\text { temperatures }\end{array}$ & Genotypes & $\begin{array}{c}{\left[\mathrm{CO}_{2}\right]} \\
350 \mathrm{ppm}\end{array}$ & $\begin{array}{c}{\left[\mathrm{CO}_{2}\right]} \\
700 \mathrm{ppm}\end{array}$ & $\begin{array}{c}{\left[\mathrm{CO}_{2}\right]} \\
350 \mathrm{ppm}\end{array}$ & $\begin{array}{r}{\left[\mathrm{CO}_{2}\right]} \\
700 \mathrm{ppm}\end{array}$ \\
\hline & & \multicolumn{2}{|c|}{ Leaf area $\mathrm{dm}^{2} /$ plant } & \multicolumn{2}{|c|}{ Shoot biomass g/plant } \\
\hline \multirow[t]{4}{*}{$33 / 20^{\circ} \mathrm{C}$} & CB5 & 43 & 56 & 90 & 109 \\
\hline & 7964 & 35 & 30 & 66 & 89 \\
\hline & 518 & 39 & 46 & 79 & 117 \\
\hline & Mean & 39 & 44 & 79 & 105 \\
\hline \multirow[t]{5}{*}{$33 / 30^{\circ} \mathrm{C}$} & CB5 & 36 & 44 & 76 & 82 \\
\hline & 7964 & 31 & 34 & 58 & 63 \\
\hline & 518 & 37 & 33 & 91 & 93 \\
\hline & Mean & 34 & 37 & 75 & 79 \\
\hline & & \multicolumn{2}{|c|}{ No. flowers/plant } & \multicolumn{2}{|c|}{ Pod set \% } \\
\hline \multirow[t]{4}{*}{$33 / 20^{\circ} \mathrm{C}$} & CB5 & 74 & 84 & 20 & 31 \\
\hline & 7964 & 65 & 64 & 36 & 43 \\
\hline & 518 & 60 & 81 & 34 & 51 \\
\hline & Mean & 66 & 76 & 29 & 42 \\
\hline \multirow[t]{4}{*}{$33 / 30^{\circ} \mathrm{C}$} & CB5 & NIL & NIL & NIL & NIL \\
\hline & 7964 & 100 & 104 & NIL & NIL \\
\hline & 518 & 75 & 71 & 36 & 57 \\
\hline & & \multicolumn{2}{|c|}{ No. pods/plant } & \multicolumn{2}{|c|}{ Pod weight g/plant } \\
\hline \multirow[t]{4}{*}{$33 / 20^{\circ} \mathrm{C}$} & CB5 & 15 & 26 & 4 & 11 \\
\hline & 7964 & 23 & 27 & 10 & 12 \\
\hline & 518 & 20 & 42 & 21 & 37 \\
\hline & Mean & 19 & 32 & 12 & 20 \\
\hline \multirow[t]{3}{*}{$33 / 30^{\circ} \mathrm{C}$} & CB5 & NIL & NIL & NIL & NIL \\
\hline & 7964 & NIL & NIL. & NIL & NIL \\
\hline & 518 & 27 & 40 & 23 & 28 \\
\hline
\end{tabular}


Table 3. Interactive effects of heat stress and elcvated $\left[\mathrm{CO}_{2}\right]$ on photosynthesis and stomatal conductance measured at photon fluxes of $500 \mu \mathrm{mol} \mathrm{m}^{-2} \mathrm{~s}^{-1}$ and temperature of $33^{\circ} \mathrm{C}$

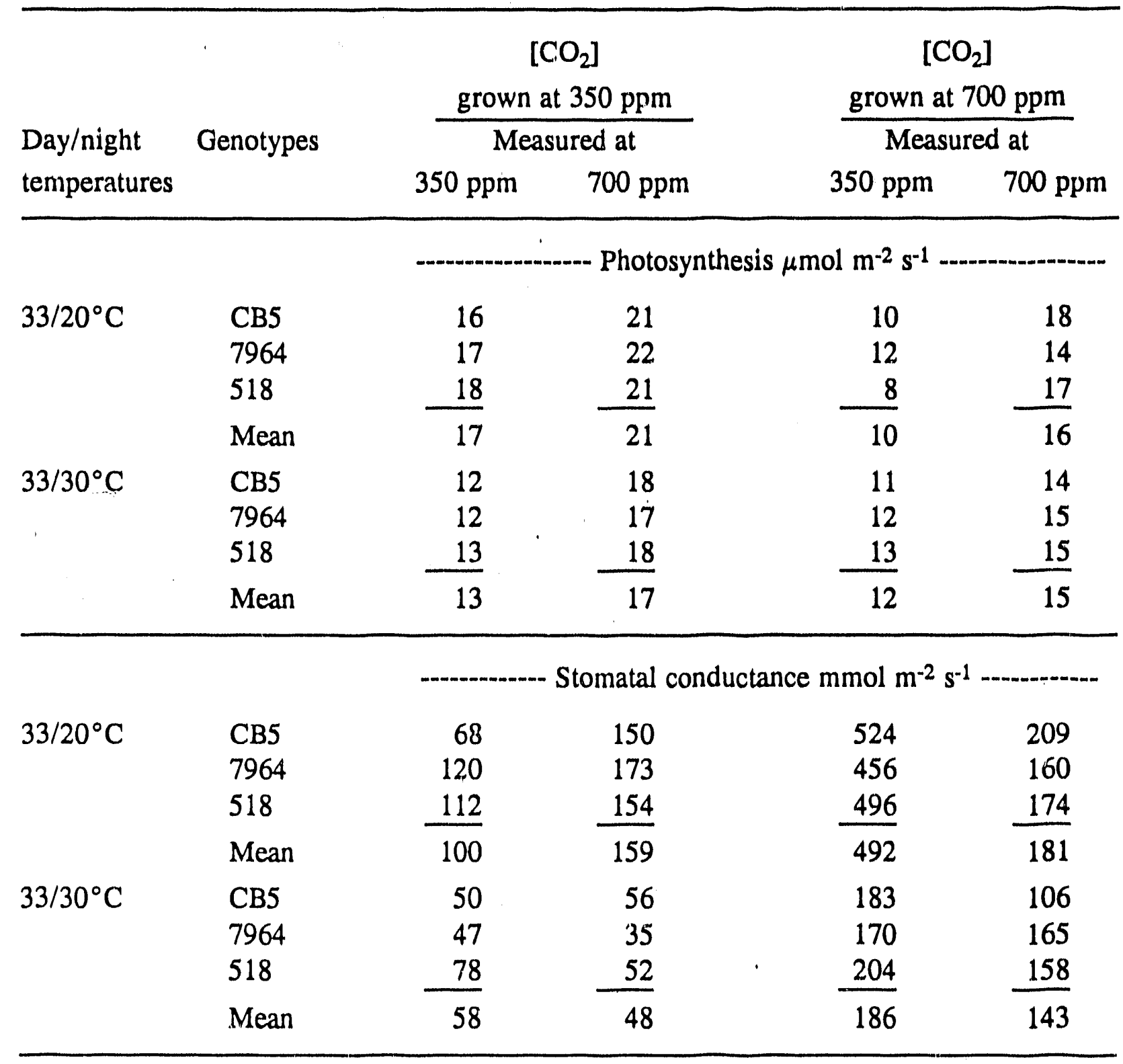


Table 4. Interactive effects of heat stress and elevated $\left[\mathrm{CO}_{2}\right]$ on chlorophyll content and specific leaf weight (dry weight/area)

\begin{tabular}{|c|c|c|c|c|c|}
\hline \multirow[b]{2}{*}{$\begin{array}{l}\text { Day/night } \\
\text { temperatures }\end{array}$} & \multirow[b]{2}{*}{ Genotypes } & \multicolumn{2}{|c|}{ Chlorophyll content } & \multicolumn{2}{|c|}{ Specific leaf weight } \\
\hline & & $\begin{array}{c}{\left[\mathrm{CO}_{2}\right]} \\
350 \mathrm{ppm}\end{array}$ & $\begin{array}{c}{\left[\mathrm{CO}_{2}\right]} \\
700 \mathrm{ppm}\end{array}$ & $\begin{array}{r}{\left[\mathrm{CO}_{2}\right]} \\
350 \mathrm{ppm}\end{array}$ & $\begin{array}{r}{\left[\mathrm{CO}_{2}\right]} \\
700 \mathrm{ppm}\end{array}$ \\
\hline \multirow[t]{2}{*}{$33 / 20^{\circ} \mathrm{C}$} & $\begin{array}{l}\text { CB5 } \\
7964 \\
518\end{array}$ & $\begin{array}{l}6.5 \\
6.9 \\
7.6\end{array}$ & $\begin{array}{l}7.9 \\
7.9 \\
8.2\end{array}$ & $\begin{array}{l}525 \\
572 \\
654 \\
\end{array}$ & $\begin{array}{l}600 \\
721 \\
644 \\
\end{array}$ \\
\hline & Mean & 7.0 & 8.0 & 584 & 655 \\
\hline \multirow[t]{2}{*}{$33 / 30^{\circ} \mathrm{C}$} & $\begin{array}{l}\text { CB5 } \\
7964 \\
518\end{array}$ & $\begin{array}{l}5.7 \\
7.0 \\
5.9 \\
\end{array}$ & $\begin{array}{l}5.4 \\
5.3 \\
6.3 \\
\end{array}$ & $\begin{array}{l}426 \\
467 \\
372 \\
\end{array}$ & $\begin{array}{l}337 \\
462 \\
393 \\
\end{array}$ \\
\hline & Mean & 6.2 & 6.7 & 422 & 397 \\
\hline
\end{tabular}

364

B. G. Drake ot a..

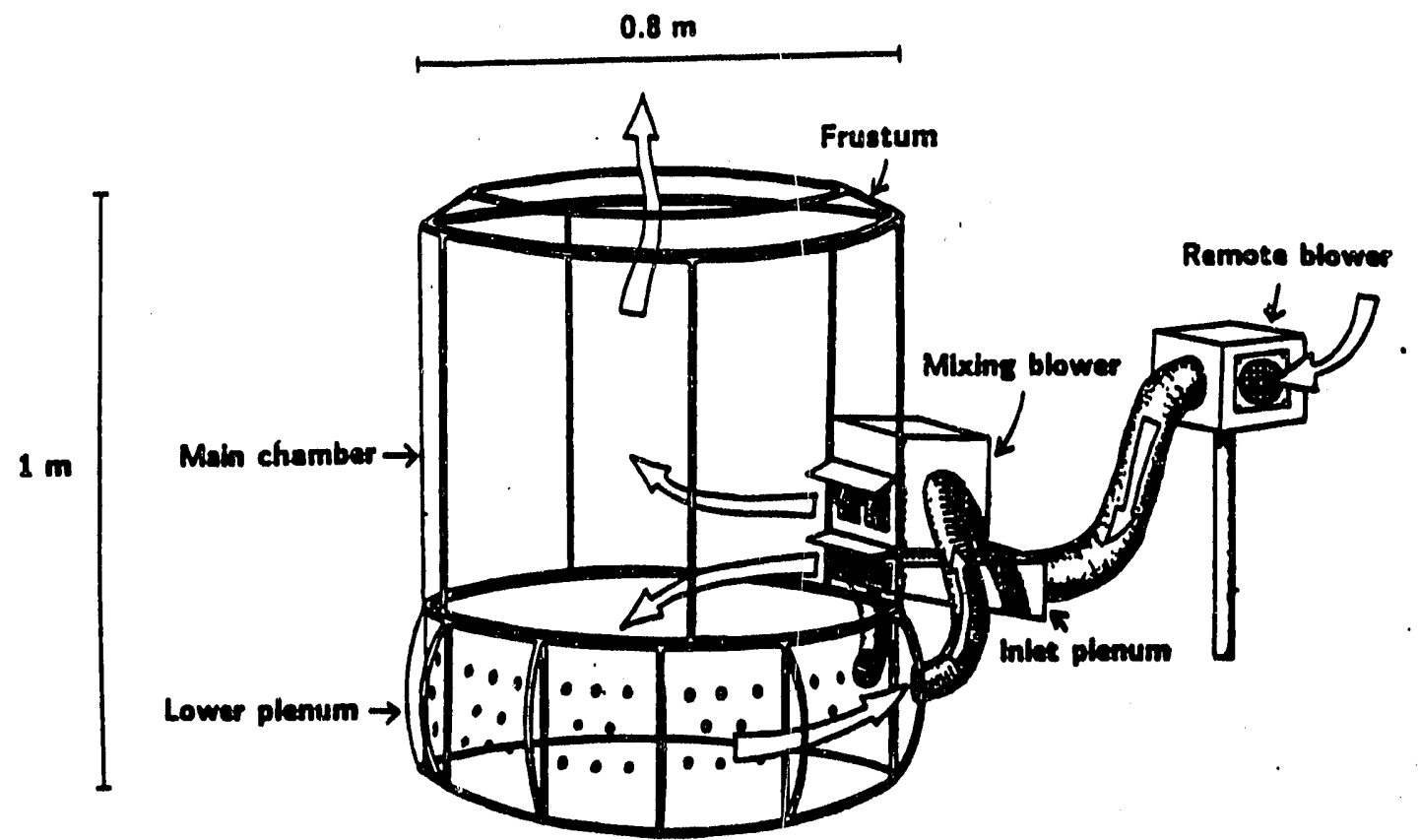

Fis. 1. Open top chnmber detailling flow of air. Air is drawn into the nomoto blower and blown through the inlet plonum into the chnmber. The mixing blower draws air from inside the chember through the perforated inner wrill of the lower plenum and blowe it back into the chamber. Air exdis tho charaber through the frustum. 
Table 5. Harvest index (ratio of seed yield to total shoot biomass) of cowpea genotypes under field conditions.

\begin{tabular}{|c|c|c|}
\hline Genotype & Origin & Harvest Index \\
\hline $\begin{array}{l}\text { H8-9 } \\
\text { L2-8 } \\
\text { W18-7 } \\
\text { W19-15 } \\
\text { W9-2 } \\
38 / 31 / 4 B \\
\text { W9-15 } \\
\text { CB46 } \\
\text { W22-11 } \\
\text { W18-10 } \\
\text { H6-16 } \\
\text { H14-10 } \\
1393 \\
524 B \\
\text { L1-6 } \\
\text { H35-5 } \\
\text { L1-4 } \\
\text { CB88 } \\
\text { H8-14 } \\
\text { CB5 } \\
\text { W22-3 } \\
\text { H8-8 } \\
\text { W1-15 } \\
8685\end{array}$ & 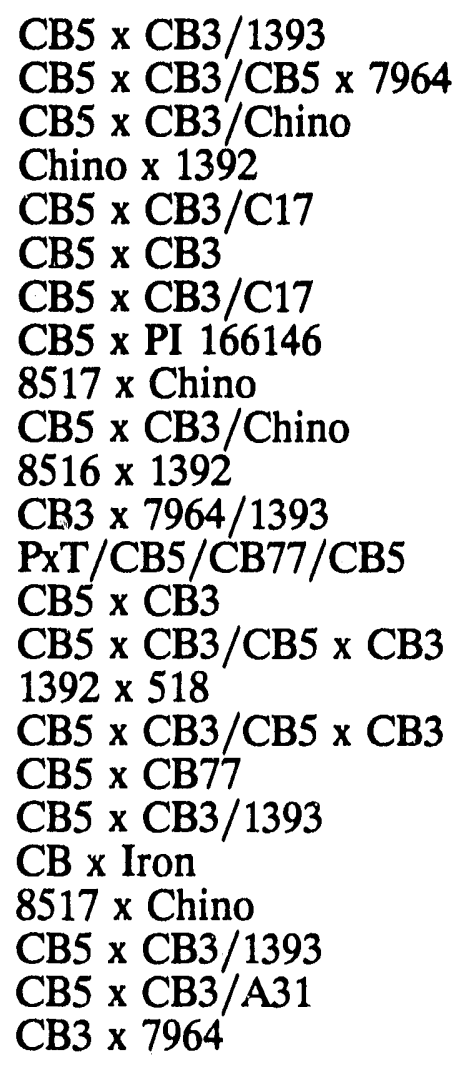 & $\begin{array}{l}0.51 \\
0.49 \\
0.49 \\
0.49 \\
0.48 \\
0.48 \\
0.47 \\
0.47 \\
0.47 \\
0.47 \\
0.46 \\
0.46 \\
0.46 \\
0.45 \\
0.45 \\
0.45 \\
0.44 \\
0.43 \\
0.43 \\
0.43 \\
0.43 \\
0.43 \\
0.43 \\
0.33\end{array}$ \\
\hline LSD. $_{.05}$ & & $0.0^{4}$ \\
\hline
\end{tabular}




\title{
Modeling the Response of the California Current System to Global Greenhouse Warming
}

\author{
Alejandro Pares-Sierra and Richard C. J. Somerville \\ Scripps Institution of Oceanography
}

Objective: To investigate the changes in regional ocean climate and their effects on regional atmospheric climate in response to global warming. The long-term goal is to improve the assessment of the possible impact that global climate change may have in western North America. As a prerequisite to this, we need to understand and catalog the possible scenarios of regional changes in the California current region and their possible impact on the regional atmospheric circulation.

Approach: Two indirect mechanisms exist whereby global warming could alter the regional climate in the California current region: first, through an enhancement of the coastal upwelling/downwelling regimes by the intensification of the local winds, and second through the effects of remotely generated (of equatorial origin, for example) warm and cold events propagating into the region in the form of coastal waves. With the help of wind-forced ocean circulation models, we are investigating the relative importance of these two mechanisms and their possible effect on the regional climate.

Results to Date: The project, up to now, has had two main thrusts: 1) upgrading and fine tuning our ocean circulation model to tackle the scales (in time and space) that are needed for this research, and 2) a parallel effort to carry out preliminary numerical experiments to assess the capability of our models. Progress has been accomplished on each of these thrusts.

1) We implemented a mixed-layer model to augment our adiabatic multilayer primitive equation model. This upgrading is essential in order to predict real sea-surface temperatures (instead of the SST proxy we have been using, i.e., upper-layer-thickness) and, more importantly, to be able to couple our ocean model to an atmospheric model. The formulation of the mixed-layer model is based on the one presented by McCreary and Kundu (1988) which in turn is based on the Kraus-Turner one-dimensional formulation. The depth and thickness of the mixed layer is controlled by entrainment and detrainment in the mixed layer, which are determined by wind stirring and cooling at the ocean surface.

The rate of entrainment is controlled by two mechanisms: the shear instability that occurs at the base of the layer whenever the bulk Richardson number of the dynamical layer is less than unity (i.e., when, where, and, are the temperature, depth and velocity of the layer, respectively, and, are the coefficient of thermal expansion and temperature of the deep ocean, respectively), and the classical Kraus-Turner balance between the opposing contributions of the wind stirring and the surface cooling (i.e., whether the nest rate of generation of turbulent kinetic energy is positive or negative, with and being the contributions due to wind stirring and surface cooling, respectively, and the rate of viscous dissipation [McCreary and Kundu, 1989]). The mixed-layer formulation has been implemented in one version of our model. Substantial testing and fine tuning is still required before we can use it.

2) We have performed experiments to assess the relative importance of local versus remote forcing on the local oceanic response to global warming. The experiments have clearly shown that, although the enhancement of coastal upwelling and downwelling regions by the intensification of the local winds is an extremely important mechanism in determining the regional climate, its effectiveness critically depends on the long term modulation of the equatorial contribution. One of these experiments, the hindcast of the big 1982 El Nino events, shows that most of the anomalous signal in the California current region in this year was produced by the contribution of the equatorial forcing and that the enhanced upwelling driven by the more intense winds produced only a relatively minor contribution. These experiments have shown that the local and remote contributions can interact in such a way as to reinforce (or cancel) each other to produce an enhanced (or suppressed) response in the coastal North Pacific. 
3) We implemented a new version of the California current model based on McCreary, et al, work (JGR, 1991). We have continued experimenting with the response of the model to different wind forcings associated to possible greenhouse scenarios. In particular, we have been investigating the seasonability of the upwelling frontal instability near the coast of California. Marked seasonal changes in the stabilities characteristics of the upwelling fronts have been found. These changes are associated to the annual variations of the wind strength at the coast.

\title{
Global Warming Trends and Internal Climate Oscillations: Detection and Modeling
}

\author{
Michael Ghil and David Neelin \\ University of California, Los Angeles
}

Objective: To decompose the existing multi-decadal records of surface temperature, sea-level pressure and sea-level height into their principal components, with respect to spatial and temporal variability, and to relate these dominant statistical features to bio-geochemical, physical, and dynamical mechanisms, natural or connected with humanity's activities.

Product: Evaluation of climate variability on interdecadal time scales, and of the implications of this variability for the reliable detection and prediction of systematic global warming trends.

Approach: One of the crucial questions connected with global change is the reliable detection of a systematic warming trend in global surface temperatures, on the time scale of decades to a century. This detection is rendered difficult by the presence of substantial variability on time scales both shorter and longer than the one of interest. Greenhouse trace gases have increased rapidly over the last century, e.g., carbon dioxide $\mathrm{CO}_{2}$ by about $25 \%$. Documented temperature change over the same time interval is only about $0.5^{\circ} \mathrm{C}$, this is both smaller than climate models would suggest, and marred by nonnegligible uncertainties. These uncertainties are due to temperature variability on other time scales, and to the possible effect of climatic mechanisms unrelated to trace gases.

Advanced tools for the statistical analysis of climatic oscillations, and of their spatial patterns, have been developed by M. Ghil and collaborators in connection with paleoclimatic studies (Vautard and Ghil, Physica $D, 35: 395-424,1989$ ) and with studies of low-frequency atmospheric variability (Ghil and Mo, J. Atmos. Sci., 48:752-790, 1991). Singular spectrum analysis (SSA) is a generalization of spectral analysis which uses data-adaptive filters and is particularly well suited for ihe study of nonlinear, slightly-irregular oscillations.

Results to Date: SSA has been applied to globally- and hemispherically-averaged surface temperatures (Bottomley et al., 1990; Folland et al., 1990) trying to separate a secular trend from the above-mentioned oscillations on this important time series. The results (Ghil and Vautard, Nature, 350:324-327, 1991) have been remarkably encouraging. A secular warming trend and a small number of oscillatory modes are separated from the noise. The oscillations exhibit interdecadal periods of 21 and 16 years, and interannual periods of 6 and 5 years. The oscillatory components have combined (peak-to-peak) amplitudes of $>0.2^{\circ} \mathrm{C}$, and therefore limit our ability to predict whether the inferred secular warming trend of $0.005^{\circ} \mathrm{C} \mathrm{yr}^{-1}$ will continue. This could postpone incontrovertible detection of the greenhouse warming signal for one or two decades. Furthermore, warm phases of the oscillatory components have contributed significantly to the high global temperatures since 1976 . This raises the possibility that temperatures may become temporarily cooler due to natural oscillations, masking continued warming due to the long-term trend over the next few years, and makes an understanding of these oscillations a prerequisite to reliable climate change detection. 
Modeling research on the explanation of interdecadal oscillations, as detected by Ghil and Vautard (1991), has been initiated. We strongly suspect that these 20-25 year oscillations manifest in surface temperature records involve the extratropical, thermohaline ocean circulation. Changes in thermal structure of the North Atlantic, down to $2000 \mathrm{~m}$, over a few decades have been documented recently (Levitus, J. Geophys. Res., 94C: 6091-6131, 1989) as well. A bifurcation study of a simple ocean model forced by prescribed surface temperatures and salinity fluxes (Quon and Ghil, submitted) has yielded insight into the dynamics of the thermohaline circulation, especially the transition between the asymmetric, one-cell thermohaline circulation of the present Atlantic ocean and a symmetric, two-cell circulation. The continuous transition via increasingly asymmetric two-cell circulations can be understood as a function of Rayleigh number and the strength of the salt flux forcing.

\title{
Impacts of Global Warming on the Hydrologic and Aquatic Environment of a Mesoscaie Geographical Region
}

\author{
(formerty: Impacts of Global Warming on the Hydrology and Aquatic Environment of Califomia)
}

\author{
M. Levent Kavvas and Gerald T. Orlob \\ University of California, Davis
}

Objective: To develop a new methodology for bridging the gap among the spatial scales of GCMs on one hand and those of hydrology and water quality/ecology models on the other, in ordes to translate reliably the climatic findings of GCM studies on global warming and other climatic changes, to the potential impacts on the water resources and aquatic environment of any mesoscale geographical region over the USA.

Product: (1) Quantitative assessment of the atmospheric, hydrologic, and water quality/ecologic changes which may be brought about by a potential global warming and other climatic changes due to the greenhouse effect, on the topographically influenced mesoscale geographical regions of the USA; and (2) provision of better information to atmospheric models on land surface processes at micro and mesoscales by the interaction of mesoscale atmospheric models with the mesoscale hydrology model that is being developed in this project, which shall resolve the land hydrology and soil moisture dynamics from micro to mesoscales.

Approach: Since a GCM grid size is typically around $300 \mathrm{~km}$, it is not possible to translate its generally coarse climatic findings to the micro and small mesoscale subregions of geographical regions with rough terrain. This is the case in almost all western states of the USA where mountain ranges dominate the topography and strongly influence the climate.

This project is coupling an in-house mesoscale atmospheric model (MAM) with the GCM of Geophysical Fluid Dynamics Laboratory (GFDL), in order to resolve the atmospheric processes from global scales down to small mesoscales, even over rough terrain. However, the main research thrust of this project is to develop a physically-based hydrology model at small mesoscale (SM scale), which is nonexistent at present, starting from an in-house physically-based microscale hydrology model and extending its spatiai scales. The MAM simulated precipitation, radiation, wind, mixing ratio, temperature and pressure fields, corresponding to a particular climate change scenario, are then input to the SM scale hydrology model over any selected geographical SM scale region within the mesoscale region of MAM. For the application and verification of the hydrology model a region in northern California is selected. The outputs of the SM scale hydrology model simulation, corresponding to the MAM inputs, will then yield the information on the impacts of the particular climate change scenario on the hydrology of the selected SM scale region. Under a given global climate change scenario, using the atmospheric information provided by the mesoscale atmospheric model and the hydrologic information provided by the SM scale hydrology model, QUAL2E for streams and WQRRS for stream-reservoir systems will be used to simulate the traditional measures of water quality like D.O., B.O.D., temperature, nutrients, etc., and key biological variables like phytoplankton and zooplankton over the selected SM scale region. 
Results to Date: Since the project team is most familiar with the atmospheric, hydrologic, and water quality/ecologic conditions of California, this state was selected as the geographical study region. For the calibration and verification of the in-house MAM and of hydrologic and water quality/ecologic models, the dry period of October 1988 - June 1989 and the wet period of February 1986 were selected.

The MAM was applied to the case of historical heavy precipitation event of February 16-17, 1986 which caused flooding of the Sacramento Valley. This application was performed in order to verify and improve the model's microphysical representation of the precipitation processes. Then the MAM was applied to the month of April 1989 during the selected dry period in order to test and improve the model's performance during dry period simulation. For both applications the NMC analysis results at $2.5^{\circ}$ resolution were used as boundary conditions. The application results were quite satisfactory. The results of the global climate simulations by GFDL GCM under $1 \times \mathrm{CO}_{2}$ concentration and $2 \times \mathrm{CO}_{2}$ concentration scenarios were obtained and read for the western USA region within $22.6^{\circ}-58.9^{\circ}$ latitudes and $128.7^{\circ}-89.2^{\circ}$ west longitudes. This region contains California, the state chosen as the geographical study region.

For hydrologic and water quality/ecologic modeling purposes an extensive search for an SM scale region in California with respect to geology, soils, vegetation, and precipitation conditions was conducted. At the end of this search a region in northern California that is a significant water supplier for the state, was chosen. The Digital Elevation Maps (DEM) for the selected region were purchased and loaded to the GRASS Geographic Information System (GIS). Using this GIS, the DEMs were analyzed with respect to topography, aspects, slopes, and channel network morphology. The soils data for the selected region were obtained from SCS and were also loaded to the GIS. The geologic maps of the selected region were obtained and, by the help of available USGS water supply papers, the regional groundwater potentiometric surface was constructed and loaded to the GIS. The groundwater component of the in-house microscale hydrology model was extended to SM scale and was applied successfully to the selected geographical region for validation purposes. Recently, the unsaturated soil moisture flow component and surface flow component of the in-house microscale hydrology model were extended to small mesoscale validation purposes. Also, work was completed on the microscale models of snowmelt and evapotranspiration. Currently, these models are being extended to small mesoscale. Remote-sensed AVHRR data for soil surface moisture, cloud cover and net radiation estimations, and Thematic Mapper data for vegetative cover, surface temperature, soil surface moisture, snow cover, water temperature of streams and suspended sediments were purchased for the study region and are being utilized in the validation work on the developed small mesoscale soil moisture flow and surface flow models.

With respect to ecologic studies, during FY 90 a preliminary methodology for assessment of water quality impacts of global climate change was developed and tested. Temperature prediction models, currently being used by the U.S. Bureau of Reclamation, were applied to simulate thermal energy balances in the Shasta-Trinity system within the selected geographical region in northern California under a set of hypothetical climate change scenarios developed in the Global Climate Change Workshop held on the UC. Davis campus in the summer of 1989. Predicted temperatures induced in the Sacramento River downstream of Keswick Dam by alternative scenarios of climate change were compared against historical base conditions observed in the river. Results indicate increased sensitivity of the critical temperature threshold for salmon spawning which is $13.3^{\circ} \mathrm{C}$. The water quality/ecologic models, used in this preliminary study, have been critically reviewed and updated to interface with the proposed SM scale hydrologic model and the in-house MAM.

During this project year research was focused on adaptation of water quality simulation models for streams and reservoirs to boundary conditions defined by the mesoscale atmospheric model and physicallybased hydrology models. This adaptation was performed since the surface water quality systems are driven by the hydrologic fluxes. Also, the advected heat associated with direct surface runoff, and the snowmelt temporal descriptions of hydrologic processes are essential inputs to water quality simulations. Preliminary testing with hypothetical climate change scenarios, derived from GCM (GFDL and GISS for $1 \times \mathrm{CO}_{2}$ ), indicate that thermal stratification impoundments is strongly influenced by shifts in precipitation, snow line elevations and snowmelt rates. A snowmelt model, developed this year, is expected to provide one of the essential inputs for simulation of the annual thermal cycle in reservoirs. Currently, time series of atmospheric boundary conditions that govern heat exchange at the air-water interface are being developed 
from historic records at northern California meteorologic stations, including the current drought period in California, now in its fifth year. These include data on wet and dry bulb air temperatures, relative humidity, wind, cloud cover, and pan evaporation. In addition, GCM output of daily and monthly mean values for air temperature and precipitation for representative annual cycles have been obtained for grid points covering California.

\title{
Uncertainties in ISCCP C1 Cloud/Radiation Feedback Parameters
}

\author{
Bryan C. Weare \\ University of California, Davis
}

This is a report of the activities carried out under a "no cost" extension of this 1990-91 contract. Several results were partially supported by this extension.

1. Ms. Remer completed her dissertation (Remer, 1991), which analyzes the causes of observed diurnal cycles of precipitation and cloudiness over both tropical land and ocean areas. In this work she utilized a detailed analysis of International Satellite Cloud Climatology Data for the western tropical Pacific and a model of solar and infrared radiation transfer. She found that over ocean the diurnal cycle is consistent with radiative heating changes associated with the observed cloudiness and does not require an external forcing such as easterly waves.

2. During the past year the PI has completed and submitted two manuscripts dealing with Nimbus-7 cloud observations of interactions. These (Weare, 1992a,b) utilized the cloud analyses derived by the Nimbus-7 team to make global, zonal, and regional estimates of mean cloud amounts and heights. These papers show that over the tropics, cloud amount and height are quite strongly positively correlated, which has strong implications for global change theories. The latter paper also shows that in the tropics both cloud amounts and heights are positively correlated with sea surface temperatures over seasonal and short-term interannual time scales.

3. A third completed paper (Weare, 1992c), relates cloud fraction data from the Nimbus analysis with those available from the Consolidated Ocean Atmosphere Data Set (COADS) and surface temperature and relative humidity from the latter and the final European Centre for Medium-range Weather Forecasting (ECMWF) analyses. In general the COADS cloud fraction data are found to give more realistic seasonal statistics than the Nimbus data. The Nimbus data appear to substantially underestimate the magnitudes of low cloudiness and overestimate seasonal variations. The COADS and ECMWF analyses appear to give similar results within the bounds of the known uncertainties. Most importantly, using COADS data seasonal variations of total sloudiness are found to be statistically, and sometimes strongly, correlated with surface relative humidity, despite the large uncertainties in the latter. These observed cloud/thermodynamic relationships may prove to be important tests of cloud parameterizations in climate models.

\section{References}

Remer, Lorraine A. (1991) Cloud-radiative feedbacks in tropical convection. Ph.D. dissertation, University of California at Davis, $129 \mathrm{pp}$.

Weare, Bryan C. (1992a) Variations in Nimbus-7 Cloud Estimates I. Zonal Averages. Submitted to J. of Climate.

Weare, Bryan C. (1992b) Variations in Nimbus-7 Cloud Estimates II. Regional Changes. Submitted to J. of Climate.

Weare, Bryan C. (1992c) The Utility of COADS in Cloud/Climate Studies. Submitted to Quart. J. Roy. Meteror. Soc. 


\title{
Effects of Global Warming on California Climate
}

\author{
(formerly: Global Greenhouse Forcing of the Califomia Climate)
}

\author{
Su-Tzai Soong, University of California, Davis \\ and \\ Robert Lee and Marvin Dickerson, Lawrence Livermore National Laboratory
}

We have studied the effect of surface processes and radiation on short-term climate simulation over California for a heavy rain period of February 11-22, 1986 using the UCD regional scale model. The surface processes were computed using the Oregon State University planetary boundary layer model. This model is coupled with an active multi-layer soil model and a primitive plant canopy model. It is comprehensive enough to approximate the most important physical processes, yet simple enough to allow high-resolution diurnal model simulations. The model simulation indicated a strong influence of soil moisture on soil and air temperature. Over the high land east of the Sierra Nevada mountain range, where the spatial contrast of the soil moisture is the largest, surface temperature pattern is almost identical to the soil moisture pattern. West of the Sierra Nevada, the spatial variation of the surface moisture is small and the simulated surface temperature distribution is, as a consequence, much smoother. The simulated low level mixing ratio also displayed a strong resemblance to the soil moisture. In addition to the soil moisture, the horizontal moisture advection and the low level moisture convergence also contributed to the simulated moisture distribution over the upwind (west) side of the mountain slope.

The soil data we have been using were interpolated from the one degree resolution world soil data from NCAR. This data resolution is too coarse for our model, which has a resolution of $20 \mathrm{~km}$. There are obvious discrepancies between the soil data and the actual land use pattern, especially over the northern Sierra Nevada area. It is unfortunate that no finer resolution soil data is currently available. We have experimented in generating a better soil data set from precipitation and surface observations. An experiment was performed for the period of May 1-31, 1986 using the HAPEX data, where comprehensive atmospheric and soil observation were the observations of soil moisture content, surface temperature, as well as surface heat flux and evaporation. The same method is currently being used to generate a fine grid soil moisture data over our model domain for regional scale climate simulation.

We have also studied the interaction of radiation and cloud microphysical processes using our model. The radiation computation uses the Delta-Eddington solar radiation module and the modified broadband infrared radiation module. The microphysical processes include the explicit computation of the mixing ratios of cloud water, rainwater, ice, snow, and graupel. The simulated results indicate that the cloud is produced in the upwind side of the Sierra and it gradually turns into snow while drifting eastward. Some of the snow melts to form rain in the upwind side of the mountain. The rest falls as snow on the mountain tops and some to the lee side of the mountain. There is a clearly defined snow line near the top of the mountain. A layer of ice cloud also exists over the entire model domain in the higher levels. This simulation is quite interesting and it has demonstrated the importance of microphysics in mesoscale models. The radiation computation indicated that the small amount of ice cloud in the upper layer of the model produced the dominant feature of the IR radiation field with a cooling rate of about $12^{\circ} \mathrm{C}$ per day. The rain-producing clouds in the lower layers had much less impact on the IR cooling rate. As for the short wave radiation, the upper layer ice clouds and the lower layer rain clouds have similar contributions. We are in the process of verifying the simulated cloud cover, albedo, and outgoing longwave radiation with satellite observations.

One drawback with the detailed microphysical computation is the amount of computer time required to carry out a climate simulation. For a one-month simulation, it requires 100 hours of Cray resources or one month time on a RISC 6000 computer. We are currently researching a method to simplify the microphysical process while retaining its essential characteristics. One way is to assume that the liquid and 
the frozen hydrometers do not co-exdst, thereby reducing the microphysical interactions by at least $50 \%$. This assumption may not be true for cloud models but may be quite reasonable for mesoscale models where strong convection cannot be resolved. As for the computer resources, we have obtained additional Cray time on a DOE supercomputer in Las Vegas. We also installed an IBM RISC 6000, on loan from IBM for the remaining project period, to be dedicated for this project.

\section{Progress Reports Not Submitted:}

Energy, Energy Policy, and Greenhouse Warming in China, by Mark D. Levine, Lawrence Berkeley Lab

Global Studies of Trace Gas Concentrations, by F. Sherwood Rowland, University of California, Irvine

Development of an Experiment to Measure the Oxddation Capacity of the Earth's Atmosphere, by F. Sherwood Rowland, University of California, Irvine 


\section{Research Projects Starting July 1, 1991}

"Correlation of Continental and Marine Paleoclimate Records Using the Paleointensity of the Geomagnetic Field" by K. L. Verosub (UCD)

"Search for Marine Sources of Atmospheric Methyl Halides" by R. Cicerone (UCI) and M. E. Lindstrom (Cal Tech)

"Critical Uncertainties in the Links Between Global Environmental Change and Regional Effects: Implications for Policies Affecting the Western U.S." by Marvin Goldman, T. E. McKone, J. I. Daniels, and L. R. Anspaugh (UCD)

"Isotopically Labeled $\mathrm{CO}_{2}$ from the Stratosphere: A Tracer of Carbon Blogeochemistry" by Y. L. Yung (Cal Tech) and M. H. Thiemens (UCSD)

"Empirical Model for the Effect of Clouds on the Earth's Radiation Budget" by J. A. Coakley Jr. and G. Luo (Oregon State University)

"Effects of Global Climate and Atmospheric Change on the Structure and Function of Mediterranean Shrub Ecosystems and Associated Forest Ecotones in California" by W. C. Oechel (SDSU)

"Development of a Gas-to-Particle Conversion Model for Use in Three-Dimensional Global Sulfur Budget Studies" by S. M. Kreidenweis (San Jose State University)

"Plant and Ecosystem Respiration in a Changing Climate: Modeling and Empirical Studies" by H. A. Mooney and P. M. Vitousek (Stanford University)

"A Study of Hydrological Extremes in California" by J. O. Roads and S.-C. Chen (UCSD)

"Isotopic Characterization of the Sources of Atmospheric Nitrous Oxide" by H, Craig and K.-R, Kim (UCSD)

"Possible Influence of Climate Change on a Recent Increase in Non-Industrial $\mathrm{CO}_{2}$ Emissions to the Atmosphere" by C. D, Keeling (UCSD)

"Parameterization of Convective Downdrafts and its Applications to Numerical Simulations of Global Hydrology" by A. Arakawa and C. R. Merhoso (UCLA)

"Design and Installation of a Monitoring Station for Assessing the Impact of Anthropogenic Aerosols on Climate" by R. J. Charlson and D. S. Covert (University of Washington)

"Interactive Vegetation for Climate Models Over the Seasonal Cycle" by R. E. Dickinson and L. J. Graumlich (University of Arizona) 
Financial Status of Projects

Western Regional Center

FY 90 Projects

\begin{tabular}{|c|c|c|c|c|}
\hline Project Titlo/Principal Investigater(s) & $\begin{array}{l}\text { Budgot } \\
\text { Award }\end{array}$ & $\begin{array}{l}\text { Exponses } \\
\text { @ } 6 / 30 / 91\end{array}$ & $\begin{array}{l}\text { Projected } \\
\text { Expenses } \\
\text { @ } 6 / 30 / 92 \\
\end{array}$ & $\begin{array}{l}\text { Anticipated } \\
\text { Carryover }\end{array}$ \\
\hline $\begin{array}{l}\text { Modeling Analyses of Mothane Emissions from Ruminants } \\
\text { R.L. Baldwin and C.C. Calvert }\end{array}$ & 560,319 & $\$ 60,256$ & $\$ 60,319$ & $5-0$ \\
\hline $\begin{array}{l}\text { Califomia Ecological Prograin } \\
\text { Daniol B. Botkin and Rohort A. Nlabot (University of Callfornla, } \\
\text { Santa Barbara) }\end{array}$ & 87,115 & 0 & 87,115 & $-a$ \\
\hline $\begin{array}{l}\text { Analysis of Global Energy Studies } \\
\text { Paul P. Cralg and Mark D. Lovine }\end{array}$ & 89,418 & 23,306 & 89,418 & -0 \\
\hline $\begin{array}{l}\text { Analysis and Synthesis of Models for the Effects of Climate Change } \\
\text { on Agricultural Systems } \\
\text { Shu Geng, Richard E. Plant, and Robert S. Loomis }\end{array}$ & 109,794 & 73,891 & 109,724 & $-a$ \\
\hline $\begin{array}{l}\text { Global Warming Trends and Internal Climate Oscillationsi Detection } \\
\text { and Modeling } \\
\text { Michael ohil and J.D. Neelin (University of Callfornia, Los } \\
\text { Angeles) }\end{array}$ & 100,000 & 108,738 & 100,000 & -0 \\
\hline $\begin{array}{l}\text { Interactive Effects of Heat Stress and Elovated Carbon Dloxido } \\
\text { Concentration on Plant Reproduction } \\
\text { Anthony E. Hall (University of California, Riverside) }\end{array}$ & 45,000 & 24,071 & 45,000 & -0 \\
\hline $\begin{array}{l}\text { Impacts of Global Warming on the Hydrology and the Aquatic } \\
\text { Environment of Callfornia } \\
\text { M. Lovent Kavvas and Gerald Orlob }\end{array}$ & 79,803 & 82,841 & 79,803 & -0 \\
\hline $\begin{array}{l}\text { Energy, Energy Policy, and Greonhouse Warming in China } \\
\text { Mark D. Levine (Lawrence Berkeley Laboratory) }\end{array}$ & 124,346 & 22,715 & 124,346 & -0 \\
\hline $\begin{array}{l}\text { Development of an Experiment to Measure the Oxidation Capacity of } \\
\text { the Earth's Atmosphere } \\
\text { F. Sherwood Rowland (University of Callfornia, Irvine) }\end{array}$ & 51,610 & 52,655 & 51,610 & -0 \\
\hline $\begin{array}{l}\text { Global Studies of Trace Gas Concentrations } \\
\text { F. Sherwood Rowland (University of Callfornia, Irvine) }\end{array}$ & 115,000 & 115,000 & 115,000 & -0 \\
\hline $\begin{array}{l}\text { Modeling the Response of the Callfornia Current System to Global } \\
\text { Greenhouse Warming } \\
\text { Richard C.J, Somerville and A. Pares Slorra (Scripps Institution of } \\
\text { Occanography, Untversity of California, San Dlego) }\end{array}$ & 110,000 & 47,325 & 110,000 & -0 \\
\hline $\begin{array}{l}\text { Global Greenhouse Forcing of the California Climate } \\
\text { Su-Tzal Soong (University of Callformia, Davis), Robert Lee, W. } \\
\text { Lawrence Gates, Marvin Dickerson, Michael C. MacCracken } \\
\text { (Lawrence Livormore National Laboratory), and Jim Kao and } \\
\text { Sumner Barr (Los Alamos Natlonal Laboratory) }\end{array}$ & 150,000 & 75,793 & 150,000 & $-a$ \\
\hline $\begin{array}{l}\text { Uncertaintles in ISCCP C1 Cloud/Radiation Feedback Parametors } \\
\text { Bryan Weare }\end{array}$ & 60,795 & $52,82 \%$ & 60,795 & -0 \\
\hline $\begin{array}{l}\text { Northern Center Administration } \\
\text { Marvin Goldman (University of Californla, Davis) }\end{array}$ & 62,697 & 48,092 & 62,697 & -0 \\
\hline $\begin{array}{l}\text { Southem Center Administration } \\
\text { P. Sherwood Rowland (Universilty of California, Irvine) }\end{array}$ & 37,103 & 16,924 & 37,103 & $-a$ \\
\hline TOTAL & $\$ 1,283,000$ & $\$ 8804,434$ & $\$ 1,283,000$ & S-O \\
\hline
\end{tabular}


FY 91

\begin{tabular}{|c|c|c|c|}
\hline Projeot TItlo/Prinoipal Investigator(s) & $\begin{array}{l}\text { Budget } \\
\text { Awand }\end{array}$ & $\begin{array}{l}\text { Projected } \\
\text { Expensese } \\
\text { Q } 6 / 30 / 92 \\
\end{array}$ & $\begin{array}{l}\text { Antlojpated } \\
\text { Carryover }\end{array}$ \\
\hline $\begin{array}{l}\text { Corrolation of Continental and Marine Paleoclimate Records Using the } \\
\text { Paleointensity of the Geomagnetio Fleld } \\
\text { Konnoth } L \text {. Voroub }\end{array}$ & s 78,654 & s 78,654 & s. 0 \\
\hline $\begin{array}{l}\text { Intermottvo Effects of Heat Stress and Elovated Carbon Dloxide } \\
\text { Concentration on Plant Reproduction } \\
\text { Anthony E. Hall (University of Calliomia, Riverside) }\end{array}$ & 50,142 & 9,642 & 40,500 \\
\hline $\begin{array}{l}\text { Efrecte of Olobal Warming on Califormia Climate } \\
\text { Su-Teal Soong (with Robert Leo and M.H. Dickerson, Lawrence } \\
\text { Ltvermore National Laboratory) }\end{array}$ & 90,452 & 40,000 & 50,452 \\
\hline $\begin{array}{l}\text { Possible Influence of Climate CHange on a Recent Increase in Non- } \\
\text { industrial CO, Emisulons to the Atmosphere } \\
\text { Charles D. Keeling (Untuersity of Callfornia, San Diego) }\end{array}$ & 78,654 & 63,726 & 14,928 \\
\hline $\begin{array}{l}\text { Parameterization of Convective Downdrafts and lis Applications to } \\
\text { Numerical Simulations of Clobal Hydrology } \\
\text { Akio Arakawa and Carios R. Mechoso (Universily of Callfomia, Low } \\
\text { Angoles) }\end{array}$ & 54,075 & 45,062 & 9,013 \\
\hline $\begin{array}{l}\text { Interactive Vogetation for Climate Models Over the Seasonal Cycle } \\
\text { Robert E. Dlckineon and Lisa J. Graumllch (University of Arlzona) }\end{array}$ & 85,004 & -0 & 85,004 \\
\hline $\begin{array}{l}\text { Plant and Ecosystem Resplration in a Changing Climatot Modeling and } \\
\text { Emplitcal Studies } \\
\text { Harold A. Mooney and Peter M. Vltousok (Stanford Untversity) }\end{array}$ & 104,667 & 57,308 & 47,359 \\
\hline $\begin{array}{l}\text { Effects of Global Climate and Atmospheric Change on the Structure and } \\
\text { Punction of Mediterranean Shrub Ecosystems and Assoclated FOrest } \\
\text { Ecotones in Callfomia } \\
\text { Walter C. Oechel (San Dlego State University) }\end{array}$ & 85,004 & 21,122 & 63,882 \\
\hline $\begin{array}{l}\text { A Study of Hydrological Extremes in Callformia } \\
\text { John O. Roads and S.C. Chen (Untversity of Callfornia, San Dlego) }\end{array}$ & 78,654 & 25,000 & 53,654 \\
\hline $\begin{array}{l}\text { Empirical Model for the Effect of Clouds on the Earth's Radlation } \\
\text { Budget } \\
\text { Jamed A. Coakloy, Jr, and Gang Luo (Oregon State University) }\end{array}$ & 85,004 & -0 & 85,004 \\
\hline $\begin{array}{l}\text { Isotopic Characterization of the Sources of Atmospheric Nitrous Oxide } \\
\text { Harmon Craig and Kyung-Ryul Kim (University of Callfornia, San } \\
\text { Diogo) }\end{array}$ & 98,317 & 78,748 & 19,569 \\
\hline $\begin{array}{l}\text { Search for Marine Sources of Atmospheric Methyl Halides } \\
\text { Ralph Cicerono (University of California Irvine) }\end{array}$ & 56,238 & 18,580 & 37,658 \\
\hline Mary E. Lidstrom (California Institute of Technology) & 66,127 & 49,678 & 16,449 \\
\hline $\begin{array}{l}\text { Isotopically Labeled } \mathrm{CO}_{2} \text { from the Stratosphere: A Tracer of Cartoon } \\
\text { Blogeochemistry } \\
\text { Yuk L. Yung (California Institute of Technology) }\end{array}$ & 23,723 & 5,000 & 18,723 \\
\hline Mark H. Thiemons (University of Callfornia, San Diego) & 24,400 & $-a$ & 24,400 \\
\hline $\begin{array}{l}\text { Modeling the Response of the Callfornia Current System to Global } \\
\text { Greenhouse Warming } \\
\text { Rlchard Somerville and A. Pares-Sierra (University of Callfornia, San } \\
\text { Dlego }\end{array}$ & 96,352 & 66,052 & 30,300 \\
\hline
\end{tabular}




\begin{tabular}{|c|c|c|c|}
\hline Projoct TItio/Principal Investigator(s) & $\begin{array}{l}\text { Budgot } \\
\text { Award }\end{array}$ & $\begin{array}{l}\text { Projected } \\
\text { Exponses } \\
\text { (a) } 6 / 30 / 92\end{array}$ & $\begin{array}{l}\text { Antlcipated } \\
\text { Carryover }\end{array}$ \\
\hline $\begin{array}{l}\text { Impuots of Clobal Warming on the Hydrologle and Aquatic } \\
\text { Environment of a Mesoscale Ceographlcal Reglon } \\
\text { M.L. Kavvas and G,T, Orlob }\end{array}$ & 78,654 & 78,654 & - \\
\hline 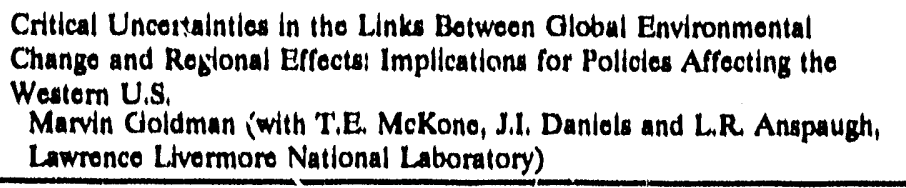 & 78,654 & 19,663 & 58,991 \\
\hline $\begin{array}{l}\text { Design and Installation of a Monitoring Station for Assessing tho Impact } \\
\text { of Anthropogenic Aerosols un CIlmato } \\
\text { Robort J. Charison and David S. Covort (Univorsity of Washington) }\end{array}$ & 104,667 & 31,540 & 73,127 \\
\hline $\begin{array}{l}\text { Olobal Warming Trends and Internal Climato Oscillations: Detection } \\
\text { and Modelling } \\
\text { Michael Ghil and J, Davld Neelin (Untvorsity of Calliomia, Los } \\
\text { Angeles) }\end{array}$ & 110,116 & 31,408 & 78,708 \\
\hline $\begin{array}{l}\text { Dovelopment of a Gas-to-Particle Conversion Model for Use in Three. } \\
\text { Dimensional Global Sulfur Budget Studies } \\
\text { Sonia M. Kroldonwols (Colorado Stato Untversity) }\end{array}$ & 45,677 & 5,000 & 40,677 \\
\hline $\begin{array}{l}\text { Modeling Analysis of Mothane Emissions from Ruminants } \\
\text { R. L. Baldwin }\end{array}$ & 58,990 & 58,990 & $-a$ \\
\hline $\begin{array}{l}\text { Global Studies of Trace Gas Concentrations/Measi rement of the } \\
\text { Oxidative Capacity of the Earth's Atmosphere } \\
\text { F. Sherwood Rowland }\end{array}$ & 147,476 & 112,146 & 35,330 \\
\hline $\begin{array}{l}\text { Conter Administration } \\
\text { Marvin Goldman and } F \text {. Sherwood Rowland }\end{array}$ & 137,489 & 63,649 & 73,840 \\
\hline $\begin{array}{l}\text { Methane Conference } \\
\text { F. Sherwood Rowland }\end{array}$ & 95,876 & 95,876 & $-a$ \\
\hline TOTAL & $\$ 2,013,066$ & $\$ 1,055,498$ & $s 957,568$ \\
\hline
\end{tabular}




\title{
National Institute Omce Program Report
}

\author{
Joseph B. Knox, Director \\ Noreen G. Dowling, Associate Director
}

The NIGEC Director has the responsibility for the management and administration of the Institute's affairs, the quality of the peer review process used in the selection of projects, and liaison and rolationships to the sponsor, the DOE. During this reporting period the NIGEC Director has reported to Vice Chancellor Robert N. Shelton, who has served us the contractual point of contact with the DOE in regard to the Cooperative Agreement. In addition, the Institute has, with prior approval of the Coordinating Board, initiated programs of particular merit or national interest, utilizing funds for the National Office. Institute programs supported as a result of Board recommendations or consistent with Board recommendations are summarized in the description of the Institute program.

\section{Institute Program}

NIGEC has supported the following projects under the category of Supermerit during the past six months. The Supermorit program supports projects which offer special cross-disciplinary efforts, involves researchers from several regions, or provides special opportunities to contribute to the critical research areas of concern to DOE in global climato change. Projects funded in FY 90 have national impacts in education or in the creation of new, unique observing platforms for global change research. In this sense, such projects have characteristics that far excced those of the average, successful, and meritorious projects at the regional level.

The National Office supported the Aurora Flight Sciences in July 1991, with funding of $\$ 150 \mathrm{~K}$ for the continued proof-of-concept of Perseus A, unmanned aircraft, and for initial flight testing in the Mojave desert during September 1991. A progress report on the project is included.

In September 1991, the National Office supported Professor William Cotton, Colorado State University (CSU) for the ARM related research project entitled "Development of a Radiative and Cloud Parameterization Scheme of Stratocumulus and Stratus Clouds which Include the Impact of CCN on Cloud Albedo" at \$287K. This action was consistent with the Board action which recommended that at least \$150K of FY 91 funds be expended in direct support of the high priority research areas of DOE designated and known as ARM and CHAMMP. The CSU proposal was reviewed by the ARM Science Committee and received very high marks; it was selected by the NIGEC Director from a set of several as being most consistent with the intent of Supermerit.

\section{Outstanding Publications}

A publication of the University of California Press entitled "Global Climate Change and California: Potential Impacts and Responses", edited by Joseph B. Knox and Ann Foley Scheuring, was distributed in December 1991. The chapters in the book are based on papers from the University of California/Department of Energy sponsored workshop held July 10-12, 1989. Topics addressed include greenhouse gases, the changing atmosphere, climate change and water resources, impact on agriculture, and the human dimensions of global climate change. This workshop was an initial step that lead to the formation of NIGEC. 


\section{Annual Conference}

The first NIGEC International Conference on atmospheric methane, organized by Professor F. S. Rowland, was held January 5 to 10, 1992 in Huntington Beach, California. The conference was attended by nearly 100 scientists from 10 countries. The scientific exchange between scientists was exceptionally productive.

\section{Policy Research}

NIGEC supported policy researchers met in Baltimore, Maryland, on December 10 and 11, 1991 to discuss common interests, project status, and general information exchange. The session was chaired by Professor Wilson, with the NIGEC meeting paralleling a national risk assessment conference.

\section{Research Projects Starting July 1, 1991}

"Development of a Radiative and Cloud Parameterization Scheme of Stratocumulus and Stratus Clouds Which Includes the Impact of CCN on Cloud Albedo", by William R. Cotton and Graeme S. Stephens, Colorado State University.

The National Office also assisted in supporting the project "Isotopic Studies of the Biogeochemical Cycle of Carbon", by John M. Hayes and L. M. Pratt, Indiana University.

\section{Special Educational Outreach Projects and Public Service}

Presidio Project: As previously reported, the Presidio Project is a consortial effort with San Francisco State University (SFSU) to develop an environmental education center on the grounds of the San Francisco Presidio (a historical army base now in the process of being transferred to the National Park Service(NPS)). Our primary thrust is to develop a Pacific Basin Study Center as part of the now defined NPS program element known as "Environmental Living and Learning" (ref: The Presidio Concepts Workbook" published by the NPS, Nov. 1991). A brief history of these consortial efforts is summarized below.

In September 1990, an informal request was received from the National Park Service to contribute ideas or visions for the future and possible uses of the San Francisco Presidio. It is expected that the Presidio will be transferred to the NPS by 1995 , at which time programs and uses of this magnificent facility should be implemented in keeping with the objectives and mission of the NPS. Exploratory discussions and information exchange occurred in late 1990 between SFSU and UC Davis. These initial discussions focused on many areas of common interest but a recurring and prominent thrust and vision was of a Pacific Rim networking of nations to address the common problems of all the nations: regional, trade, environmental, population, poverty, including the pressures of global environmental constraints.

As consensus built, and the SFSU and UCD planning group tested their ideas with the NPS, both formally and informally, the need to form a consortium of institutions emerged. In spring of 1991, the Pacific Basin Study Center (PBSC) Consortium was formed by means of an exchange of letters between President Robert A. Corrigan of SFSU and Chancellor Thcodore L. Hullar of UC Davis.

Members of the Consortium entered into the NPS planning process in winter and spring of 1991 with their participation in the Vision Workshops conducted by the NPS. The concept of establishing an educational and learning center at the Presidio for the broad purposes of addressing the common problems linking the nations of the Pacific Basin was well received at the hearings, and in all other informal contacts. In June 1991, Vice President Stanley Kardonsky of SFSU, on behalf of the PBSC Consortium, formaily submitted the Concept and Vision Statement of the PBSC to the NPS. Subsequent statements by the NPS to the press indicated that this Concept and Vision Statement had been well received; later we were informed 
that the evaluation of the Workshop inputs by the NPS Council had rated the PBSC Vision Statement very highly.

In June 1991, the Consortium established a program committee composed of Professor Charles Shapiro of SFSU and Joseph B. Knox, Director of the National Institute for Global Environmental Change, UC Davis. Others were invited to join the committee efforts and planning began for the first program, an international conference called Supercities, to be held in 1992. In the twenty-first century it is projected that a very large fraction of the world's 6 billion people will live in large urban areas, supercities, that will be the focal point determining the quality of life, environmental conditions, the prudent or imprudent uses of natural resources of each nation, and their national impact of the global commons.

Our first project is focused on convening the nations of the Pacific Basin at the Presidio, or in San Francisco, to define common problems, areas of cooperation, structure solutions whenever possible, and to develop an action plan in collaboration with those of fiscal resourcefulness. The PBSC is presently developing the conference planning document for the Supercities event.

On July 1, 1991, SFSU announced its intention to provide \$20K of seed funding to the PBSC Consortium. The Consortium meeting of August 2, yielded still further organizational actions; approval to establish the PBSC as an incorporated body in the State of California, direction to pursue other sources of seed monies, and guidance to continue developing the program content and support for the Supercities project.

For the immediate future, our path is clear: to remain involved and active in the NPS planning process; to develop planning for the Supercities conference; and to acquire long-term funding support for Consortium activities.

\title{
The Perseus Unmanned Scientific Research Aircraft
}

\author{
John S. Langford
}

Aurora Flight Sciences

Objective: To develop and demonstrate an unmanned aircraft tailored to the requirements of the atmospheric science community. The program is intended to support and stimulate research in a variety of topics, including stratospheric ozone depletion, the global carbon and methane cycles, hurricane tracking and research, the environmental impact of high-speed civil transports, stratosphere-troposphere exchange studies, the tropical water vapor budget, and ground truth for satellite measurements.

Product: A prototype of the Perseus unmanned aircraft was fabricated and flight tested. This vehicle has a wingspan of $18 \mathrm{~m}$ and a gross weight of $430 \mathrm{~kg}$. As presently configured, the aircraft can carry a $50 \mathrm{~kg}$ payload to altitudes of approximately $8 \mathrm{~km}$. Powered by a $46 \mathrm{Kw}$ internal combustion engine, it serves as both an engineering testbed for the Perseus program and as a proof-of-concept demonstrator for the science community.

Approach: Recent advances in comp'ttational aerodynamics, composite structures, microcomputer-based control systems, and lightweight propulsion systems have been combined with a philosophy that defines the essential scientific questions first and then tailors an integrated instrument/platform development program. This provides a unique tool that is accessible to individual researchers in a university environment on a time and budgetary scale considerably smaller than manned aircraft or satellites. 
Since its inception in 1989, this project has focused both on building a coalition within the scientific community and assembling the technical infrastructure needed to support the effort. Significant progress has been made in both areas. For example, a recent report by the JASONs advisory panel to the Department of Energy strongly endorsed the concept of using unmanned aircraft in future atmospheric radiation measurement programs.

Results to Date: During November, 1991 the Perseus prototype completed a series of test flights operating from El Mirage dry lake in California. The flights reached altitudes of up to $1500 \mathrm{~m}$ and lasted in excess of one hour. All major systems performed successfully. All modes of flight control were exercised, including fully manual control, autopilot control, and fully autonomous flight. The Perseus prototype was safely returned to Virginia and is presently available for further engineering tests or preliminary science experiments.

All NIGEC funds have been expended and the research program has been successfully completed.

Two operational versions of the aircraft are presently under development. The Perseus $A$ is designed to carry $50-70 \mathrm{~kg}$ payloads to altitudes of $25-28 \mathrm{~km}$ for durations of about an hour. Three vehicles are on order by the NASA Ames Research Center. First flights are expected to begin in early 1993, with initial science operations beginning in 1994. The initial missions of these aircraft are supporting environmental impact assessments for a next-generation high-speed civil transport and in supporting polar ozone studies.

Aurora has independently initiated development of a derivative version known as Perseus B. Designed for global warming studies, studies of the tropical water vapor budget, and other applications that require extended measurements at or above the tropopause, Perseus B can carry 100-200 kg payloads at 16$20 \mathrm{~km}$ altitudes for durations of $24-72$ hours. A version capable of operating at $12 \mathrm{~km}$ will be available in late 1992. A version capable of operating at altitudes of up to $20 \mathrm{~km}$ is under development for use in 1993 or 1994.

The unmanned aircraft can now be seriously considered for near-term experiments in many areas of global change research. Investigators interested in conducting experiments aboard unmanned aircraft are invited to contact Dr. John S. Langford, Aurora Flight Sciences, 10601 Observation Road, Manassas, Virginia 22111. (703) 369-3633. 


\section{National Office Budget Summary}

Project and Administrative Summary

National Institute Office

FY 90 Report

\begin{tabular}{|l|c|c|c|c|}
\hline Project Title/Principal Investigator(s) & $\begin{array}{r}\text { Budget } \\
\text { Awand }\end{array}$ & $\begin{array}{r}\text { Expenses } \\
@ 6 / 30 / 91\end{array}$ & $\begin{array}{c}\text { Projected } \\
\text { Expenses } \\
@ 6 / 30 / 92\end{array}$ & $\begin{array}{c}\text { Anticipated } \\
\text { Carryover }\end{array}$ \\
\hline $\begin{array}{l}\text { Perseus Unmanned Scientific Research Aircraft } \\
\text { John W. Langford (Aurora Flight Sciences, Alexandria, Virginia) }\end{array}$ & $\$ 100,000$ & $\$ 100,000$ & $\$ 100,000$ & $\$-0-$ \\
\hline $\begin{array}{l}\text { Development of Global Systems Science } \\
\text { Cary I. Sneider and Richard Golden (Lawrence Hall of Science, } \\
\text { University of California, Berkeley) }\end{array}$ & 170,000 & 88,720 & 170,000 & -0 \\
\hline Projects Subtotal & 270,000 & 188,720 & 270,000 & -0 \\
\hline Administration Subtotal & 514,000 & 475,298 & 514,000 & -0 \\
\hline TOTAL & $\$ 784,000$ & $\$ 664,018$ & $\$ 784,000$ & -0. \\
\hline
\end{tabular}

Project and Administrative Summary

National Institute Office

FY 91 Report

\begin{tabular}{|c|c|c|c|}
\hline Project Title/Principal Investigator(s) & $\begin{array}{l}\text { Budget } \\
\text { Award }\end{array}$ & $\begin{array}{c}\text { Projicted } \\
\text { Expenses } \\
@ 6 / 30 / 92\end{array}$ & $\begin{array}{l}\text { Anticipate } \\
\text { dCarryover }\end{array}$ \\
\hline $\begin{array}{l}\text { Isotopic Studies of the Biogeochemical Cycle of Carbon } \\
\text { John M. Hayes and L. M. Pratt (Indiana University) }\end{array}$ & $\$ 188,758$ & $\$ \$ 0,000$ & $\$ 138,758$ \\
\hline $\begin{array}{l}\text { Development of a Radiative and Cloud Parameterization Scheme of Stratocumulus } \\
\text { and Stratus Clouds Which Include the Impact of CCN on Cloud Albedo } \\
\text { William R. Cotton and Graema S. Stephens (Colorado State University) }\end{array}$ & 286,966 & 120,795 & 166,171 \\
\hline $\begin{array}{l}\text { Perseus Unmanned Scientific Research Aircraft } \\
\text { John W. Langford (Aurora Flight Sciences, Alexandria, VA) }\end{array}$ & 150,000 & 150,000 & 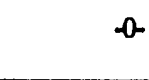 \\
\hline Projects Subtotal & 625,724 & 320,795 & 304,929 \\
\hline Administration Subtotal & 445,590 & 425,000 & 20,590 \\
\hline Subtotal & $1,071,314$ & 745,795 & 325,519 \\
\hline $\begin{array}{l}\text { Reimbursement to Midwestern and Northeast Regional Centers for their FY } 90 \\
\text { support of the Perseus project, shown above as the National Institute Office FY } 91 \\
\text { research project }\end{array}$ & $-150,000$ & $-150,000$ & -0 \\
\hline TOTAL & $\$ 921,314$ & $\$ 595,795$ & $\$ 325,519$ \\
\hline
\end{tabular}




\title{
NIGEC Host Institutions
}

\author{
National Institute Office \\ University of California, Davis
}

Joseph B. Knox, Director

1477 Drew Avenue, Suite 104

Davis, CA 95616

(916) 757-3350

Fax: (916) 756-6499
Noreen G. Dowling Associate Director

Midwestern Regional Center

Indiana University

J.C. Randolph, Director

School of Public and

Environmental Affairs

10 th \& Fee Lane

Bloomington, IN 47405

(812) 855-4953

Fax: (812) 855-7547

\author{
Ronald Hites \\ School of Public and \\ Environmental Affairs \\ 10th \& Fee Lane \\ Bloomington, IN 47405 \\ (812) 855-0193 \\ Fax: (812) 855-1076
}

\section{Northeast Regional Center \\ Harvard University}

Richard Wilson, Director

Lyman Laboratory of Physics

Cambridge, MA 02138

(617) 495-3387

Fax: (617) 495-0416
Steven Wofsy

Div. of Applied Sciences

Pierce Hall

Cambridge, MA 02138

(617) 495-4566

Fax: (617) 495-5192 
NIGEC Host Institutions (continued)

\section{Southcentral Regional Center \\ Tulane University}

Robert G. Watts, Director

Dept. of Mechanical Engineering

400 Lindy Boggs Bldg.

New Orleans, LA 70118

(504) 865-5775

Fax: (504) 865-5345
Gene D'Amour

Office of Research

316 Gibson Hall

New Orleans, LA 70118-5698

(504) 865-5272

Fax: (504) 865-5274

\section{Southeast Regional Center}

University of Alabama

Robert A. Griffin, Director

Chemical Engineering, Rm 275

Tuscaloosa, AL 35487-0203

(205) 348-8403

Fax: (205) 348-8573

Western Regional Center

University of California

(Co-Directors)

Marvin Goldman

Dept. of Radiological Sciences

Medical Sciences Building

Davis, CA 95616

(916) 757-3403

Fax: (916) 756-6499
F. Sherwood Rowland

Dept. of Chemistry

571 Physical Sciences

Irvine, CA 92717

(714) 856-6016

Fax: (714) 725-2905 


\section{Project Title Index}

Analysis and Synthesis of Models for the Effect of Climate Change on Agricultural Systems, 128

Analysis of Global Energy Studies, 128

Bellagio II: Managing the Transition to a Global Climate Change Regime, 81

California Ecological Program, 128

Carbon Dioxide, Climate and the Deep Ocean Circulation: Carbon Chemistry Model, 94

Chemical Controls on the Sinks and Sources of Carbon Dioxide: The Role of Iron, 93

Climatic Influences of Land Surface Conditions in the Midwest United States, $\mathbf{4 3}$

Decomposition Rates and Nutrient Dynamics in a Temperate Forest: Effects of $\mathrm{CO}_{2}$ and Nitrogen Enrichment, 63

Development of an Experiment to Measure the Oxidation Capacity of the Earth's Atmosphere, 144

Education Fellowships for Undergraduates in Environmental Sciences, 81

Effects of Global Warming on California Climate, 143

Energy, Linergy Policy, and Greenhouse Warming in China, 144

Formation and Emission of Methane in Rice Soils: Experimental Determination and Modeling Analysis, 108

Fuel Switching Impacts on Carbon Dioxide Emissions from Midwestern Great Lake States Electric Utilities, 49

Global Atmospheric Behavior of Polychlorinated Biphenyls, 46

Global $\mathrm{CO}_{2}$ Enrichment, Nutrient Dynamics, and Litter Decomposition in a Deciduous Forest Ecosystem: The Relationship Between Atmospheric $\mathrm{CO}_{2}$ Levels, Plant Tissue Chemistry, and Litter Decomposition, 68

Global Studies of Trace Gas Concentrations, 144

Global Warming Effects on the Release of Light Hydrocarbons from Gas Hydrate Deposits, 96

Global Warming Trends and Internal Climate Oscillations: Detection and Modeling, 139

Impact of Global Environmental Change on Biodiversity of Mammals in the Southcentral United States, 111

Impacts of Global Warming on the Hydrologic and Aquatic Environment of a Mesoscale Geographical Region, 140

Interactive Effects of Heat Stress and Elevated Carbon Dioxide Concentration on Plant Reproduction, 130

International Research Archive on Science Policy Dimensions of Global Environmental Change, 81

Isotopic Studies of the Biogeochemical Cycle of Carbon: Relationships Between ${ }_{p} \mathrm{CO}_{2}$ and the Abundance of ${ }^{12} \mathrm{C}$ in Sedimentary Organic Matter, 44 


\section{Project Title Index (continued)}

Modeling Analyses of Methane Emissions from Ruminants, 119

Modeling the Response of the California Current System to Global Greenhouse Warming, 138

Net Exchange of $\mathrm{CO}_{2}$ in Midlatitude Forests, 64

Past Climates and Factors Regulating Past Climate Change, 67

Photochemistry Relevant to Ozone Depletion and Global Warming, 98

Physical Basis for Climate Change Models, 81

Recent and Paleo-Climatic Variations and the Greenhouse Gas-Climate Signal: Detecting Climate Change, 101

Risk Assessments and Elucidation of Uncertainties, 65

Soil Chemistry and Throughfall at Harvard Forest, 64

Supra-Regional Modeling of Groundwater Response to Climate Change, 43

Temporal and Spatial Variability of Methane Cycling in Wetland Ecosystems of the Northern Temperate Zone, 50

The Economic Consequences and $\mathrm{CO}_{2}$ Emissions Impact of Energy Taxation, 47

The Effect of Global Climate Change on Wetland Function and Distribution, and the Consequent Land Use and Economic Change, 53

The Efferts of Global Warming on the Interfacial Properties and Structure of Soil, 103

The Engineering Response to Global Climate Change: Planning A Research and Development Agenda, 100

The Impact of the Corporate Average Fuel Economy Standards on the Life Span and Lifetime Energy

Consumption of Automobiles: A Population Dynamics Approach, 48

The Influence of Climatic Change on the Long-Term Hydrological and Biogeochemical Trajectories of North American Watershed-Lake Ecosystems, 52

The Perseus Unmanned Scientific Research Aircraft, 151

The Utilization of Sclerochronology to Establish Sea-Surface Temperature Fluctuation, 91

Turbulence and Turbulent Exchange at Harvard Forest, 75

Uncertainties in ISCCP C1 Cloud/Radiation Feedback Parameters, 142 
Aber, John D., 64

Baldwin, R. L., 119

Bazzaz, Fakhri A., 68

Boering, K. A., 64

Botkin, Daniel B., 128

Burley, J. D., 64

Cameron, Guy N., 111

Carleton, A. M., 43

Chayes, Abram, 81

Clark, William, 81

Craig, Paul P., 128

Daube, B. C., 64

Dickerson, Marvin, 143

Fitzjarrald, D. R., 75

Geng, Shu, 128

Ghil, Michael, 139

Gill, Ivan, 91

Goldstein, A. H., 64

Goody, R. M., 81

Gouldin, M. L., 64

Grimmond, Sue, 43

Haitjema, Hendrik M., 43

Hall, Anthony E., 130

Hayes, J. M., 44

Hites, Ronald A., 46

Hubbard, Dennis K., 91

John, V. T., 96

Kavvas, M. Levent, 140

Koplitz, Brent, 98

Koplitz, Lynn V., 93

Krutilla, Kerry M., 47

Lancaster, J., 65

Langford, John S., 151

Law, Victor J., 108

Lee, Robert, 143

Levine, Mark D., 144

Lindau, C. W., 108

Loomis, R., 128

Marino, B. D., 67

McElroy, Michael, 67, 81

Melillo, Jerry, 63

Menawat, Anil S., 94
Mitter, Eric L., 48

Moore, K. E., 75

Munger, J. W., 64

Nadelhoffer, Knut, 63

Nealson, Kenneth H., 50

Neelin, David, 139

Nisbet, Robert A., 128

O'Connor, K. C., 108

Orlob, Gerald T., 140

Papadopoulos, Kyriakos, 103

Pares-Sierra, Alejandro, 138

Patrick, William H., 108

Plant, R., 128

Pratt, L. M., 44

Randolph, J. C., 49

Rowland, F. Sherwood, 144

Schwarz, S. G., 96

Shlyakhter, A., 65

Skolnikoff, Eugene B., 81

Somerville, R. C. J., 138

Soong, Su-Tzai, 143

Steudler, Paul, 63

Sweets, Paul R., 52

Watts, Robert G., 94, 100, 101

Weare, Bryan C., 142

White, Jeffrey R., 50, 52

Whitehead, D. R., 52

Willard, Daniel E., 53

Wilson, Richard, 65

Wofsy, Steven C., 64 
Acknowledgements: The NIGEC semi-annual report was written and compiled by Glenn $C$. Werth, Technical Consultant to the National Institute Office. The technical reports were written by the individual Principal Investigators. The report was produced, typed, and arranged by Alisa M. McManus. 

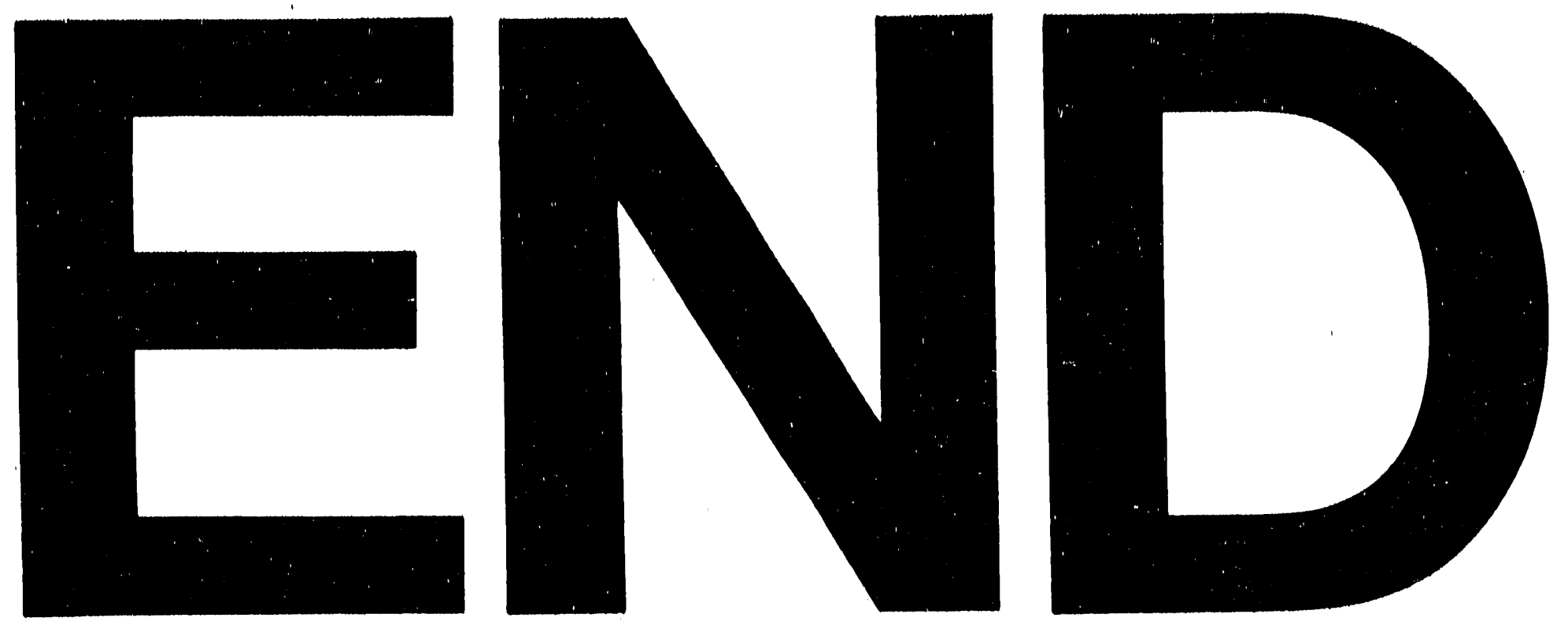

1
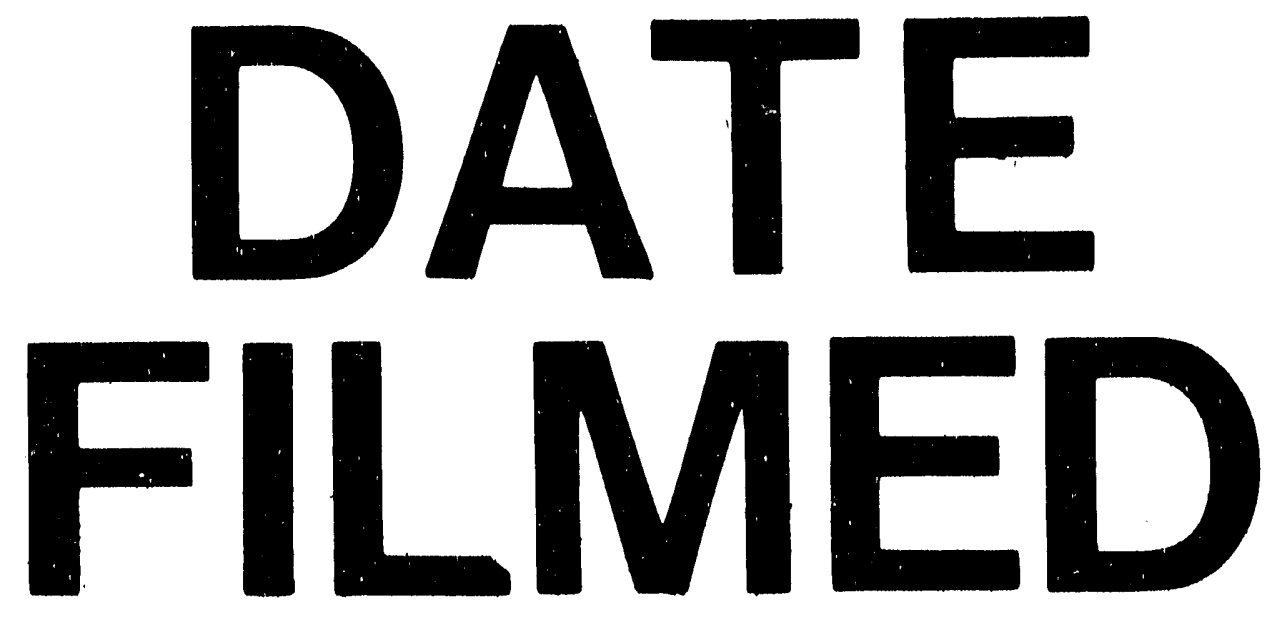

$6 / 24 / 92$ 
